\title{
Hungarian Turcology 1945-1974 \\ Bibliography
}

Edited by

Zsuzsa Kakuk

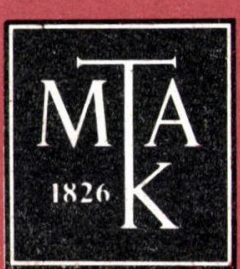

Budapest-1981 
Hungarian

Turcology

1945-1974

Bibliography 


\section{Keleti Tanulmányok \\ Oriental Studies}




\section{Hungarian \\ Turcology \\ 1945-1974}

Bibliography

Edited by

\section{Zsuzsa Kakuk}

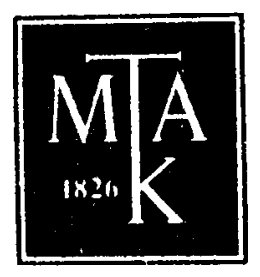

Budapest-1981 
MAGYAR TUDOMÁNYOS AKADÉMIA KÖNYVTÁRA LIBRARY OF THE HUNGARIAN ACADEMY OF SCIENCES

ISSN $0133-6193$

$\begin{array}{lllll}\text { ISBN } & 963 & 7301 & 37 & 2\end{array}$ 
This bibliog raphy, which contains nearly 2,000 entries, presents the output of Hungarian turcology in 30 years.

It includes the works, articles and reviews written by Hungarian authors and published in this country or abroad, the Hungarian and foreing appreciations and reviews of Hungarian authors and their works, and also the articles written by foreign authors and published in Hungary.

The bibliography first presents works dealing with the historical and general aspects of turcology, then arranges thematically the works examining former and contemporary Turkish peoples, their languages and literature. Following chronological order, it presents the research literature about Turco-Hungarian contacts before the Magyar conquest of Hungary, in the Middle Ages, during the Ottoman occupation of Hungary and in later times, respectively.

Connections are made explicit by cross-references. A detailed table of contents and an index of names also help the reader to orientate himself in the material. 


\section{.}




\section{INTRODUCTION}

The kernel of this bibliography is a product of my teaching work at the university. In 1975, $\mathrm{J}$ and my third-yearstudents: Imre Baski, Ibolya Gerelyes, Zsuzsa Kovács and Annamária Marosi compiled a bibliography of the past thirty years of Hungarian turcology for a Conference of Students' Scholarly Societies. The material has increased and the principles of its arrangement have evolved since then, but its aim has not changed: the bibliography is intended to present and arrange thematically the output of Hungarian turcology produced in 30 years.

Our bibliography includes the works, articles and reviews written by Hungarian authors and published in Hungary and elsewhere, the Hungarian and foreign appreciations and reviews of Hungarian authors and their works, as well as the articles written by foreign authors and published in Hungary. The closing date of 1974 has been observed even for the reviews of Hungarian works, although in some cases the number of such reviews inc reased considerably in the years that followed.

It has not been easy to delimit the subject of "turcology" and keep it distinct from related disciplines, such as e.g. history, a rcheology and ethnography. We have decided on a narrow definition and included only works belonging to the subject of "Turkic philology", though the special problems of Hungarian turcology - such as e.g. the historical background of Turco-Hungarian contacts before the Magyar conquest, or the questions of economic history during the 16th and 17 th $\mathrm{c}$. Ottoman occupation of Hungary - have made us treat the limits somewhat flexibly in certain fields. Even so, this bibliography is more homogeneous in its choice of material than the earlier bibliographies of Hungarian turcology [1]. We have not included in our material the Hungarian translations of literary works. On the other hand, we have admitted the studies /introductions, commentary postscripts/ appended to such literary works.

[1] Julius Moravesik, Ungarische Bibliographie der Turkologie und der orientalisch-ungarischen Beziehungen. 1914-1925. In: KCsA 2 (1926), 199-236. - L. Rásonyi, Ungarische Bibliog raphie der Turkologie und der orientalish-ungarischen Beziehungen. 1926-1934. In: KCsA I. Ergänzungsband (1935), 1-66. 
Following earlier examples in the arrangement of the material we have put the general turcological topics and the specific Hungarian topics under separate headings. This can be justified on practical grounds but the two ranges of subjects are in fact mutually connected by their internal historical relationships. Thus e.g. to gain information about the Bulgar-Turks, Khazars, Pechenegs, Cumanians is not only the aim of general turcology but also a specific Hungarian task. Since each item has been listed only once, connections between them have been pointed out by means of cross-references. Cross references a re also made in cases where an article was published both in Hungarian and in a foreign language.

Hoping that this work will be a useful contribution not only to Hungarian but also to international turcology, we have supplied the titles of the Hungarian publications with their English translations. A detailed table of contents and an index of names also assist orientation.

I would like to acknowledge my indebtedness to the Research Group of Altaistic Studies of the Hungarian Academy of Sciences for their support and financial aid. I feel obliged to Edmond Schuitz for his useful ideas and hints with which he has helped me in my work and to P. Golden for checking the English translation of the Hungarian entries.

Budapest, 1978. 


\section{I.}

\section{GEMERAL WORKS ON TURCOLOGY}

\section{BIBLIOG RAPHIES}

1. Analecta Linguistica. Informational Bullet in of Linguistics. Redigit A. Róna-Tas. Budapest, 1971 -.

2. BENDA Kálmán: Walter Sturminger, Bibliographie und Ikonographie der Türkenbelagerungen Wiens 1529 und 1683. Graz-Köln, 1955. Review = Száz. $93(1959)$, pp. $662-663$.

3. BORSA Gedeon - HERVAY Ferenc - HOLL Béla - KÄFER István - KELECSÉNYI Ákos: Régi magya rországi nyomtatványok [Old prints of Hungary]. Budapest, 1971. $928 \mathrm{pp} .+41 \mathrm{pl}$.

Reviewed by Ritoók Zsigmondné = MTud, 16 (1971), pp. 800-802.

4. GULYA Viktória: 25 év uráli nyelvészeti irodalma Magyarországon (1945-1969). Összeállította - - [A bibliog raphy of Uralic linguistics in Hungary: 1945-1969. Comp. by -- ] = Anal Lingu. 1:1 (1971), pp. 212-251.

5. HAZAI, G[yörgy]: Aktualne zagadnienia dokumentacji i bibliografii w dziedzinie altaistyki $=$ PrOr. $3(1963)$, pp. 181-189.

See Nos. 6, 7 .

6. HAZAI György: Az altajisztikai dokumentációs és bibliográfiai munka néhány aktuạ́lis problémájáról [Some present-day problems in Altaistic documentation and bibliography] = Fil Közl. 10(1964), pp. 192-194.

See Nos. 5,7 .

7. HAZAI [ György], Georg: Dokumentation und Bibliographie in der Altaistik = UAJb. $35(1964)$, pp. $403-416$.

See Nos. 5,6 .

8. HAZAI, G[yörgy]: H.J. Kornrumpf, Osmanische Bibliographie mit besonderer Berücksichtigung der Türkei in Europa. Leiden, 1973. / Handbuch der Orientalistik, 1. Abt. , Erg. - Bd. 8./. Review = JAH 8 (1974), pp. 165-167 and DLZ 95 (1974), pp. 193-195. 
9. HAZAI, G[yörgy]: H.F. Hofmar, Turkish literature. A bio-bibliographical survey. Section II. Part I-II.: Vol. 1-6. Leiden, 1969. Review = OLZ 69(1974). cols. 62-64.

10. Hungarian publications on Asia and Africa. 1950-1962. A selected bibliography. Magyar sze rzók Ázsiáról és Afriká ról. 1950-1962. Válogatott bibliog ráfia. Comp. by E. Apor and H. Ecsecty. Budapest, 1963. 106 pp.

Reviewed by Dán Róbert = MKsz. 80 (1964), pp. 195-196.

11. KOZOCSA Sándor - RADÓ György: A szovjet népek irodalmának magyar bibliográfiája 1944-ig [Hungarian bibliography of the literature of the Soviet Peoples to 1944]. Budapest, 1956; 1945-1949. Budapest, 1950; 1950. Budapest, 1952; 1951. Budapest, 1953; 1952. Budapest, 1954; 1954. Budapest, 1957.

12. A magyarországi nyelvtudomány bibliográfiája. Bibliographie linguistique de la Hongrie. 1961-1965. Budapest, 1963-1969. / A MTA Nyelvtudományi Intézetének Közleményei. Uj folyam 1-5.

13. MOLNÁR, József: Selected bibliography of early Hungarian records. Comp. by -- = Anal Lingu. 4 (1974), pp. 205-218.

14. NÉMETH, |Gyula| J.: J.Benzing, Einfüh rung in das Studium der altaischen Philologie und der Turkologie. Wiesbaden, 1953. Review = OLZ 50(1955), cols. 146-148.

See No. 16.

15. NÉAETH, \{Gyula\} J.: Zum Geleit : Sovietico-Turcica, pp. 5-10. See No, 17 .

16. RÁSONYI, L\{ászlô\}: J. Benzing, Einführung in das Studium der altaischen Philologie und der Turkologie. Wiesbaden, 1953. Review - NyK 59 (1957), pp. 279-283 and AOH 7(1957), pp. 309-320.

See No. 14.

17. Sovietico-Turcica. Beiträge zur Bibliographie der türkischen Sprachwissenschaft in russischer Sprache in der Sowjetunion 1917-1957. Unter Mitwirkung einer Arbeitsgemeinschaft des Turkologischen Instituts der Universität Budapest, red. von Georg Hazai. Budapest, 1960,319 pp. /BOH IX./.

Reviewed by Ašnin, F. D. = IzvAN OLJa. 20 (1961), pp. 530-541; Barkan, P. = Bulletin des Bibliothèques de France $6(1961)$, no. 9/10; Blagova, G. F. = VJaz. 10 (1961), No 5, pp. 136-139; Kenesbaev, S. - Sy zdykova, P. = Vestnik Akademii Nauk Kazachskoj SSR XVII (1961), No. 10 (199), pp. 112-114; Kóhalmi Katalin = MTud. 6 (1961), pp. 642-643; Mijatev, P. = Bălgarski ezik 11 (1961); pp. 190-192; Rísonyi László = I. OK 18 (1961), pp. 369-373; Saadiev, S. M. = IzvAN Azerb. SSR, Serija obscestvennych nauk, Baku, 1961, No. 6, pp. 193-195; Tietze, A. $=$ Oriens 13/14(1961), pp. 453-455; Acaroğlu, Türker = Kitap Belleten 乙 (1962), no. 15/16, pp. 20-21 and Milliyet (Istanbul, 1962), 3, pp. 22; Fehér Géza $=$ ArchÉrt. 89(1962), pp. 263-264 and Biblor. 21 (1964), p. 381; Chasenov, A.-Črkasskij, M. A. = NarAzAfr. (1962), No. 2, p. 250; Gabain, 
A. v. = UAJb. 34 (1962), pp. 15i-158; Kakuk Zsuzsa, N. = NyK 64(1962), pp. 255-256; R[eychman], J. = Przegląd Orientalistyczny 1961, Nr. 3 (39), p. 329; Benzing, J. = OLZ 60 (1965), cols. 380-381; Duda, H. W. = WZKM 63/64(1972), p. 343.

See also Nos. $103,157,162,173,176,177,194,213,216,223,235,241,243$.

\section{PERIODICALS, SERIES, COLLECTED PAPERS}

\section{a) Hungarian publications}

18. Acta Orientalia Academiae Scientia rum Hungaricae. Adiuvantibus K. Czeglédy, B. Csongor (1971-), A. Dobrovits (1969-1964), L. Fekete (-1970), G. Kara (1965- ), J. Németh, S. Telegdi, redigit L. Ligeti. Budapest, 1950- .

19. Analecta Orientalis memoriae Alexandri Csoma de Körös dicata. Edendo operi praefuit L. Ligeti. Budapestini, 1942-1947. $224 \mathrm{pp}$. / BOH 5./. Reviewed by Eren, Hasan = A ÜDTCFI) 8 (1950), pp. 250-251.

20. Bibliotheca Orientalis Hungarica. Budapest, Tomus V. 1942-1947 - .

21. HAZAI, G[yörgy]: Acta Orientalia Academiae Scientiarum Hungaricae. 1-2 (1950-1952). Review $=$ Oriens $7(1954)$, pp. 3:35-397.

22. HAZAI, Glyörgy ]: Journées des Orientalistes Hongrois = AOH 5(1955), pp. 313-314.

23. HAZAI, G[yörgy] - ZIEME, Pleterl: Sprache, Geschichte und kultur der altaischen Völker. Protokollband der XII. Tagung der Permanent International Altaistic Conference 1969 in Berlin. Ed. by --. Berlin, 1974, 668 pp. +55 pl. /Schriften zur Geschichte und Kultur der Alten Orients. 5./.

24. HAZAI, G[yörgy]: Zum Geleit : Protokollband (197-1), p. 3. See No. 23.

25. HAZAI, G[yörgy]: Eröffnungs rede = Protokollband (1974), p. 15 . See No. 23.

26. Keletkutatás 1973. Tanulmányok az orientalisztika köréböl [Oriental Studies 1973. Studies in the field of Orientalism]. Red. György Kara - József Terjék. Budapest, Kórösi Csoma Társaság, 1974. 171 pp.

27. Körösi Csoma Kiskönyvtár [Körösi Csoma Library]. Szerkeszti [Redigit] Ligeti Lajos. Budapest, 1966-.

28. Lốrincz, L[ászló]: Acta Orientalia $1970=$ Nouvelles F́tudes llongroises 1972, p. 237. 
29. The Muslim East. Studies in honour of Julius Germanus. Edited by Gyula Káldy-Nagy. Budapest, Loránd Eötvös University, 1974. 264. pp. + XIII. pl.

30. Németh Armağanı. Hazırlayanlar János Eckmann, Agah Sırrı Levend, Mecdut Mansuroglu. Ankara, 1962. 393 pp. /TDKY 191./.

31. Studia Turcica. Edited by Louis Ligeti. Budapest, 1971. 498 pp. /BOH 17./. Reviewed by Gabain, A.v. = UAJb. 44 (1972), pp. 292-294; Kakuk Zs. = MTud. 17 (1972), pp. 524-526 and AnnLingu. 4 (1973), pp. 185-188; Zieme, $P .=$ MIO 17 (1971/72), p. 488; BSOAS 35(1972), p. 433; Hazai, G. = AASt. 9(1973), pp. 226-228; Karadeniz, Şadan = Belleten 37 (1973), pp. 248-249; Korogly, Ch. G. $=$ NarAzAfr. 1973, No. 6. pp. 185-189; Menges, K. H.: Ein wertvolles Kompendium zu aktuellen Forschungsfragen der Turkologie = OLZ 69(1974), cols. 325-338.

32. Studia Turco-Hungarica. Redigit Gy. Káldy-Nagy. Budapest, 1974-.

33. Studia Uralo-Altaica. Redigunt P. Hajdú et A. Róna-Tas. Szeged, 1973-.

34. SZÉKELY, György: Preface - Önsöz = Studia Turco-Hungarica L. (Budapegt, 1974), pp. 5-12.

See No. 32 .

b/ Reviews on collected papers edited abroad

35. ECSEDY, [Ildikó] H.: TjurkologiCeskij sbornik k sestidesjatiletiju Andreja Nikolajevica Kononova. Moskva, 1966. Review $=$ ALH 19(1969), pp. 257-260.

36. HAZAI, Glyörgy ]: Akademisyen Layos Ligeti'nin 60' unc1 doğum yildönümüne armağan. Review = TD Sayı $143(1963)$, pp. 781-782.

37. KAKUK, [Zsuzsa] Suzanne: TjurkologiCeskij sbornik k sestidesjatiletiju Andreja Nikolajeviða Kononova. Moskva, 1966. Review = AOH 20(1967), pp. 369-373.

38. KAKUK, [Zsuzsa] Suzanne: Voprosy tjurkologii. K \&estidesjatiletiju akademika AN Azerbajdžanskoj SSR. M. S. Siralieva. Baku, 1971. Review = AOH 26 (1972), pp. 389-394.

39. KAKUK, [Zsuzsa] Suzanne: Tjurkologiceskij Sbornik 1971. Pamjati akademika Vasilija Vasiljevica Radlova posvjascaetsja. Moskva, 1972. Review $=$ AOH 28 (1974), pp. 151-157.

40. KÖH ALMI, [Katalin] Käthe: Haec Studia Orientalia Professori Linguarum Turcicarum in Universitate Helsingiensi Martti Räsänen Anno 1953 Sexagenario. Helsinki, 1954. /StOr. 19./. Review = OLZ 52 (1957), cols. 493-496. 


\section{REPORTS}

\section{a/ Conferences held in Hungary}

41. BARTHA Antal: Altájisztikai napok Budapesten. 1965 május 17-19 [Altaic Studies Days in Budapest. 17-19 May 1965] = Száz. 99(1965), pp. 1037-1039.

42. BARTHA Antal: Magyar östörténeti konferencia [Conference on Hungarian ancient history] $=$ П. OK 23 (1974), pp. 255-258.

43. RÓNA-TAS, A[ndrás]: The Conference of the Hungarian Altaicists 17-19th May $1965=\mathrm{AOH} 18$ (1965), pp. 378-379.

44. URAY Géza: Az I. Orientalisztikai Konferencia munkája [The activity of the 1st Orientalist Conference $]=1, \mathrm{OK} 10(1957)$, pp. 82-83.

45. Orientalisztikai konferencia /Orientalist Conference] $=\mathrm{Nyr} .80$ (1956), pp. 157-158.

46. A Magyar Tudományos Akadémia Orientalisztikai Konferenciájának hatá rozatai [Resolutions of the Orientalist Conference of the Hungarian Academy of Sciences $]=1$. OK $10(1957)$, pp. 84-86.

b/ Hungarian participation in international meetings

47. CZEGLÉDY, Klároly ]: The XXLXth International Congress of Orientalists = AOH 28 (197.1), pp. 288-290.

48. FEKETE: Lajos: Beszámoló az 1956. évi török törlénelmi kong resszus ról [Report on the Congress of Turkish History 1956] = I. OK 10 (1957), pp. 405-413.

49. FEKETE Lajos: Jelentés az 1961 október 20-26 -án Ankarában megtartott török történelmi kongresszus ról [Report on the Turkish Historical Congress held in Ankara, 20-26 October 1961] $=$ MNy. 58 (1962), pp. 520-523.

50. GALLA Endre - HAZAI György: Nemzetközi orientalista kongresszus Indiában [International Orientalist Conference in India (New Delhi 4-10 Jan. 1964)] = Fil.Közl. 11 (1965), pp. $231-233$.

51. HARMATTA János: Beszámoló a XXV. Nemzetközi Orientalista Kongresszus ról [Report on the 25th International Orientalist Conference] $=$ ArchÉrt. 88 (1961), pp. 127-129.

52. HAZAI György: A moszkvai Nemzetközi Orientalista Kongresszus /The International Orientalist Conference of Moscow $\}=$ Valóság 3(1960), No. 6. pp. 102-104.

53. HAZAI, Glyörgy]: Die V. Tagung über die Fragen der Dialektologie der türkischen Sprachen (Pjatoe sovešcanie po voprosam dialektologii tjurkskich jazykov, 5-8 oktjabrja 1959 g., Baku) =- Orbis 15(1966), pp. 288-291. 
54. HAZAI, G[yörgy]: Permanent International Altaistic Conference = MIO 14 (1968), pp. 507-508.

55. HAZAI György: A XXVII. Nemzetközi Orientalista Kongresszus [The 27 th International Orientalist Conference] $=$ Fil.Közl. 1970: 1-2, pp. 239-240.

56. HAZAI, G[yörgy]: Aktuelle wissenschaftsorganisatorische Probleme der Permanent International Altaistic Conference $=$ PIAC News. 6(1971), pp. 6-9.

57. HAZAI, [György] Georg: Letter to the secretary-general from --. (Berlin, 28 October 1970) = PIAC News. 6 (1971), pp. 6-9.

58. HAZAI, G[yörgy ]: Proceedings of the Twenty-Sixth International Congress of Orientalists. I-III. New Delhi, 1966-1970. Review $=$ OLZ 68 (1973), cols. $238-246$.

59. HOPP Lajos: Vocazione europea della Turchia. A Reformtol a Köztársaságig. (Az 1973. október 8-9-i velencei uilésszak ismertetése) [From Reform to Republic. (A review of the Venice session held 8-9 October 1973)] = Helikon 1973: $2-3$, pp. $462-464$.

60. KAKUK, [Zsuzsa] Suzanne: Le I ${ }^{\mathrm{er}}$ Congrès de Linguistique Turque $=$ AOH 27 (1973), pp. 239-240.

61. KARA, Glyörgy]: La XII ${ }^{\mathrm{e}}$ session de la P. I. A.C. = AOH $23(1970)$, pp. 233-234.

62. KARA, Glyörgy l: La XIV ${ }^{e}$ session de la P.I. A. C. = AOH 26 (1972), pp. 152-153.

63. KARA, G[yörgy]: La conférence internationale de $1^{\prime}$ UNESCO sur l'Asie Centrale, Achkhabad, $1972=\mathrm{AOH} 27$ (1973), pp. 135-137.

64. MELLES, K[ornélia]: Proceedings of the 3rd East Asian Altaistic Conference. August 17-24. 1969, edited by Ch'en Chieh-Hsien and Jagchid Sechin. Taipei. Review $=$ AOH 24 (1971), pp. 395-398.

65. SCH ÜTZ, [Ödön] $\mathrm{E}_{\odot}:$ The 11 th session of the Permanent International Altaistic Conference (PIAC) in Hørsholm, Denmark, 2-6. June, $1968=$ AOH 22 (1969), pp. 273-277.

66. ZHUKOVSKAYA, N. - MOLCHANOVA, O.: Papers on orientology at the anthroponymic conference "Personal Names" = AOH 22 (1969), pp. 277-281.

67. A varsói orientalista konferencia [The Warsaw Orientalist Conference) = M Tud. 2 (1957), pp. 426-427.

c/ Journeys, field-work and expeditions

68. DIÓSZEGI Vilmos: 72 nap Törökországban $[72$ days in Turkey $]=$ Múzeumi Hi radó 1954 , pp. $354-356$.

See No. 69. 
69. DIÓSZ EGI Vilmos: Magyar néprajz-kutatók küllföldi útjai 1954-ben. Törökország [Journeys of Hungarian ethnngraphers abroad in 1954. Turkey] = Népr.Ërt. 37 (1955), pp. 304-305.

See No. 68.

70. DIÓSZ EGI Vilmos: Beszámoló lening rádi, valamint szibériai tanulmányutamról [Report on a study-tour in Leningrad and Siberia] = Ethn. $69(1958)$, pp. $628-635$.

See No. 71 .

71. DIÓSZ EGI, Vilmos: Bericht für eine Forschungs reise nach Südsibirien = Sociologus N. F. 9(1959), pp. 60-66.

See No. 70 .

72. DIÓSZ EGI Vilmos: A mongóliai samanizmus kérdései (Beszámoló az 1960. évi mongóliai gy uijtőútról) [Problems of Mongolian Shamanism (Report of an expedition made in 1960 to Mongolia)] = Ethn. 72 (1961), pp. 537-554. [Résumé in German and Russian].

See No. 73.

73. DIÓSZ FGI, Vilmos: Problems of Mongolian Schamanism (Report of an expedition made in 1960 in Mongolia) = AEthn. $10(1961)$, pp. 195-206.

See No. 72 .

74. ERDÉLYI I[stván] - NAVAAN D. : Az 1963. évi mongol-magyar régészeti expedíció eredményei [ Results of the Mongolian-Hungarian archeological expedition of 1963] = ArchÉrt. $92(1965)$, pp. 73-84.

75. ERDÉLYI István: Elözetes jelentés az 1971. évi mongóliai régészeti kutatásainkról |Preliminary report on the archeological investigations in Mongolia in 1971] = ArchÉrt. 101 (1974), pp. 139-145.

76. KARA György - KÓHALMI Katalin U. - RÓNA-TAS András: Jelentés mongóliai tanulmányutunkról [ Report on our study-tour in Mongolia] = I.OK 12 (1958), pp. $409-414$.

77. KARA György - KÓHALMI Katalin U. - RÓNA-TAS András: Nyelvészeti és néprajzi tanulmányúton Mongóliában [On a linguistic and ethnographic study -tour in Mongolia] $=$ MTud, 1958 , pp. 305-328.

78. NÉMETH Gyula: Beszámoló bolgáriai tanulmányutamról [Report on my studytour in Bulgarial = 1 . OK 5(1954), pp. 213-218.

See Nos. 733,734 .

79. RÓNA-TAS András: Magyar néprajzi és nyelvészeti expedíció Mongóliában (A Hungarian ethnographic and linguistic expedition in Mongolia] = Ethn. $68(1957)$, эp. 636-638.

80. RÓNA-TAS András: Jelentés második mongóliai tanulmányutam ról [Report on my second study-tour in Mongolia] = I. OK 14(1959), pp. 345-350. 
81. RÓNA-TAS András: Beszámoló csuvas tanulmányutam ról [Report on a Chuvash study-tour] = I. OK 23(1966), pp. 325-334.

See No. 82 .

82. RÓNA-TAS, András: Report on a fieldwork in the Chuvash Autonomous Republic $=$ PIAC News. $2(1966)$, pp. 15-16.

See No. 81.

\section{REPORTS ON TURCOLOGICAL RESEARCH}

a/ In Hungary

83. BETHLENFALVY, G[6za]: Vengerskie raboty po orientalistike 1959-1964 gG. $=$ NarAzAfr. 1966:6, pp. 161-168.

84. BETHLENFALVY Géza: Beszámoló az Orientalisztikai Szakosztály müködéséról [Report on the activity of the Oriental Section of the Hungarian Academy of Sciences $]=$ MNy. 66 (1970), pp. 125-126.

85. CZEGLÉDY, K[ároly]: Oriental Studies = Science in Hungary (Budapest, 1965), pp. 287-305.

צ6. CZEGLÉDY K[ároly]: Orientalisztika [Orientılism] = Az Eötvös Loránd Tudomânyegyetem története 1945-1970. (Budapest, 1972), pp. 554-569.

87. ECSEDY, |Ildik6́ Hilda: The Körösi Csoma Society, $1969=$ AOH $23(1970), p p$. $373-374$.

88. ECSEDY, [Ildikó\} Hilda: The Körösi Csoma Society, $1970=$ AOH 26 (1972), pp. $151-15$ ?.

89. ECSEDY, [Ildikó] Hilda: The Körösi Csoma Society on the eve of the second triennium $=$ AOH 26 (1972), pp. 381-384.

90. FEKETE, Lajos: Macaristan'da Türk tarih kaynakları üzerinde yapilan araştırmalar ve istikbale ait planlar $=\mathrm{V}$. Türk Tarih Kongresi. Ankara, 12-17 nişan 1956 (Ankara, 1960), pp. 464-477.

See Nos. $91,92,93$.

91. FEKETE Lajos: Török nyelvü forráskiadásaink kérdéséhez [On the problem of publication of the Turkish sources of Hungarian history] $=\mathrm{MNy} .57$ (1961), pp. $319-325$.

See Nos. 90, 92, 93 .

92. FEKETE Lajos: Hozzászólás a török nyelvü történeti források kiadásának kérdéséhez (Comments on the problem of the publication of Turkish historical sources $\mid$ = Száz. 95(1961), pp. 211-212.

See Nos. 90, 91, 93 . 
93. FEKETE, L/ajos ]: $\mathrm{K}$ problematike víberu a vydávania tureckých pa ramenov = Historický Casopis 10 (1962), pp. 90-100.

Reviewed by: Hazai, G[yörgy] = [AJb. 35 (1965), pp. 432.

See Nos. $90,91,92$.

94. GERMANL'S, Gy[ula]: Hungarian Orientalists - Past and Present = Indo-Asian Culture 6 (1957), pp. $291-298$.

95. HAZAI György: Hozzászólás Ki rály Péter "A Nyelvtudományi Intézet feladatai" c. beszámolójához [A comment on P. Király's report:"Tasks of the Hungarian Linguistic Institute'"] = I. OK 18 (1961), pp. 81-84.

96. HAZAI György: A szovjet népek irodalmának teljesebb megismeréséért [For a more complete knowledge of the Soviet peoples' literature] = Él 6:15(1962), p. 12 .

97. HAZAI, Glyörgy ]: On the Oriental Study in Hungary = The Toyo Gakuho (Reports of the Oriental Society) 52:3(1969), pp. 54-78.

98. HAZAI György: Még egyszer a magyar turkológiáról [Once again on Hungarian Turcology] = Valóság 16 (1973), pp. 100-102.

99. H EGEDÜS József: A török-magyar nyelvrokonság korai cáfolatá ról (An early refutation of the Turkish-Hungarian linguistic relationship] $=\mathrm{MNy} .55$ (1959), pp. 107-110.

100. HEGEDŨS József: A magyar nyelv összehasonlításának kezdetei az egykorú európai nyelvtudomány tuikrében [Beginnings of the comparis on of the Hungarian language as reflected in contemporary European linguistics] = NyelvtudÉrt. $56(1966)$, pp. 5-115.

101. HOPP Lajos: Orientalisztikai ujdonságok [Novelties in oriental studies] = Helikon 1972:3-4, pp. 535-537.

102. KAKUK, [Zsuzsa) Suzanne: Cent ans d'enseignement de philologie turque à l'Université de Budapest = St Turc. (1971), pp. 7-28.

103. KAKUK, ZS[uzsa]: TjurkologiXeskie issledovanija $v$ Vengrii = SovTjurk. 1974:1, pp. 79-92.

104. KARA György: A magyar altajisztika helvzete és feladatai [The situation and tasks of Hungarian Altaistic studies] = MTud. 76 (1969), pp. 686-691.

105. KARA, Glyörgy]: Recherches hongroises sur les langues orientales, 1945-1970 = ALH 21 (1971), pp. 165-171.

106. KARA György: Öshazakutatás a XLX. században [19th century research into the original home of the Hungarian people] = Magyar utazók (1973), pp. 181-189.

107. KARA György: Az öshazakutatás állása a XX. században |The state of 20th century research into the original home of the Hungarian people J = Magyar utazók (1973), pp. 316-319. 
108. KOŞAY, Hâmit $Z$.: Budapeşte Türkoloji kürsüsü kuruluşunun yiuzïncü yıldönümü kutland1 $=$ Tïrk Kültürü 98 (1970 Aralık), pp. 179-180.

109. LIGETI Lajos: A magyar orientalisztika idószerú kérdései (Relevant problems of Hungarian orientalism] = I. OK 10 (1957), pp. $71-79$.

110. LIGETI Lajos: Orientalisztika [Orientalism] = M'Tud. 15(1970), pp. 217-219.

111. [LIGETI Lajos]: Macaristan'da Türk dili kürsüsünün kuruluşunun yüzüncü yılını kutlama töreninde bu kürsünün profesörü ve akademi ủyesi Lajos Ligeti'nin açıs konuşması $=$ Türk Kültürü 98 (1970 Aralık), pp. 181-183.

112. LIGETI Lajos: Keletkutatásunk helyzete [The present situation of Hungarian Oriental studies] = Keletkutatás 1973 (Budapest, Kőrösi Csoma Társaság, 1974), pp. 5-13.

113. LIGET1, [Lajos] Louis: Les recherches orientales en Hongrie = Nouvelles Études Hong roises 1974, pp. 57-68.

114. NÉMETH, GY[ula]: Macaristan turkologyası 1939-1946 = AÜDTCFD 8 (1950), pp. 239-240.

115. NÉMETH, [Gyula] Ju.: Specialjnye problemy tjurskogo jazykoznanija v Vengrii = VJaz. $12(1963): 6$, pp. 126-136.

116. NÉMETH, [Gyula] Ju.: Obšđ̇ie problemy tjurskogo jazykoznanija v Vengrii = VJaz. $13(1964): 6$, pp. 119-125.

117. NÉMETH, [Gyula| J.: Linguistics $=$ Science in Hungary $\left(E d\right.$, by $T_{0}$ Erdey $-G$ rúz and I. Trencsényi-Waldapfel, Budapest, 1965), pp. 179-197.

118. NÉMETH, [Gyula] J.: Die Orientalistik in Ungarn $1938=$ The Muslim East (1974), pp. 11-22.

119. RÁSONYI László: A magyar keletkutatás orosz kapcsolatai [The Pussian connections of IIungarian orientalism]. Budapest, 1962. $20 \mathrm{pp}$. / Publicationes Bibl. Ac. Sc. Hung. 26./ [Résumé in Russian and English]. Reviewed by Hazai, G. = UAJb. $35(1964)$, p. 425.

120. RÅSONYI, L[ászló]: Macar Bilimler Akademisi = Türk Kültürü 67 (1968, Miay 1s), pp. 477-181.

121. RÓNA-TAS, András: Ten years of Altaic (Philological) Studies in Hungary = Acta Asiatica - Toho Gakkaj. 3(1962), Tokyo, pp. 70-83.

122. RÓNA-TAS, A[ndrás]: The oriental comittee of the Itungarian Academy of Sciences on the co-operation of Uralic and Altaic studies $=A O H 20$ (1967), pp. $367-368$.

123. SCH ÜTZ, IÖdön] E.: Die Tätigkeit der ungarischen Altaisten, 1965. Die gegenwärtige Lage und Prognose $=$ PIAC News. 1 (1966), pp. 14-15. 
124. TERJÉK József: Tudósítások Körösi Csoma Sándorról. Közreadja -- [Reports on Alexander Csoma de Kórös. Published by -- ] Budapest, Kónoosi Csoma Társaság, 1971. [Without pagination].

125. URAY Géza: Az Orientalisztikai Bizottság beszámolójának vitája (A vitát öszszefoglalta - ) [Debate on the report of the Oriental Committee (Summarized by --$)]=$ I. OK $10(1957)$, pp. 80-81.

126. URAY, G[éza]: Raboty vengerskich ucenych po vostokovedeniju v 1956-1957 godach = Problemy vostokovedenija (Moskva, 1959), No.1, pp. 144-152. Abridged version: Hangarī gakusha no tōhō kenkyū katsudō - 1956-57 nen = Shonö 1959. oct. pp. 28-29.

127. VASS Előd: A magyar turkológia [Turcology in Hungary] = Valóság 16 (1973):7, pp. 30-39.

\section{b/ Abroad}

128. BASKAKOV, N. $A_{\bullet}:$ L'étude des langues turques en Union Soviétique $=\mathrm{AOH}$ 9 (1959), pp. 39-53.

129. DÉCSY, Gyula: Hungary - Soviet and East European linguistics = Th. A. Sebeok, Current trends in linguistics. Vol. I. (The Hague, 1963), pp. 523-537.

130. ERDÖDI József: Uralisztika és altajisztika az Egyesiilt Államokban [Uralic and Altaic studies in the United States] $=$ NyK. $66(1964)$, pp. $438-443$.

131. FEKETE, L,ajos]: Über Archivalien und Archivwesen in der Türkei $=A O H$ 3 (1953), pp. 179-205.

132. FEKETE, L[ajos]: Arbeiten der grusinischen Orientalistik auf dem Gebiete der türkischen und persischen Paläographie und die Frage der Formel sözúmuz $=\mathrm{AOH} 7$ (1957), pp. 1-20.

133. H AJDÚ Pêter: Nyelvtudományi munkásság a Szovjetunióban [Linguistic ac-tivity in the Soviet Union] = Nyr. $71(1947)$, pp. 138-141.

134. HAZAI, G[yörgy]: Zwei neue Organe der Turkologie = MIO 17 (1971), pp. 145-147.

135. HAZAI, G[yörgy]: International Journal of Middle Last Studies. $1(1970)=\mathrm{OLZ}$ 68 (1973), col. 109.

136. HAZAI, Glyörgy]: lo Jahre der "Uralic and Altaic Series" der Indiana University Publications $=$ AASt. 9, 1973 (1974), pp. $171-173$.

137. JANDUŠKıN, S.: Tájkutató Múzeum a Csuvas Autonóm Szovjet Szocialista Köztársaságban [The Regional Museum in the Chuvash Autonomous Soviet Socialist Republic] $=$ Ethn. $63(1952)$, p. 203.

138. Kí LDY-NAGY, Gyula: Midhat Se rtoğlu, Muhteva bakımından Baş̧vekâlet Arşivi. Ankara, 1955. Review $=$ AOH 6 (1956), pp. 295-298 and I.K (1958), pp. 237-239. 
139. KONONOV, A. N.: Török filológia a Szovjetunióban (1917-1967) [Turkish philology in the Soviet Union (1917-1967)] = I. OK 24 (1967), pp. 3-28.

140. NÉMETH Gyula: A szovjet turkológia [Soviet Turcology] = I. OK 4 (1953), pp. 105-116.

Contributions by Czeglédy Ká roly: pp. 117-119; Rásonyi László: pp. 119-122; Angyal Endre: p. 122; Pais Dezső: p. 123.

141. PERÉNYI József: A török történetírás [Turkish historiography] = Száz. 81 (1947), pp. 192-202.

142. POUCHA, PAVEL: A csehszlovák orientalisztika munkája, célkitûzései és szervezete [The activities, programmes and organisation of Orientalis $m$ in Czecho-Slovakia] = I. OK. 7 (1955), pp. 91-101.

143. [RÁSONYI László]: Türkiyede mânevi bilimlerin geleceği = Türk Kültürü 6 (1968), pp. $151-157$.

144. SZÉPE, GY[örgy]: J. Lotz, The Uralic and Altaic program of the American Council of Learned Societies (1959-1965). Bloomington, 1966. Review $=$ ALH 18 (1968), pp. 453-454 and NyK 69 (1967), pp. 440-442.

See also Nos. $14,16,482,487,489,490$.

\section{PERSONALIA}

A 1 m á s y György

145. SZÉKELY András: Almásy György közép-ázsiai expedíciói [György Almásy's expeditions to Central-Asia] = Magyar utazók (1973), pp. 288-290.

\section{B á $l$ i n t Gábor}

146. HAZAI, G[yörgy]: Gábor Bálint (1844-1913) = TD Sayı 143 (1963), pp. 780-781.

147. KARA György: Bálint Gábor keleti levelei. Jelentése Oroszország-és Ázsiában tett utazásáról. Bevezetővel új ra közreadja -- [G. Bálint's oriental letters. $\mathrm{His}$ report on his journey to Russia and Asia. Republished with a preface by:--] Budapest, Körösi Csoma Társaság 1973. [Without pagination].

B á r c z i Géza

148. BENKÓ Loránd: Bárczi Géza hetven éves [Géza Bárczi.A commemorative essay on his 70th birthday $]=$ NyelvtudÉrt. $40(1963)$, pp. 5-15. 
149. BENKő Loránd: Bárczi Géza köszöntése a Magyar Nyelvtudományi Társaságban születésének nyolcvanadik évfordulóján [Géza Bárczi. Felicitations on his 80 th birthday in the Hungarian Linguistic Society] $=\mathrm{MNy} .70(1974), \mathrm{pp}$. 249-250.

B a r tó k Béla

150. RÂSONYI László levelei Bartók Bélához [László Rásonyi's letters to Béla Bartók) = Documenta Bartókiana 3 (Budapest, 1968), pp. 179, 183, 193-195, $197-201$.

B e s s e János

151. SZẾKELY András: Besse János = Magyar utazók (1973), pp. 196-198.

152. VÁSÁRY István: Ó-Gyallai Besse János kaukázusi tudósitásai [The reports of János Besse of Ó-Gyalla from the Caucasus. Published by --1. Budapest, Körösi Csoma Társaság, 1971. (Without pagination).

Brockelmann. Carl

153. CZEGLÉDY, K[ároly]: Carl Brockelmann $(1868-1956)=\mathrm{AOH} 7(1957)$, pp. 105-107.

B u d e n z József

154. BEKE Ödön: Budenz József. (Halálának 65. évfordulója alkalmából) (József Budenz. (On the occasion of the 65th anniversary of his death)] = MTud. 2 (1957), pp. 53-57.

C z e g l é dy Károly

155. HARMATTA János: Czeglédy Károly hatvan éves [Károly Czeglédy. A commemorative essay on his 60 th birthdayl = AT 21 (1974), p. 266.

Diószegi Vilmos

156. KÓHALMI, [Katalin] KATHE, $\mathrm{C}$.: In memoriam Vilmos Diószegi 1923-1972= AOH 26 (1972), pp. 377-379.

157. VA RGA Mária: Diószegi Vilmos munkâinak bibliog ráfiája. Gondozta - - IVilmos Diószegi, a bibliography. Comp. by Mária Varga] = Ethn. 43 (1972), pp. $534-539$. 
E ren, Hasan

158. BÁRCZI Géza: Hasan Eren tiszteletbeli tagunk üdvözlése [A salute to Hasan Eren, honorary member of the Hungarian Linguistic Society] $=$ MNy, $64(1968)$, pp. $380-381$.

$\mathrm{F}$ eh ế $\mathrm{r}$ Gêza

159. HARMATtA J[ános]: Fehér Géza = ArchF̂́rt. 82 (1955), pp. 229-230. See No. 160.

160. HARMATTA, J[ános]: Géza Fehér = AArch. 5 (1955), pp. 297-299. See No. 159.

161. KOŞAY, Hâmit Zübeyr: Tiirkolog ve Bizantolog Géza Fehér'in hayatı ve eserleri. 1890-1955 = Belleten XLX/76 (1955), pp. 529-534; English: pp. 535-540.

F e k e t e Lajos

162. BAYERLE, G[ustav]: Lajos l'ekete 1891-1969 [A bibliography] = ArchOtt. 1 (1969), pp. 303-316.

163. CZEGLÉDY, K[ároly]: Prof. L. Fekete $=$ AOH 13 (1961), pp. 3-8.

164. HEGYI Klára: Fekete Lajos (1891-1969) = LK 41 (1970), pp. 387-388.

165. KAKUK Zsuzsa: Fekete Lajos 1891-1969 = NyK 71 (1969), pp. 417-418.

166. KÁLDY-NAGY, GY[ula]: Lajos Fekete (1891-1969) = ALH 20 (1970), pp. 407-410.

167. LIGETI Lajos -- CSONGOR Barnabás -- KÁLDY NAGY [Gyula], István [sic!]: Búcsú Fekete Lajostól [Lajos Fekete: in memoriam.] = I. OK 26 (1969), pp. 415-419.

See Nos. $168,169$.

168. LIGETI, L[ajos]: Prof. L. Fekete, 1891-1969= AOH 22 (1969), pp. 379-381. See Nos. 167, 169.

169. LIGETI, Lajos: Fekete Lajos 1891-1969 = MTud. 14 (1969), pp. 633-636. See Nos. 167, 168.

170. MLJATEV, P.: Lajos (Ludwig) Fekete (1891-1969) = EtBalk. 8 (1969): 2, pp. 144-146.

171. SINKOVICS István: Fekete Lajos. 1891-1969. = Száz. 105 (1971), pp. 219-221.

172. VASS Elöd: Fekete Lajos. $1891-1969=$ LevSz. 19 (1969), pp. 805-806. 
173. VASS, Ellödl: Lajos Felsete. 1891-1969 [A biblingraphy] Anallingu. 1(1971) 2. pp. $135-138$.

See also Nn. 102.

Fok os - Fuchs Dávid

174. SEBESTYÝ́N Irén, N.: Fokos-Fuchs Dávid nyolcvan éves (Dávid Fokos-Fuchs. A commemorative essay on his 80 th birthdayl $=$ NyK 66(1964), pp. 429-431.

175. VÉRTES, Edith: D. R. Fokos-Fuchs zum Gruss = ALH 24 (1974), pp. 3-14.

176. Veröffentlichungen von D. R. Fokos-Fuchs. 1905-1973=ALH 24(1974), pp. 15-27.

Ge $r$ m a n us Gula

177. DÁVID, G[éza]: A bibliography of the works of prof. Julius Germanus. Comp. by $--=$ The Muslim East (1974), pp. 253-264.

178. KÅLDY-NAGY, Gy[ula]: Julius Germanus = The Muslim East (1974), pp. 7-10.

G o I d z i h e r Ignác

179. CZEG LÉDY Ká roly: Emlékezés Goldziher Ignácra |Ignác Goldziher - A commemorative essay] = Világosság 12 (1971), pp. 713-716.

180. NÉMETH, [Gyula] J.: Goldzihers Jugend = AOH 1 (1950-51), pp. 7-25.

G o $\mathrm{m}$ b o c $z$ Zoltán

181. KOVALOVSZKY Miklós: Gombocz Zoltán = MNy. 51 (1955), pp. 405-421.

182. NÉMETH Gyula: Gombocz Zoltán. Budapest, 1972. 258 pp. /A mult magyar tudósai./.

See No. 183.

183. NÉMETH, |Gyula| J.: Zoltán Gombocz. Ein ungarischer Sprachforscher $(1877-1935)=$ ALH 22 (1972), pp. 1-40.

184. RÁSONYı, Iászló: Gombocz Zoltán (1877-1935) = Türk Kültürü 10(1972), pp. $443-146$.

J e g o r ov, V.G.

185. RÓNA-TAS András: V.G. Jegorov kilencven éves ( V.G. Jegorov - A commemorative essay on his ninetieth birthday] $=$ NyK 72 (1970), pp. 217-218. 
J e r n e y János

186. HA LÂSZ Gyula: Jerney János = Világjá ró magyarok (1945), pp. 93-105.

See also No. 1575 .

Kn i e $z$ s a Istvăn

187. LIGETI Lajos: Kniezsa István $=$ MNy. 61 (1965), pp. 129-131.

Kon on ov, A. N.

188. Andrei Nikolaievitch Kononov élu membre honoraire de l'Académie des Sciences de Hongrie $=$ AOH 28 (1974), p. 287.

Ko vá c h János

189. BANNER János: Kovách János a tarcali magyar-török szótáríró [János Kovách of Tarcal a compiler of a Hungarian-Turkish dictionary] = Hermann Ottó Múzeum Évkönyve 8 (1969), pp. $221-231$.

Kö p r ül üz a de Mehmet Fuat

190. NÉMETH, [Gyula] J.: Köprülüzade Mehmet Fuat $(1890-1966)=A O H 20(1967)$, pp. 363-366.

K ú n o s Ignác

191. KAKUK Zsuzsa, N.: Künos Ignác emlékezete [Ignác Kúnos. A commemorative essay] = Nagyvilág 5 (1960), p. 1582 .

See also Nos. 791,873 .

L ig e $t$ i Lajos

192. [BÁ RCZI Géza]: Ligeti Lajos hatvanadik születési évfordulójához [Lajos Ligeti. A commemorative essay on his sixtieth birthday] $=\mathrm{MNy} .58(1962), \mathrm{pp}$. $525-527$.

193. SANŽEEV, G. D.: Akademik Lajos Ligeti i razvitie altaistiki $v$ Vengrii $=$ NarAzAfr. 1962:5, pp. 155-158.

194. SZILÁGYI, [Éva] ÈVE, R.: Louis Ligeti a 70 ans [A bibliography]. Mise au point par -- = Anal Lingu. Vol. 2(1972):2, pp. 29-31. 
195. LIGETI Lajos belső-mongóliai kutatóńtja / L. Ligeti's study-tour in CentralMongolia] = A nagyvilág magyar vándorai / Régi magyar világjárók/. (Budapest, 1955), pp. 218-240.

196. Hommage des orientalistes hongrois a $\mathrm{M}$. Louis Ligeti $=\mathrm{AOH} 15(1962)$, pp. 5-6.

197. Bibliographie des oeuvres du Prof. L. Ligeti $=$ AOH 15 (1962), pp. 7-13. See also No. 36.

M a n s u ro ğ l u, Mecdut

198. HAZAI, Glyörgyl: Mecdut Mansuroğlu = Orbis 10 (1961), pp. 254-256.

See No. 199.

199. HAZAI, G[yörgy]: Mecdut Mansuroğlu (1910-1960) = Onoma 7 (1961), pp. 511-512.

See No. 198.

$\mathrm{M}$ o $6 \mathrm{r}$ Elemér

200. H AJDÚ Péter: Moór Elemér 75. születésnapjára |Elemér Moór. A commemorative essay on his 75 th birthday $]=$ NyK 69 (1967), pp. $430-432$.

M O r a c s i k Gyula

201. BENEDICTY, R.: Die literarische Tätigkeit von Gyula Moravcsik. Zgest. von -- = AAnt. 10(1962), pp. 295-313.

202. BESEVLIEV, V.: Gyula Moravesik = EtBalk. 1973, pp. 147-148.

203. ERDÉLYI, I[stván]: Gyula Moravesik (1892-1972) = AArch. 25 (1973), pp. $371-373$.

204. HARMATTA János: Búcsú Moravcsik Gyulától [Gyula Moravcsik - in nemoriam] = II. OK 12 (1973), pp. 111-112.

See No. 205.

205. HARMATTA János: Moravesik Gyula. 1892-1972 = MTud. 18 (1973), pp. $683-686$.

See No. 204.

206. KÁDÁR, Z[oltán]: Gyula Moravcsik (1892-1972)= ByzSI. 34 (1973), p. 251 .

207. MARÓT Károly: Moravcsik Gyula hetven éves [Gyula Moravcsik. A commemorative essay on his 70th birthday J = AT 9(1962), pp. 109-112.

208. MÁTRAI László - HARMATTA János - RITOÓK Zsigmond: Moravesik Gyula emlékezete [Gyula Moravcsik - in memoriam] = II. OK 21 (1972), pp. 295-300. 
209. SZÉKELY György: Moravcsik Gyula (1892-1972) = AnnHist. 14(1973), pp. 359-364 and Száz. 108 (1974), pp. 547-550.

M unkácsi Bernát

210. KOROMPAY Bertalan: Munkácsi Bemát és a néptudomány [Bernath Munkácsi and ethnology $=$ MNy, 57 (1961), pp. 377-383.

211. PALLÓ Margit, $K_{\text {. }}$ : Munkácsi Bernát jelentősége a magyar turkológiában [Bernath Munkácsi's importance in Hungarian Turcology j $=\mathrm{I}$. OK 16 (1960), pp. $397-402$.

$\mathrm{N}$ ê m e $\mathrm{th}$ Gyula

212. AŚniN, F.D.: Diula Nemet (K semidesjatipjatiletiju so dnja rożdenija) = NarAzAfr. 1965: 6, pp. 213-215.

213. ECKMANN, J[ános]: Gyula Németh. (Dogumunun 60-lnes yıldönümü münasebetivle) $=$ TD Savi 14-15(1950), pp. 81 95.

21 t. EREN, Hasan: Gyula Németh'e armağan = Németh Armağanı (Ankara, 1962), pp. VII-XI.

215. HAZAI, Glyörgy $]:$ Gyula Németh = Németh Armağanı (Ankara, 1962), pp. 1-1+.

216. HAZAI, Glyörgv] : Grula Németh' in eserleri = Németh Armağanı (Ankara, 1962), pp. $15-41$.

21i. KAKLK Zsuzsa, N.: Nemeth Gyula 70 éves [Julius Németh. A commemorative essay on his 70th birthday $)=$ NyK $62(1960)$, pp. 354-355.

218. KÁLMÁN Bêla: Németh Gyula hetven êves (Julius Németh. A commemorative essay on his 7 oth birthday $=$ MNy. $56(1960)$, pp. 492-494.

219. LIGETI, L[ajos]: M. Jules Németh = AOH 11 (1960), pp, 5-9.

220. LIGETI, L[ajos]: Julius Németh zum Gruss $=$ ALH 20(1970), pp. 241-244.

221. SZÉKELY György: Németh Gyula professzor életpályája és tudományos tevékenvsége [Professor Gyula Németh's career and his scientific activity] = ELTE Êrt. 1970/71. pp. 31-37.

222. SZÉKELY, GY[örgy ]: Gyula Németh und unsere Sprachwissenschaft = AnnLingu. 3 (1972), pp. $3-30$.

223. IRAY, G|éza]: A bibliography of the works of prof. J. Németh $=$ AOH $11(1960)$, pp. $11-28$.

See also Nos. 30, 102, 236. 
ó n o d y Bertalan

224. SZÉKELY András: Ónody Bertalan, a turáni öntözéses gazdálkodâs tanulmányozója [Bertalan Ónody, an investigator of irrigation in Turan] = Magyar utazók (1973), pp. 174-175.

Rá s o n y i László

225. LIGETI, L(ajos]: Le professeur L. Rásonyi $=$ AOH 28 (1974), pp. 147-151.

R e vi c z k y Károly

226. REYCHMAN, J.: Une correspondance "turque" entre Charles Reviczky et Adam Casimir Czartoryski $=$ AOH 13(1961), pp. 85-8:.

S e b e s t y é n Gyula

227. SCHELKEN Pálma, "Hej regii rejtem ...". Emlékezés Sebestyén Ciyulára I"Hej, regö rejtem ...". A commemorative essay in memoriam Gyula Sebestyén] = Magyar Zene 1:4(1961), pp. $411-143$.

St e in Aurél

228. HALÁSZ Gyula: Stein Aurél = Világiá ró magvarok 11945), pp. 36ĩ-398.

229. IÁAG Sándor - RÁSONYI lászló: Stein Aurél, századunk legnagyobb Ázsiakutatója [Aurel Stein, the greatest explorer of Asia in our century] = Magyar utazók (1973), pp. 274-282.

230. LIGkTI Lajos: Stein Aurél emlékezete [Aurel Stein. A commemorative essay] = MTud. 13(1968), pp. 667-673.

231. RÁSONYI Lászlo: Stein Aurél és hagvatéka [Aurêl Stein and his legacy]. Budapest, 1960. 37 pp. /Publicationes Bibl. Ac. Sc. Hung. 18./.

See No. 232 .

232. RÁSONYI, Llászló]: Sir Aurel Stein and his legacy = The New Hungarian Quarterly 2 (1961), pp. 217-224.

See No. 231.

233. RÁSONYI László: Stein Aurél = Természettudományi Közlöny 93 (1962), pp. $566-568$.

See No. 234.

234. RÁSONYI, I,ászló]: Sir Aurel Stein (On the centenary of his birth) $=\mathrm{AOH}$ 14 (1962), pp. $241-252$.

See No. 233. 
Th ú r y József

235. CSIKAI, Valéria: József Thúry. 1861-1906. [A bibliog raphy] Zusammengestellt von -- = Anallingu. 3 (1973) No. 2, pp. 139-141.

236. NÉMETH, GY[ula]: J. Thury. Çeviren Ziya Tugal. Istanbul, 1950. XVIII + 34 pp., 1 pl. /Macar Bilim Eserleri Serisi. 1./ [On pp. V-XVIII : a bibliography of the works of J. Németh by T. Halasi Kun and H. Eren.]

See also No. 102 .

\section{Ú j f a l v y Károly}

237. HALÁSZ Gyula: Újfalvy Károly = Világjá ró magyarok (1945), pp. 269-271.

238. SZÉKELY András: Újfalvy Károly = Magyar utazók (1973), pp. 214-215.

V á m bé r y Ármin

239. CSINÁDY Gerô: Vámbéry Ármin emlékezete [Ármin Vámbéry. A commemorative essay ] = Földrajzi Közlemények. Új folyam. 11 (1963), pp. 1-4.

240. HALÁSZ Gyula: Vámbéry Ármin = Világjá ró magyarok (1945), pp. 193-225.

241. HAZAI György: Megemlékezés Vámbéry Árminról [Ảrmin Vámbéry. A commemorative essay] = NyK 65 (1963), pp. 196-198. See No. 242.

242. HAZAI, Glyörgy]: Büyüuk türkolog Armin Vambery $(1832-1913)=$ Kitap Belleten. Yeni Seri 2 (26), Ağustos 1963, pp. 3-4. See No. 241.

243. HAZAI, G[yörgy]: Ármin Vámbéry 1832-1913. A bio-bibliography. Budapest 1963. 1 microfiche $30 \mathrm{p.} /$ Micropublications of the Library of the Hungarian Academy of Sciences. 3./

244. KISS József: Vámbéry nyomában. Egy filmrendezö naplójából [In Vámbêry's tracks. From the diary of a director]. Budapest, $1972176 \mathrm{pp}$.

245. RÁSONYI, L[ászló]: Ármin Vámbéry = Türk Kültiürü 8 (1970), pp. 276-279.

246. RUBINYI Mózes: Vámbéry Ārmin = Rubinyi Mózes, Emlékezések és tanulmányok (Budapest, 1962), pp. 59-63.

247. VÉCSEY Zoltán: Vámbéry Ármin = Magyar utazók (1973), pp. 208-213.

248. VIHAR Béla: Szovjet -orosz író elbeszélése Vámbéry Ármin ról [A SovietRussian short story on Ármin Vámbéry] = Ethn. 58 (1947), pp. 348-349.

See also Nos. $102,946$. 
$\mathrm{Z}$ i c h y Jenö

249. HALísZ Gvula: Zichv Jenö = Világjáró magyarok (1945), pp. 250-268.

250. CSINÁDY Ge rö: Zichy Jenó Ázsia-expediciói |Jenö Zichy's expeditions to Asia $=$ Magyar utazók (1973), pp. 134-139. 


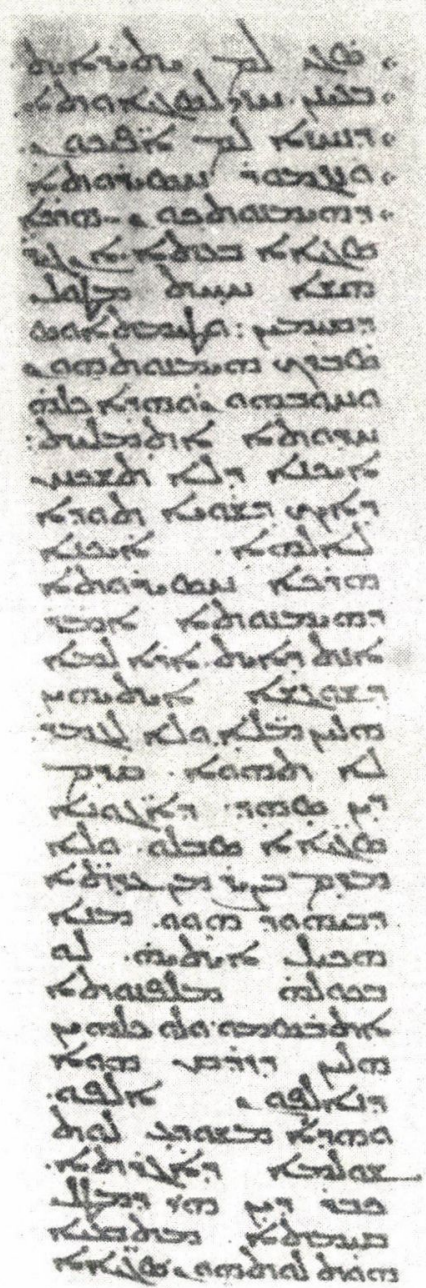

wank -saln wid. Furla pasios ent Lurke wien avectyo - al hato rúadon-aret calow navise meran - $\Delta k$. const cidars ms kif

( misla. pratiks ens arsenúswas kbsmintor ms arure

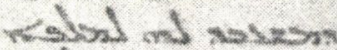
waler jouco cojiss Kons mull o kink

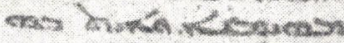

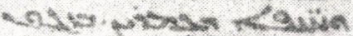

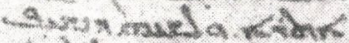

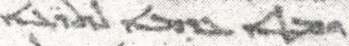

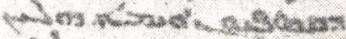
asta cuseturs anoa

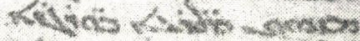
Koly Kons - nemsesa -ars dakna wirisisa

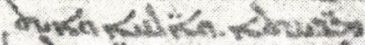

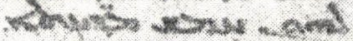
- issta mon enviana nevel In ria rkilly Kons truen kisai.

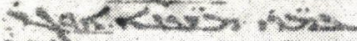
\$Sorvas usias ista - Sostrer tobo iark

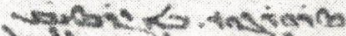
dulderi Jrixí colno

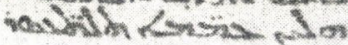
palua klasion isnam

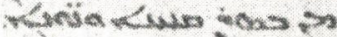
intirar Ris on autia

From "Pseudo-Zacharias rhetor on the nomads" by K. Czeglédy (in StTurc. See No. 1180.) 


\title{
II. \\ ON TURKIC PEOPLES AND LANGUAGES IN GENERAL
}

\author{
1. URAL-ALTAIC RELATIONS
}

251. BESE, L[ajos] - DEZSÓ, L[ászló] - GULYA, J[ános]: On the syntactic typology of the Uralic and Altaic languages = Theoretical problems of typology and the Northern Eurasian languages. Edited by L. Dezsö and P. Hajdú (Budapest, 1970), pp. 113-128.

252. BONNERJEA, R.: Is there any relationship between Eskimo-Aleut and UraloAltaic? = ALH 21 (1971), pp. 401-407.

253. ERDÓDI, J[ózsef]: Über einen $w \sim m$ Wechsel in den uralischen und türkischen Sprachen $=$ Proceedings of the Fifth International Congress of Phonetic Sciences (Munster, 16-22 August 1965), Ed. Eberhard Zwirner and Wolfgang Bethge. Basel-New York, 1965, pp. 264-266.

254. FOKOS [ - FUCHS] Dávid: A fónév mint tulajdonságjelző a mongolban [The noun as descriptive adjective in the Mongolian language $)=$ Ny r. $70(1946)$, pp. $13-20$ and $41-44$.

255. FOKOS [-FUCHS] Dávid: A párhuzamos jelentésváltozás kérdéséhez [On the problem of parallel semantic changes] $=$ Nyr. $70(1946)$, pp. 78-79.

256. FOKOS-FUCHS, D[ávid] R.: Aus der Syntax der ural-altaischen Sprachen = ALH 10 (1960), pp. 423-456.

Reviewed Sauvageot,A. = BSL $56(1961)$, pp. 272-273.

257. FOKOS [- FUCHS] Dávid: U ráli és altaji összehasonlitó szintaktikai tanulmá nyok [Uralic and Altaic comparative syntactical studies] = NyK 62 (1960), pp. 213-241; 63 (1961), pp. 63-81, 263-291; 64 (1962), pp. 13-55. Reviewed by Sauvageot, A. = BSL 57 (1962), pp. 206-207 and 211-212; 58 (1963), pp. $247-248$.

See No. 258. 
258. FOKOS-FUCHS, D[ávid] R.: Rolle der Syntax in der Frage nach Sprachverwandtschaft - mit besonderer Rücksicht auf das Problem der ural-altaischen Sprachverwandtschaft. Wiesbaden, 1962. $137 \mathrm{pp}$. /Ural-Altaische Bibliothek $11 . /$.

Reviewed by Jokinen, R. = Vir. 67 (1963), p. 190; Németh, J. = ALH 14 (1964), pp. $381-384$; Schlachter, W.: Zur ural-altaischen Sprachverwandtschaft = UAJb. 36 (1965), pp. 167-174; Doerfer, G. = ibid. pp. 174-178. See No, 257.

259. [FOKOS-] FUCHS, D. [ávid] R.: Eine charakteristische Ablativ-Konstruktion = MSFOu. 125 (1962), pp. 41-52.

Reviewed by Sauvageot, A. = BSL 59 (1964), p. 242.

260. FOKOS [-FLCHS] Dávid: A jelöletlenség mint az urál-altáji nyelvek egyik jellemzö szintaktikai sajátossága (The lack of suffixes as a peculiar syntactic characteristic of the Ural-Altaic languages] = NyK 65(1963) pp. 3-48. Reviewed by Sauvageot, A. = BSL 59(1964), p. 239.

261. FOKOS-FCCHS Dávid: Az uráli és altaji nyelvek szóösszetételeiról [Compounds in the Uralic and Altaic languages] = Altnapok (1965), p. 5. See No. 262.

262. FOKOS-FUCHS, Dlávid]: Aus dem Gebiete der Komposita der uralischen und altaischen Sprachen $=\mathrm{AOH} 18$ (1965), pp. 33-45.

See No. 261.

263. FOKOS-FUCHS, D[ávid]: Zur ural-altaischen Sprachverwandtschaft $=$ UAJb. 37 (1966), p. 123 .

264. HAJDÚ Péter: Szamojéd népek és nyelvek [Samoyedic peoples and languages] $=$ Nyr. 73 (1949), pp. 9-13,64-68, 225-231 and 336-340.

265. HAJDÚ Péter: Az ugor kor helyének és idejének kérdésénez [On the problem of location and chronology of the Ugric period] = NyK 54 (1952), pp. 264-269.

266. HAJDÚ Péter: A magyarság kialakulásának elózményei [The antecendents of the formation of the Hungarians]. Budapest, $1953.82 \mathrm{pp} .+3 \mathrm{pl}$. / NyelvtudÉrt. 2.\%.

267. HAJDÚ Péter: A magyarság eredete [The origin of the Hungarians]. Budapest, 1954, 20 pp. (Litogr.).

268. HAJDÚ Péter: Finnugor népek és nyelvek [Finno-Ugrian peoples and languages ]. Budapest, 1962. 425 pp. + pl.

Reviewed by Schellbach, I. = FUF 34(1962), pp. 240-241; Kodolányi, J. = A Ethn. 12 (1963), pp. 433-438; Nyíri Antal = AUSz. SEL 7 (1963), pp. 179-183; Rohan-Csermák, Géza de = EFFOu. 2 (1965), pp. 97-99; Sauvageot, A. = BSL 60 (1965), pp. 204-206; Wickman, B., Neue zusammenfassende Arbeiten für die uralischen Sprachen $=$ UAJb. $36(1965)$, pp. 179-181. 
269. HAJDÚ Pêter: Észrevételek Lászl6 Gyula "Óstörténetünk legkorábbi szakaszaki. A finnugor östörténet régészeti emlékei a szovjetföldön" c. könyvéhez [Notes on Gy. Lászlo's book "The earliest phases of Hungarian ancient history. Archeological finds concerning Finno-Ugric prehistory in the Soviet-Lnion"] = ArchÉrt. 91 (1964), pp. 118-123.

See Nos. 273, 276.

270. JUHÁSZ Jenó: Szómutató Munkácsi Bernát "Ârja és kaukázusi elemek a finnmagyar nyelve'kben" c. müvéhez. Összeállította -- [Word index to B. Munkácsi's "Arian and Caucasian elements in the Finno-Hungarian languages" Comp. $2 y--]=$ NyK 62 (1960). Supplement. 58 pp.

Reviewed by D[écsy, Gy.] = UAJb. 33 (1961), p. 293.

271. LÁNG János: Az ősi közösségek szerkezetének kialakulása és fejlödése [Formation and development of the structure of ancient societies]. Budapest, 1961. 248 pp. (KandÉrt. - Manuscript).

272. LÁNG, János: The identical structure of the kinship systems of certain UralAltaic and Indian peoples = AEthn. 11 (1962), pp. 205-212.

273. LẢSZLÓ Gyula: Östörténetünk legkorábbi szakaszai. A finnugor őstörténet régészeti emlékei a szovjetföldön (The earliest phases of Hungarian ancient history. Archeological finds concerning Finno-Ugric prehistory in the SovietUnion]. Budapest, 1961, $211 \mathrm{pp}$.

Reviewed by Erdélyi István = II. OK 12 (1962), pp. 143-147; Gulya, J. = A LH 12 (1962), pp. 409-413; Kodolányi, J. (jr.) = AEthn. 11 (1962), pp. 233-234; Schellbach, I. = FUF 34 (1962), p. 242 and pp. 244-245; Blogyay, T. I = UAJb. 35 (1963), p. 120; Gábori, M. = AArch. 15(1963), pp. 431-444; Lakó György = Ny K 65 (1963), pp. 473-475; Zólyomi Bálint = ibid. pp. 475-477; Bartha Antal $=$ AnnHist. 7 (1965), pp. 205-207. See Nos. 269, 274, 277.

274. LÁSZLÓ, Gy[ula]: Die ältesten Epochen der uralischen Vorgeschichte = CongrFenno-Ugr. (1963), pp. 416-419. See Nos. 273, 277.

275. LẢSZ LÓ Gyula: Az uráli őshaza kérdéséröl [The problem of the Uralic ancient habitat] $=$ NyK 66 (1964), pp. 179-181.

276. LÂSZLÓ Gyula: Az uráli őshaza kutatásáról. Megjegyzések Hajdú Péter észrevételeire [The search for the Uralic ancient habitat. Comments on P. Hajdú's notes] = A rchÉrt. 92 (1965), pp. 68-71.

See Nos. 269, 273.

277. LÃSZLÓ Gyula: Óstörténetünk legkorábbi szakaszai |The earliest phases of Hurgarian ancient history]. /Dokt Ért. - Manuscript./. Budapest, 1965. See Nos. 273, 274.

278. LIG ETI Lajos: Az uráli és altaji uyelvek riszonjanak kérdése [The relations:ip between the Uralic and Altaic languages] = I. OK 4(1950), 333-364. 
Contributions by Sebestyén Irén, N.: pp. 365-270; Kálmán Béla: pp. 371-372; Köhalmi Katalin, U.: pp. 372-376.

279. MARTINKÓ András: A magyar viss zaható névmâs eredete. Milyen "mag" ból fejlödött a maga? [The origin of the Hungarian reflexive pronoun. Was "maga" (you) derived from "mag" (seed)?] = NyelvtudÉrt. 38 (1963), pp. $40-47$.

280. MINISSI, N.: Genuskategorie im Ural-Altaischen $=$ ALH 24 (1974), pp. 261-266.

281. NÉMETH [Gyula], J.: Probleme der türkischen Urzeit = AnalOr. (1942-47), pp. 57-102.

282. RAUN, A.: On stress and length in Proto-Finno-Ugric = ALH 24 (1974), pp. $303-306$.

283. RONA-TAS András: A mongol-magyar rokonságról [Notes on the MongolianHungarian relationshipl $=\hat{E} l$ Tud. 22 (1967), pp. 1250-1255.

284. RONA-TAS, András: Historical linguisties. Linguistic typology. Linguistic relationship : Theoretical problems of typology and the Northern Eurasian Languages. Ed. L. Dezsö and P. Hajdú (Budapest, 1970), pp. 145-149.

285. SEREBRENNIKOV, B, A.: U priěinach neodinakovogo porjadka raspoloženıןa pritjazateljnych suffiksov $v$ uraljskich i altajskich jazykach $=$ AOH 15(1962), pp. $311-313$.

286. SFREBRENNIKOV, B. A.: Formgeschichtliche Untersuchungen $=$ ALH 13 (1963), pp. $257-273$.

287. SINOR, D.: Un suffixe de lieu ouralo-altaique = AOH 12 (1961), pp. 169-178.

288. (TOTH Tibor| Tot, T.: Turko-finnougorskie vzaimootnosenija v zone r. Beloj po antropologiCeskim danny $m=$ CongrFenno-Ugr. (1963), pp. 445-448.

See also Nos, $1101,1406$.

\section{ALTAIC RELATIONS}

289. BARTHA Antal: L. Krader, Social Organization of the Mongol-Turkic Pastoral Nomads. Bloomington - The Hague, 1963. /UAS 20./. Review = Világtörténet (1967), No. 14-15. pp. 136-138.

290. BAZIN, L.: Les noms turcs et mongols de la constellation des "Pléiades" = AOH 10(1960), pp. 295-297.

291. BAZIN, Louis: Note sur ang,irt, nom turco-mongol d'une variété de "canard" = StTurc. $/ 1971 /$, pp. $55-59$. 
292. BESE, L[ajos]: D. Sinor, Aspects of Altaic Civilization. Proceedings of the fifth meeting of the Permanent International Altaistic Conference held at Indiana University June 4-9, 1962. Bloomington - The Hague, 1963. /UAS 23. . Review = OLZ 62 (1967), cols. 490-492.

293. CSONGOR Barnabás: Az altaji nyelvesalád [The Altaic family of languages] = Antal László, Csongor Barnabás, Fodor István: A világ nyelvei (Budapest, 1970), pp. 173-186.

294. CZEGLÉDY, K[á roly]: D. Sinor, Inner Asia. History - civilization - languages. A syllabus. Bloomington - The Hague, 1969. /UAS 96./. Review = ALH 22 (1972), pp. $452-455$.

See Nos. 313,322 .

295. EREN, Hasan: Le terme "altaïque" sauya "cadeau" = AOH 25 (1972), pp. $237-243$.

296. HAZAI, Glyörgy]: N. Poppe, Introduction to Altaic linguistics. Wiesbaden, 1965. Review = AASt. 3 (1967), pp. 198-201.

297. HAZAI, Glyörgy ]: Neuere Literatur über Volksepen der altaischen Völker in der Sowjetunion =Volksepen der uralischen und altaischen Völker. Vort räge des Hamburger Symposions von 16-17. Dezember 1965 (Wiesbaden, 1968), pp. 66-74.

298. KARA, G[yörgy]: Le dictionnaire étymologique et la langue mongole $=\mathrm{AOH}$ 18 (1965), pp. 1-32.

299. KÖHALMI Katalin, U.: A mongol népek és nyelvek [The Mongolian peoples and languages $]=$ Nyr. $80(1956), p p .88-93$ and 220-227.

300. LIGETI, L[ajos]: Les anciens éléments mongols dans le mandchou $=A O H$ $10(1960)$, pp. $231-248$.

See Nos. 301, 302 .

301. LIGETI Lajos: A mandzsu nyelv régi mongol elemei [Old-Mongolian elements of the Manchu languagel $=$ I. OK $17(1961)$, pp. 31-46.

See Nos. 300,302 .

302. LIGETI, L[ajos]: Drevnie mongoljskie elementy $v$ manjčzurskom jazyke = Trudy 3 (1963), p. 257.

See Nos. 300,301 .

303. LIGETI, L[ajos]: Altajskaja teorija i leksikostatistika = VJaz, 1971. 3, pp. $21-33$.

See No. 304.

304. LIGETI Lajos: Az altaji nyelvrokonság és a szókészlet-statisztika (Altaic linguistic affinity and vocabulary-statistics] = I. OK 28 (1973), pp. 159-275. See No. 303. 
305. LÖRINCZ, L[ászló]: Paralellen in der mongolischen und altaitürkischen Epik = StTurc. (1971), pp. 321-330.

306. LŐRINCZ, L[ászló]: Epos in Innerasien? = CAJ 17 (1973), pp. 176-179.

307. MÁNDOKI, L[ászló]: Asiatische Sternnamen = Glaubenswelt (1963), pp. $519-532$.

Reviewed by Kara, G. = AOH $17(1964)$, pp. 355-356.

See No. 308.

308. MÁ NDOKI, L[ászló]: Two Asiatic sidereal names = Popular beliefs (1968), pp. $485-496$.

See No. 307.

309. RONA-TAS, A[ndrás]: Preliminary report on a study of the dwellings of the Altaic peoples $=$ UAS $23(1963)$, pp. 47-56.

310. RÓNA-TAS András: Néhány gondolat a nyelvrokonság ról [Some thoughts on the genetic relationship of languages] = NyK 71 (1969), pp. 261-279. [Résumé in English].

See No. 316.

311. RÓNA-TAS András: Az altaji nyelv rokonság vizsgálatának alapjai (A nyelvrokonság elmélete és a csuvas-mongol nyelvviszony) (The bases for the investigation of the Altaic linguistic affinity (The theory of linguistic affinity and the Chuvash-Mongolian linguistic relationship)]. Budapest, 1970. 1025 pp. /DoktÉrt. - Manuscript/. Theses. Budapest, 1970. 23. pp.

312. RÓNA-TAS, A[ndrás]: Some problems of Ancient Turkic = Acta Orientalia. Havniae. 32 (1970), pp. 209-228.

313. RÓNA-TAS, A[ndrás]: D. Sinor, Inner Asia. History-civilization - languages. A syllabus. Bloomington - The Hague, 1969. /UAS 96. $/$ Review $=$ JAH 1970:1, pp. 89-90.

See Nos. 294, 322.

314. RÓNA-TAS, A[ndrás]: Dream, magic power and divination in the Altaic world $=$ AOH 25 (1972), pp. 227-236.

315. RÓNA-TAS, A[ndrás]: Tocharische Elemente in den altaischen Sprachen? = Protokollband (1974), pp. 499-504.

316. RÓNA-TAS, A[ndrás]: Obščee nasledie ili zaimstvovanija. K probleme rodstva altajskich jazykov $=$ V Jaz. 1974:2. pp. 31-45.

See No. 310.

317. SCH U̇TZ [Ödön], E.: Remarks on Altaic personal pronouns = AOH 28 (1974), pp. $139-145$.

318. SINOR, D.: Some Altaic names for bovines = AOH 15(1962), pp. 315-324. 
319. SINOR, Denis: Mongol and Turkic words in the Latin versions of John of Plano Carpini's journey to the Mongols (1245-1247) = Mongolian Studies (Budapest, 1970), pp. 537-551.

320. TEKIN, T.: Zetacism and Sigmatism in Proto-Turkic $=\mathrm{AOH} 22(1969)$, pp. $51-80$.

321. TOMKA, P[éter]: Les termes de l'enterrement chez les peuples mongols = AOH 18 (1965), pp. 159-181.

322. VÁSÁRY, I[stván]: D. Sinor, Inner Asia. History - civilization - languages. A syllabus. Bloomington - The Hague, 1969. /UAS 96./. Review $=A O H$ $23(1970)$, pp. 378-380.

See Nos. $294,313$.

See also Nos. $1014,1015,1238,1239,1406,1524,1539,1550-1552$.

\section{REFERENCE WORKS}

323. ERDÖDI József: A Szovjetunióban 1969-ben végzett népszámlálás adataiból [Data from the census of the Soviet Union taken in 1969] = NyK 73(1971), pp. $448-451$.

324. FABRICIUS-KOVÁCS, Flerenc]: Mladopisjmennye jazyki na rodov SSSR. Otv. red. E. A. Bokarev i Ju. D. Deseriev. AN SSSR, Institut Jazykoznanija. Moskva - Leningrad, 1959. Review = ALH 12 (1962). pp. 21 0-212.

See No. 336.

325. HAZAI György: Török népek [Turkic peoples] = A Kultúra Világa. A föld országai, a világ népei (Budapest, 1965), pp. 742-759.

326. HAZAI, G[yörgy]: The Turkic peoples. Selected Russian entries from the Great Soviet Encyclopedia with an index in English. Red. by J. R. Krueger. Bloomington - The Hague, 1963. Review = OLZ 62 (1967), cols. 390-391.

327. HAZAI, Glyörgy]: Philologiae Turcicae Fundamenta. Tomus II. Wiesbaden, 1964-65. Review = Göttingische Gelehrte Anzeigen 219:1-2 (1967), pp. 120-128 and AASt. 4 (1968), pp. 176-180.

328. HEGYI Imre: S. A. Tokarev, Êtnografija narodov SSSR. Moskva, 1958. Review $=$ Ethn. $71(1960), \mathrm{pp} .148-149$.

329. KAKUK Zsuzsa: Philologiae Turcicae Fundamenta. Tomus I. Wiesbaden, 1959. Review $=$ NyK 63 (1961), pp. 252-254.

See No. 331.

330. MOLNÁR Nándor: Adalékok a nem szláv cirillbetüs szavak címátírásához [Data on transcription of non-Slavic words in Cyrillic script] : Magyar Könyvszemle 77(1961), pp. 196-198. 
331. NÉM ETH [Gyula], J.: Philologiae Turcicae Fundamenta. Tomus I. Wiesbaden, 1959. Review = OLZ 57 (1962), cols. 61-71.

See No. 329 .

332. NÉMETH [Gyula], J.: Turkologie. Mit Beiträgen von A.v. Gabain, O. Pritsak, N. Poppe, J. Benzing, K. H. Menges, A. Temir, Z.V. Togan, F. Taeschner, O. Spies, A. Caferoğlu, A. Battal-Taymas. Leiden-Köln, 1963. / Handbuch der Orientalistik Abt. I., Bd. V, 1: Altaistik/. Review = OLZ 61 (1966), cols. 479-482.

333. NÉMETH [Gyula], J.: K. H. Menges, The Turkic languages and peoples. An introduction to Turkic studies. Wiesbaden, 1968. /Ural-Altaische Bibliothek 15. /. Review = ALH 21 (1971), pp. 471-473.

See No, 337.

334. RÁSONYI, L[ászló]: Tarihte Türklük. Anka ra, 1971, I-VIII + 420 pp. /Türk Kültürünü Araştırma Enstitüsui yayınla rı 39. Seri III. Sayı A 11./.

335. RÓNA-TAS, A[ndrás]: L. Krader, Peoples of Central Asia. Bloomington The Hague, 1963. Review = JAOS 85 (1965), pp. 230-231.

336. SÁNDOR István: Mladopisjmennye jazyki na rodov SSSR. Otv. Red. E. A. Bokarev i Ju. D. Dešeriev. Moskva - Leningrad, 1959. Review = Index Ethn. 5 (1960-1961), p. 14.

See No. 324.

337. VÁSÁRY, I[stván]: K.H. Menges, The Turkic languages and peoples. An introduction to Turkic studies. Wiesbaden, 1968. /Ural-Altaische Bibliothek 15. $/$. Review $=$ AOH 23 (1970), pp. 239-241.

See No. 333 .

\section{COMPARATIVE LINGUISTICS: TURKIC PHONETICS, MORPHOLOGY AND LEXICOLOGY}

338. BASKAKOV, N. A.: Priroda i funkcionaljnoe znacenie svjazki v sostave predloženija $v$ tjurkskich jazykach $=$ StTurc. (1971), pp. 47-54.

339. FEKETE Lajos: Doquz - a törökben és a perzsában [Doquz - in Turkish and in Persian] = Pais Emlk. (1956), pp. 647-652.

See No. 343 .

340. GABAIN, Annemarie v.: Vom Sinn symbolischer Farbenbezeichnung $=\mathrm{AOH}$ 15 (1962), pp. 111-117.

341. HAZAI, G[yörgy]: G. Doerfer, Türkische und mongolische Elemente im Neupe rsischen. I-III. Wiesbaden 1963-67. Review = AASt. 7 (1973), pp. 149-155. See Nos. 346, 348. 
342. LIGETI, Lajos: Histoire du lexique des langues turques $=\mathrm{RO} 17(1953), \mathrm{pp}$. 80-91.

343. LIGETI Lajos: Az "ajándék" két török-perzsa neve [Two Turkish-Persian words for "gift"] = MNy. 53 (1957), pp. 157-159.

See No. 339.

344. LIGETI Lajos: Gombocz a török nomen-verbumokról [Gombocz on the Turkic nomenverbums] $=$ MNy. 58 (1962), pp. 464-466.

345. LIGETI, L[ajos]: Les voyelles longues en moghol $=A O H 17$ (1964), pp. 1-48.

346. LIGETI, Llajos ]: G. Doerfer, Türkische und mongolische Elemente im Neupersischen. Band I: Mongolische Elemente im Neupers ischen. Wiesbaden, 1963. Review $=$ AOH 17 (1964), pp. 343-349.

See No. 341,348 .

347. LIGETI Lajos: A török nyelvek etimológiai szótárai \{Ety mological dictionaries of the Turkic languages] = Altnapok (1965), p. 2.

348. LIGETI, L[ajos]: G. Doerfer, Türkische und mongolische Elemente im Neupersischen. Band II. Wiesbaden, 1965. Band III. Wiesbader, 1967. Review :- AOH 21 (1968), pp. 119-130.

See No. 341,346 .

349. LÓ́RINCZ, L.ászló): La terminologie du folklore kalmouk = AOH 18 (1965), pp. 149-158.

350. NËMETH [Gyula], J.: Zu den E-Lauten im Türkischen : StOr. 28:14(1964), $19 \mathrm{pp}$.

351. NÉMETH [Gyula], J.: Ilse Laude-Cirtautas, Der Gebrauch der Fa rbbezeichnungen in den Türkdialekten. Wiesbaden, 1961. Review = OLZ 60(1965), cols. $62-64$.

352. NÉMETH [Gyula], J.: Proishozdenie russkogo slova karandaš = Tjurkologiceskij sbornik k sestidesjatiletiju Andreja Nikolaeviča Kononova (Moskva, 1966), pp. 105-114.

See No. 353.

353. NÉMETH [Gyula], J.: Das russische Wort xaparzau "Bleistift" = ALH 17 (1967), pp. $211-221$.

See No. 352 .

354. RÓNA-TAS András: Martti Räsänen, Versuch eines etymologischen Wörterbuchs der Türksprachen. Helsinki, 1969. Review = NyK 73 (1971), pp. 466-470.

355. SEREBRENNiKOV, B. A.: Zur Geschichte des Perfekts in den türkischen Sprachen $=$ AOH $12(1961)$, pp. 163-168.

356. TENISLV, E. E.: $\mathrm{K}$ istorii tjurkskogo us lovnogo naklonenija = StTurc. (1971), pp. $441-449$. 
357. THOMSEN, K. : Bemerkungen über das türkische Vokalsystem der zweiten Silbe $=A O H 16(1963)$, pp. 313-318.

See also Nos. $378,1307,1309,1310$.

\section{ONOMASTICS}

358. CZEGLÉDY Ká roly: A karluk törzsek nevei [The names of the Karluk tribes] $=$ MNy. 45 (1949), pp. 164-168.

359. NÉMETH [Gyula], J.: Le système des noms des peuples turcs = Actes du $\mathrm{XXI}^{\mathrm{e}}$ Congrès International des Orientalistes (Paris, 1949), p. 174. See No. 360 .

360. NÉMETH [Gyula], J.: Le système des noms des peuples turcs = JA 239 (1951), pp. 69-70.

See No. 359 .

361. NÉMETH [Gyula], J.: Herbert W. Duda,Die Seltschukengeschichte des Ibn Bỉbī. Kopenhagen, 1959. Review $=$ AOH $10(1960)$, pp. 307-308.

362. NÉMETH [Gyula], J.: Der Volksname Karluk und seine semantische Gruppe $=$ ALH 19(1969), pp. 13-18.

363. RÁSONYI, L[ászló]: Sur quelques catégories de noms de personnes en turc $=$ ALH 3 (1953), pp. 323-350.

Reviewed by Gabain, A. v. = OLZ $50(1955)$, cols. $240-242$; Hambis, L. $=$ JA 245 (1957), p. 223.

364. RÁSONYI, L[ászló]: Miscellanea Arabo-Turcica. I. = Goldziher Ignace memorial volume. P.2. (Jerusalem, 1958), pp. 113-135.

See No. 366.

365. RĀSONYI, L[ászló]: Les noms de nombre dans l'anthroponymie turque = AOH 12 (1961), pp. 45-71.

366. RÁSONYI, L[ászló]: Zu den Namen der ersten türkischen Herren von Jerusalem $=$ AOH 13 (1961), pp. 89-94.

See No. 364 .

367. RÁSONYI, L[ászló]: Les noms de personnes impératifs ches les peuples turques $=\mathrm{AOH} 15(1962)$, pp. 233-243.

368. RÁSONYI, L[ászló]: Der Frauenname bei den Türkvölkern = UAJb. 34 (1962), pp. 223-239.

See No. 369 .

369. RẢSONYI, L[âszlô]: Türklükte kadın adları = TDAYB 1963(1964), pp. 63-87. See No. 368. 
370. RÁSONYI, L[ászlo] : Türk özel adlarının kaynakları = Türkoloji Dergisi I. (Ankara, 1964), pp. 71-101.

371. RÁSONYI, L[ászlo] : Türk özel adları ve leksikografyası = Bilimsel Bildiriler 1966, (1968), pp. 39-48.

See also Nos. $436,438-443,749-755,1418-1473,1555-1568,1784,1863-1875$. 


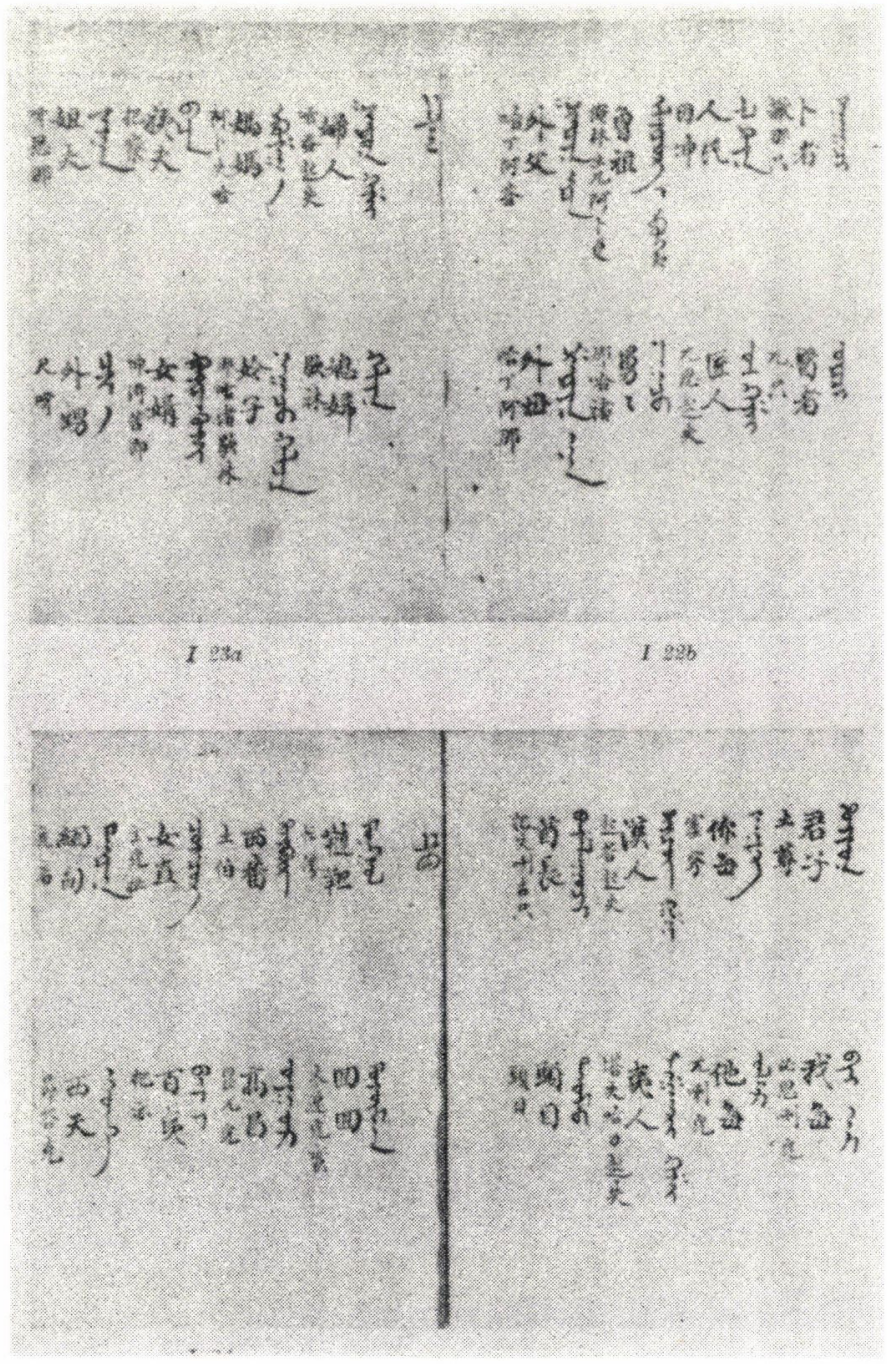

From "Un vocabulaire sino-ouigour des Ming" by L. Ligeti (in $\mathrm{AOH} 19(1966)$. See No. 497.) 


\title{
III. ANCIENT TURKIC PEOPLES AMd LANGUAGES
}

\author{
G ENERAL WORKS
}

372. CZEGLÉDY Ká roly: Gyula Moravcsik, Byzantinoturcica. I. Die byzantinischen Quellen der Geschichte der Türkvölker. II. Sprach reste der Türkvölker in den byzantinischen Quellen. Budapest, 1942-1943. Review = Ny r. 72 (1948), pp. 136-138.

See No. 377.

373. CZEGLÉDY Károly: IV-IX. századi népmozgalmak a steppén [Migrations in the steppe in the 4th - 9th centuries] Budapest, 1954, 45 pp. /MNyTK 84./. See Nos. 374, 550 .

374. CZEGLÉDY Ká roly: Heftaliták, hunok, avarok, onogurok [Hephtalites, Huns, Avars, Onogurs] = MNy. 50(1954), pp. 142-151.

See No. 373.

375. LIG ETI, L[ajos]: Bilinmiyen İc-Asya. Macarcadan çeviren Sadrettin Karatay. Istanbul, 1946, 362 pp. /A ỦDTCFY 52. - Hunga roloji Enstitlisü. 2.\% See No. 376.

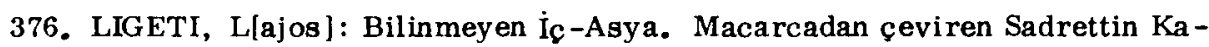
ratay. Vol. I. $18+270$ pp.; Vol. II. 244 pp. Istanbul 1970. /1000 Temel Eser. 33, 34./.

See No. 375.

377. MORAVCSIK, Gy[ula]: Byzantinoturcica. I: Die byzantinischen Quellen der Geschichte der Türkvölker. II: Sprachreste der Türkvölker in den byzant:nischen Quellen. Zweite durchgearbeitete Auflage. /Berliner Byzantinische $\therefore:^{2}$ eiten 10, 11./. Berlin, 1958. 609 and $376 \mathrm{pp}$.

Reviewed by Czeglédy K[ároly] = AAnt. 8 (1960), pp. 455-460 and AT 8 (1961), F. 113-117; Eyice, Semavi = Belleten XXIV/95 (1960), pp. 493-497; Ligeti, $I_{.}=\Lambda C: 110(1960)$, pp. 301-307; Dujeev, I. = ByzZ 54 (1961), pp. 129-135; I:Dn, Alexandru = Studia et Acta Orientalia 3 (Bucuresti, 1961), pp. 235-242; i...in, 3. = Historische Zeitschrift 193 (München, 1961), pp. 728-729; Zás- 
těrová, Bohumila = Slavia, Casopis pro slovanskom filologii 31 (Praha, 1962), pp. 120-125; Winkelman, F. = OLZ 58 (1963), cols. 437-447.

See No. 372 .

1. T'OPA, HSIUNG-NU, JUAN-JUAN, HEPHTALITES, KARLUKS;

EUROPEAN HUNS AND AV ARS

378. CZEGLÉDY Ká roly: Beg ['Bey"] = MNy. 47 (1951), p. 272.

379. CZEGLÉDY Ká roly: Kaukázusi hunok, kaukázusi avarok [Caucasian Huns, Caucasian Avars] = AT 2 (1955), pp. 121-140.

380. CZHGLÉDY Károly: A késő ókori Belső-Ázsia történeti földrajzához (Notes on the historical geography of Inner-Asia in late antiquity] = AT 9(1964), pp. 123-126.

381. CZEGLÉDY Ká roly: Nomád népek vándorlása Napkelettől Napnyugatig (The migration of nomadic peoples from the Orient to the Occident] Budapest, $1969,160 \mathrm{pp}$. $+15 \mathrm{pl}$. /Körösi Csoma Kiskönyvtár 8./.

Reviewed by Ecsedy, H. = AT 17(1970), pp. 82-84 and AOH 24(1971), pp. 129-130; Fehér J. M. = TörtSz, 2(1971), pp. 141-142; Koşay, H. Z. = Belleten XXXV /138 (1971), pp. 303-308 + pl.; Köhegyi M. = Ethn. 82 (1971), p. 105 and AArch. 24(1972), pp. 427-428; Kara, G. = ALH 22 (1972), pp. $450-452$.

382. CZEGLÉDY, K[ároly]: Petre Iberis Siriulis cxovrebis gamo = Agmosavluri philologia 1 (Tbilisi, 1969), pp. 7-15.

383. ECKHARDT, Sándor: Efsanede Attila = Attila ve Hunları (1962), pp. 141-214 and 305-313.

384. ECSEDY Ildikó: Adalékok a karluk nép történetéhez kínai források alapjân [Additional material on the history of the Karluk people in Chinese sources] Budapest, 1961. /Bölcs Ért. - Manuscript/.

385. ECSEDY [Ildikó], Hilda: [Reviews of articles on Sino-Barbarian themes] = Revue Bibliographique de Sinologie (Paris - La Haye), 1960-1964, 1967-68 and 1971-73.

386. FETTICH, Nándor: Hunların arkeolojik hatıraları = Attila ve Hunları (1962), pp. 225-260 and 314-318.

387. HARMATTA János: Franz Altheim, Hunnische Runen. Halle, 1948. Review $=$ ArchÉrt. $77(1950)$, pp. 59-60.

388. HA RMATTA János: A hun aranyíj [The golden bow of the Huns] $=I 1$. OK 1 (1951), pp. 123-187.

Reviewed by: Szilágyi J. = ArchÉrt. 78 (1951), p. 143; Gyóni M. = ByzSl. 13 (1952), p. 181 .

See No. 389. 
289. HARMATTA,János: The golden bow of the Huns = AArch. 1 (1951), pp. 107-151.

Reviewedi by Gyóni,M. = ByzZ 45 (1952), pp. 174-175; Schefild, K. = Museum Helveticum 10 (1953).

See No. 388 .

390. HARMATTA János: A hun birodalom felbomlása. I. A hun társadalom Attila torában (The dissolution of the IIun Empire. I. Hun society in the age of Attila ! = II. OK 2 (1952), pp. 147-192.

See No. 391.

391. HARMATTA, János: The dissolution of the Hun Empire. I. Hun society in the age of Attila = AArch. 2(1952), pp. 277-305.

Reviewed by Rybová, A. = Archeologické Rozhledy 6(1954), pp. 261-262. See No. 390 .

392. HARMitta János: Fr. Altheim - $R$. Stiehl, Das erste Auftreten der Hunnen. Das Alter der Jesaja-Rolle. Baden-Baden 1953. Review $=$ AT 2 (1955), pp. $290-291$.

393. HARMATTA, János: La sociétê des Huns à l'époque d'Attila = Recherches Internationales 2 (1957), No. 2. pp. 179-239.

394. HEGYI Imre: L. N. Gumilev, Drevnie tjurki. Moskva, 1967. Review = Ethn. $83(1972)$, pp. 120-123.

395. LIGETI, L\{ajos\}: Hiunğ-nu'ların dili = TD sayı 12-13 (1949), pp. 102-105.

396. LIGETI Lajos: Egy karluk törzs neve kínai átírásban [A Karluk tribal name in Chinese transcription! $=$ MNy 45 (1949), pp. 168-170.

397. LIGETI, L[ajos]: Mots de civilisation de Haute Asie en transcription chinoise $=$ AOH 1 (1950-1951), pp. 141-185.

See No. 398.

398. LIGETI, L[ajos]: Cin yazısiyle yazılmıs barbar glossaları meselesi = AÜDTCFY 9 (1951), pp. 301-327.

See No. 297.

399. LIGETI, L[ajos]: Asya Hunları = Attila ve Hunları (1962), pp. 29-56 and 268-273.

400. LIGETI, L[ajos]: Attila Hunlarının menșei = Attila ve Hunları (1962), pp. $7-26$ and $266-268$.

401. LIGETI, L[ajos]: Tabgačskij jazyk -- dialekt Sjanjzijskogo = NarAzAfr. 1969:1, pp. 107-117.

See No. 402 .

402. LIGETI, L[ajos]: Le tabghatch, un dialecte de la langue sien-pi = Mongolian Studies (Budapest, 1970), pp. 265-303.

See No. 401. 
403. LIGETI [Lajos], Louis: A propos du "Rapport sur les rois demeurant dans le Nord" = Études tibétaines dédiées à la mémoire de Marcelle Lalou (Paris, 1971), pp. 166-189.

404. MOÓR Elemér: A hunok származásának kérdése fó tekintettel a nyelvi forrasanyagra [The origin of the Huns. A study based mainly on linguistic source-material] $=$ MNy. 59 (1963), pp. 53-66.

See Nos. 405, 406.

405. MOÓR, Elemér: Zur Herkunft der Hunnen mit besonderer Berücksichtigung ih res Namenmaterials $=\mathrm{BzN} 14$ (1963), pp. 63-104. Contribution by Maenchen-Helfen, $\mathrm{O}$. = ibid. pp. 273-278. See Nos. $404,406$.

406. MOÓR, Elemêr: Noch einmal zum Hunnenproblem $=\mathrm{BzN} 16(1965)$, pp. 14-22. See Nos. 404, 405 .

407. MORAVCSIK, Gy[ula]: Hunlar meselesinin bugünkü hah = Tarih Dergis i 2 (1952), pp. 109-117.

408. MORAVCSIK Gyula: Priszkosz rétor. Malálasz és Theofánisz. Menandrosz [Priskos rhetor, Malalas and Theofanis. Menandros] = A magyarok elödeiröl (1958), pp. 24-25, 44-50 and 205-206, 209-210. [Translation of excerpts and notes].

409. NÉMETH, Gy[ula]: Hunlarin dili = TD sayı 12-13 (1949), pp. 106-111. See No. 412.

410. NÉMETH [Gyula], J.: Attila ve Hunları. Istanbul, 1962,328 pp. + XX pl. / AÜDTCFY 106./.

411. NÉMETH [Gyula], J.: Önsöz = Attila ve Hunları (1962), pp. 3-6.

412. NÉMETH [Gyula], J.: Hunlarun dili = Attila ve Hunları (1962), pp. 215-224 and $313-314$. See No. 409 .

413. NÉMETH [Gyula], J.: Hunlar ve Macarlar = Attila ve Hunlari (1962), pp. $261-265$ and $318-320$.

414. RÁSONYI, L[ászlo] : Bô-kolabur = Türk Tarih Kurumu Halil Ethem Hâtıra Kitabı (Ankara, 1947), pp. 242-248.

415. SCHMITT, G.: Wo siedelten nachweis lich türkische Stämme im ersten Jahrhundert vor bzw. nach der Zeitenwende? = AOH 24(1971), pp. 337-358.

416. SZÁDECZKY - KA RDOSS Samu: Hitvalló Theophanés az avarokról [Theophanes the Confessor on the Avars l = AT 17 (1070), pp. 121-147.

417. SZADECZKY-KARDOSS, S[amu]: Ein Versuch zur Sammlung und ch ronoligischen Anordnung der griechischen Quellen der Awarengeschichte rebst einer Auswahl von anderssprachigen Quellen. Mitarbeiterin des Buches:

T. Olajos. Szeged, 1972. 
418. VÁCZY, Pêter: Hunlar Avropada = Attila ve Hunlar (1962), pp. 57-140 and $273-305$.

See also Nos. $358,362,373,599,645,1105,1177-1179,1450$.

\section{OLD KIRGHIZ}

419. CZEGLÉDY Ká roly: Új adatok a steppe-népek és északi szomszédaik történetêhez [Some new data on the history of the peoples of the steppe and their northern neighbours] $=$ MNy. 47 (1951), pp. 64-67.

420. ECSEDY, [Ildikó] Hilda: Ja. A. Ser, Kamennye izvajanija Semirecja. MoskvaI rening rad, 1966. Review $=\mathrm{AOH} 20$ (1967), pp. 373-376.

421. ECSEDY, [Ildikб] Hilda: L. R. Kyzlasov, Istorija Tuvy v s rednie veka. Moskva, 1969. Review = UAJb. 46 (1974), pp. 182-184.

422. HAJDÚ, Péte̊r: Die ältesten Berïhrungen zwischen den Samojeden und den jenisseischen Völkern $=\mathrm{AOH} 3(1953)$, pp. $73-102$.

423. HAJDÚ Péter: A paleo-szibériai népek és nyelvek [Paleo-Siberian peoples and languages] $=$ Ny r. 77 (1953), pp. 71-78.

424. HAZAI, G[yörgy]: D. G. Messerschmidt, Forschungs reise durch Sibirien 1720-1727. I-IV. Berlin, 1962-1968. Review = AASt. 7 (1973), pp. 235-237.

425. NÉMFTH [Gyula], J.: M. Räsänen, Beiträge zu den türkischen Kuneninschriften. Helsinki, 1952. /StOr. XVII:6./ Review = OLZ 53(1958), col. 567.

426. THOMSEN, Vilhelm: Zur Deutung der Talas-Insch riften. (Mit Vorbernerkung des Herausgebers: J. Németh) = ALH 22 (1972), pp. 245-250.

427. VÁSÁRY, I[stván] : Käm, an early Samoyed name of Yenisey = StTurc.(1971), pp. $469-482$.

See also Nos. $375,376,975$.

\section{EASTERN TURKS}

428. BODROGLIGETI András: A régi török könyv [The old Turkic book] =: Altnapok (1965), p. 15 .

See No. 429.

429. BODROGLIGETI, A[ndrás ]: Harly Turkish terms connected with books and writing $=\mathrm{AOH} 18(1965)$, pp. 93-117.

See No. 428. 
430. BOMBACI, A.: The husbands of princess Hsien-li Bilgä = St Turc. (1971), pp. 103-123.

131. CLAUSON, Sir Gerard: Some notes un the inscription of Toñuqua = StTurc. (1971), pp. 125-132.

432. CSONGOR Barnabás: Idegen irásos kínai szövegek és szórványok a 7-10.századból. (A közép-kínai nyelvtörténet kérdéseihez) [7th-10th century Chinese texts and fragments in foreign script. (Problems of Middle-Chinese linguistic history)]. Budapest, 1960. 269 pp. /KandÉrt. - Manuscript /. - Theses. 4 pp. - Summary: Miklós Pál = I. OK 18 (1961), pp. 329-330.

433. CZEGLÉDY Károly: A török népek és nyelvek tagolódásának kérdéséhez [The problem of the division of the Turkic peoples and languages] $=\mathrm{MNy}, 45$ (1949), pp. 291-296.

134. CZEGLÉDY Ká roly: Bahräm Čóbìn = AT 4 (1957), pp. 301-302. See No. 435.

435. CZEGLÉDY, K[ároly]: Bahräm Coobin and the Persian apoçalyptic literature $=\mathrm{AOH} 8$ (1958), pp. 21-43.

See No. 434.

436. CZEGLÉDY Ká roly: A rézvárus [The copper city] = AT 7 (1960), pp. 211-216.

437. CZEGLÉDY, K[á roly]: Die spätsassanidischen und schiitischen Mahdi-Erwartungen $=X$. Internationaler Kongress für Religionsgeschichte (Marburg, 1961), pp. 147-148.

438. CZEGLÉDY, Károly: TEPMATZOY $\Sigma=$ AAnt. 10 (1962), pp. 79-84.

439. CZEGLÉDY, K[ároly]: Čoyay-quzï, Qura-qum, Kök-öng = AOH 15(1962), pp. 55-69.

See No. 440.

440. CZEGLÉDY Ká roly: Čołay-quzï, Qura-quin, Kök-Öng = I. OK 20 (1963), pp. 279-294.

See No. 439 .

441. CZEGLÉDY Károly: A régi török törzsszövetségek numerikus felosztásának kérdésêhez [Ancient Turkic tribal confederations - on the numerical composition] $=$ MNy. $59(1963)$, pp. 456-461.

See No. 443.

442. CZEGLÉDY, Ká roly: Old Turkish Historical Geography / Kängü Tarban and Firdausi's Kang/ = Proceedings of the XXVIth Interntional Congress of Orientalists. II. (New Delhi, 1968), pp. 83-85.

443. CZEGLÉDY, Kiá roly]: On the numerical composition of the ancient Turkish tribal confederation $=\mathrm{AOH} 25(1972), p \mathrm{p}, 275-281$.

See No. 411. 
444. CZ EGLEDY, K[ároly]: History and the Turkic Inscriptions = Kole of the Nomadic Peoples in the Civilization of Central Asia. A record of papers and discussions of the International UNESCO Symposium. Editors: Sh. Bira, A. Luvsandendev (Ulan-Bator, 1974), pp. 303-305.

445. ECSEDY Ildikó: Kínaỉ eredetü türk méltóságnevek lOld Turkic titles of Chinese origin] = Altnapok (1965), p. 11 .

See No. 446 .

446. ECSEDY [Ildikô], Hilda: Old Turkic titles of Chinese origin $=\mathrm{AOH} 18$ (1965), pp. 83-91.

See No. 445.

447. ECSEDY [Ildikó], Hilda: S.G. KIiastornyj, Drevnetjurkskie runičeskie pamjatniki po istorii Srednej Azii. Moskva, 196. Review = AASt. 2(1966), pp. $180-181$.

448. ECSEDY [Ildik 6 ], Hilda: Trade-and-war relations between the Turks and China in the second half of the 6th century = AOH 21 (1968), pp. 131-180.

449. ECSEDY Ildik6: Nomád gazdaság, nomád társadalom [Nomadic economy, nomadic society] = Magyar Filozófiai Szemle 13 (1969), pp. 855-875.

450. ECSEDY [Ildikó], Hilda: Tribe and tribal society in the 6th century Turk empire $=$ AOH 25 (1972), pp. 245-262.

See No. 451.

451. ECSEDY Ildikó: Törzs és törzsi társadalom a VI. századi türk birodalomban [Tribe and tribal society in the 6th century Turk empire] = Keletkutatás 1973 (Budapest, 1974), pp. 65-83.

See No. 450.

452. ERDÉLYI, Iatván: A tomb of the Turkic period in Northern Mongolia. A report on the discoveries of the Mongol-Hungarian Archeological Expedition of $1963=$ Belleten XXX/118 (1966), pp. $197-203+3 \mathrm{pl}$.

453. GYÖRFFY, György: Die Rolle des buyruq in der alttürkischen Gesellschaft = AOH $11(1960)$, pp. 169-179.

454. HAMILTON, J.: Opla-/yopla-, uf-/yuf-et autres formes semblables en turc ancien $=\mathrm{AOH} 28(1974), \mathrm{pp} .111-117$.

455. HARMATTA, J[ános ]: Byzantinoturcica = AAnt. 10(1962), pp. 131-150.

Reviewed by: M[oravesik], Gy. = ByzZ 55 (1962), p. 378 and ByzSl. 24 (1963), p. $186 ; \mathrm{H}[\mathrm{azai}, \mathrm{G}]=$. UAJb. 35 (1964), p. 429 .

See No. 456.

456. HARMATTA János: Bizánc és a türkök kapcsolatainak kezdetei (The beginnings of Byzantine-Türk relationsl = AT 9(1962), pp. 39-53.

See No. 455. 
457. HAZAI, G[yörgy]: Sur un passage de l'inscription de Tonyuquq = Turcica 2 (1972), pp. 25-31.

See No. 458 .

458. HAZAI, G[yörgy]: Zu einer Stelle der Tonyukuk-Inschrift =- Protokollband (1974), pp. 265-269.

See No. 457.

459. KAKUK Zsuzsa: Az orkhoni feliratok [The Orkhon inscriptions] = A magyarok elödeiról (1958), pp. 27-43 and 207-209. ['Translation of excerpts and notes].

460. KÉPES Géza: Orkuni feliratok [The inscriptions of Orkun (Orkhon)] = Kepes Géza, Fordított világ (Budapest, 1973), pp. 87-126.

461. KLJAŠTORNYJ, S. G.: Runiceskaja nadpisj iz Vostoðnoj Gobi = StTurc.(1971), pp. 249-258.

462. KLJASTTORNYJ, S. G. - LIVSIC, V.A.: The Sogdian inscription of Bugut revised $=$ AOH $26(1972)$, pp. 69-102.

463. LÁSZLó, v.F[erencz] : Die Tokuz-Oguz und die Köktürken = AnalOr. (19421947), pp. 103-109.

464. NÉMETH,Gyula: [Orthun kitâbelerinin izahı = IÜEFTDED 1(1946), pp. 53-61.

465. NÉMETH [Gyula], J.: A. von Gabain, Alttürkische Grammatik, mit Bibliographie, Lesestuicken und Wörterverzeichnis, auch neutürkish. Mit vier Schrifttafeln und sieben Schriftproben. 2. verbesserte Auflage. Leipzig, 1950. Review = ALH 1(1951), pp. 239-241.

466. NÉMETH [Gyula], J.: Annemarie von Gabain, Inhalt und magische Bedeutung der alttürkischen Inschriften. Freiburg, 1953. /S. -A. aus Anthropos Bd. 48./. Review = OLZ 50 (1955), cols. 461-463.

467. NÉNIETH [Gyula], J.: ẗ̉or alttürkische Sternnamen = ALH 18 (1968), pp. $1-6$.

See No. 468.

468. NÉMETH [Gyula], F.: 'Türk dillerinde yıldiz adları ve ülker kelimesinin menşei $=$ Voprosy tjurkologii. K Sestidesjatiletiju akademika AN Azerb. SSR M. S. Siralieva (Baku, 1971), pp. 18-26.

See No. 467.

469. VÁSÁRY, I[stván]: Talât Tekin, A Grammar of Orklıon Turkic. Bloomington, 1968. /UAS, 69./ Review $=$ AOH $23(1970)$, pp. 133-135.

See also Nos. $74,75,380,394,420,421,424,545,606,608,1146$. 


\section{UIGHURS}

470. AALTO, Pentti: Iranian contacts of the Turks in Pre-Islamic Times = StTurc. (1971), pp. 29-37.

471. CSONGOR, B[arnabás]: Chinese in the Uighur script of the $T^{\prime}$ ang-period = AOH 2 (1952), pp. 73-122.

472. CSONGOR, B[araabás]: Some more Chinese glosses in Uighur script $=\mathrm{AOH}$ $4(1955)$, p. 251.

473. CSONGOR, B[amabás]: Chinese glosses in Uighur texts written in Brahmi = AOH 15(1962), pp. 49-53.

474. CZEG LEDY, K[aroly]: The foundation of the Turfan Uyghur Empire = XXIXth International Congress of Orientalists (Paris, 1973), p. 30.

475. ECSEDY [Ildikó], Hilda: Uigurs and Tibetans in Pei-t'ing (790-791 A. D.) $=\mathrm{AOH} 17$ (1964), pp. 83-104.

476. ECSEDY [Ildikó], Hilda: C. Mackerras, The Uighur empire (744-840) according to the T'ang dynastic histories. /Occasional Paper 8./ Canberra, Centre of Oriental Studies, The Australian National University, 1968. Review = Asia Major XV: 1(1969), pp. 129-130.

477. ECSEDY [Ildikó], Hilda: E. Pinks, Die Uiguren von Kan-chou in der frühen Sung-Zeit (960-1028). Wiesbaden, 1968. /Asiatische Forschungen 24./. Review $=$ AOH $23(1970)$, pp. 131-133.

478. ECSEDY [Ildik 6 ], Hilda: C. Mackerras, The Uighur empire according to the T'ang dynastic histories. A study in Sino-Uighur relations 744-840. Canberra, 1972. /Asian Publication Series 2./. Review = UAJb. 46 (1974), pp. 179-181.

479. ECSEDY [Ildik6], Hilda: A.von Gabain, Das Leben im uigurischen Königreich von Qoco (850-1250). I-II. Wiesbaden, 1973. Review = Asia Major 19(1974), pp. $256-258$.

480. GABAIN, Annemarie von: Frühe Zeugen der Scherengitter-Jurte = StTurc. (1971), pp. 169-173.

481. HARMATTA, J[ános]: Irano-Turcica = AOH 25(1972), pp. 263-273.

482. HAZAI, G[yörgy]: Intensivierung der Turfan-Forschung = MIO 14(1968), pp. 127-128.

483. HAZAI, G[yörgy] - ZIEME, P[eter]: Ein uigurisches Blockdruckfragment einer Einleitung zum Vajracchedikāsūtra $=A O H 21$ (1968), pp. 1-14.

484. HAZAI, G[yörgy] - ZIEME, P[eter]: Zu einigen Fragen der Bearbeitung türkischer Sprachdenkmäler $=$ Acta Orientalia $32($ Havniae, 1970), pp. 125-140.

485. HAZAI, Glyörgy !: Ein buddhistisches Gedicht aus der Berliner Turfan-Sammlung $=$ AOH 23 (1970), pp. 1-21. 
486. HAZAI [György], Georg - ZIEME, Peter: Fragmente der uigurischen Version des "Jin'gangjing mit den Gathas des Meister Fu", nebst einem Anhang von T. Inokuchi, Berlin, 1971, 36 pp. + LX pl. (Schriften zu Geschichte und Kultur des Alten Orients 3. Berliner Turfantexte I). Reviewed by A. v. Gabain = UAJb. 44(1972), pp. 295-297.

487. HAZAI, G[yörgy]: Berlin'de Turfan yazmaları üzerinde çalışmalar = TDAYB 1971 (1971), §p. 11-20.

488. HAZAI [György], Georg: Sprachwissenschaftliche Ergebnisse der deutschen Turfan-Forschung. Text-Editionen und Interpretationen von A. A. Le Coq, F. W. K. Müller, W. Bang, A. von Gabain, G. R. Rachmati, W. Thomsen. Gesammelte Berliner Akademieschriften 1908-1938. Mit Vorwort von --. 1-2. Leipzig, 1972. $623 \mathrm{pp}$. $+24 \mathrm{pl}$. and $411 \mathrm{pp} .+15 \mathrm{pl}$. Reviewed by Zieme, P. = OLZ 69(1974), cols. 173-174.

489. HAZAI, Glyörgy]: Eine neue Veröffentlichungsreihe für die Berliner Turfantexte $=$ PLAC News. 7 (1972), pp. 6-8.

490. HAZAl, Glyörgy]: Die Turfantexte und ihre Erforschung = Das Altertum 20:4(1974), pp. 230-236.

491. KARA,Gy[örgy]: A. von Gabain, Die Drucke der Turfan-Sammlung. Berlin 1967. Review $=$ NarAzAfr, 1968:5, pp. 205-207.

492. KARA [György], George: On a lost Mongol book and its Uighur version = Protokollband (1974), pp. 287-289.

493. LIGETI, L[ajos]: Notes sur le colophon du "Yitikän sudur" = Asiatica. Festschrift Friedrich Weller zum 65. Geburtstag gewidmet (Leipzig, 1954), pp. 397-404.

494. LIG ETI [Lajos], Louis: Sur quelques transcriptions sino-ouigoures des Juan = UAJb. 33 (1961), pp. 235-244.

495. LIGETI, L[ajos]: Sur un passage du Räjāvavādaka-Sütra ouigour = Németh Armağanı (Ankara, 1962), pp. 319-330.

496. LIGETI, L[ajos]: Les fragments du Subhāșitaratnanidhi mongol en écriture 'phags-pa. Mongol préclassique et moyen mongol = AOH 17 (1964), pp. 239-292.

497. LIGETI, L[ajos] : Un vocabulaire sino-ouigour des Ming. Le Kao-tch'ang-kouan yi-chou du Bureau des Traducteurs $=$ AOH 19(1966), pp. 117-199 and 237-316.

498. LIGETI, L[ajos]: Documents sino-ouigours du Bureau des Traducteurs = AOH 20 (1967), pp. 253-306.

499. LIGETI', L[ajos]: Documents sino-ouigours du Bureau des Traducteurs = AOH 21 (1968), pp. 45-108. 
500. LICETI, L[ajos]: Glossaire supplémentaire au Vocabulaire sino-ouigour du Bureau des Traducteures $=\mathrm{AOH} 22(1969)$, pp. 1-49 and 191-243. / Budapest Oriental Studies $2 . \%$

501. LIGETI (Lajos $\mathrm{j}$, Louis: Autour du Säkiz yijkmäk yaruq = StTurc. (1971), pp. 291-319.

502. LIG ETI, L[ajos]: Les sept monastères nestoriens de Mar Sargis $=A O H$ 26 (1972), pp. 169-178.

503. LIGETI, L[ajos]: A propos d'un document ouigour de l'époque mongole = AOH 27 (1973), pp. 1-18.

504. NÉMETH [Gyula], J.: A. v. Gabain, Das uigurische Königreich von Chotscho 850-1250. Berlin, 1961. Review = OLZ 84 (1963), cols. 305-306.

505. RÓNA-TAS. A[ndrás]: Some notes on the terminology of Mongolian writing = AOH 18 (1965), pp. 119-147.

506. SÁRKÖZI, Alice: Tợin Guił̌i's Mongol Vajracchedikä = AOH 27 (1973), pp. 43-102.

507. TEZCAN, Semih - ZIEME, Peter: Uigurische Brieffragmente = St Turc. (1971), pp. $451-460$.

508. TUGUŠEVA, L. JU.: Three letters of Uighur princes $=$ AOH 24 (1971), pp. 173-187.

509. VEKERDI Jర́zsef - TASNÁDI Edit: Avadána = VIL 1, pp. 573-574.

510. YAMADA, Nobuo: Four notes on several names for weights and measures in Uighur documents $=$ St Turc. (1971), pp. 491-498.

511. ZIEME, P[eter]: Ein uigurisches Sündenbekenntnis = AOH 22 (1969), pp. 107-121.

512. ZIEME, Peter: Bas = VIL 1 p. 733.

513. ZIEME, P[eter]: Ein manichäisch-türkisches Fragment in manichäischer Schrift $=$ AOH $23(1970)$, pp. 157-165.

514. ZIEME, P[eter]: Ein uigurisches Turfanfragment der Erzählung vom guten und vom bösen Prinzen $=$ AOH 28 (1974), pp. 263-268.

See also Nos, $375,376,394,421,428,429,432,433,454,465-467$.

\section{THE MIDDLE TURKIC PERIOD}

515. BODROGLIGETI, A[ndrás] : Islamic terms in Eastern Middle Turkic $=A O H$ $25(1972)$, pp. 355-367. 
516. NÉMETH [Gyula], J.: Carl Brockelmann, Osttürkische Grammatik der islamischen Litteratursprachen Mittelasiens, 1. Lfg. Leiden, 1951. Review = OLZ 48 (1953), cols. 265-269.

See No. 517 .

517. NÉMETH [Gyula], J.: Carl Brockelmann, Osttürkische Grammatik der islamischen Litteratursprachen Mittelasiens, 2-6. Lfg. Leiden, 1951-1954. Review = OLZ 51 (1956), cols. 444-446.

See No. 516.

518. TEKIN, T[alât]: Determination of Middle Turkic long vowels through Arū $=$ AOH 20 (1967), pp. $151-170$.

See also Nos, $428,429,433,441,442,454$.

\section{a/ Karakhanids}

519. BAZIN, Louis: Les dates de rédaction du "Divan" de Kăşgarì = AOH 7 (1957), pp. 21-25.

520. BODROGLIGETI András: Ahmet Jeszevi = VIL 1, pp. 103-104.

521. CZ EGLÉDY Ká roly: Kā̧ğari földrajzi neveihez. [On Kăłgarī's geographical names ] $=$ NyelvtlidÉrt. 40 (1963), pp. 60-65.

522. HAZAI György: Ảhmed Edib bin Mahmud Yiukneki = VIL 1, p. 102.

\section{b/ Khwa rezmian}

523. BODROGLIGETI, A[ndrás]: On the prosody of 'Alì's Qissa-i Yüsuf = AOH 19 (1966), pp. 79-97.

524. BODROGLIGETI [András], Andraß: Ê. Fazylov, Starouzbekskij jazyk. Chorezmijskie pamjatniki XIV. veka. I-II. Otvestvennyj redaktor --. Taakent. 1966. $649 \mathrm{pp}$. and 1971. $777 \mathrm{pp}$.

525. BODROGLIGETI, A[ndrás]: Feriduiddin Attar, "Tezkeretü'l-Evliya" adlı eserinin ilk Türkçe terclimesi hakkında = Bilimsel Bildiriler 1966(1968), pp. 87-112.

526. BODROGLIGETI, A[ndrás]: The fragments of the Cavăhiru'l-as rār = CAJ 16 (1972), pp. 290-303.

527. BODROGLIGETI, Alndrás]: Ahmad's Baraq-nāme - A Central Asian Islamic work in Eastern Middle Turkic $=$ CAJ 18 (1974), pp. 83-128 + VII pl.

528. BOROVKOV, A. K.: Tjurkskie glossy v Bucharskom spiske "Mukaddimat $a l-a d a b "=$ AOH 15(1962), pp. 31-39.

529. FCKMANN, János: Eastern Turcic translations of the Koran = StTurc. (1971) ค. 1 149-159. 
530. HAZAI, G[yörgy]: Johannes Benzing, Das chwaresmische Sprachmaterial einer Handschrift der Muqaddimat al-adab von Zamaxsari. L. Teil. Wiesbaden, 1968. Review = MIO 16 (1970), pp. 491-492.

531. NÉM ETH [Gyula], J.: Rabghuzi, Narrationes de Prophetis: Cod. Mus. Brit. Add. 7851. Reproduced in facsimile. With an introduction by $K$. Grönbech. Copenhagen, 1.948. Review = ALH 1 (1951), pp. 237-239.

532. RÁSONY1, L[âszló]: Feridüddin Attar "Tezkeretü'1-Evliya"nun Budapeggte yazmas $1=$ Bilimsel Bildiriler 1966 (1968), pp. 83-86.

533. TOLszTOV, Sz. P.: Az ósi Chorezin (Ancient Chorezm). Budapest, 1950. $336 \mathrm{pp},+\mathrm{pl}$.

534. ZAJACZKOWSKI, A.: Sur quelques termes cosmographiques et éthniques dans le monument littéraire de la Horde d'Or = AOH 15(1962), pp. 361-368.

See also Nos. $564-569,571,572$.

\section{c/ Chaghatay}

535. BODROG IIGETI András: Abülgazi Bahádur kân = VIL 1, p. 34; Bajkara, Huszajn = ibid, p. 636 .

536. BRODSZKY Erzsébet: Utószó - Alisír Nevái, Ferhád és Sirin. Budrogligeti András nyersfordítása alapján fordította - - Postscript = Alishir Nevai "Ferhad and Shirin". Prose translation by A. Bodrogligeti. Versification by - -l Budapest, 1966. , 2nd ed. 1974.

Reviewed by Fábián Lászl6 = Nagyvilág 1968:6, p. 940.

537. ECKMANN, J[ános !: Mirzā Mehdis Darstellung der tschagataischen Sprache = AnalOr. (1942-1947), pp. 156-222.

538. ECKMANN, János: Chagataica $=$ AOH 25 (1972), pp. 349-353.

539. HAZAI György: Bábur, Zahireddin Muhammed = VIL 1, p. 613.

540. HAZAI György: Csagatáj irodalom [Chagatay literature] = VIL 2, pp. 401-403.

541. SČERBAK, A.: Zameð̌anija o tekste i jazyke Ta ałšk-name = StTurc. (1971), pp. $431-440$.

542. TASNÁDI Edit: Atai $=$ VIL 1, p. 535 .

\section{KIPCHAKS}

543. BĹRÓ Margit: Tînliszi Abo vítája [The life of Abo of Tbilisi] Buclapest, 1971. 191 pp. /BölcsÉrt. - Manuscript/. 
544. BÍRó [Margit], Margaret B.: The "Kipchaks" in the Georgian Martyrdom of David and Constantine = AnnLingu. $+(1973)$, pp. 161-168.

545. SCHÜTZ Ödön: The history of the world-conqueror by Ala-Ad-Din Ata-Malik Juvaini. Translated by J. A. Boyle. Manchester, 1958. Vols. I-II. Review = Száz. 95 (1961), pp. 189-191.

546. SCH ÜTZ [Ödön], Edmond: Könige und Eidechsen. Bemerkungen zum Fortleben des ungarischen Wortes király "König" in kiptschakischen Sprachen = Proceedings of the IXth Meeting of the PIAC (Naples, 1970), pp. 259-267.

547. SCHÜTZ [Ödön], E。: Remarks on initial d- in Kipchak languages $=A O H$ 25 (1972), pp. 369-381.

548. SCH ÜTZ [Ödön], Edmond: Tata renstürme in Gebirgsgelände (Transkaukasien, $1220,1236)=$ CAJ $17(1973)$, pp. 253-273.

\section{a/ Pechenegs and Cumans}

549. CZEGLÉDY Károly: Új adat a besenyơk történetéhez [New data on the history of the Petchenegs $]=$ MNy. $46(1950)$, pp. 361-362.

550. CZEG LÉDY Ká roly: A kangarok (besenyők) a VI. száza di szír forrásokban [The Kangars (Pechenegs) in 6th century Sy riac sources] $=$ I. OK 5(1954), pp. 243-276.

See No. 373 .

551. CZEGLÉDY Károly: Kangarok és zavarok [Kangars and misunderstandings] = MNy. $52(1956)$, pp. 120-125.

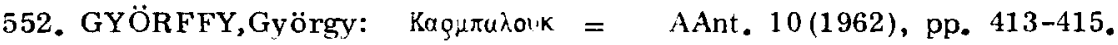

553. HARMATTA János: Színes lovú népek [Peoples with coloured horses] = MNy. 42 (1946), pp. 26-34.

554. ISTVÁNOVITS Márton: Adatok a besenyók történetéhez a grúz krónikák alapján [Data on the history of the Pechenegs based on Georgian sources] = Ethn. $71(1963)$, pp. $106-108$.

See Nos. 555.

555. ISTVÁNOVITS, M[árton]: Georgian data bearing on the history of the Petcheneg $=$ AOH 16 (1963), pp. 319-325.

See No. 554 .

556. MORAVCSIK, Gy[ula]: Koy:vtov - peðeně̌skoe ili russkoe slovo? = AAnt. 1 (1951), pp. 225-231.

557. TRYJARSKI, Edward: A note on the relations between the Pechenegs and Poland $=$ StTurc. (1971), pp. 461-468. 
See also Nos. $373,643,1076,1078,1146,1147,1169,1171,1341,1533-1540$, $1542,1550-1552$.
b/ The Codex Cumanicus

558. BODROGLIGETI, A[ndrás ]: The persian vocabuiar of the Codex Cumanicus. Budapest, 1971. 235 pp. /BOH 16.. .

Reviewed by Doerfer, G. = WZKM 65/66 (1973/74, pp. 387-394; Fazylov, E.. I. = NarAzAfr. 1973:6, pp. 189-191; Klíma $0 .=$ Archur. 42 (1974), p. 185.

559. GYÖRFFY, Glyörgy l: Autour du Codex Cumanicus = AnalOr. (1942-1947), pp. 110-137.

560. HAZAI György: Codex Cumanicus = VIL 2, p. 280.

561. LIGETI Lajos: Dengizikh és Bécs állitólagos kun megfelelöi (Hypothetical Cuman equivalents of the words Dengizikh and Bécs $]=M N y .58(1962)$, pp. 146-152.

See No. 562 .

562. LIGETI, L[ajos]: Sur deux mots comans = AAnt. $10(1962)$, pp. 167-174. See No. 561.

563. NEMETH [Gyula], J.: A. Tietze, The Koman riddles and Turkic folklore. Berkeley and Los Angeles 1966. Review = CAJ 15 (1973), pp. 314-317.

c/ Mamluk monuments

564. BODROGLIGETI András: Elömunkálatok a török - iráni nyelvi vonatkozások vizsgálatához [ Proliminary investigations into Turkish - Persian linguistíc relations]. Budapest, 1961. 476 pp. /KandÉrt. - Manuscript/. - Theses 1962. $22 \mathrm{pp}$.

565. BODROGLIGETI, A[ndrás] ]: Glosses on Sayf-i Sarāyì's Gülistān bi-t-türki = AOH 14(1962), pp. 207-218.

566. BODROGLIGETI, Alndrás]: Notes on the Turkish literature at the Mameluke court $=$ AOH 14(1962), pp. 273-282.

567. BODROGLIGETI, A[ndrás]: A Turkish folk song from the Golden Horde = AOH 15 (1962), pp. 23-30.

568. BODROGLIGETI, A[ndrás]: A collection of Turkish poems from the 14th century [The appendix of Sayf-i Saräyi's "Gülistán bi' $t-t$ iurki"] = AOH 16 (1963), pp. 245-311.

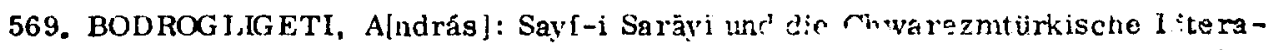
tur. Ein Beitrag zur Philologie des Chwarezmtükischen = JSFOu. 65 (196?), pp. 79-89. 
570. BODROG LIGETI, A[ndrás ]: A. Zajączkowski, Le traité arabe Muḳaddima d'Abou-1-Lait as-Samarḳandī en version mamelouk-kiptchak (Ms. Istanbul, Aya Sofya 1451). Warszawa, 1962. Review $=$ OLZ 60 (1965), cols. 54-56.

571. BODROGLIGETI, A[ndrás] : A fourteenth century Turkic translation of Sa 'dì's Gulistān (Sayf -i Sarāyī's Gulistān bi't-turkỉ). Budapest - Bloomington, 1969. $450 \mathrm{pp}$.

Reviewed by Vásáry, 1. = Nouvelles Études Hongroises 1971, pp. 284-285; Hazai György = NyK 74 (1972), pp. 267-271; Karamanlıoğlu, A. F. , Utber die Ausgabe der "Gülistãn-Übersetzung" von Sayf-1 Sarāỹ̄ = OLZ 67 (1972), cols. 325-333; Schütz, E. = ALH 22 (1972), pp. 455-456; Fazylov, E. I. = NarAzAfr. 1973:6, pp. 189-191; Kelly, James M. = JAOS 93 (1973), pp. 238-239.

572. BODROGLIGETI, A[ndrás] : Finite forms in -isar, -isar in the 14th century Turkish literary documents $=$ AOH $23(1970)$, pp. 167-176, ,

573. BODROGLIGETI, A[ndrás ]: A grammar of Mameluke-Kipchak = StTurc. (1971), pp. 89-102.

574. LIGETT, L[ajos]: Un vocabulaire mongol d' Istanboul = AOH 14 (1962), pp. 3-99.

575. LIGETI, L\{ajos ]: Notes sur le vocabulaire mongol d'Istanboul $=A O H 16$ (1963), pp. 107-174.

576. MORAVCSIK, Gy[ula]: G receskaja gramota mamljukskogo sultana vizantijskomu imperatoru =Vizantijskij V remennik 18 (1961), pp. 105-115. Author's summary = ByzZ 54 (1961), p. 431 and ByzSl. 23 (1962), p. 150.

577. MORAVCSIK, Gy[ula]: Vizantijsko-mamljukskie otnosenija $v$ XV. . $^{=}$Trudy I. (1962), pp. 442-443.

See also No. 366 .

d/ Armeno-Kipchak monuments

578. LIGETI, L[ajos]: Le lexique mongol de Kirakos de Gandzak = AOH 18 (1965), pp. 241-295.

579. SCH ƯTZ [Ödön], E.: An Armeno-Kipchak print from Lvov = AOH 13 (1961), pp. 123-130.

See No. 581.

580. SCHÜTZ [Ödön], E.: On the transcription of Armeno-Kipchak $=A O H 12(1961)$, pp. 139-161.

581. SCH ÜTZ [Ödön], E.: Armeno-Kipchak texts from Lvov (A. D. 1618) =AOH 15 (1962), pp. $291-309$.

See No. 579.

582. SCH UTTZ [Ödön], E.: Notes on the Armeno-Kipcak script and its historical brokground = UAS 23 (1903), pp. 145-154. 
583. SCH ƯTZ Ödơn: A podóliai örmények és örmény-kipcsak nyelvemlékeik [The Armenians of Podolia and their Armeno-Kipchak linguistic records] Budapest, 1964. 393 pp. /KandErt. - Manuscript/. Theses. 1964. 11 pp.

584. SCH ỦTZ [Ödön], E.: Tangsux in Armenia = AOH 17 (1964), pp. 105-112.

585. SCH UTZ Ödön: A podóliai örmenyek nyelvcseréje [The language-change of the Armenians of Podolia $]=$ Altnapok (1965), pp. 13-14.

586. SCHÜTZ [Ödön], E.: Jean Deny et Edward Tryarski, "Histoire du sage Hikar" dans la version arméno-kipchak = RO 27:2 (1964), pp. 7-61. Review $=$ AOH 19(1966), pp. 365-368.

587. SCH ÜTZ [Ödön], E。: Re-Armenisation and lexicon. From Armeno-Kipchak back to Armenian = AOH 19(1966), pp. 99-115.

588. SCH ÜTZ [Ödön], E, : An Armeno-Kipchak chronicle on the Polish-Turkish wars in 1620-1621. Budapest, 1968, $215 \mathrm{pp}$. /BOH 11./.

Reviewed by Doerfer, G. = UAJb. 40 (1968), pp. 250-252; V. L. M. = BSOAS 32 (1969), p. 228; Dopierala, $K_{\text {. }}=$ Rocznik Historyczny 1969, pp. 188-189; Daskevic, $J_{0}=$ NarAzAfr. 1970:1, pp. 182-185; Spuler, B. = ZDMG 119 (1970), pp. 386-387; Tryjarski, E. = OLZ 65 (1970), cols. 533-541; Benzing, J. = Zeitschrift für Ostforschung 1971:2 pp. 346-347; Brands, W. = CAJ 15 (1971), pp. 77-78; Reychman, J. = Przeglad Orientalistyczny 1971, pp. $61-71$; Çắatay, S. = Oriens 23-24 (1974), pp. 533-535.

589. SCH ÜTZ [Ödön], E.: T.I. Grunin, Dokumenty na poloveckom jazyke XVI.v. (Sudebnye akty kamenec-podolskoj armjanskoj obł̌ciny). Moskva, 1967. /Pamjatniki pisjmennosti vostoka. 3. /. Review = AOH 22 (1969), pp. 283-285.

590. SCH ÜTZ [Ödön], E.: E. Tryjarski, Dictionnaire arméno-kiptchak d'après trois manuscrits des collections viennoises. Tome I. fasc. 1,2. Warsawa, 1968. Review = OLZ 64 (1969), cols. 372-374. See No. 594.

591. SCH ÜTZ [Ödön], E.: Armeno-kiptschakische Ehekontrakte und Testamente $=$ AOH 24 (1971), pp. 265-300.

592. VẢSÁ RY [István], S.: Armeno-Kipchak parts from the Kamenets chronicle $=A O H 22$ (1969), pp. 139-189.

593. VÁSÁ RY István: Egy örmény -kipcsak nyelvemlék. (A kameneci krónika kiadatlan részei: szöveg, fordítás, szójegyzék, nyelvtan) [An Armeno-kipchak linguistic record. (Unpublished parts of the chronicle of Kamenec: text, translation, glossary, grammar)]. Budapest, 1970. $50+50$ pp. (Bölcs Ért. Manuscript/.

594. VÁSÁ RY, I[stván]: E. Tryjarski, Dictionnaire arméno-kiptchak d'après trois manuscrits des collections viennoises. Tome I, fasc. 1-4. Warszawa, 1968, 1969, 1972. Review $=$ AOH 28 (1971), pp. 158-159.

See No. 590 . 


\section{WESTERN TURKIC PEOPLES AND LANGUAGES}

a/ Turco-Bolgars

595. NÉMETH [Gyula], J.: La provenance du nom Bulgar (Prochodžennja nazvy "Bolgary") = Onomastica No. 28 /Winnipeg, 1964/, 12 pp. Reviewed by Doerfer, G. = ZDMG 116 (1966), pp. 199-200.

See also Nos. 615, 624, 1076, 1078, 1079, 1087, 1088, 1090, 1091, 1098, 1133, $1146,1168-1170,1180,1342,1343$.

\section{$\alpha$ / Danubian Bolgars}

596. BESEVLIEV, V.: Ein byzantinischer Brauch bei den Protobulgaren = AAnt. 10 (1962), pp. 17-21.

597. ECKHARDT Sándor: Anonymus döly fös bolgá rjai (The haughty Bulgarians of the Anonymus] $=$ MNy. $56(1960), p p, 148-250$.

598. MELICH János: Néhány balkáni és bolgárorszăgi helynévról [Notes on some place-names in the Balkans and Bulgarial = NyelvtudÉrt. $11(1957)$, pp. $63-70$.

599. SZÁDECZKY -KA RDOSS Samu: Kuvrat fiának, Kubernek a története és az avarkori régészeti leletanyag [The history of Kuvrat's son, Kuber and the archeological finds of the Avar period] $=\mathrm{AT} 15$ (1968), pp. 84-88.

\section{B / Volga Bolgars}

600. CZEGLÉDY, K[ároly]: Volga Bulgarlari fle Islavların X. asırdaki münagebeti meselesine dair = Türkiyat Mecmuası 9 (1951), pp. 180-187.

601. HALIKOVA, J. A.: Volgai Bulgária ês a X. századi Magyarország népessége etnikai rokonságának kerdéséhez [On the problem of the ethnic affinity of the populations of Volga-Bulgaria and 10th century Hungary] = Hajdúsági Múzeum Évkönyve (Hajdúböszörmény, 1973), pp. 21-35.

602. RÉDEI Károly - RÓNA-TAS András: A permi nyelvek őspermi kori bolgártörök jövevényszavai (Bulgar-Turkic loan-words of the Permian languages in the Proto-Permian period] $=\operatorname{NyK} 74(1972)$, pp. 281-298. [Résume in English].

603. RÓNA-TAS András - FODOR Sándor: Epigraphica Bulgarica. A volgai bolgártörök feliratok [The Volga Bulgar-Turkic inscriptions]. Szeged, 1973, 190 pp. /Studia Uralo-Altaica. 1./.

Reviewed by Fedotov, M. R. = SovTjurk. 1974:5, pp. 105-108.

See also Nos, 1164, 1165, 1167, 1168, 1345. 


\section{b/ Khazars}

604. ARTAMONOV, M. L.: Hazarskaja krepostj Sarkel - AArch. 7 (1956), pp. $321-341$.

See No. 605 .

605. ARTAMONOV, M. I.: Kazár vár a cimljanski tengerben [A Khazar castle in the Tsimljansk Seal = Természet és Társadalom 115(1956), pp. 290-293. See No. 604.

606. BARTHA Antal: A keleteurópai és belsöázsiai feudalizmus történeti kapcsolatai [Historical contacts between East European and Central Asiatic feudalism] = Száz. 97 (1963), pp. 261 -292 and 503-527. [Résumé in Russian and French ].

607. BARTHA Antal: M. I. Artamonov, Istorija Hazar. Leningrad, 1962. Review = Száz. 98 (1964), pp. 807-810.

See No. 623 .

608. BARTHA Antal: Kijev és Itil [Kiev and Itil] = TörtSz. $7(1964)$, pp. 223-254.

609. BARTHA Antal: Történeti fölưrajz és történelem [Historical geography and history] = TörtSz. $11(1968)$, pp. 19-27.

610. BARTHA, Antal: Graves from the age of the Hungarian Conquest at Bana = AArch. 22 (1970), pp. 219-260.

611. CZEGLÉDY Károly: Egy kazár méltóságnév [A Khazar title] = MNy . 43(1947), pp. 290-291.

612. CZEG LÉDY Ká roly: Sarkel = MNy. 48 (1952), pp. 79-86. See No. 620.

613. CZEGLÉDY Ká roly: Herakleios török szövetségesei [The Turkic allies of Herakleios] $=$ MNy. $49(1953)$, pp. 319-323.

614. CZEGLÉDY Károly: A kazár kil kel eredete [The origin of Khazar kil kel] $=\mathrm{MNy}$. 49(1953), pp. 175-178.

615. CZEGLÉDY, K[á roly]: V. Minorsky, A history of Sharvān and Darband in the 10th -11 th centuries. Cambridge, 1958. Review $=$ AOH 9(1959), pp. 329-333.

616. CZEGLÉDY, K[ároly]: Khazar raids in Transcaucasia in 762-764 A. D. = AOH 11 (1960), pp. 75-88.

617. CZEGLÉDY Károly: A korai kazár történelem forrásainak kritikájához [A critical evaluation of the sources for Early-Khazar historvl = I. OK 15(1960), pp. 107-128.

See Nos. 618, 619 .

618. CZFG LEDY, K[ároly]: Bemerkungen zur Geschichte der Chazaren $=\Lambda \mathrm{OH}$ 13 (1961), pp. 239-251.

See Nos. 617,619 . 
619. CZEG LÉDY, Ká roly: Notes on some Problems of the early Khazar history = Trudy III (1963), pp. 336-338.

See Nos. 617,618 .

620. CZEG LÉDY, K[ă roly ]: 弁arkel. An ancient Turkish word for "House" = UAS 23 (1963), pp. 23-31.

See No. 612.

621. CZEG LÉDY Ká roly: A kazár nyelv emlékei [Monuments of the Khazar language $]=$ Altnapok (1965) pp. 9-10.

622. ERDÉLYI,István: Les relations Hungaro-Khazares = Studia et Acta Orientalia 4, 1962 (Bucureşti, 1963), pp. 39-44.

623. ERDÉLYI I[stván] - KẢDÁR Z|oltán] - OJTOZI Elszter] : A kazá rok történetének első összefoglalása [The first synthes is of Khazar history] =A rchÉrt. 92 (1965), pp. $85-90$.

See No. 607.

624. FEF'ËR, Géza: Zur Geschichte der Steppenvölker von Südrussland im 9-10. Jh. = StSl. 5 (1959), pp. 257-326.

625. GLMILEV, 1. N.: New data on the history of the Khazars = AArch. 19(1967), pp. $61-103$.

026. GLMLLV , L. N.: A kazărok utódai (A csapadekeloszlás ingadozásai és az etnogenezis kêrdése Délkelet-Európában a VII-XVI. században) (Successors of the Khazars (Fluctuation of the distribution of rainfall and the problem of ethno-genes is in South-Eastern Europe in the 7-16 centuries)] = TörtSz. $11(1968)$, pp. $11-18$.

627. HARMATTA János: A kazár kil szó magyarázatához [Notes on the explanation of the Khazar word kil $]=$ MNy. 49 (1953), pp. 178-183.

628. KISS, Alttilal: 11 th century Khazar rings from Hungary with Hebrew letters and signs = AArch. $22(1970)$, pp. 341-348.

629. LANG Dezső: A kazárok zsidósága [The Judaism of the Khazars] $=$ MNy. 44 (1948), pp. 37-42.

630. MERPERT, N. Ja.: A kazár probléma elferdítése ellen (Against the distortion of the Khazar problem] = SzRég. 11(1955), pp. 126-145.

631. ZAJ AcCZKOWSKI, A.: Khazarian culture and its inheritors $=A O H 12(1961)$, pp. 299-307.

See also Nos. $373,374,381,394,441,4+3,834,1076,1078,1080-1082,1087$, $1088,1090,1091,1096,1098,1133,1146,1168,1425,1427$. 

c/ Runiform inscriptions in South-Eastern Europe
ж) Monuments from Khazaria

632. SĆERBAK, A, M. : Néhánv szó a Don vidékén talált runikus feliratok olvasásának módozatairól [Some notes on the possible readings of the runic inscriptions found in the Don region] = SzReg. 10 (1954), pp. 124-13\%.

633. SČERBAK, A. M.: Les inscriptions inconnues sur les pierres de Khoumara (au Caucase du Nord) et le problème de l'alphabet runique des Turcs occidentaux $=$ AOH 15(1962), pp. 283-290.

\section{B: The Nagyszentmiklós Treasure}

634. CSALLÁNY, D[ezsö]: Ungarische Zierschreiben aus dem X. Jahrhundert = AArch. 10 (1959), pp. $281-325$.

635. CSALLÁNY Dezső: A nagyszentmiklósi a ranykincs rovásfeliratainak megfejtése ês történeti hattere [Decipherment of the runic inscriptions and the historical background of the Nagyszentmiklós treasurel = A Nyiregyházi Jósa András Múzeum Évkönyve 10(1967), pp. 31 -84. [Résumé in German].

636. CSALLÁNY Dezső: A nagvszentmiklósi rovásfeliratok és a battonyai Árpádkori rovásírásos gyürü kapesolatai /Connections between the runic inscriptions of the Nagyszentmiklis treasure and the runes on the ring of Battonya from the Arpadian age $\mid=A$ Nyi regyházi Jósa András Múzeum Évkönyve 11 (1968), pp. 89-95. [Résumé in German].

637. CSALLÁNY Dezső: A Csanádok kincse [The Csanád treasure] = Az V. Alföldi Régés zeti Tudományos Üléss zak előadása inak bekiildött tézisei (Szeged, 1968), pp. $18-19$.

See No. 638 .

638. CSALIÂNY, Dezső: Der Schatz der Csanáden = A Szegedi Móra Ferenc Múzeum Évkönyve 1969. pp. $201-205$.

See No. 6.37 .

639. KÁDÁR Zoltán: A nagys zentmiklósi kincs triumfális kêptípusainak eredeté röl (Notes on the origin of the triumphal tvpes of pictures of the treasure of Nagyszentmiklós $\mid=$ FolArch. 13(1961), pp. 117-126. iRésumé in French]. Reviewed by M\{oravcsik\} Gy. = ByzZ 55 (1962), p. 413.

640. IÁszló Gyula: Jegyzetek a nagyszentmiklósi kincs ról / Notes on the treasure of Nagyszentmiklós] = FolArch. 9(1957), pp. 141-152.

641. LÁszLÓ, Gyula: Contribution à l'a rcheologie de l'époque des migrations. III. Notes sur le tresor de Nagyszentmiklós = AArch. 8(1957), pp. 186-198. 
642. LÁSZLÓ Gvula: A nagvszentmiklósi kincs [The treasure of Nagvszentmiklós] = Régi Jolg. t(1962), pp. 59-64.

643. NÉMETH [Gyula], J.: Die Inschriften des Schatzes von Nagy-Szent-Miklós. Mit zwei Anhängen: I. Die Sprache der Petschenegen und Komanen. II. Die ungarische Kerbschrift. Budapest, 1932. BOH 2./. Photomechanischer Neudruck. The Hague, 196\%. 85 pp.

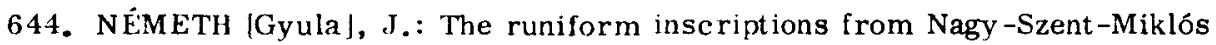
and the runiform scripts in Eastern Furope = ALH $21(1971)$, pp. $1-52$.

$\gamma$. Monuments in Hungary from the Avar Period

645. VÁSÁRY, I[stván]: Runiform signs on objects of the Avar period (6th-8th C.C.A.D.) = AOH 25(1972), pp. 335-347.

See also Nos. 1474-1497. 


\section{IV. \\ MODERN TURKIC PEOPLES AND LANGUAGES}

1. TURKISH /OTTOMAN, ANATOLIAN, RUMELIAN ETC./

\section{a/ Language history}

646. ADAMOVIĆ, M.: Giovanni Molino und seine tiirkische Grammatik = ALH 24 (1974), pp. 37-67.

647. BODROGLIGETI, A[ndrás]: On the Turkish vocabulary of the Ișfahān Anonymous $=A O H 21(1968)$, pp. 15-43.

648. HAZAI György: A bulgáriai cirill-betũs török nyelvemlékek [Turkish linguistic records from Bulgaria in Cyrillic letters]. Budapest, 1958. $2+321 \mathrm{pp}$. /KandÉrt. Manuscript/. - Theses. 1958. 4 pp. Summary of debate by I. Sipos $=$ I. OK $15(1960)$, pp. 399-402.

See No. 649.

649. HAZAI, Glyörgy]: Kiril harfleriyle yazılan Tïrk metinleri: Bilimsel Bildiriler 1957 (1960), pp. 83-86.

Reviewed by Nuriachmetov, A. Ch. = NarAzAfr. $1961: 4$ p. 245.

See No. 648 .

650. HAZAI, Glyörgy ]: Monuments linguistiques os manlis-turcs en caractères cyrilliques dans les recueils de Bulgarie $=A O H 11(1960)$, pp. $221-233$.

Reviewed by Nuriachmetov, A. Ch. = NarAzAfr. 1961:4, p. 245.

See Nos. 664,681 .

651. HAZAI, Glyörgyl: Remarques sur les rapports des langues slaves des Balkans avec le turc-osmanli $=$ StSl. 7 (1961), pp. $97-138$.

652. HAZAI [György], Georg: Über den osmanisch-türkischen Abschnitt des dreisprachigen Sprachfïhrers von Saloniki = UAJb. 33(1961), pp. 66-72.

653. HAZAI, Glyörgy l: J. Križanić'in "Illy ria" başlıklı eserindeki Làtin harfle riyle yazılı bir Türkçe metin hakkında = Németh Armağanı (Ankara, 1962), pp. 257-262+ I pl. 
654. HAZAI, G[yörgy ]: $\grave{A}$ propos d'un changement phonétique dans le moyen-osmanli $=$ AOH 15(1962), pp. 147-154.

See No. 658 .

655. HAZAI [György], Djordj: $K$ periodizacii istorii tureckogo jazyka $=$ Trudy III (1963), pp. 358-359.

See No. 656 .

656. HAZAI, G[yörgy]: Tïrk dilinde tarihsel gelişme dönemleri = Bilimsel Bil diriler 1963 (1964), pp. 57-60.

See No. 655.

657. HAZAI, G[yörgy]: Rumeli ağızları tarihinin iki kaynă̆ı üzerine = TDAYB 1963 (1964), pp. $117-120+8$ pl.

658. HAZAI, G[yörgy]: Remarques supplémentaires sur un changement phonétique dans le moyen-osmanli $=$ AOH $17(1964)$, pp. 139-144.

See No. 654 .

659. HAZAI, G[yörgy]: Un texte Osmanli-Turc en transcription latine du XVII ${ }^{\text {e }}$ siècle = AASt. 1 (1965), pp. 104-111.

660. HAZAI György: Harsányi-Nagy Jakab török szövegei. A XVII. századi oszmántörök nvelv problémái ITurkish texts of Jakab Harsányi-Nagy. Problems of the 17th century Ottoman-Turkish language]. Budapest, 1964. 628 pp. /DoktËrt. - Manuscript/ - Theses. 1965. 31 pp.

See Nos. 670,674, 677,680.

661. HAZAI, G[yörgy]: About a term in Old-Anatolian and Rumelian-Turkish = Indo-Asian Studies, Part 2:1-2 (New Delhi, 1965), pp. 1-2.

662. HAZAI, G[yörgy]: Prilog istorijatu morfeme -LUK = Zbornik za filologiju i lingvistiku 7 (1965), pp. 59-62.

663. HAZAI, Glyörgy l: Tureckij transkripcionny j tekst napisannyj kyrylicej = Tjurkologičeskij sbornik. K šestidesjatiletiju Andreja Nikolaeviða Kononova (Moskva, 1966), pp. 128-134.

See Nos. 664, 668.

664. HAZAI, G/vörgy]: Ein kyrillischer Transkriptionstext des Tiirkischen = StSl. 12 (1966), pp. $173-179$.

See Nos. 650, 681 .

665. HAZAI, G[yörgyl: Methodologische Fragen in der Periodisierung der tiirkischen Sprachgeschichte $=$ Omagiu lui Alexandru Rosetti la 70 de ani (Bucureşti, 1966), pp. 349-451.

666. HAZAI, Glyörgv l: Probleme und Aufgaben der Balkan-Turkologie /Sprachwissenschaft/ = Ier Congrès International des Études Balkaniques et Sud-Est Européennes, Sofia, 26 août - 1 septembre 1966. Résumés des communications. Linguistique (Sofia, 1966), pp. 92-100. See Nos. 667, 671 . 
667. HAZAI, G[yörgy] - BOMBACI, A.: Die sprachwissenschaftlichen Probleme der Balkan-Turkologie auf dem Balkanologen-Kongress = Orbis 16 (1967), pp. $269-272$.

See Nos. 666,671 .

668. HAZAI, Glyörgy]: Kiril harfleriyle yazılı bir Türkçe metin üstüne = TDAYB 1966 (1967), pp. 145-155.

669. HAZAI, Glyörgy]: Dil çalışmalarının makineleştirilmesi = TDAYB 1966 (1967), 259-265.

670. HAZAI, Glyörgy]: Anadolu ve Rumeli Tiirkçesinin bir yadigârı iistiinde. Yakab Nagy de Harsány' in dil kılavuzu (1672) = Bilimsel Bildiriler 1966 (1968), pp. 13-16.

See Nos. $660,674,677,680$.

671. HAZAI, Glyörgy]: Probleme und Aufgaben der Balkan-Turkologie (Sprachwissenschaft) $=$ Actes du Premier Congrès International des Études Balkaniques et Sud-Est-Européennes, VI, Linguistique (Sofia, 1968), pp.

95-100.

See Nos. 666,667 .

6\%2. HAZAI, G[yörgy]: The memoirs of general Makriyannis 1797-1864. Ed. and transl. by H. A. Lidderdale. London - New York - Toronto, 1966. Review = OLZ 65(1970), cols. 62-63.

673. HAZAI, G[yörgy]: On some questions of the Turkish historical grammar = Proceedings. VIIIth International Congress of Anthropological and Ethnological Sciences, 1968. Tokyo and Kyoto, Vol. II. Ethnology, Science Council of Japan (Tokyo, 1970), pp. 418-419.

See No. 675.

674. HAZAI, Glyörgyl: Yakab Harsânyi-Nagy' in Latin harfle riyle yazılmış Tïrkçe metinleri = TDAYB 1971 (1971), pp. 47-59.

See Nos. $660,670,677,680$.

675. HAZAI, G[yörgy]: On some questions of the Turkish historical grammar Proceedings of the Twenty -Seventh International Congress of Orientalist, Ann-A rbor, Michigan, 13th-19th august 1967 (Wiesbaden, 1971), pp. 596-597. See No. 673 .

676. HAZAI, G[yörgy]: Zur Frage der historischen Entwicklung der Personalendungen im Osmanisch-Tïrkischen = StTurc. (1971), pp. 231-234.

677. HAZAI György: Harsányi-Nagy Jakab latin betũs török szövegei. [Summary: Die osmanisch-tiirkischen Texte von Jakab Harsányi-Nagy in lateinischer Schrift] $=$ NyK 74 (1972), pp. 417-426.

See Nos. 660, 670, 674, 680 . 
678. HAZAI, G[yörgy] - MEYER, I.: Zur historischen Morphonologie des Os manisch-Tiirkischen $=$ ArchOtt. 1, 1969 (1973), pp. 92-104.

679. HAZAI, G[yörgy]: $\grave{A}$ propos de la critique des monuments de la transcription du turc ottoman $=\mathrm{XXX}^{\mathrm{e}}$ Congrès International des Orientalists. Résumés des Communications. Sections 6-7,6. Asie Centrale, 7. Inde (Paris, 1973), p. 34 .

680. HAZAI, György: Das Osmanisch-Tïrkische im XVII. Jahrhundert. Untersuchungen an den Transkriptionstexten von Jakab Nagy de Harsány. Budapest, 1973. 498 pp. / BOH 18/ and The Hague - Paris, 1973. 498 pp. /Near and Middle East Monographs 15/ 1; Language Monuments of the Ottomans in Non-Turkish Scripts 1./.

Reviewed by Werner, E. = Zeitschrift für Geschichtwissenschaft 21 (1973), p. 1546; Blałkovið, J. =AASt. 10 (1974), pp. 231-233; Doerfer, G. = ZBalk. 11 (1974), pp. 116-118; Hřbið̌ek, L. = ArchOr. 42 (1974), pp. 84-85; Johanson, L. = Orientalia Suecana (Uppsala) 22, 1973 (1974), pp. 191-197; Kleinmichel, S. = Asien Afrika Lateinamerika (Berlin) 2-3 (1974), pp. 480-482; Kononov, A. N. = VJaz. 1974:2, pp. 131-134; Lörincz L.: Nouvelles Études Hongroises 9(1974), pp. 256-257; Nasilov, D. M. = Sov'Tjurk. 1974:4, pp. 111-112; Repin, B. = Izvestija Akademii Nauk Kazachskoj SSR, Serija filologiðeskaja 1974:3, pp. 60-63. See Nos. $660,670,674,677$.

681. HAZAI, G[yörgy]: Ein kyrillischer Transkriptionstext des Osmanisch-Türkischen = Vostočnaja Filologija 3 (Tbilisi, 1973), pp. 266-280. See Nos, 650,664 .

682. HAZAI, György: Bartholomaeus Georgievits os zmán-török szövegeinek balkâni hátteréhez. [Summary: Zum balkanischen Hinterg rund der osmanischtürkischen Texte von Bartholomaeus Georgievits] = NyK 76 (1974), pp. 199-228. See No. 683.

683. HAZAI, G[yörgy]: Zum balkanischen Hinterg rund der osmanisch-türkischen Transkriptionstexte von Bartholomaeus Georgievits = StSl. 20 (1974), pp. $71-106$.

See No. 682.

684. KENESSEY Mária: Francisco-Maria Maggio XVII. sz. -i török nyelvtana [Francisco-Maria Maggio's 17th century 'Turkish grammar]. Budapest,1974. 145 pp. / Bölcs Ért. - Manuscript/.

685. KENESSEY [Mária], Mary: A Turkish grammar from the 17 th century $=\mathrm{AOH} 28$ (1974), pp. 119-125.

686. NÉMETH Gyula, Balassa Bálint és a török költészet [Valentine Balassa and Turkish poetry] =: Magyar Századok, Irodalmi müveltségünk történetéhez. (Budapest 1918), pp. 80-100. Reviewed by Eckmann, J. = IÜEFTDED 1950. See Nos. 687, 690, 691, 1896. 
687. NÉMETH [Gyula], J.: Die türkischen Texte des Valentin Balassa $=A O H$ 2 (1952), pp. 23-61.

See Nos. $686,690,691,1896$.

688. NÉMETH Gyula: A kevert nyelvrendszer kérdéséhez (Az oszmán-török nyelv kettős rendszere) (On the problem of the mixed language-system (The double system of the Osmanli-Turkish language)] = I. OK 2 (1952), pp. 313-332. Contributions by Ligeti Lajos: pp. 332-338; Telegdi Zsigmond: pp. 338-342; Tamás Lajos: pp. 343-345.

See No. 689 .

689. NÉMETH [Gyula], J.: Zur Kenntnis der Mischsprachen (Das doppelte Sprachsystem des Osmanischen) = ALH 3 (1953), pp. 159-199. See No. 688 .

690. NÉMETH Gyula: Balassi Bálint török verseihez [Notes on Bálint Balassa's Turkish poems] = ItK. 58 (1954), pp. 386-392.

See Nos. 686, 687, 691, 1896.

691. NÉMETH [Gyula], J.: Türkische Balassa-Texte in Karagöz-Spielen $=A O H$ 5 (1955), pp. 175-180.

See Nos. 686, 687, 690, 1896 .

692. NÉMETH [Gyula], J.: Zu den türkischen Aufzeichnungen des Georgievits = Charisteria Orientalia praecipue ad Persiam pertinentia, Ioanni Rypka... hoc volumen sacrum (Praha, 1956), pp. 202-209.

See No. 696.

693. NÉMETH [Gyula], J.: Osmanlı Türk dili tarihi araştırmalarının yeni yolları

= Bilimsel Bildiriler 1957 (1960), pp. 1-14.

Reviewed by Benzing, J. = OLZ 57 (1962), cols. 289-290.

694. NÉMETH Gyula: A magya rországi oszmán-török nyelv. חlésházy Miklós török nyelvkönyve 1668 -ból |The Osmanli-Turkish language in Hungary. Miklós II lésházy's Turkish grammar from 1668) = NyK 69 (1967), pp. 57-109.

See Nos. 695, 697 .

695. NÉMETH [Gyula], J.: Tureckij jazyk v Vengrii = VJaz. $17(1968): 2$, pp. 89-95.

See Nos. 694,697 .

696. NÉMETH [Gyula], J.: Die türkische Sprache des Bartholomaeus Georgievits = ALH 18 (1968), pp. 263-271.

See No. 692 .

697. NÉMETH [Gyula], J.: Die tiirkische Sprache in Ungarn im siebzehnten Jahrhundert. Budapest-Amsterdam, 1970, $281 \mathrm{pp.} / \mathrm{BOH} 13 . /$.

Reviewed by Agazade, N. = SovTjurk. 1971:1, pp. 90-107; Hazai, G. = DLZ 92 (1971), pp. 902-903; Kop̌̌an, V. = AASt. 7 (1971), pp. 155-156; Vásáry, I. = AOH 24(1971), pp. 127-129 and Nouvelles Études Hongroises 7(1972), p. 
228; Guzev, V. G. = NarAzAfr. 1972:2, pp. 186-189; Vesela-Přenosilovă, $Z_{\text {. }}=$ ArchOr. $17(1974)$, p. 267; Schiitz, E. = UAJb. 46 (1974), pp. 173-176. See Nos. 694, 695.

698. REUTER Camillo: Bejegyzések egy "Kisded Szô-tá r" -ból [Notes from the "Tiny Dictionary"] = MNy. 61 (1965), pp. 103-108.

699. RITOÓK Zsigmondné: Egy 16. századi vándor literátor: Bartholomaeus Georgievits [A 16th century wandering scholar: B. G.] = Szomszédság és közösség (Budapest, 1972), pp. 53-70.

700. SCHÜTZ [Ödön], E.: The Turkish loan-words in Simeon Lehaci's travel accounts $=$ AOH 20(1967), pp. 307-324.

701. SCHÜTZ [Ödön], E.: Jeremia Celebis türkische Werke (Zur Phonetik des Mittelosmanischen) $=$ StTurc. (1971), pp. $401-430$.

See also Nos. $339,341,343,346,348,350,709-712,714-716,718,719,731$, $733-736,738,752,753,858,1778,1779,1783-1785$.

\section{b/ Dialectology}

702. BOROSS Marietta: V. Marinov, Prinos kăm izučaveneto na bita i kulturata na turcite i gagauzite v severoiztoxna Bălgarija. Sofia, 1956. Review $=$ Ethn. 69 (1958), pp. 197-498.

703. EREN, Hasan: Énigmes populaires turques de Chypre $=$ AOH $11(1960)$, pp. $105-111$.

704. HAZAI, G[vörgy]: Les dialects tures du Rhodope = AOH 9 (1959), pp. 205-229. See Nos. $705,706$.

705. HAZAI, Glyörgyl: Textes turcs du Rhodope $=$ AOH 10 (1960), pp. 185-229. See Nos. 701, 706.

706. HAZAI, Glyörgv|: Rodop Türk ăgızları = Bilimsel Bildiriler 1957 (1960), pp. $127-130$.

See Nos. 704,705 .

707. HAZAI, Glyörgy l: Rumeli ağızlarının tarihi ïzerine = TDAYB 1960 (1960), pp. 205-211.

708. HAZAI, G|vörgy |: Beiträge zur kenntnis der tiirkischen Mundarten Mazedoniens $=$ RO $23(1.960)$, pp. 83-100.

709. HAZAI, G|vörgyl: Prinos kăm văprosa za klasifikacijata na balkanskite turski govori : Ezikovedsko-etnogratski izsledovanija $v$ pamet na akad. St. Romanski (Sofia, 1960), pp. j05-510.

See No. 710 .

710. HAZAI. Glvörgyl: Contribution à l'histoire d'une limite dialectale dans les Balkans = ()rbis $10(1961)$, pp. 15-19.

see No. 709 . 
711. HAZAI, G[yörgy]: Contributions à l'histoire des dialectes osmanlis -turcs. Helsinki, 1964. 9 pp. /StOr. 28:4/.

712. HAZAI, G[yörgy]: O nekotorych aktualjnych voprosach issledovanija balkanotureckich dialektov $=$ BalkEz. $9(1964)$, pp. 57-69.

713. HAZAI, G[yörgy]: Mes enquêtes sur les parlers turcs des Balkans = Communications et rapports du Premier Congrès International de Dialectologie Générale (Louvain du 21 au 25 août; Bruxelles les 26 et 27 août 1960), organisé par Sever Pop, publiés par A. J. Windekens, $2^{e}$ partie (Louvain, 1964), pp. 85-90.

714. HAZAI György: A balkáni oszmán-török nvelviárások jövevényszó kutatásának néhány kérdése [Some questions of the research in loan-words of the Balkan Ottoman-Turkish dialects] = Altnapok (1965), pp. 12-13. See No. 715.

715. HAZAI, Glyörgy]: Beiträge zu einigen Problemen der Lehnwörterforschung in den osmanisch-tiirkischen Mundarten des Balkans = AOH 18 (1965), pp. 183-190.

See No. 714.

716. HAZAI, G[yörgy]: Zur Geschichte der osmanisch-tiirkischen Mundarten = Second International Congress of Dialectologists, Marburg /L. 5-10. 9. 1965. Papers to be read, 7.

See No. 717.

717. HAZAI, G[yörgy]: Zur Geschichte der osmanisch-türkischen Mundarten = Zeitschrift für Mundartforschung. Beihefte, Neue Folge Nr. 3 und 4. Verhandlungen des $\mathrm{Z}$ weiten Internationalen Dialektologen Kongresses (Wiesbaden, 1967), pp. $342-345$.

See No. 716 .

718. HAZAI, G[yörgy]: Anadolu ve Rumeli Türk ağızlarının tasnıf $ı$ istüne = Voprosy tjurkologii. K sestidesjatiletiju akademika AN Azerb. SSR M. S. Šralieva (Baku, 1971), pp. 84-86.

719. HAZAI, G[yörgy]: Der Dialekthinterg rund der türkischen Literatursprache = III. Congrès International d'Études du Sud-Est-Européen. Résumés des Communications, Tome II, Linguistique, littérature, folklore, ethnog raphie, arts, droit et institutions (Bucureşti, 1974), p. 108.

720. KAKUK [Zsuzsa], Suzanne: Le dialecte ture de Kazanlyk = AOH 8 (1958), pp. 169-187.

See No. 721.

721. KAKUK [Zsuzsa], Suzanne: Textes turcs de Kazanlyk $=\mathrm{AOH} 8$ (1958), pp. 241-311.

See No. 720. 
722. KAKUK [Zsuzsa], Susanne: Constructions hypotactiques dans le dialecte turc de la Bulgarie Occidentale $=\mathrm{AOH} 11$ (1960), pp. 249-257.

723. KAKUK [Zsuzsa], Susanne: Tiirkische Volksmärchen aus Kiistendil $=$ UAJb. 33 (1961), pp. $90-94$.

See No. 724.

724. KAKUK, Zsuzsanna: Die tiirkische Mundart von Kiistendil und Michailovgrad $=\mathrm{ALH} 11(1961)$, pp. 301-386.

See No. 723.

725. KAKUK [Zsuzsa], Susanne: Le dialecte turc d'Ohrid en Macédoine $=\mathrm{AOH}$ $26(1972)$, pp. 227-283.

726. MOLLOVA, Mefküre: Les noms des jours chez les Turcs des Balkans = AOH 20 (1967), pp. $101-109$.

727. MOLLOVA, Mefkiire: Croyances que les Turcs des Balkans attachent aux jours de la semaine $=$ AOH 22 (1969), pp. $361-376$.

728. NÉMETH [Gyula], Julius: La cérémonie du tewhīì à Vidin = Ignace Goldziher memorial volume P.1. (Budapest, 1948), pp. 329-335.

See No. 729 .

729. NÉMETH Gyula: A mohamedán vallásgyakorlat népi formáinak ismeretéhez (A tevhit szertartása Vidinben) [Data on the popular forms of Muslim worship (The ceremony of tevhit in Vidin)] = Ethn. $59(1948), \mathrm{pp} .1-4$. [Résumé in French].

See No. 728.

730. NÉMETH [Gyula], J.: Die Zeremonie des Mevlud in Vidin $=A O H 1(1950-51)$, pp. $134-140$.

731. NÉMETH [Gyula], J.: Le passage ö ) ü dans les parlers turcs de la Roumélie nord-ouest $=$ RO 17 (1951-1952), pp. 114-121.

732. NÉMETH [Gyula], Julius: Ein tiirkischer Text aus Vidin iiber die Pilgerfahrt = Documenta is lamica inedita, Ricardo Hartmann viro de studiis is lamicis meritissimo sacrum (Berlin, 1952), pp. 273-277.

733. NÉMETH Gyula: Bulgária török nyelvjárásainak felos ztásához [On the classification of the Turkish dialects of Bulgarial $=$ I. OK $10(1957)$, pp. 1-60. Contributions by Kakuk Zsuzsa N.: pp. 61-64; Rásonyi László: p. 64; Hazai György: pp. 64-66; Fekete Lajos: pp. 66-69.

See Nos. 78,734 .

734. NÉMETH [Gyula], J.: Zur Einteilung der tiirkischen Mundarten Bulgariens. Sofia, 1956. $74 \mathrm{pp}$.

Reviewed by Pritsak, O. = UAJb. $29(1957)$, p. 268; Benzing, J. = ZDMG 112 (1962), pp. $196-197$.

See Nos. 78,733 . 
735. NÉMETH [Gyula], J.: Spuren der tïrkischen Sprache in Albanien = Akten des Vierundzwanzigsten Internationalen Orientalisten-Kongresses, München, 28. August bis 4. September 1957 (Wisbaden, 1959), pp. 378-380.

See No. 736.

736. NÉMETH [Gyula], J.: Traces of the Turkish language in Albania $=A O H$ 13 (1961), pp. 9-29.

See No. 735.

737. NÉMETH [Gyula], J.: Die "I,ebensrute" in einem türkischen Märchen von Vidin = Oriens 15 (1962), pp. 304-314.

See No. 739.

738. NÉMETH [Gyula], J.: Die Tiirken von Vidin. Sprache, Folklore, Religion. Budapest, 1965, $420 \mathrm{pp}$. /BOH 10./.

Reviewed by Bainbridge, M. = BSOAS 29 (1966), pp. 625-626; Caferoğlu, A. = IUtEFTDED 14(1966), pp. 130-132; Clauson, G. = JRAS 1966, pp. 153-154; Hazai Gy. = I. OK 23(1966), pp. 335-336 and UAJb. 39(1967), pp. 119-121; Kakuk, S. = AOH 19(1966), pp. 361-363; Kononov, A. N. = VJaz. 15:2, pp. 158-164; Mijatev, P. = EtBalk. 5 (1966), pp. 225-228; Stachowski, $\mathrm{S}_{\text {. }}=$ FolOr. 8 (1966), pp. 243-247; Vakarelszki, H. = Ethn. 77 (1966), pp. $621-622$; Bajraktarević, F. = Der Is lam $43(1967)$, p. 220; Celjniker, S. S. = NarAzAfr. 1967:4, pp. 208-210; Doerfer, G. = MIO 13 (1967), pp. 155-157; Tietze, A. = OLZ 62 (1967), cols. 492-494; Jäschke, G. = Die Welt des Islam 11 (1968), p. 225; Hrebicek, L. = ArchOr. 39 (1971), pp. 105-106.

739. NÉMETH Gyula: Az "életvesszó" egy vidini török mesében [The "Tree of li$\mathrm{fe}^{\prime \prime}$ in a Turkish tale from Vidin $]=$ Ethn. 77 (1966), pp. 451-452. See No. 737.

740. NÉMETH [Gyula], Ju.: Vengerskie elementy v leksike vidinskogo govora tureckogo jazyka = Annales Instituti Philologiae Slavicae Universitatis Debreceniensis de Ludovico Kossuth Nominatae 8 (1968), pp. 181-184.

See also Nos. $53,78,648,651,657,666,667,670,671,682,683,694,696$.

c/ Turkish loan-words in the Balkan languages

741. EREN, Hasan: Oláh indic [The Wallachian indic ("trench")] = MNy. 43 (1947), p. 295 .

742. GRANNES, $A_{\bullet}:$ Les turcismes dans un parler bulgare de la Bulgarie de l'Est $=$ AOH 28 (1974), pp. 269-285.

743. HAZAI, Glyörgy l: J. Zaimov, Mestnite imena v Pirdopske. Sofia, 1959. Review $=$ StSl. 8 (1962), pp. 199-202.

744. HAZAI, G[yörgy]: A. Škaljić, Turcizmi u na rodnom govoru i na rodnoj knjiZevnosti Bosne i Hercegovine. 1-2. Sa rajevo, 1957. Review = StSl. 8 (1962), pp. 202-205. 
745. HAZAI, G[yörgy] : Kăm njakoi văprosi na osmansko-turskite zaemki v južnoslavjanskite ezici $=$ StSl. 9(1963), pp. 387-391.

746. HAZAI, G[yörgy]: St. Stachowski, Przy rostki obcego pochodzienia w języku serbochorvackim. Kraków, 1961. Review = StSl. 10 (1964), pp. 472-473.

747. HAZAI, G[yörgy]: A. Knežević, Die Turzismen in der Sprache der Kroaten und Serben. Meisenheim amGlan, 1962. Review = StSl. 10 (1964), pp. 212-215.

748. TAMÁS Lajos: Az albán nemzeti és irodalmi nyelv kérdése [The problem of the Albanian national and literary language] $=$ I. OK 3 (1953), pp. 265-293.

See also Nos. $651,666,667,671,735,736,1780-1784,1818,1819$.

\section{d/ Onomastics}

749. FEKETE, L[ajos]: Beiname (lagab), Personenname (isim) und Apposition $\underline{\left(n a^{c} t\right)}$ in den Ofner Muqätáa ${ }^{c}$-Deftern $=$ AOH 15 (1962), pp. 97-109.

750. FEKETE Lajos: Számnevek török helynevekben [Numerals in Turkish placenames] = Altnapok (1965), pp. 7-8.

See No. 751 .

751. FEKETE, L[ajos]: Mit Zahlwörtern gebildete osmanisch-tiirkische Ortsnamen $=\mathrm{AOH} 18$ (1965), pp. 61-71.

See No. 750 .

752. KAKUK [Zsuzsa], Suzanne: Quelques catégories de noms de personne turcs $=$ AOH $28(1974)$, pp. $1-35$.

753. KAKUK, Zsuzsa: Anthroponymes turcs mahométans = The Muslim East (1974), pp. 161-173.

754. MORAVCSIK Gyula: Bizánc neveinek tiikrében (Byzantium in the light of her names] $=\mathrm{AT} 13(1966), \mathrm{pp} .227-234$.

755. SZABÓ $T$. Attila: Az Is ztambul-, illetóleg a Malomba-típusú helynévkölcsönzés kérdéséhez [Notes on the problem of borrowing toponyms of the types Istanbul i.e. Malomba "into the mill"] = MNyj. 7 (1961), pp. 3-21. [Résumé in German]. Correction = MNyj. 8 (1962), p. 126.

See also Nos. $377,1784$.

e/ Modern Turkish

756. AKSOY, Ömer Asım: Nyelvújítási munkálatok Törökországban [Language reform activity in Turkey] $=$ NyK 75 (1973), pp. 257-263.

757. BODROG LIGETI, A[ndrás] : On modern Turkish üstünköriü and yüzükoyun = AOH 26 (1972), pp. 145-150. 
758. HAZAI, Gy[örgy]: H. and R. Kahane, A. Tietze, The lingua franca in the Levant. Turkish nautical terms of Italian and Greek origin. Urbana, 1958. Review $=$ RO 26 (1963), pp. 163-165 and NyK 66 (1964), pp. 228-230.

759. HAZAI, G[yörgy]: K. Steue rwald, Unte rsuchungen zur tiirkischen Sprache der Gegenwart. Teil I: Die tiirkische Sprachpolitik seit 1928. Berlin, 1963. Review = OLZ 60 (1965), cols. 176-179. Teil II:Zur Orthographie und Lautung des Tiirkischen. Berlin, 1964. Review = OLZ 62 (1967), cols. 61-62. Teil III: Zur Ablösung des arabischen und persischen Grammatikgutes. Berlin, 1966. Review = OLZ 64 (1969), cols. 376-377.

760. HAZAI, Glyörgy]: Linguistics and language issues in Turkey $=$ Current Trends in Linguistics 6. Linguistics in South West Asia and North Africa (The Hague, 1971), pp. 746-758.

See No. 763 .

761. HAZAI, Glyörgy]: Turkish = Current Trends in Linguistics 6. Linguistics in South West Asia and North Africa (The Hague, 1971), pp. 183-216.

762. HAZAI, Glyörgy ]: J. Th. Zenker, Tiirkisch-a rabisch-pers isches Handwörterbuch. I-II. Hildesheim, 1967 (Reprog raphischer Nachdruck der Ausgabe Leipzig 1866). Review = OLZ 67 (1972), cols. 377-378.

763. HAZAI [György], George: Linguistics and language issues in Turkey = Advances in language planning / Contributions of the Sociology of Language. No. 5./ (The Hague - Paris, 1974), pp. 127-161. See No. 760 .

764. KÁLDY-NAGY, Gyula: G. L. Lewis, Turkish Grammar. Oxford, 1967. Review = BiblOr. 26 (1969), pp. 256-257.

765. NÉMETH [Gyula], J.: Heuser - Şevket, Türkçe-almanca lûgat. Tïrkischdeutsches Wörterbuch, 3., verb. u. stark erweit. Aufl., Wiesbaden, 1953. Review = OLZ 49 (1954), cols. 349-352.

See No. 768 .

766. NÊMETH [Gyula], J.: Jean Deny, Principes de grammaire turque ('Turk" de Turquie). Paris, 1955. Review := OLZ 54(1959), cols. 609-613.

767. NÉMETH [Gyula], J.: Turkish grammar. English adaptation of the German original by T. Halasi -Kun. 's-Gravenhage, 1962, $111 \mathrm{pp}$. / Publications in Near and Middle East Studies, Columbia University. Series B. 1./. Reviewed by Lees, R. B. = Language 39 (Baltimore, 1963), pp. 548-556.

768. NÉMETH [Gyula], J.: Heuser - Şevket, Türkçe-almanca lûgat. Tiirkischdeutsches Wörterbuch. 5., verb. Aufl., Wiesbaden, 1962. Review = OLZ 58 (1963), cols. $592-593$.

See No. 765 . 
769. NÉMETH |Gyula], J.: 'Turkish reader for beginners. English translation of the German original by T. Halasi-Kun. The Hague - Paris, 1966, $71 \mathrm{pp}$. Publications in Near and Middle kast Studies, Columbia Iniversity. Series B. 2..

Reviewed by Kreutel, F. = ZDMG 11 - (1968), pp. 430-432; Tietze, A. :Oriens 21-22 (1963-1969), p. 503; Kildv-Nagy, Gv. = BiblOr. $27(1970)$, pp. 86-87; Ilrebicek, L. =ArchOr. 39) (1971), pp. 501-502.

770. NEMFTH [Gvula], J.: A. Tietze, Turkish Literary Reader. The Hague 1963. /UAS 22./. Review : OLZ 61 (1966), cols. 165-166. See No. 798.

771. NÉMETH [Gvula], J.: Redhouse Yeni Tïrkçe-Ingilizce Sözliik (New Redhouse 'Turkish-English Dictionary). Istanbul, 1968. Review = OLZ 68 (1973), cols. $38.4-386$.

772. RÁSONYI László: Török nvelvtan. I-II. fiizet [Turkish grammar.Parts I-II. ] Budapest, 1957-58. 96. pp. (Xerographed). /József Attila Szabadegyetem/.

773. RÁSONYI Lászlô: Török nyelvtan [Turkish grammar] Budapest, 1960. 168 pp. (József Attila Szabadegyetem).

See also No. 719.

\section{f/ Literature}

T. . BICARI, Hasan: Tiirk edebiyatı. I. Başlangıçtan Tanzimata kadar türk edebiyatı. Budapest, 1969. 276 pp. Eötvöş Lorand Üniversitesi Türk Filolojisi Kiirsiisii.

775. BICARI, Hasan: Tïrk edebiyatı. II. XIX. yüzyıl türk edebiyatı. Budapeşte, 1973. 132 pp. Eötvös Lorand Universitesi Türk Filojisi Kïrsiisii.

776. BODROGLIGETI András: Csobánzáde, Bekir Szidki = VIL 2, p. 463.

77. ВÖDFY, Joseph: les échos des guerres turco-hongroises dans la poésie populaire bulgare $=$ Revue d'histoire comparée (Budapest, 1947), pp. 56-68.

778. DÉGH Linda: Pertev Boratav, Contes Tures. Paris, 1955. Review = Ethn. $69(1958)$, pp. $300-301$.

779. DFGH Linda: Elsa Sophia von Kamphoevener, Am Nachtleuern der Karayansts rail. (Märchen und Geschichten alttiirkischer Nomaden). Hamburg,

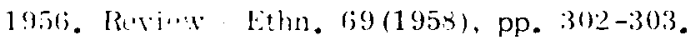

-n. möiäjoin íkos: P. Aganin - I. Alikaeva - M. Kerimov, Tureckie skazki. Noskial. 1960. Review Ethn. T1(19,33), pp. 311-315.

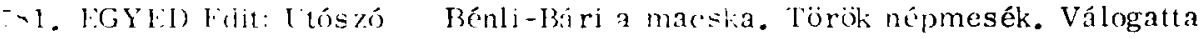
es fordituta Bartós. Hona. IPostserpt "Isenli-Bairi. the cat". Turkish folk-talcs. selected and translated by I. Bartón. I Burlapest, 1959. Revilued br Dobos Ilona. Indextithn. j(1)f(0), p. 12 . 
782. FÁBIÁN László: Nyelvújítás és irodalom Törökors zágban lLanguage reform and literature in Turkey] = Nagyvilág 1967: 3, pp. 414-442.

783. FÁ BlÁN László: Áli Bev Mehmet - VII 1, p. 189; Burhan Arpad = ibid. p. 1195.

784. HAZAI György: Nem Cahit - Dzsáhit [Dzsáhit - and not Cahit!] = ÉI 1961: 19 , p. 2 .

785. HAZAI György: Regény a török Rózsa Sándorról [A novel about Turkish Sándor Rózsa) = Nagyvilág 1963:7, pp. 1104-1106. [Yaşar Kemal, Ince Memed]. See No. 786.

786. HAZAI György: Vihar egy török regény körïl [The storm about a Turkish novel] = Nagvvilág $1963: 2$, pp. 317-318.

See No. 785.

787. HAZAI György: Utószó = Nazim llikmet, Nehéz a távollét. Versek. Fordította Tornai József. Válogatta Hazai Györgv, Árpád Imre. Nyers forditás: Hazai György. |Postscript = Nazim Hikmet "Exile is difficult". Poems. Translated by J. Tornai. Selected by Gy. Hazai, I. Á rpád. Rough translation by Gy. Hazai]. Budapest, 1963.

788. HAZAI György: Előszó = Jasar Kemal, A sovány Mehmed. Fordította Koryürek Péter (Preface = Yaşar Kemal "Thin Mehmed", Translated by. P. Koryiirek] Magvetó, Budapest, 1963.

789. HAZAI György: Názím Hikmet, Romantika. Fordította Brodszky Erzsébet. A szöveget a török nyelvû́ eredetivel egvbevetette és a jegyzeteket írta -- INazim Hikmet "Romance". Translated by E. Brodszky. Collated with the Turkish original and annotated by --]. Budapest, 1964.

790. HAZAI György: Nasz reddin Hodzsa = Rádiólexikon (1964), pp. 76-77.

791. HAZAI, G[yörgy]: Ignacz Kunoş ve Nasreddin Hoca = Tïrk Folklor Araştırmalar1 180 (1964), pp. 344-345.

792. HAZ AI György: IrodaImi boszorkányper Törökszországban [A literary "witchcraft trial" in Turkey] = Nagyvilág 1965:6, p. 957.

793. HAZAI György: Abasıyanık, Sait Faik = VIL 1(1970), pp. 6-7; Ahmed Fakih = ibid. p. 102; Ahmedî = ibid. pp. 102-103; Ahmet Vekif Paşa = ibid. p. 104; Aka Gïndiiz = ibid. p. 124; Âkif Paşa =ibid. p. 128; Anday, Melih Cevdet $=$ ibid. p. 291; Ataç, Nurullah = ibid. p. 535; Başkurt, Cevat Fehmi = ibid. p. 737; Baykurt, Fakir = ibid, p. 759; Boratav, Pertev Naili = ibid. p. 1037; Cahit Sıtkı Tarancı = ibiä. p. 12\%3; Çağlar, Behçet Kemal = ibid. pp. $1232-1233$.

794. HAZAI György: Halide Edip Adivar $=$ XX. sz. p. 14; Yahya Kemal Beyatl $1=$ ibid. p. 57; Fazil Hiisnii Dağlarca = ibid. p. 102; Reşat Nuri Gintekin = ibid. p. 165; Nazim Hikmet $=$ ibid. p. 295; Aziz. Nesin $=$ ibid. p. 298; Orhan Veli $=$ 
ibid. p. 310; Ömer Seyfettin =ibid. p. 314; Sabahattin Ali = ibid. p. 365; Sait Faik = ibid. p. 369; Taner Haldun =ibid. p. 408; Yaşar Kemal =ibid. p. 455 .

795. HIKMET, Nazim: Orhan Kemal = Nagyvilág 1959:4, pp. 533-534.

796. JÁVORSZKY Béla: Babic, Iyyes ? = ÉI 5 (1961), 18, p. 2.

797. JEREMIÁS Éva - SCHÜTZ Ödön - SZENDE Tamás - TASNÁDI Edit, Ásik = VIL 1, pp. 509-511.

798. KAKUK [Zsuzsa], S.: A. Tietze, Turkish Literary Reader. The Hague 1963. /UAS 22./. Review = ALH 17 (1967), pp. 193-195. See No. 770.

799. KAKUK Zsuzsa: Török költő a magyar irodalomról. Részletek Ilhan Berk naplójából. Fordította -- |A Turkish poet on Hungarian literature. Extracts from Ilhan Berk's diary. Translated by --] = Nagyvilág 1969:6, pp. 952-953.

800. KAKLiK [Zsuzsa], Suzanne: Über die tiirkische Blumensprache $=A O H 23$ (1970), pp. 285-295.

See No. 801 .

801. KAKUK Zsuzsa: A török virágnyelvról [On the Turkish cryptolanguage] = Keletkutatás 1973 (Budapest, 1974), pp. 55-63.

See No. 800 .

802. KORKNIAZ, Zeynep: Wer ist der Übersetzer des Qābūs-nāme und des Ma rzubān-nāme? = StTurc. (1971), pp. 259-266.

803. KOVÁCS Ágnes: W. Eberhard - P. N. Boratav, Typen tiirkischer Volksmärchen. Wiesbaden, 1953. Review = Ethn. 67(1956), pp. 192-193.

804. I.ENGYEL Béla: Nigjár binti Oszmán = FilKözl, 1967:1-2, pp. 189-193.

805. LÜKớ Gábor: A magyar népdals zövegek régi stílusa (The a rchaic style of the texts of the Hungarian folk-songs $\mid=$ NéprËrt. $39(1957)$, pp. 5-46. [Résumé in Russian and English].

Reviewed by Katona, Imre $=$ Demos $3(1962)$, pp. 97-98.

806. NÉMETH [Gyula], J.: Hellmut Ritter, Karagös, Türkische Schattenspiele. Dritte Folge, Wiesbaden, 1953. Review = OLZ 53(1958), col. 466.

807. NÉMETH Gyula: Âşık Paşa = VIL 1, p. 511; Bâki, Mahmûd Abdulbâki = ibid. p. 639; Evliyā Çelebi = ibid, 2, pp. 1314-1315.

808. RÂSONYI László: A török költészet fejlödésének vázlata [An outline of the development of Turkish poetry] = Szenvedélyek tengere. A török költészet antológiája. Edited by G. Hazai (Budapest, 1961), pp. 409-420.

809. RÁSONYI László: Abdiilhak Hâmit Tarhan = VIL 1, p. 10; Adıvar, Halide Edip = ibid. pp. 62-63; Ahmet Hâşım = ibid. p. 103; Ahmet Hikmet, Müftioğlu = ibid.; Ahmet Mithat $=$ ibid. p. 101; Ahmet Paşa =ibid.; Ahmet Rasim =ibid.; Aşık Ömer = ibid. p. 511; Beyatı, Yahya Kemal = ibid. p. 901. 
810. RUBOVSZKY Edit: Jegyzetek a török szépprózáról [Notes on Turkish prose] = Nagyvilág 1973:6, pp. 924-929.

811. RUBOVBzKY Edit: Utószó, életrajzi jegyzetek = Török elbeszélók. Válogat ta -- [Postscript and biog raphical notes in "Turkish short stories". Selected by -- ]. Budapest, 1974.

812. RYPKA, J.: Ein Ghasel Bāṭis, uibersetzt und erklärt = AOH 12 (1961), pp. 103-107.

813. SCHUT'Z [Ödön], E.: Ilhan Başgöz, Turkish folklore reader. Bloomington, 1971. /UAS 120./. Review $=$ AOH 27 (1973), pp. 249-250.

814. SMMÓ Jenő: Utószó = Nazim Hikmet, Volt-e hát Ivan Ivanovics? Komédia. Fordítotte Horváth László [Postscript = Nazim Hikmet "Did Ivan Ivanovich live, then?" A comedy. Translated by L. Horvátn]. Budapest, 1958.

815. SIMON Róbert, TASNÁDI Edit: Díván = VIL 2, pp. 777-778; dzsinász = ibid. p. 933.

816. SOMLYÓ Gyơrgy: Bevezető = Názim Hikmet, Válogatott versei. A fordítå-

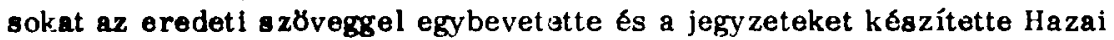
György [Introduction = Nazim Hikmet's Selected poems. Collated with the original and annotated by Gy. Hazai]. Budapest, 1956.

817. SZALMASI Pál: Agapi hikjajeszi = VII, 1, p. 81.

818. SZENDE Tamás: Cem Sultan =VIL 2, p. 131; Cenap Şahabettin =ibid. p. 132; Cevdet Paşa = ibid. p. 151.

819. SZERTE L, Szabiha: Elöszó = Szabahattin Ali, A malom. Élbeszélések. Fordította Kemény Ferenc. [Preface = Sabahattin Ali "The mill". Short stories. Translated by F. Kemény]. Budapest, 1953.

820. TANDORI Dezső: Ut6szó = Fazil IItisnü Dağlarca, Öltözködne a halott. Versek. Válogatta Necil Togay. Forditotta --. [Postscript = F. H. Dağlarca "The dead would put on his clothes". Selected by N. Togay. Translated by -- ]. Budapest, 1972.

Reviewed by Fábián László = Nagyvilág 1973:8, pp. 1270-1272.

821. TASNÁDI Edit: Aruz vezni $=$ VIL 1, p. 503; azand $=$ ibid. p. 596 ; bilmece = ibid. p. 935-936; csinge $=$ ibid. 2, p. 459; destan $=$ ibid. p. 670 ; divan edebiyat $1=$ ibid. p. 778 .

822. TASNÅDI Edit: Eşref = VIL 2, p. 1234.

823. TASNÁDI Edit - SZENDE Tamás: Agıt = VIL 1, pp. 85-86.

824. TIMÁR György: Nazim Hikmet = Nagyvilág 1963:7, pp. 1112-1113.

825. VAS István: Egy-két szб egy török költöról [Some notes on a Turkish poet] = ÉI 1960, 34, p. 5. [Rusen Eşref]. 
826. Mahmut Makal, A Village in Anatolia. Transl. by Wyndham Deedes. London 1956. Review = Index Ethn. 6 (1961):1, p. 36.

827. Agahi, Muhammad Riza = VIL 1, p. 81; Attilà, Osman =ibid. p. 548; Batu, Selâhattin =ibid. p. 748; Bener, 1 ikmet Erhan =ibid. p. 824; Birsel, Salâh =ibid. p. 945; Bolayır, Ali Ekrem = ibid. p. 1015; Cumalı, Necati = ibid. 2 , p. 484.

828. Beyt $=$ VIL 1, p. $901 ;$ Cönk $=$ ibid. 2, p. 322 .

\section{AZERBAIJANI}

829. KENESSEY [Mária], Mary: H. Mirzäzadä, Azärbayjan dilinin tarixi sintaksisi. Baky, 1968. Review $=$ AOH 26(1972), pp. 157-158.

830. KENESSEY [Mária], Mary: F. Zejnalov, Miiasir türk dillärindä kömäkči nitg hissäläri. (Oguz grupu dillärinin materiallarï äsasinda). Baky, 1971. Review = AOH 27 (1973), pp. 250-252.

831. LIGETI, L[ajos]: Sur la langue des Afchars d'Afghanistan $=A O H \quad 7(1957)$, pp. 109-156.

See No. 832 .

832. LIGETI, L[ajos]: Afganistan Avşarlarının dili üzerine = Bilimsel Bildiriler 1957 (1960), pp. 57-64.

See No. 831.

833. LIGETI, L[ajos]: Mongoljskie elementy $\mathrm{v}$ dialektach hazara $\mathrm{v}$ Afganistane = Kratkie soobšcenija Instituta Narodov Azii /Mongolevedenie i tjurkologija/ 93 (Moskva, 1964), pp. 5-22.

834. MINORSKIJ, V. F.: Rusj $\vee$ Zakavkazje (Novye dannye) $=$ AOH 3 (1953), pp. 207-210.

835. SIRALIEV, M. A.: Sur l'origine de l'affixe personnel $\underline{v}$ dans les dialectes de la langue azerbaïdjanaise $=\mathrm{AOH} 13(1961)$, pp. 119-121.

836. SZEVORTJAN, E. V.: Mozgást jelentô igék az azerbajdzsán nyelvben [Verbs expressing movement in the Azerbaijani language] $=$ I. OK 17 (1961), pp. 103-112.

See No. 837.

837. SEVORTJAN, $\hat{E}$.V.: Les verbes de mouvement dans la langue azerbaïdjanaise $=\mathrm{AOH} 1+(1962)$, pp. 101-122.

See No. 836. 


\section{Lite rature}

838. [BICARI, Hasan] Haszán Bidzsári: Imadeddin Neszími. (Törökböl fordította Kakuk Zsuzsa) [Imadeddin Nesimi. (Translated from the Turkish by Zsuzsa Kakuk)]= Nagyvilág 1969:8, pp. 121s-1219.

839. BICARI, H[asan]: Fuzulinin allegorik eserleri StTurc. (1971), pp. 61-72.

840. BICARI, Hasan: Dünya edebiyat ı haznesinde yeni bir şaheser = Protokollband (1974), pp. 119-124.

841. HAZAI György: Ahmed Burhaneddin, Kadı VIl 1, p. 102; Ahundov, Mirza Fatali = ibid. pp. 105-106.

842. HAZAI György: Azerbajdzsán irodalom [Azerbaijani literature] = VIL 1, pp. 596-597.

843. MÁNDOKY István: Ahundov, Szulejmán Szaní = VIL 1, p. 106; Ahverdov, Abdurragim bek Aszadbek ogli = ibid; Dzsabarli, Dzsefer = ibid. 2, p. 922.

844. TASNÁDI Edit: Aszli és Kerem $\mid$ Asli and Kerem] = VIL 1, p. 534.

845. ZAHEMSZKY László: Utószó = Anar, Fehér kikötő. Fordította Hernig Margit, Vándor Anna [Postscript = Anar "White harbour". Translated by M. Hernig, A. Vándor]. Budapest, 1973.

846. Alekperzade, Abulgaszan $=$ VIL 1, p. 173; Azeroglu, Balas = ibid. p. 597; Babajev, Nabi Elekperoglu = ibid, p. 606; Efendi, Iljász = ibid. 2, p. 962.

See also Nos. $946,948,949$.

\section{TURKMEN}

847. ASCHNIN, F. D.: Die Demonstrativpronomina im Turkmenischen $=$ ALH 12 (1962), pp. 117-136.

\section{Literature}

848. SZKOSZIREV, P.: Bevezetö = Berdi Kerbabajev, A döntï lépés. Fordította Leszev Irén [Introduction = Berdi Kerbabajev "The decisive step". Translated by I. Leszev] Budapest, 1950.

849. Berdi Muradovics Kerbabajev KX. s7. p. 216.

850. Andalib, Nurmuhamed Garip VIL 1, p. 291; Asirov, Csíri = ibid, p. 512; Bajrám Sáhir = ibid, p. 636; Burunov, karadzsa ibid. p. 1206 ; Durdi Kilics = ibid. 2, p. 907; Eszenova, Tavsan = ibid. pp. 12+1-12t2.

See also Nos. $946,948,949$. 


\section{GAGAUZ}

851. DRIMBA, V1.: Sur le vocatif en gagauz = AOH 13(1961), pp. 252-260.

See also No. 702 .

\section{KARAITE}

852. DUBIŃSKI, A.: Über die slavischen Einflüsse in der karaimischen Sprache = StSl. 15 (1969), pp. 139-144.

853. SCH EIBER [Sándor], A.: Meschullam b. Qalonymos' nach Constantinopel in Sachen der Karäer = AOH 24(1971), pp. 359-370.

See also No. 873 .

\section{CRIMEAN TATAR AND TATAR OF DOBRUDJA}

854. DRIMBA, Vl.: La répartition des parlers turcs de Dobroudja $=A O H \quad 23(1970)$, pp. 23-54.

855. MÁNDOKY [István], É.: Devinettes tatares de Bulgarie = AOH 21 (1968), pp. 369-379.

856. MÁNDOKY [István], É.: Chants šing des Tatars de la Dobroudja recueillis en Bulgarie $=$ StTurc. (1971), pp. 331-348.

857. MÁNDOKY [István], É.: Trois contes populaires tatares du Dobroudja $=A O H$ 28 (1974), pp. 127-137.

858. NÉMETH [Gyula], Julius: Kereit, Kèrey, Giray = UAJb. 36 (1865), pp. 360365 .

859. PENKOV, MINKO: A bulgáriai "tatárok" (Rövid történeti attekintés) [The Bulgarian "Tatars" (A short historical survey)] = Ethn. 74 (1963), pp. 418-434.

Literature

860. BODROGLIGETI András: Bora = VIL 1, p. 1037.

See also Nos, 702,873 . 
7. KARACHAY -BALKAR, KUMYK, NOGHAY

\section{Literature}

861. HAZAI György: Balkár irodalom (Balkar literature) = VIL 1, p. 651.

862. MÁNDOKY István: Bajkulov, Daut Pagojevics = VIL 1, p. 636.

863. Adzsijev, Anvar Abdulgamidovics = VIL 1, p. 68.

See also No. 873 .

\section{TATAR}

864. BAICURA, U. S.: Experimental-phonetische Beiträge zur Untersuchung des Wortakzentes des Kasan-Tatarischen = ALH 5(1955), pp. 265-280.

865. BAIČURA, U. S.: Experimentell-phonetische Beiträge zur Kenntnis des Lautbestandes des Kasan-Tatarischen = ALH 8 (1958), pp. 173-247.

866. BALASSA Iván: M. I. Vorobjev, Kazanskie tatary. Kazanj, 1953. Review = Ethn. 67 (1956), pp. 663-664.

867. ERDÉLYI István: A. P. Feoktistov, Mordovskie jazyki i jeh dialekty = Voprosy êtnið̌eskoj istorii mordovskogo naroda (Moskva, 1960), pp. 63-82. Review = NyK 64 (1962), pp. 393-394.

868. ERDÉLY I István: B. A. Vasiljev, Problema burtasov i mordva = Voprosy êtniCeskoj istorii mordovskogo naroda (Moskva, 1960), pp. 180-209. Review $=\mathrm{NyK} 64$ (1962), pp. 395-396.

869. ERDÉLYI István: V. N. Belicer, Mordva-karataj i ich kuljtura (K voprosu o proischoždenii) = Voprosy êtniŁeskoj istorii mordovskogo naroda (Moskva, 1960), pp. 227-255. Review $=$ NyK 64 (1962), p. 396.

870. ERDóDI József: A középfok jelének egy sajátos funkciójáról [A peculiar function of the comparative suffix $]=$ NytudÉrt. $40(1963)$, pp. 73-77.

870a.HALASI KUN, $T[$ ibor]: Monuments de la langue tatare de Kazan = AnalOr. (1942-1947), pp. 138-155.

871. [JUSUPOV, G.V.] Jussopow, G.W.: Totemistische Relikte bei den Kasaner Tataren $=$ Glaubenswelt (1963), pp. 209-222.

See No. 872.

872. JUSUPOV, G.V.: Survivals of totemism in the ancestor cult of the Kazan Tatars = Popular beliefs (1968), pp. 193-20.4

See No. 871. 
873. KAKUK [Zsuzsa], Suzanne: Poésie populaire tatare recueillie par I. Kúnos = AOH 16 (1963), pp. 83-97.

874. KISS Jenő: A cseremisz térszínformanevek [Cheremiss topographic names] $=$ NyK 69 (1967), pp. 395-403.

875. SEREBRENNIKOV, B. A.: Über den Charakter des Verbalsystems des AltKasantatarischen $=$ ALH 10(1960), pp. 1-17.

876. STEINITZ, W.: Einige tiirkische Lehnwörter im Ostjakischen $=$ AOH 12 (1961), pp. $179-181$.

877. STEINITZ, W.: Etymologische Beiträge (IV.). Tatarische Lehnwörter im Ostjakischen und Wogulischen = ALH 15(1965), pp. 85-96.

878. VOROBJEV, N.I.: A kazáni tatárok eredete a néprajzi adatok alapján [The origin of the Kazan Tatars according to ethnographic data] = SzNépr. 1950 pp. $1-19$.

\section{Literature}

879. ECSEDY Andorné - GÁLICZKY Éva: Musza Musztafijevics Dzsalil (1906$1944)=$ Gorkijtól - napjainkig. Írta és szerkesztette -- [From Gorkiy to our days. Written and edited by A. Ecsedy, É. Gáliczky] Budapest, 1967, Vol. 2, pp. 60-64.

880. MÂNDOKY István: Dzselil, Musza = VIL 2, p. 932.

881. RADVÁNYI Ervin: Utószó = Musza Dzsalil, Magános tũz. Válogatta Katona Edith. Fordította Gurszky István, Jánosy István stb. [Postscript = Mus za Dzsalil "Solitary fire". Selected by E. Katona, Translated by I. Gurszky, I. Jánosy etc. ]. Budapest, 1957.

882. VIKÁ R László: Népzenegyüjtés a tatárok földjén [Collection of folk-music in the land of the Tatars ] = Ethn. $82(1971)$, pp. 262-266.

883. Musza Dzsalil $=$ XX. sz. p. 117 .

884. Abszaljamov, Abdurahmán Szafijevics = VIL 1, p. 26; Ahmadijev, Sahit = ibid p. 100; Basir, Gomar = ibid. p. 736; Battálov, Szalih = ibid. p. 747; Bigejev, Zágir $=$ ibid. p. 926; Burnas, Fethi $=$ ibid. p. 1199; Dumaví, Nadzsip = ibid. 2, p. 895 .

\section{BASHKIR}

885. CSIKAI, Valéria: Eine unveröffentlichte baschkirische Volksmärchen-Variante $=$ AOH $28(1974)$, pp. 37-63. 
886. HOFER Tamás: S. I. Rudenko, Baskiry. Moskva-Leningrad 1955, Review = Index Ethn, 1956, pp. 10-11.

\section{Literature}

887. HAZAI György: Baskír irodalom [Bashkir literature] = VIL 1, pp. 736-737. 888. MÁNDOKY István: Davletsin, Gubej Kirejevics = VIL 2, p. 592.

889. Abdullin, Ibragim Ahmetovics $=$ VIL 1, p. 12; Akmollá, Miftáheddin Kemá lettinovics $=$ ibid. p. 136; Babics, Sejhzáde Möhemmetzákiruli = ibid. p. 609; Bikbaj, Bajazit Gajarovics = ibid. p. 928; Bikcsentajev, Anver Gadejevics = ibid. p. 928; Bikkulov, Sarif Szagadatovies = ibid.; Dajan, Kádir =ibid. 2, p. 516 .

See also Nos. 1124-1145.

\section{KAZAKH}

890. KRIZA Ildik6: B. G. Erzakovið, Fesennaja kuljtura kazachskogo naroda (Muzykaljnogo-istoriCeskoe issledovanie). Alma-Ata, 1966. Review = Ethn. 79 (1968), pp. 97-298.

891. RÓNA-TAS, A[ndrás]: Notes on the Kazak yurt of West Mongolia $=$ AOH 12 (1961), pp. 79-102.

See No. 892 .

892. RÓNA-TAS, A[ndrás]: Felt-making in Mongolia = AOH 16(1963), pp. 199215.

See No. 891 .

893. A Kazah Szovjet Szövetséges Szocialista Köztá rsaság [The Kazakh Soviet Socialist Republic] $=$ Nyr. 74 (1950), p. 399 .

\section{Literature}

894. BALÂZS, Béla: Das goldene Zelt. Kasachische Volksepen und Märchen. Nachdichtung der Verse von --. Berlin, 1960. 179 pp.

895. DOBOS Ilona: A fakó lovacska. Kazak népmesék [The cream-coloured colt. Kazakh folk-tales] Budapest, 1949.82 pp. 2 nd. ed. 1958. 173 pp. Review = Index Ethn. $5(1960)$, p. 44 .

896. ECSEDY Andomé-GÁLICZKY Éva: Muhtar Omarhanovics Auézov (18971961 ) = Gorkijtól - napjainkig. İrta és szerkesztette - [From Gorkiy to our days. Written and edited by A. Ecsedy, É. Gáliczky]. Budapest, 1967, Vol. 1, pp. $428-433$. 
897. HAZAI György: Auezov, Muhtar Omarhanovics = VIl 1, p. 558.

898. LESZKOVSZKY Márta, N.: Magyar szerzók kazah nyelven [Hungarian authors in Kazakh translation] = Nagyvilág 1970:1, pp. 148-150.

899. MÁNDOKY István: Bajganin, Nurpejsz = VIL 1, p. 635; Dzsambul Dzsabájev =ibid. 2, p. 927; Dzsanszugorov, Iljász = ibid. pp. 928-929; Dzsumalijev, Kazsigali Dzsumalijevics = ibid. p. 936.

900. TASNÁDI Edit: Abaj Kunanbajogli, Ibrahim = VIL 1, p. 5 .

901. TASNÂDI Edit, Ajtisz = VIL 1, p. 123; akin =ibid. pp. 128-129.

902. TRENCSÉNYI-WALDAPFEL Imre: Izsambul Dzsabajev. Összeállította és az öss zekötő szöveget írta -- [Edition and running commentary by --]. Budapest, 1955, $32 \mathrm{pp}$.

903. TRENCSÉNYI-WALDAPFEL Imre: Dzsambul Dzsabajev = Nagyvilág, 1957:8, pp. 1174-1176.

904. TRENCSÉNYI-WALDAPFEL Imre: Dzsambul = Szovjet irodalom. Szerkesztette, a bevezetót írta Kardos László [Soviet literature. Edited and introduced by L. Kardos]. Budapest, 1959, pp. 227-258.

905. TRENCSÉNYI-WALDAPFEL Imre: Jegyzetek a kazah irodalomról |Notes on Kazakh lite rature] = Nagyvilág 1969:4, pp. 601-603.

906. Muhtár Auézov halálára [In memoriam Muhtar Auezov] = Nagyvilág 1961:8, pp. 1262 .

907. Muhtar Omarbanovics Auezov $=$ XX.sz. p. 38; Dzsambul Dzsabajev $=$ ibid. p. 117 .

908. Abdulkadirogli, Kalmakan = VIL 1, p. 11; Abilev, Dihan = ibid. p. 19;

Abisev, Alzsappar = ibid.; Altinszarin, Ibraj = ibid, p. 241.

909. Dzsoktav $=$ VIL 2, p. 934 .

See also Nos. 922, 1023-1026.

\section{KARAKALPAK}

910. DIÓSZ EGI Vilmos: T. A. Ždanko, Očerki istoriceskoj êtnografii karakalpakov. Rodoplemennaja struktura u rasselenie v XIX-nacale XX veka. MoskvaLeningrad, 1950. /Trudy Instituta êtnografii im N. N. Miklucho-Maklaja AN SSSR, Novaja serija.9./. Review = Ethn. 64 (1953), pp. 467-468.

Literature

911. MÁNDOKY István: Berdák = VIL 1, p. 845 . 
912. Ajmurzajev, Zsolmurza Murzajevics = VIL 1, p. 122.

\section{KIRGHIZ}

913. ABRAMZON, S. M.: Die Stammesgliederung der Kirgisen und die Frage nach ihrer Herkunft $=$ AOH $14(1962)$, pp. 197-206.

Reviewed by H[azai, G.] = UAJb. $35(1964)$, p. 434.

914. BESCHKOVITSCH, A. S.: Winterlicher Weidgang und Stallfütterung bei den Kirgisen = AEthn. 18 (1969), pp. 229-235.

915. DIÓSz EGI Vilmos: Kirgíz folklore [Kirgiz folklore] = Ethn. 59(1948), p. 247.

916. ERDÉLYI Igtván: Az 1956. évi pamíri expedíció néprajzi jegyzetei [Ethnog raphical notes of the Pamir expedition in 1956J = Ethn. $73(1962)$, pp. 103-126. 126. [Résumé in English and luussian].

\section{Literature}

917. Á RVAY János: Utószó = Csingiz Ajtmatov, Dzsamila szerelme. Elbeszélések. Fordította Tarisznyás Györgyi, Árvai János, Láng Anikó [Postscript $=$ Ch. Aytmatov "Djamila's love". Short stories. Translated by Gy. Tarisznyás, J. Árvai, A. Lángl. Budapest, 1963.

918. DERSI Tamás: Csingiz Ajtmatov, Dzsamila szerelme [Ch. Aytmatov "Djamila's love" ]. Budapest, 1960. Review = Nagyvilág 1961:2, pp. 294-295.

919. D[IÓSZEGI] V[ilmos]: Medina Bogdanova, Kirgiz irodalom [Kirgiz literature]. Review = Ethn. $59(1948)$, p. 247 .

920. ECSEDY Andorné - GÁLICZKY Éva: Csingiz Ajtmatov (1928-) = Gorkijtól napjainkig. Írta és szerkesztette - [From Gorkiy to our days. Written and edited by A. Ecsedy, E. Gáliczky]. Budapest, 1967, Vol. 2, pp. 131-139.

921. ELBERT János: Dzsingisz Ajtmatov a "Fehér Gőzhajó"-ról [Djingis Aytmatov on his "White Steamship"] = Nagyvilág 1971:1, pp. 149-152.

922. ELBERT János: Bevezető Dzsingiz Ajtmatov - Altaj Muhamedzsánov "Fent a Fudzsijámán"c. drámájához [Introduction to Djingis Aytmatov - Altai Muhamejzanov's play "On the top of the Fujiyama"] = Nagyvilág 1973:10, p. 1472 .

923. FEHÉR Ferenc: Kirgiz sztyeppéken az eltünt idő nyomában (Cs. Ajtmatov regényéröl) [In steps of bygone days in the Kirgiz steppe (Notes on Ch. Ajtmatov's novel)] = Úí 9(1969): 5, pp. 101-109. and 9(1969):6, pp. 97-102.

924. FEHER Pál, E.: Csingiz Ajtmatov mủhelyében (In Chingiz Aytmatov's workshop] = Úí 11 (1971), 1, pp. 74-84. 
925. FEHÉR Pál, E.: Csingiz Ajtmatov = Napjaink szovjet írói [Contemporary Soviet writers]. Budapest, 1973, pp. 12-16.

926. KOROKNAI Zsuzsa: Ajtmatov és Zaligin a szovjet Állami Díj kituintetettjei [Aytmatov and Zaligin, Soviet State Prize winners] = Nagyvilág 1969:1, p. 153.

927. KRISTÓ NAGY István: Ajtmatov = Az új szovjet irodalom. Szerk. Elbert János, Kardos László [The new Soviet literature. Edited by J. Elbert, L. Kardos]. Budapest, 1967, pp. 305-318.

928. MÁNDOKY István: Dzsantosev, Kaszimali = VIL 2, p. 929.

929. MESZERICS István: Az érzelmek, szenvedélyek pátosza (Megjegyzések Ajtmatov prózájáról) [The pathos of emotions and passions (Notes on Aytmatov's prose)] = Nagyvilág 1964:8, pp. 1237-1240.

930. SARJó Sándor: Manász, a kirgiz nép hósi eposza [Manas, the heroic epos of the Kirgiz] = Jövendö 1947 No. 3.

931-932. TAKÁCS Imre: Ajtmatov és Merle [Aytmatov and Merle] = Úí 2 (1962), 5, pp. 513-515.

933. VA RGA Mihály: Ajtmatov, Csingiz = VIL 1, pp. 123-124.

934. Csingiz Ajtmatov $=$ XX.sz. p. 17.

935. Abdumomunov, Toktobolot $=$ VIL 1, p. 13; Akijev, Kalik =ibid. p. 128; Bajálinov, Kászimali = ibid. p. 635; Bokonbajev, Dzsovmart $=$ ibid, p. 1013.

936. Beszélgetés szovjet írókkal [ Conversation with Soviet writers] = Úí 2 (1972); 11, pp. 1264-1266. [Alekszandr Gyementyev, Szergej Antonov, Anatolij Kuznyecov, Csingiz Ajtmatov].

See also No. 876 .

\section{UZBEK}

937. BALASSA Iván: O. A. Suchareva, Drevnie certy $v$ formach golovnych uborov Srednej Azii = Sredneasiatskij Etnograficeskij Sbornik (Moskva, 1954), pp. 299-353. Review $=$ Ethn. 67 (1956), pp. 378-380.

938. BALASSA Iván: Narodnoe dekorativnoe iskusstvo Sovetskogo-Uzbekistana. Tekstilj. Taskent, 1954. Review = Ethn. 67 (1956), pp. 378-380.

939. BALASSA Iván: O. A. Suchareva - M. A. Bikzaiova: Prołloe i nastojałčee selenija Ajkyran. Taskent, 1955. Review = Ethn. 67 (1956), pp. 378-380.

940. BALOGH Sándorné: A parandzsától és a rabszolgaplactól indultak el. A közép-ázsiai népek útja a szocializmushoz [From the paranja and the slavemarket. The road of the Central Asiatic peoples to socialism] $=$ ElTud. 28 (1968), pp. $632-638$. 
941. BIHARI, J[бzzef]: A. N. Tichonov, IzuCenie vidov russkogo glagola v uzbekskoj skole. Tałkent, 1970. Review $=\mathrm{St}^{\prime}, 19(1973)$, pp. 427-430.

942. DOBOS, Éva: A Qïpčaq-Uzbek tale from Qarabau = AOH 27 (1973), pp. 163-189.

943. DOBOS, Éva: An Oghuz dialect of Uzbek spoken in Urgench $=$ AOH $28(1974)$, pp. $75-97$.

944. DOBOS, Êva: Özbek chalq šewalari luyati. Compiled by A. Iక̌aev, Š. Nåsirov, H. Uzåqov, D. Abdurahmånov. Edited by S. Såabdurahmånov. Tåakent, 1971 . 407 pp. Review $=$ AOH 28 (1974), pp. 159-161.

945. HEGYI Imre: M. S. Andreev, Tadžiki doliny Chuf (verchovja Amu-Darji). Podgotovlen $k$ pečati i snabžen primečnijami i dopolnenijami A. K. Pisarčik. Otv. red. A. A. Semenov. Stal inabad, 1958. Review = Ethn. 73(1962), pp. 636-638.

946. KAKUK Zsuzsa: Vámbêry Ármin, Dervis ruhában Közêp-Ảzsián át. Lektorálta, a bevezetést és a jegyzeteket írta -- [T ravels in dervish-costume through Central Asia. Edited, introducted and annotated by --] Budapest, 1966. 437 pp. + pl. /Világjárók. Klasszikus útleírások.8./.

947. LAUDE-CIRTAUTAS, Ilse: Uzbek matrimonial forms of adress = StTurc. (1971), pp. 281-289.

948. LIGETI Lajos: Afganisztán mongol és török nyelvei [Mongol and Turkic languages in Afghanistan] $=1$. OK $3(1953)$, pp. 231-248. See No. 949.

949. LIGETI, L[ajos]: O mongoljskich i tjurkskich jazykach i dialektach Afganis$\tan a=\mathrm{AOH} 4$ (1954), pp. 93-114. [Résumé in French pp. 114-117].

See No. 948.

950. LIGETI [ Lajos], Louis: Le lexique moghol de R. Leech $=$ AOH 4(1954), pp. 119-157.

951. NÉMETH [Gyula], J.: W. M. Žirmunskij, Skazanie ob Alpamyse i bogatyrskaja skazka. Moskva, 1960. Review = OLZ 59(1964), cols. 589-592.

952. TELEGDI Zsigmond: Török nyelvi hatás a tadzsikban [Turkic linguistic influence on the Tadzhik] $=$ NyK 73 (1971), pp. 208-216.

\section{Literature}

953. HAZAI György - VOIGT Vilmos: Alpamis = VIL 1, pp. 234-235.

954. TASNÁDI Edit: Alimdzsan, Hamid = VIL 1, p. 191.

955. Abdulla Szabir = VIL 1, p. 12; Ajbek = ibid. p. 121 .

See also Nos. 831-833. 
14. MODERN UGHUR, SALAR, YELLOW UIGHUR

956. KAKUK [Zsuzsa], Suzanne: Textes salars $==$ AOH 13(1961), pp. 95-117.

957. KAKUK [Zsuzsa], Suzanne: Un vocabulaire salar $=A O H 14(1962)$, pp. 173-196.

958. KAKUK [Zsuzsa], Suzanne: Sur la phonétique de la langue salare $=$ AOH 15 (1962), pp. 161-172.

959. KAKUK, Zs[uzsa]: G. Jarring, An Eastern Turki-English dialect dictionary. Lund, 1964. Review = OLZ 61 (1966), cols. 586-589. See No. 963.

960. KAKUK [Zsuzsa], Suzanne: Chants ouigours de Chine $=$ AOH 25 (1972), pp. 415-429.

961. NÉME'TH [Gyula], J.: K. H. Menges, Glossar zu den volkskundlichen Texten aus Ost-Turkistan. I. Wiesbaden, 1955. Review = OLZ 55(1960), cols. $70-71$.

962. RÓNA-TAS,András: Tibetan loan-words in the Shera Yögur language $=A O H$ 15 (1 62 ), pp. 259-271.

Reviewed by Mlenges, K. H. I = UAJb. 35 (1964), pp. 247-248.

963. RÓNA-TAS, A[ndrás]: G. Jarring, An Lastern Turki-English dialect dictionary. Lund, 1964. Review $=$ ALH 16 (1966), pp. 431-435.

See No. 959.

964. TENIŠEV, $\hat{E}_{\bullet}$ : Sur le folklore et la langue des salars = AOH 14(1962), pp. $253-272$.

\section{ALTAI-TURK, KHAKASS, TUVA}

965. BASKAKOV, N. A.: La classification des dialectes de la langue turque d' Altaï = AOH 8 (1958), pp. 9-15.

966. KARA, G[yörgy]: V. I. Rassadin, Fonetika i leksika tofalarskogo jazyka. Ulan-Ude, 1971. Review $=$ AOH 27 (1973), pp. $241-249$.

967. NÉMETH [Gyula], J.: A.J. Joki, Wörterverzeichnis der Kyzyl-Sprache. Helsinki, 1953. /StOr. XIX/1./. Review = OLZ 54 (1959), cols. 51-52.

968. RÄSÄNEN, M.: Die chakassischen $\underline{i}-$ Laute $=$ AOH 15 (1962), pp. 245-247.

\section{Literature}

969. HAI MOS, I[stván]: A. N. Aksenov, Tuvinskaja narodnaja muzyka. Moskva, 1964. Review $=$ AEthn. 15 (1966), pp. 364-367. 
970. HAZAI György: Ak Köbök = VIL, 1, p. 135.

971. HAZAI György: Altaji irodalom [Altaic literature] = VII, 1, p. 236.

972. HEGYI Imre: Utószó = Szamá rfülũ kán. Tuvai népmesék. Fordította, válogattr -- [Postscript = "The khan with donkey's earg". Tuvay folk tales. Translated and selected by --]. Budapest, 1959.

Reviewed by Kovács Ágnes = Index Ethn. 3 (1958): 2, p. 179.

973. ISTVÁNOVITS Márton: M. A. Ungvickaja, Chakasskaja bytovaja skazka. Abakan, 1966. Review = Ethn. 78 (1967), p. 147.

974. KÖHALMI [Katalin], Käthe, U.: Griechisch-sibirische mythologische Parallelen $=$ AOII $25(1972)$, pp. 137-147.

975. KÖHALMI Katalin: Sámándobok, szóljatok! Szibéria őslakosságának népköltészete. Fordította Bede Anna. Válogatta és magya rázó szövegekkel ellátta - [Let the shaman-drums be beaten. The popular poetry of the Siberian aborigines. Translated by A. Bede. Selected and commented by - - B Budapest, 1973. 405 pp.

Reviewed by Pusztay János = Üî 14 (1974), 6, pp. 126-128.

Shamanism amongst the Sout-Siberian Turks

976. DIÓSz EGI Vilmos: A karagasz sámándob készítésmódja [The Kha ragas method of preparing the shaman's drum] = NéprKözl. 4:1-2 (1959), pp. 17-34.

977. DIÓsz EGI Vilmos: A sámánköpeny készítése a karagaszoknál [The Kharagas method of preparing the shaman's cloak] = NéprKözl. 4:4 (1959), pp. 101 106.

978. DIÓSZ EGI Vilmos: A szagáj sámán sámánná válása [How to become a shaman among the Sagai] = NéprKözl. 4:1-2 (1959), pp. 222-232.

See No. 985.

979. DIÓSZEGI Vilmos: A karagasz sámánhit etnikus egyöntetûségének kérdése [The problem of the ethnic homogeneity of Kharagas shamanism] = Néprért. 41 (1959), pp. 145-194. [Résumé in Russian].

See Nos. $986,993$.

980. DIÓSZ EGI Vilmos: Az északkeleti szojotok sámánhitéhez [Notes on shamanism among the northeastern Soyots] $=$ Ethn. 70(1959), pp. 77-137. [Résumé in Russian and German].

See No. 982.

981. DIósZEGI Vilmos: A burját sámánhitkutatás megalapozója Hangalov M. N.

[M. N. Hangalov, the founder of Buriat Shamanistic studies] = Ethn. $70(1959)$, pp. 453-459. 
982. DIÓSZ EGI, Vilmos: Der Werdegang zum Schamanen bei den nordöstlichen Sojoten $=$ A Ethn. 8 (1959), pp. 269-291 and Suppl. pp. 6-7.

See No. 980 .

983. DIÓSZEGI Vilmos: Sámánok nyomában Szibéria földjén. Egy néprajzi kutatóút törtenete [On the tracks of the shamans in Siberia. An account of ethnographical fieldwork]. Budapest, 1960, $251 \mathrm{pp} .+13 \mathrm{pl}$.

Reviewed by Kodolányi J. = Ethn. 72 (1961), pp. 297-298.

984. DIÓSZ EGI, Vilmos: Tuva shamanism. Intraethnic differences and interethnic analogies = AEthn. 11 (1962), pp. 143-189+ pl.

985. DIÓSZEGI, Vilmos: How to become a shaman among the Sagais $=$ AOH 15 (1962), pp. 87-96 and Suppl. 4. p.

See No. 978 .

986. DIÓSZEGI, Vilmos: Zum Problem der ethnischen Homogenität des tofischen (karagassischen) Schamanismus = Glaubenswelt (1963), pp. 261-357.

See Nos. 979, 993.

987. DIÓSZEGI, Vilmos: Ethnogenetic aspects of Darkhat shamanism $=$ AOH 16 (1963), pp. 55-81.

988. DIÓSZEGI Vilmos: A szamojéd kultūra emlékei a keletszajâni népek samanizmusában [Traces of Samoyede culture in the shamanism of the East Sayan peoples] = Ethn. 74(1963), pp. 435-465. [Résumé in Russian and German]. Reviewed by Györgyi E. = AEthn. 15 (1966), p. 202.

See No. 989.

989. DIÓSZ EGI, Vilmos: Denkmäler der samojedischen Kultur im Schamanismus der ostsajanischen Völker = AEthn. 12 (1963), pp. 139-178.

See No. 988.

990. DIÓSZ EGI, V[ilmos]: Glaubenswelt und Folklore der sibirischen Völker. Herausgegeben von --. Budapest, 1963, 534 pp.

Reviewed by Kara, G. = AOH 17 (1964), pp. 354-356; Johansons, $A_{0}=$ Ethnos 30 (1965), pp. 176-176; Kálmán, B. = OLZ 60 (1965), cols. 384-387; Kodolányi, J. = A Ethn. 14(1965), pp. 207-210; Vajda, L. = Sociologus N. F. 15 (1965), pp. 181-183; Menges, K. H. = Oriens 21-22(1971), pp. 546-568. See No. 994.

991. DIÓSZEGI Vilmos: A szibériai népek samanizmusa [Shamanism among the Siberian peoples] = Világosság 5(1964), pp. 343-346.

992. DIÓSZEGI Vilmos: Dél-Szibéria utolsó samánjai között [Among the last shamans of Southern-Siberia] = Világosság 6 (1965), pp. 430-434.

993. DIÓSZEGI, Vilmos: The problem of the ethnic homogeneity of Tofa (Karagas) shamanis $m=$ Popular beliefs (1968), pp. 239-329.

See Nos. 979, 986. 
994. DIÓsZEGI,V[ilmos]: Popular beliefs and folklore tradition in Siberia. Ed. by --. Budapest, 1968. 498 pp. and Bloomington - The Hague, 1968. 498 pp. /UAS $57 . \%$

Reviewed by Cernecov, V. N. = Sovetskaja Êtnog rafija 1969:5. pp. 165-168; Hoppál Mihály = Ethn. $80(1969)$, pp. 602-605; Eberhard, W. = Journal of American Folklore 83(1970), p. 82; Kodolányi, János = AEthn. 20 (1971), p. 451; Libby, D. = American Anthropologist 72 (1970), pp. 396-398; Lot-Falck, E. = I'Homme 11 (1971), pp. 108-111; Dragomir, A. I. = Revista de Etnografie şi Folclor $17(1972)$, pp. $341-343$; Hazai, G. = OLZ 67 (1972), cols. $376-377$.

See No. 990 .

995. DIÓSZ EGI, Vilmos: Libation songs of the Altaic Turks = AEthn. 19(1970), pp. 95-106.

996. DIÓSZ EGI Vilmos: A baraba törökök iszlám elötti samanizmusa és etnogenetikai tanulságai [Pre-Islamic shamanism among the Baraba Turks and its ethnogenetic evidence $\}=$ Népi kultúra - népi tá rsadalom 4(1970), pp, 161-241. Reviewed by Kriza Ildik6 = A Ethn. 20(1971), pp. 449-450.

997. DY RENKOVA, N. P.: Kinderschutz bei den Schoren = Glaubenswelt (1963), pp. 257-259.

See No. 998.

998. DY RENKOVA, N. P.: The protection of children among the Shors = Popular beliefs (1968), pp. 235-237.

See No. 997.

999. NAHODIL, O.: Mutterkult in Sibirien = Glaubenswelt (1963), pp. $491-511$. See No. 1000.

1000. NAHODIL, O.: Mother cult in Siberia = Popular beliefs (1968), pp. 459-477. See No. 999.

1001. [POTAPOV] Potapow, L. P.: Die Schamanentrommel bei den altaischen Völkerschaften $=$ Glaubenswelt $(1963)$, pp. 223-256.

See No. 1002 .

1002. POTAPOV, L. P.: Shaman's drums of Altaic ethnic groups = Popular beliefs (1968), pp. 205-234.

See No. 1001 .

1003. [VAJNST EJN] Weinstein, S. I.: Die Schamanentrommel der Tuwa und die Zeremonie ihrer "Belebung" = Glaubenswelt (1963), pp. 359-367.

See No. 1004.

1004. VAJNŠTEJN, S. I.: The Tuvan (Soyot) shaman's drum and the ceremony of its "enlivening" = Popular beliefs (1968), pp. 331-338.

See No. 1003. 
1005. VOIGT Vilmos: A sámánizmus mint etnológiai kutatási probléma [Shamanism as a problem of researeh in ethnology] $=$ NyK 67 (1965), pp. 379-390.

The ethnography of the South-Siberian Turkic peoples

1006. DIÓSzEGI Vilmos: S. V. Kiselev, Drevnaja istorija Južnoj Sibiri. Moskva, 1951. Review = Ethn. $62(1951)$, pp. 488-491.

1007. DIÓSZ EGI, Vlilmos!: S. V. Ivanov, Materialy po izobraziteljnomu iskussivu narodov Sibiri XIX - načala XX vv. Moskva - Leningrad, 1954. Review = Ethn. 66 (1955), pp. 627-630 and Index Ethn. 1 (1956), pp. 28-29.

1008. DIÓSZZEGI, V[ilmos $\}: M$. G. Levin - L. P. Potapov, Istoriko êtnograficeskij atlas Sibiri. Moskva - Leningrad, 1961. Review = A Ethn. 12 (1963), pp. $228-230$.

1009. ERDóDI József: Jazyki i toponimija Sibiri. Pod red. A. P. Duljzona. Tomsk, 1960. Review = NyK 70 (1968), pp. 252-253.

1010. HEGYI Imre: Boris Osipovie Dolgich, Rodovoj i plemennoj sostav narodov Sibiri v XVII. v. Otv. red. G. F. Debec. Moskva, 1960. / Trudy Instituta Êtnografii im NN. Muklucho-Maklaja. AN SSSR. Novaja serija 55./. Review = Ethn. 73(1962), pp. 634-635 and AEthn. 11(1962), pp. 461-463.

1011. KÖHALMI [Katalin], K[äthe], U.: Über die pfeifenden Pfeile der innerasiatischen Reiternomaden $=\mathrm{AOH} 3(1953)$, pp. 45-71.

1012 KÖHALMI [Katalin], Käthe, U.: Der Pfeil bei den innerasiatischen Reiternomaden und ihren Nachbarn $=$ AOH 6 (1956), pp. 109-161.

1013. KÓHALMI [Katalin], K.: Über die Wörter qurlug und sāaag der chakassischen Folklore $=$ AOH 11 (1960), pp. 293-297.

1014. KÖHALMI [Katalin], Käthe, U.: Der Abschnitt der Waffenbehälter und des Waffengürtels in den polyglotten Wörterbüchern der Ch'ing-Epoche $=\mathbf{A O H}$ 15 (1962), pp. 195-206.

Reviewed by M[enges, K. H. ] = UAJb. 35 (1964), p. 245 .

1015. KÓHALMI [Katalin], Käthe, Uray: Lexikologisches und Kulturgeschichtliches über Köcher und Bogenfutteral der Steppenvölker = Trudy III (1963), pp. 434-499.

1016. KÖHALMI [Katalin], Käthe, U.: Die Farbbezeichnungen der Pferde in den mandschu-tungus ischen Sprachen $=\mathrm{AOH} 19(1966)$, pp. 45-55.

1017. KÓHALMI [Katalin], K[äthe]: Sibirische Parallelen zur Ethnographie der Geheimen Geschichte der Mongolen = Mongolian Studies (Budapest, 1970), pp. $247-264$. 
1018. KÖHALMI [Katalin], Käthe, U.: Drei alte innerasiatische Benennungen des Waffengürtels = St Turc. (1971), pp. 267-279.

1019. KÖHALMI Katalin U.: A steppék nomádja lóháton, fegyverben [The nomads of the steppes - on horseback and armed]. Budapest, 1972. $217 \mathrm{pp}$. and pl. /Körösi Csoma Kiskönyvtár 12./.

Reviewed by Róna-Tas, András = AEthn. 23 (1974), pp. 386-388; MTud. $18(1973)$, p. 404.

1020. KÖHALMI [Katalin], K[äthe]: Die Bedeutung der Kulturgeschichte des Karpatenbeckens für die Erforschung der Kultur der zentralasiatischen Reiternomaden $=$ Protokollband (1974), pp. 637-644+1 pl.

1021. KÖHALMI [Katalin], K[äthe]: La périodisation de l'histoire des armements des nomades des Steppes. De l'époque des Cimmériens à la chute de l' $\mathrm{Em}$ pire mandchou = Études Mongoles 5 (Paris, 1974), pp. 145-155.

1022. LEVIN, M. G.: Szibéria néprajzi atlasza [The ethnographical atlas of Siberia] = Ethn. 64(1953), pp. 410-414.

1023. RÓNA-TAS András: Nomádok nyomában. Ethnog ráfus szemmel Mongóliában [In the tracks of the Nomads. An ethnographer in Mongolia]. Budapest, 1961. $276 \mathrm{pp}$.

See Nos. 1024-1026.

1024. [RÓNA-TAS András] Rona-Tał, A.: Po sledam kođevnikov. Mongolija glazami etnografa. Moskva, $1964,310 \mathrm{pp}$.

Reviewed by Aubin,F. = L' Année Sociologique 18 (1967), pp. 370-371. See Nos 1023, $1025,1026$.

1025. RÓNA-TAS, A[ndrás]: Mongolia śladami nomadów. Z wȩgierskiego przetozył E. Mroczko. Warszawa, 1965, 532 pp.

See Nos. 1023, 1024, 1026.

1026. RÓNA-TAS, A[ndrás]: Mōko no yūbokumin wo tazunete. Hi kyō Tanken sōsho. Tökyō, 1966. 239 pp.

See Nos. 1023-1025.

1027. VOIGT, V[ilmos]: Jean-Paul Roux, Faune et flore sacrées dans les sociétés Altaïques. Paris, 1966. Review $=$ OLZ 66(1971), cols. 410-412.

See also Nos. $70-73,76,77,299,305,306,876,1498-1511$.

\section{YAKI'T}

1028. HAZAI, G[yörgy]: O. Böhtlingk, Über die Sprache der Jakuten. The Hague, 1964. Review = OLZ 62 (1967), cols. 390-391.

1029. KARA, G[yörgy]: Le glossaire yakoute de Witsen = AOH 25 (1972), pp. $431-439$. 
1030. LIGETI, L[ajos]: St. Kałużyński, Mongolische Elemente in der jakutischen Sprache. Warszawa, 1961. Review = AOH 16 (1963), pp. 325-329.

\section{Literature}

1031. DÖMÖTÖR Ákos: I. V. Puhov, Jakutskij geroiðeskij êpos Olonho. Osnovnye obrazy. Moskva, 1962. Review = Ethn. 74 (1963), pp. 312-314.

1032. KÖHALMI Katalin, U.: Abaginszkij, Arhip = VIL 1, p. 5; Berijak, Alekszej Alekszejevics $=$ ibid. p. 856; Csagilgan $=$ ibid. 2, p. 403; Csemyih $-\mathrm{Ja}-$ kutszkij = ibid. p. 449; Elljaj = ibid. p. 1066; Erisztyin, Erillik = ibid. p. 1201.

1033. KÖHALMI Katalin, U.: Csabirgak = VIL 2, p. 401.

1034. MÁNDOKY Istuán: Danyilov, Szemjon Petrovics = VIL 2, p. 566.

1035. Danyilov, Szofron Petrovics = VIL 2, p. 566.

See also No. 975.

\section{CHUV ASH}

1036. BEKE Ödön: Egy régi csuvas jövevényszó a cseremiszben [ An old Chuvash loan-word in the Cheremis language] = NyK 53 (1951), p. 251.

1037. BEKE Ödön: Egy régi csuvas jövevényszó az udmurtban [An old Chuvash loan-word in the Udmurt language] $=$ NyK $56(1954)$, p. 271 .

1038. BERECZKI Gábor: Etimológiai megjegyzések [Etymological notes] = NyK 66 (1964), pp. 117-121.

1039. ERDóDI József: A mari lašman szó eredetéröl [The origin of the Cheremis word lašman] $=$ NyK $62(1960)$, pp. 131-133.

1040. Harmincéves a Csuvas és a Tatár Autonóm Szocialista Szovjet Köztársaság [The 30th anniversary of the Chuvash and the Tatar Autonomous Soviet Socialist Republics] = Nyr. $74(1950)$, p. 313 .

1041. HAZAI, G[yörgy]: N. I. Ashmarin, Thesaurus Linguae Tschuwaschorum. I-II. Bloomington - The Hague, 1968. Review = Zeitschrift für Phonetik und Kommunikations forschung 26 (1974), pp. 718-719.

1042. LÜKÖ Gábor: A pentaton hangrendszer [The pentatonic tone system] = Ethn. 73 (1962), pp. 277-301. [Résumé in Russian and German].

1043. LYTKIN, V.I.: O nekotorych tjurkskich zaimstvovanijach v komi jazyke= NyK 60 (1958), pp. 109-112. 
1044. NÉMETH [Gyula], J.: V. G. Egorov, Êtimologiðeskij slovarj cuvašskogo jazyka. Ceboksary, 1964. Review = OLZ 65(1970), cols. 172-173.

1045. PALLÓ, Margit K.: V. G. Egorov, Sovremennyj Cuvašskij literaturnyj jazyk v sravniteljno-istoriðeskom osveð̌enii. Častj. 1. Ceboksary, 1954. Review $=$ NyK 57 (1955), pp. 310-313.

1046. PALLó [Margit], Margarete K.: Zur Frage der tschuwaschischen vProthese $=$ AOH $12(1961)$, pp. 33-44.

1047. PALLÓ, Margit K.: Die mittlere Stufe des tschuwaschischen Lautwandels $\underline{\mathrm{d}}>\underline{d}>\underline{\mathrm{r}}=$ UAJb. $43(1971)$, pp. 79-88.

1048. REYCHMAN, Jan: Tschuwassich salygaj $=$ Nachtigall (luscinia luscinia) $?=$ StTurc. (1971), pp. 385-387.

1049. RÓNA-TAS, A[ndrás]: Materıaly po čuvašskoj dialektologii. Vyp. I, Čeboksary 1960, Vyp. II, Ceboksary, 1963. Review $=$ AOH 18 (1965), pp. 385-387.

1050. RÓNA-TAS András: A csuvas s zóvégi gutturális zárhangok történetéhez [On the history of the Chuvash guttural stops in final position] $=\mathrm{NyK} 73(1971)$, pp. 198-207.

See No. 1051.

1051. RÓNA-TAS, A[ndrás]: On the Chuvash guttural stops in the final position = St Turc. (1971), pp. 389-399.

See No. 1050.

1052. RÓNA-TAS András: Középmongol eredetû́ jövevényszavak a csuvasban. I-II. [Middle-Mongolian loanwords of the Chuvash language] =AUSz. SEL 14-15 (1971-72 and 1973-74), pp. 77-88 and pp. 125-141. /Nyelvészeti dolgozatok $114,115 . /$.

1053. [RÓNA-TAS András], RONA-TAŠ, A.: Ob odnom zaimstvovannom s rednemongoljakom slove $\mathrm{v}$ marijskom jazyke = Issledovanija po vostoðnoj filologi1. K semidesjati letiju professora G. D. Sanžeeva (Moskva, 1974), pp. 230-234.

1054. RÓNA-TAS, A[ndrás]: H. Paas onen, Tschuwaschisches Wörterverzeichnis. Eingeleitet von --. Szeged, 1974. 244 pp./Studia Uralo-Altaica. 4./. [Reprint of H. Paasonen "Csuvas Sz6jegyzék" Budapest, 1908].

1055. SEREBRENNIKOV, B. A.: Ungeklärte Fragen der Geschichte der permischen Sprachen = ALH 11 (1961), pp. 43-64.

Reviowed by Sauvageot, A. = BSL 57 (1962), fasc. 2, pp. 216-217.

1056. SEREBRENNIKOV, B. A.: Über tschuwaschische Themen = AOH $17(1964)$, pp. 129-138.

1057. SEREBRENNIKOV, B. A.: Zur Frage nach dem Ursprung der prothetischen $\underline{\mathrm{v}}$ und $\mathrm{j}$ im Tschuwaschischen $=$ AOH 19(1966), pp. 57-65. 
1058. VOROBJOV, N. I. : A csuvas anyagi kultúra tanulmányozásának röviden összefoglalt eredményei [A concise survey of the results in investigations in Chuvash material culture] $=$ SzNépr. 1953:4, pp. 61-76.

1059. V. G. Jegorov, Êtnogenez čuvašej po dannym jazyka = Sovetskaja Etnografija 1950:3, pp. 79-92. Review = Múzeumi Híradó 1951:1, p. 61.

1060. M. N. Tihomirov, Prisoedinenie cuvasii k russkomu gosudarstvu= Sovetskaja Êtnografija, 1950:3, pp. 93-106. Review = Múzeumi Hírad6 1951:1, p. 61 .

\section{Literature}

1061. ÁHI Jolán: Ajgi Gennagyij = VIL 1, p. 121.

1062. GRIGORJEV-ESZRELY Sz. G.: Néhány szó a csuvas népköltés ról [Some notes on Chuvash popular poetry] = Ethn. 63(1952), pp. 44-62.

1063. HAZ AI György: Egy csuvas költő útja (Peder Huzangaj, Az Aptraman család) [The life of a Chuvash poet (Peder Hazangaj, The Aptraman family)] = Nagy világ, 1962:1, pp. 121-123.

1064. RAB Zsuzsa: Utószó = Ajgi Gennadij, A sámán fia. Válogatta Bolgár Magda. Fordította Ladányi Mihály, Oravecz Imre [Postscript = Ajgi Gennadij "The shaman's son". Selected by M. Bolgár. Translated by M. Ladányi, I. Oravecz]. Budapest, 1973.

1065. RÓNA-TAS András: Csuvas irodalom [Chuvash literature] = VIL 2, pp. 479-481; Csuvas irodalmi formák [Chuvash literary forms] = ibid. p. 479.

1066. RÓNA-TAS András: Elger, Szemjon Vasziljevics = VIL 2, p. 1047.

1067. VIKÁR László: Egy új csuvas gyũjtês tanulságai [The evidence of a new collection of Chuvash folk-songs ] = I. OK 23 (1966), pp. 189-199.

1068. VIKÁR Lászlô: Cseremisz és csuvas népdalgyứjtés 1966-ban [Collection of folk-songs among the Cheremiss and the Chuvash in 1966] = NyK $71(1969)$, pp. $3-20$.

See also Nos. $81,82,310-312,316,602,603,867,868,874,1256,1257,1260$. 


\title{
v. \\ PRE- 10 th-CENTURY TURCO-HUNGARIAN RELATIONS
}

\author{
1. GENERAL WORKS
}

1069. BAI,ASSA Iván: A magyar ekés földmũvelés kezdetei [Beginnings of the Hungarian plough agriculture] = Magyar Mezőgazdasági Múzeum Közleményei, 1969-70, pp. 45-68.

1070. BALASSA Iván: Az eke és a szántás története Magyarországon IThe history of the plough and ploughing in Hungaryl. Budapest, 1973. $630 \mathrm{pp}$.

1071. BARTHA,Antal: Vostocnaja Evropa i ranee srednevekovye Vengrii do serediny XI-go veka $=$ Nouvelles Études Historiques (Budapest, 1965), pp. 11-26.

1072. BARTHA Antal: A IX-X. századi magyar tá rsadalom lHungarian society in the IX-Xth centuries]. Budapest, 1968. 193 pp. 2nd Ed. 1973. 193. pp. Reviewed by Heckenast Gusztáv = Száz. 105 (1971), pp. 1013-1015; László Gyula = StSl. 17 (1971), pp. 207-213.

1073. BARTHA Antal: Gazdaságtörténet és szavak [Economic history and technical terms] = MNy. 65(1969), pp. 11-25.

See No. 1074.

1074. BARTIA, Alntal]: Wirtschaftgeschichte und Wörter = AL.H 21 (1971), pp. 105-119.

See No. 1073 .

1075. BARTHA,A[ntal]: Istoki vengerskoj kuljtury $\mathrm{X}$-go veka = Problemy archeologii i drevnej istorii ugrov (Moskva, 1972), pp. 118-127.

1076. CZEGLÉDY Károly: A [X. századi magyar történelem fóbb kérdései |The principal questions of 9 th century IIungarian history $J=M N y .41(1945), p p$. $33-35$.

1077. CZ EGLÉDY Károly: Iíj adatok a\% onogurok történetéhez (New data on the history of the Onogurs] = MNy. $47(1051)$, ?p. 266-267. 
1078. CZEGLÉDY Ká roly - HAJDú Pêter: A magyar östörténet kérdései. A Magyar Nelvtudományi Társaság vitaülése. 1953 december 1. Szerk. -- [Problems of Hungarian ancient history. A debate of the Hungarian Linguistic Society. Ed. --] Budapest, 1955. 93 pp. /NyelvtudÉrt. 5./. Reviewed by Fokos [-Fuchs] Dávid = Nyr. 80(1956), pp. 129-132.

1079. CZEGLÉDY Ká roly: A szavárd-kérdés Thúry József előtt és után ['The Savard question before and after József Thúry\} = MNy. 55(1959), pp. 373385.

1080. CZEGLÉDY, K[á roly]: Das sakrale Königtum bei den Steppenvölkern = Numen (International Review for the History of Religions) 13(1966), pp. 14-26. See No. 1082.

1081. CZEGLÉDY Ká roly: Megjegyzések a honfoglalás előtti magyar királyság intézményéhez (Notes on the institution of Hungarian kingship before the conquest $]=$ NyelvtudÉrt. 58 (1967), pp. 83-87.

1082. CZEGLÉDY Ká roly: A szakrális királyság a steppei népeknél (a kazá roknál és a magyaroknál) [Sacral kingship with the steppe peoples (the Khazars and the Hungarians)] $=\mathrm{MNy}$. 70 (1974), pp. 11-17.

See No. 1080 .

1083. DEÊR József: A IX. századi magyar történet idórendjéhez [Notes on the chronology of 9th century Hungarian historyl = Száz. 79-80 (1945-46), pp. $3-20$.

1084. DIENES István: A honfoglaló magya rok [The conquest-period Hungarians] . Budapest, 1974.

1085. DIÓSZ EGI Vilmos: A magyarság eredetênek kérdês êhez IThe problem of the origin of the Hungarians] = Ethn. $65(1954)$, pp. 244-253 and NyelvtudÉrt. 5 (1955), pp. $71-80$.

1086. ERDÉLYI István: A honfoglaló magyarság régészeti emlékanyaga kelet-európai kapesolatainak néhány kérdéséról [Some problems of the East-European relations of the conquest-period Hungarians' a rcheological finds] = ArchÉrt. 1960 , pp. 168-172.

1087. ERDÉLYI, I[stván]: Résultats des recherches archéologiques relatives aux trouvailles des cavaliers nomades orientaux en Hongrie (1953-1964) $=\mathrm{AOH}$ 18 (1965), pp. 373-378.

1088. ERDÉLYI István: Nomád életforma - nomád társadalom [The nomadic way of life and nomadic society」=Valóság 1972:5, pp. 13-20.

1089. FÖLDES, László: Viehwirtschaft und Hirtenkultur. Ethnographische Studien. Hrsg. von --. (Unter redaktioneller Mitwirkung von Béla Gunda.) Budapest, 1969,903 pp. 
1090. GYÖRFFY György: Magyar őstörténet [Ancient history of the Hungarians]. Budapest, 1951. 45 pp. /A Budapesti Eötvös Loránd Tudományegyetem Bölcsészkarának jegyzetei/ [Lecture notes of the Faculty of Arts, Eötvös Loránd University, Budapest].

1091. GYÖRFFY György: Kurszán és Kurszán vára. A magyar fejedelemség kialakulása és Óbuda honfoglaláskori története [Kursan and Kursan's castle. The development of the Hungarian principality and the history of Obuda in the time of the conquest] $=$ Budapest Régis égei 16 (1955), pp. 9-40. Reviewed by Moravcsik, Gy. = ByzSl. 17 (1956), p. 381 and ByzZ 1956, pp. 489-490; Saria, B. = Südost-Forschungen 16 (1957), p. 201; Soproni Sándor $=$ ArchÉrt. 84 (1957), p. 94 and Archeologické Rozhledy 1957, p. 294; Makkai László = Száz. 92 (1958), pp. 394-396.

1092. GYÖRFFY György: A magyar nemzetségtöl a vármegyéig, a törzstől az országig [From the Hungarian clan to the county from the tribe to the country] = Száz. 92 (1958), pp. 12-87, 565-615.

Reviewed by Moravesik Gy. = ByzZ. 1959, p. 489 and ByzSl. 1960 p. 163; Deér J. = Historische Zeitschrift 1960, p. 435 and 1961, pp. 436-437.

1093. GYÖRFFY György: Tanulmányok a magyar állam eredetéröl. A nemzetségtöl a vármegyéig, a törzstöl az ors zágig, Kurszán és Kurszán vára [Studies on the origins of the Hungarian state. From the clan to the county from the tribe to the country, Kursan and Kursan's castle]. Budapest, 1959. 168. pp. + pl. /A Magyar Néprajzi Társaság Könyvtára/.

Reviewed by Dercsényi $D_{.}=$Mữért. 1960, pp. 256-257; Sándor I. = Index Ethn. 5 (1960-1961), p. 17; Vargyas L. = AEthn. 9 (1960), pp. $421-424$ and Ethn. 72 (1961), pp. 302-304; Gerö L. = Mũemlékvédelem 5 (1961), pp.119122; Kubinyi $A_{.}=$TBM 14 (1961), pp. 639-640; Schellbach, I. = FL' F 34 (1962), pp. 242-244.

1094. GYÖRFFY György: A magyar östörténet néhány kérdéséről [On some problems of Hungarian ancient history] = TörtSz. 4(1961), pp. 417-425. [Résumé in Russian and Frenchl. Reviewed by Ratkos, L. = Historicky Casopis 1962, pp. 606-607.

1095. GYÖRF FY György: Az Árpád-kori Magyarország történeti földrajza. I. [A historical geography of Hungary in the Age of the Arpads. I.). Budapest, 1963. 907 pp. +15 pl.

1096. GYÖRF FY, György: L. Musset, Les invasions. Le seconde assaut contre l'Europe chrétienne (VII ${ }^{\mathrm{e}}-\mathrm{XI}^{\mathrm{e}}$ siècles). Paris, 1965. Review = Cahiers de Civilisation Mediévale 12 (1969) pp. 71-76 and Arch Ért. 96 (1969), pp. $277-280$.

1097. GYÖRF FY György: A honfoglaló magyarok települési rendjéröl [The settlement system of the conquest-period Hungarians] = A rchÉrt. $97(1970)$, pp. $191-242$. 
1098. GYÖRFFY György: A tízes és százas szervezet [Decimal and centesimal organization] $=\mathrm{II}$. OK $22(1973), \mathrm{pp} .57-64$.

1099. HAZAI, Gy[örgy]: Tarih boyunca Macar-Türk bağları. Budapest, 1963, $31+5 \mathrm{pp}$.

1100. HORVÁTH János [jun.]: Török politikai intézmények nyomai a középkori magyar állam életében [Traces of Turkic political institutions in the life of the medieval Hungarian State] = Ethn. 81(1970), pp. 265-275.

1101. KODOLÁNYI Jânos, ifj. [jun.]: A finnugor ôshaza nyomában. Válogatta és szerkesztette -- [On the tracks of Finno-ugric ancient habitat. Selected and red, by --1. Budapest, 1973. 448 pp. + pl.

Reviewed by Zaicz Gábor = MNy. 70 (1974), pp. 241-244.

1102. LAKÓ György: Az újabb óstörténeti kutatâsok eredményei és a nyelvtudomány [Results of recent ancient historical studies in relation to linguistics] = NyelvtudÉrt. 5 (1955), pp. 8-19.

1103. LAKÓ György: Az óstörténeti vita tanulságai [Conclusions of the debate on ancient history] $=$ NyelvtudÉrt. 5 (1955), pp. 85-93.

1104. LÁSZLÓ Gyula: A magyar óstörténet régészete [The archeology of Hungarian ancient history] $=$ II.OK 5 (1954), pp. 459-479.

Contributions by Hajdú Péter: pp. 480-481; Czeglêdy Károly: pp. 481-483; Móor Elemér: pp. 484-486; Fehér Géza: p. 486.

1105. IAÁSZLÓ Gyula: A "kettôs honfoglalás"-ról [Notes on the "dual conquest"] = ArchÊrt. 97(1970), pp. 161-187. [Résumé in Russian and German].

1106. LÁSZLó Gyula: A honfoglalókról. Diószegi Vilmos emlékének [The Hungarians of the conquest period. In memoriam V. Diószegi]. Budapest, 1973; 21974. $76 \mathrm{pp}$. /Történelemtudomány - történelemtanítás./.

1107. LÁSZLó, Gy[ula]: Les onoughours en Europe-Centrale = Balcano-slavica 1 (1974), pp. 113-119.

1108. A magyarok eredete. Geröné Fazekas Erzsébet beszélgetése két kiváló szovjet tudóssal a magyarok származásá ról (1941) [The origin of the Hungarians: an interview with two eminent Soviet scholars by Erzs ébet Geró (1941)] = Nyr. 73 (1949), pp. 208-215.

1109. MARTINKÓ András: Néhány jelentéstani megjegyzés [Some notes on semantics $\}=$ NyelvtudÉrt. $5(1955)$, pp. $81-84$.

See No. 1110.

1110. MOLNÁR Erik: A magyar társadalom története az őskortól az Árpád-korig [Hungarian social history from prehistory to the Arpadian age]. Budapest, 1945. 352 pp.; 2nd ed. Budapest, 1949. 344 pp.

1111. MOLNÁR Erik: A magyar nép óstörténete [The ancient history of the Hungarian people 1. Budapest, 1953. 113 pp. + 3 pl.; 2nd ed. Budapest, 1954. 175 pp. $+3 \mathrm{pl}$.

See No. 1123. 
1112. MOLNÁR, Erik: Einige Fragen zur ungarischen Urgeschichtsforschung = AHist. 4 (1955), pp. 45-71.

1113. MOLNÁR, Érik: Problemy êtnogeneza i drevnej istorii vengerskogo naroda. Budapest, 1955. 137 pp. /StHist. 13./.

1114. MOÓR Elemér: A magyar nyelvtörténet őstörténeti vonatkozásai (Adalékok a az ösmagyar nép és nyelv kialakulásának kérdéséhez) [The contributions of the linguistic history to ancient historical studies (Data on the formation of the ancient Hungarian people and language)] $=$ Nyr. $70(1946)$, pp. 121-128; 71 (1947), pp. 39-42, 85-87, 151-154; 72 (1948), pp. 8-12, 49-51, 106-109, $242-244 ; 73(1949)$, pp. 20-22, 78-81.

1115. MOÓR Elemér: A nomád magyar törzsek X. szá zadi szállásterületei a Kárpat-medencében [1 0th century settlement-regions of the nomadic Hungarian tribes in the Carpathian basin] = Nyelvtudért. 70 (1970), pp. 45-50.

1116. MOÓR Elemér: A Kaukázuson túli állítólagos "szavárd-magyarok" kérdéséhez [On the question of the alleged Transcaucasian "Savard-Hungarians"] = Száz. 105 (1971), pp. 961-965.

1117. PAIS Dezső: Melich János, A honfoglaláskori Magyarország (Hungary of the conquest period]. Budapest, 1925. / A magyar nyelvtudomány kézikönyve 1/6/. Review $=$ MNy . 53(1957), pp. 13-17.

1118. PAIS Dezső: A magyarsággal kapesolatos IX-X. századi népelemek és népmozgalmak. - A székelyek eredetéhez és a székelys ég kialakulásához [9th and 10 th century ethnic groups and migrations connected with the Hungarians. - The origin and formation of the Székely] = MNy. 63(1967), pp. $71-73$.

1119. SZABADFALVJ József: A magyar takarmánygazdálkodás honfoglalás elötti rétegéhez (A stratum of the pre-conquest period cattle fodder economy in Hungary $]=$ Ethn. 79(1968), pp. 338-349.

1120. SZABADFAIJl, József: Nomadic wintering system on the great Hungarian plain = A Ethn. 17 (1968), pp. 139-167.

1121. TÖRÖK,Gyula: Die Bewohner von Halimba im 10. und 11. Jahrhundert. Übers, von Otto Rátz = Archeologia Hungarica. Series nova 39, Budapest, 1962. p. 169.

Reviewed by László Gyula = Száz. 98 (1964), pp. 804-806.

1122. URAY,G[éza]: Die Bedeutung der Kulturgeschichte der Karpatenbeckens für die Erforschung der Kultur der zentralasiatischen Reiternomaden = Protokoll band (Berlin, 1974), pp. 637-644.

1123. ZSIRAI Miklós: Megjegyzések Molnár Erik őstörténeti munká já ról [Remarks on E. Molnár's work on Hungarian ancient history] = NyelvtudÉrt. 5 (1955), pp. 4-7. 
Contributions by Kálmán Béla: pp. 23-27; Harmatta János: pp. 27-30; Czeglédy Ká roly: pp. 30-35; Moravesik Gyula: pp. 35-37; Lipták Pál: pp. 37-38; László Gyula: pp. 38-43; Szabolesi Bence: p. 43; Elekes Lajos: pp. 43-45; Molnár Erik: pp. 45-49; Kniezsa István: pp. 50-52.

See No. 1111.

See also Nos. $372-374,377,379,381,408,413,441,443,453,459,460,597$, $599,601,606-612,614-631,634-638,645,1133,1233,1236,1240,1245$, $1246,1249-1253,1425-1427,1431,1433,1447-1449$.

\section{2. "MAGNA HUNGARIA"}

124. BENDEFY László: A Keleten maradt magyarok nyomában [On the track of Hungarians who remained in the East l = Magyar utazók (1973), pp. 18-27.

1125. ERDÉLYI, I[stván]: "Bolsaja Vengrija" = AArch. 13 (1961), pp. 307-319.

1126. ERDÉLYI, I[stván]: Teorii vengerskich uCenych o povolžskom proischoždenii drevnich vengrov = Archeologija i Êtnografija Baškirii IV. (Ufa, 1971), pp. $108-112$.

1127. ERDÉLYI István: Régészeti kutatások Baskîriában és a magyar őstörténet [Archeological researches in Bashkiria and Hungarian ancient history] = ArchÉrt. (1972), pp. 244-248.

1128. ERDÉLYI, I[stván]: Fouilles archéologiques en Bachkirie et la prehistoire hongroise $=$ AOH 25 (1972), pp. 301-312.

1129. GYÖRFFY György: Chr. Dawson, The Mongol Mission. London-New-York 1955. Review = Száz. $94(1960)$, p. 427.

1130. GYÖRFFY György: Napkelet felfedezése. Julianus, Plano Carpini és Rubruk útijelentései. Közreadja -- [The discovery of the Orient. Julianus, Plano Carpini and Rubruk's travel accounts. Published by --]. Budapest, 1965. 274. pp.

Reviewed by Cseres T. = ÉI 9(1965), No. 34, p. 2; Diószegi Vilmos = Ethn. 77 (1966), pp. 594-595; Kristó Gyula = ItK 71 (1967), pp. 353-354.

1131. LIGETI Lajos: Gyarmat és Jenö [The tribal names Gyarmat and Jenö] = NyelvtudÉrt. 40 (1963), pp. 230-239.

1132. LIGETI Lajos: A magyar nép mongolkori nevei (magyar, baskír, ki rály) [The names of the Hungarian people in the Mongol period "Magyar", "Baskír" " "Király"/] = MNy. 60(1964), pp. 385-404.

1133. MOÓR,Elemér: Die Vorfahren der Ungarn überschreiten die Wolga = CongrFenno-Ugr. 1963, pp. 420-427. 
1134. NÉMETH Gyula: Magyar törzsnevek a baskíroknál (Hungarian tribal names among the Bashkirs] $=$ NyK 68 (1956), pp. 35-50.

See Nos. $1135,1137$.

1135. NÉMETH [Gyula], J.: Ungarische Stammesnamen bei den Baschkiren $=$ ALH $16(1966)$, pp. $1-21$.

See Nos. $1134,1137$.

1136. NÉMETH Gyula: A Baskír földi magyar óshazáról [On the original habitat of the Hungarians in the Bashkir territory] = ÉlTud. 21 (1966), pp. 596-599.

1137. NEMETH [Gyula], Ju.: Vengerskie plemennye nazvanija u baškir = Archeologija i Êtnografija Baškirii IV. (L'fa, 1971) pp. 249-262.

See Nos. $1134,1135$.

1138. NÉMETH [Gyula], J.: Magyar und Mišer = AOH 25 (1972), pp. 293-299.

1139. PERÉNYI József: A Magna Hungaria kérdéséhez [Notes on the problem of Magna Hungaria] $=$ MNy. 55 (1959), pp. 385-391 and 488-499.

Reviewed by Sauvageot, A. = BSL 56 (1961), fasc. 2, pp. 335-336.

1140. PERÉNYI József: A honfoglalás elótt elszakadt magyarokról [The Hungarians who broke away before the conquest period] = Él'Tud. 15 (1960), pp. 967-970.

1141. RÁSONYI, L[ászló]: Başkurt ve Macar yurtlarındakı ortak coğrafî adlar üzerine = Bilimsel Bildiriler 1963 (1964), pp. 105-112.

1142. RÁSONYI, L[ászló]: Macarca "gyermek" kelimesi ve "Yermak" adı = Rę̧id Rahmeti Arat için (Ankara, 1966), pp. 382-387.

1143. RÄSÅNEN, M.: Gibt es im Baschkirischen etwas Ugrisches? = AOH 12 (1961), pp. 73-78.

1144. VÁSÁRY István: A jezsuita Cseles Márton és a Julianus-jelentés (A Magna Hungaria - és a Jugria-kérdés történetéhez) [The Jesuit Martin Cseles and the Julianus-report. On the qestion of Magna Hungaria and Yugrial = Középkori kútfóink kritikus kérdései (Budapest, 1974), pp. 261-275.

1145. VÉRTES O. András: XVII. századi közlés a Volga menti magyarokról [An 17 th century report on the Hungarians along the Volga] $=\mathrm{NyK} 65(1963)$, pp. 411-412.

\section{SOURCES}

1146. GYÖRFFY György: A magyarok elódeiról és a honfoglalás ról. Kortársak és krónikások híradásai. Sajtó alá rendezte -- [Sources on the ancestors of the Hungarians and the conquest of Hungary. Reports by contemporaries and chroniclers. Edited by - -1. Budapest, 1958. $266 \mathrm{pp}$. and pl. 
Reviewed by Hajdú Péter $=$ Nyr. 83 (1959), pp. 361-362; Szoboszlay B. = Borsodi Szemle $2(1959)$, p. 40; Kovács S. J. = ItK 1960, p. 403; Morawski, K. = Studia Zródloznawcze 5 (1960).

\section{a/ Byzantine sources}

1147. ALTHEIM, F. - STIEHL, R.: Byzantino-turcicum = AAnt. 10 (1962), pp. 13-15.

Reviewed by M[oravcsik], Gy. = ByzZ 55 (1962), p. 426 and ByzSl. 24 (1963), p. 200 .

1148. MORAVCSIK, Gy[ula]: Constantine Porphyrogenitus: De administrando Imperio. Greek text edited by --. English translation by R. J. H. Jenkins. Budapest, 1949. 347. pp. /Magyar-görög tanulmányok. 29./.

See Nos. $1149,1154,1156,1158$.

1149. MORAVCSIK Gyula: Bíborbanszületett Konstantin: A birodalom kormányzása. A görög szöveget kiadta és magyarra fordította -- [Constantine Porphy roge nitus: De administrando imperio. The Greek text edited and translated to Hungarian by --1. Budapest, 1950. 348 pp., 1 pl. See Nos. $1148,1154,1156,1158$.

1150. MORAVCSIK Gyula: Böles Leó Taktikája, mint magyar történeti forrás [Leo the Wise's Tactics as a source of Hunga rian history] = Száz. 85(1951), pp. $334-353$.

See No. 1151 .

1151. MORAVCSIK, Gy[ula]: La Tactique de Léon le Sage, comme source historique hongroise $=$ AHist. 1 (1952), pp. 161-184.

See No. 1150.

1152. MORAVCSIK Gyula: Bizánc és a magyarság [Byzantium and the Magyars]. Budapest, 1955. 119 pp., 1 pl. Reviewed by Gyóni, M. = AAnt. $4(1956)$, p. 326. See No. 1160.

1153. MORAVCSIK Gyula: Bizánci krónikák a honfoglalás elötti magyarságról [Byzantine chronicles on the pre-conquest period Hungarians] $=$ AT 4 (1957), pp. $275-288$.

1154. MORAVCSIK Gyula: György ba rát krónikájának folytatása. Böles Leó, Taktika. Bíborbanszületett Konstantin, $A$ bi rodalom kormányzása [The continuation of friar George's chronicle. Leo the Wise: Tactica. Constantine Porphy rogenetos: De administrando imperiol $=\Lambda$ magyarok elödeiról (1958), pp. 68 86 and $211-213$. [Translation of excerpts and notes].

1155. MORAVCSIK Gyula: Dr. E., v. Ivánka, By zantinische Geschichtssch reiber. I-IV. Graz-Wien-Köln, 1956-53. Review = AT 6 (1959), p. 157. 
1156. MORAVCSIK, Gy[ula]: Constant ine I'orphy rogenitus: De Administ rando Imperio. Volume II. Commentary ly F. Dvornik, R. J. H. Jenkins, B. Lewis, --, D. Obolensky, S. Runciman. Edited by R. J. H. Jenkins. I,ondon, $1962 . \mathrm{X}+221 \mathrm{pp}$.

Reviewed by Gvörffy Gy. = ByzZ 55 (1962), pp. 302-309 and Száz. 98 (1964), pp. $218-253$.

See Nos. 1148,1158 .

1157. MORAVCSIK, Gylula : Byzant in ische Mission im Kreise der Türkvölker an der Nordküste des Schwarzen Meeres. Oxford, 1966.14. pp. 1 pl.

1158. MORAVCSIK, Gylulal: Constant ine Porphyrogenitus: De administrando Imperio. Greek text edited by --. English translation by R. J.H. Jenkins. New, revised edition. Washington, 1967. Dumbarton Oaks 1967. IX. 341. pp. See Nos. $1148,1156$.

1159. MORAV CSIK, Gy[ula]: Studia Byzantina. Curavit: János Harmatta. Budapest, 1967, 438. pp.

Reviewed by Czeglédy Ká roly = AT 17(1970), pp. 74-75; Györffy György = StSl. 16 (1970), pp. 385-386; Mezev I.́́szló = ItK 74 (1970), pp. $101-402$.

1160. MORAVCSIK, Gyula: Byzantium and the Magyars. Budapest, 1970. 147 pp., $12 \mathrm{pl}$.

Reviewed by Vásáry, István = StSI. $17(1971)$, pp. 393-394; Korenchy Éva = NyK 74 (1972), pp. 272-273; Szádeczky-Kardoss Samu =AT 19 (1972), p. 283.

See No. 1152.

1161. NÉMETH Gyula: kgy magvar jövevényszó Bizáncban a X. században [ $A$ 10 th century Hungarian loan-word in Byzantium $]=$ Ny r. 89(1965), pp. 231-234.

See No. 1162 .

1162. NÉMETH [Gyula], J.: Ein ungarisches Lehnwort in Byzanz im 10. Jahrhundert = Beiträge zur Sprachwissenschaft, Volkskunde und Literaturforschung. Wolfgang Steinitz zum 60. Geburtstag am 28. Februar 1965 dargebracht (Berlin, 1965), pp. $291-294$.

See No. 1161 .

1163. OROSZ L[ajos]: Nikephoros "Breviárium"-ának londoni kézirata [The London manuscript of Nikephoros's "Breviary". (Ed. with an introduction by --)]. Budapest, 1948. $27 \mathrm{pp}$. /Magyar-Görög Tanulmányok 28./.

See also Nos. $372,377,408,416,417,438,455,456,552,556,613$.

b/ Musiim sources

1 164. CZEGLÉDY, K[á roly] - HARMATTA, J[ános]: Ibn Fạ̣lān über die Bestattung bei den Wolga-Bulgaren = A rchÉrt. 7-9 (1946-1948), pp. 362-364. 
1165. CZEGLÉDY, K[á roly]: Z. V. Togan, Ibn Faḍlāns Reisebericht. Leipzig, 1939. / Abhandlungen für die Kunde des Morgenlandes. Bd. 4, No. 3./. Review = E.tudes Slaves et Roumaines 1 (1948), pp. 62-64.

1166. CZEGLÉDY, K[á roly]: Die Karte der Donaulandschaftgruppe nach al-Huwă rizmì = AOH $1(1950-51)$, pp. 46-79.

1167. CZEGLÉDY, K[á roly]: Zur Meschheder Handschrift von Ibn Faḍlāns Reisebericht $=$ AOH 1 (1950-51), pp. 217-260.

1168. CZEGLÉDY Károly: Ibn Ruszta és Gardízí. Balkhí. Ibn Fadlán. Maszúdí = A magyarok elödeiröl (1958), pp. 51-67 and 210-211. |Translation of excerpts and notes].

1169. CZEGLÊDY Károly: Gardizi "török" fejezetének magyarázatához [Notes towards the explanation of Gardizi's "Turkish" chapter $]=\mathrm{MNy} .68$ (1972), pp. $138-145$.

See No. 1170.

1170. CZEGLÉDY, K[á roly]: Gardizi on the history of Central Asia (745-780 A.D.) $=$ AOH 27 (1973), pp. 257-267.

See No. 1169.

1171. HAZAI, G[yörgy]: Les manuscrits, conservés à Sofia, des remaniements médiévals de Marvazi et Auf $1=$ AOH 7 (1957), pp. 157-197.

Reviewed by Nuriachmetov, A. Ch. = NarAzAfr. 1961:4, p. 245.

1172. HAZAI, Glyörgy ]: Notes sur le "Tarı̧-i Lingurus" de Terdžumān Mạ̣mūd $=$ AOH $13(1961)$, pp. $71-84$.

See Nos. 1173,1174 .

1173. HAZAI, G[yörgy]: Tarih-i Ungurus (Macar Bilimler Akademisi Doğu Kütüphanesinde bulunan Tercüman Mahmud'un eseri üzerine notlar =VI. Türk Tarih Kongresi, 20-26 Ekim 1961, Ankara. Bildiri özetleri (Ankara, 1961), pp. 57-58.

See Nos. 1172,1174 .

1174. IIAZAI, G[yörgy]: Tarih-i Ungurus (Macar Bilimsel Akademisi Doğu Kütuiphanesinde bulunan 'Tercüman Mahmud' un eseri üzerine notlar) = VI. Türk I arih Kongresi, Ankara 20-26 Lkim 1961, Kongreye sunulan bildiriler (Ankara, 1967 ), pp. 355-358.

See Nos. $1172,1173$.

1175 . ISTVÁXOVITS Márton: Épigraficeskie pamjatniki Severnogo Kavkaza. Na arabskom, persidskom i tureckom jazykach. Castj I. Nadpisi X-XVII vv. Teksty, perevody, kommentarii, rvedenie i prilozenija L. I. Lavrova. Moskva, 1866 g. Pamjatniki pisjmennosti Vostoka II, 1. Review = Ethn. $79(1968)$, pp. 139-140.

See also Nos. $373,374,379,381,419,433-443,474,549-551,611-621,1076-1082$, 1574 . 


\section{c/ Syrian sources}

1176. CZEG LÉDY, K[ároly]: Monographs on Syriac and Muhammadan sources in the literary remains of M. Kmoskó = AOH 4(1954), pp. 19-91.

1177. CZEGLÉDY, K[á roly]: The Syriac legend concerning Alexander the Great = AOH 7 (1957), pp. 231 -249.

See No. 1178 .

1178. CZEGLÉDY Károly: A szír Nagy Sándor-legenda |The Syriac legend concerning Alexander the Great ] = I. OK 13 (1958), pp. 3-20.

See No. 1177.

1179. CZEGLÉDY Károly: Középperzsa eredetũ szír tudósítísok [Syriac reports of Middle-Persian origin] = AT 5 (1958), pp. 251-253.

1180. CZEGLÉDY, K[á roly]: Pseudo-Zacharias rhetor on the nomads = StTurc. (1971), pp. 133-148.

See also Nos. $373,374,379,381,550,551,617,1574$.

\section{d/ Armenian and Georgian sources}

See Nos. $373,379,382,438,541,546,554,555,613,616,1072,1079,1401$, $1.105,1425,1427$.

\section{e/ Slavic sources}

1181. FEIHÉR, G[éza]: Die landnehmenden Ungarn und ihr Verhältnis zu den Slawen des mittleren Donaubeckens = StSl. 3 (1957), pp. 7-58.

1182. KIRíly Pêter: A magyarok említése a Metód-legendában [The notice on the Hungarians in the L.egend of Methodius] $=$ MNy. $70(1974), p p .269-285$ and $406-430$.

1183. KIRÁLY Pêter: A magyarok említése a Konstantin-legendában [The notice on the IIungarians in the Legend of Constantine $]=\mathrm{MNy}, 70(1971), \mathrm{pp}, 1-11$ and 157-173.

1184. KISS, Lajos: Istorija odnogo polonizma v russkom jazyke: vengry = Studia linguistica in honorem Thaddaei Lehr-Splawiński (Warszawa, 1963), pp. $305-311$.

1185. KNIEZSA István: Orosz évkönyvek (Nesztor-krónika); A Cirill-legenda; $A$ Metód-legenda (The Russian Annals (The Nestor chronicle); The Cyrill Legend; The Methodius Legend] $=\Lambda$ magyarok elödeiról (1958), pp. 87-90 anı1 213-214 [Translation of excerpts and notes]. 
1186. PERÉNYI József: A magyarok és a keleti szlávok kapcsolatai a honfoglalás elótt [Pre-conquest contacts between the Hungarians and the Eastern Slavs] = Magyar-orosz történelmi kapcsolatok (Budapest, 1956), pp. 5-34. See No. 1187.

1187. PERÉNYI, József: Vzaimootnosenija meždu vengrami i vostő̌noslavjanskimi plemenami $=$ StSl. $2(1956)$, pp. 1-29.

See No. 1186.

1188. PERÉNYI József: Az orosz évkönyvek magyar vonatkozásai [Russian annals on the Hungarians] = Tanulmányok a magyar-orosz irodalmi kapcsolatok köréból (Budapest, 1961), pp. 28-55.

1189. PERÉNYI József: Gazdaság és társadalom-történeti fejlódési tájak KeletEurópában [Economic and social historical areas in Eastern Europe] = Tanulmányok Kelet-Eurôpa történetéból I. (Budapest, 1972), pp. 5-40.

1190. PERÉNYI, J[ózsef]: Ugri v "Povesti vremennych let" = Letopisi i chroniki (Moskva, 1974), pp. 92-102.

1191. VÂSÁRY, I[stván]: L. Boba, Nomads, Northmen and Slavs. Eastern Europe in the ninth century. Wiesbaden, 1967. Review = AOH 24 (1971), pp. 259-261.

See also Nos. $1249,1250,1252,1253$.

\section{f/ Latin sources}

1192. CZEGLÉDY Károly: Oszmán apósa Anonymusnál? [Osman's father-in-law in the Anonymus's chronicle?] = MNy. 55 (1959), p. 519.

1193. GYÖRFFY György: Krrónikáink és a magyar őstörténet [Hungarian chronicles and Hungarian ancient history]. Budapest, 1948. 191. pp.

Reviewed by Gyóni M. = ByzSl. 10 (1949), p. 346.

1194. GYÖRFFY György: A magyarok története (Gesta Ungarorum). Fordította -[History of the Hungarians (Gesta Ungarorum). Translated from Lat in by --] = A magyarok elódeiról (1958), pp. 91-94. [Translation of excerpts and notes].

1195. GYÖRF FY György: Kézai Simon, A magyarok története. Fordította -[Kézai Simon, History of the Hungarians. Translated from Latin by --]= A magyarok elódeiról (1958), pp. 139-149. [Translation of excerpts and notes].

1196. GYÖRFFY, Gy[örgy]: Formation d'États au IX ${ }^{\mathrm{e}}$ siècle suivant les "Gesta Hungarorum" du Notaire Anonyme = Nouvelles Études Historiques 1965:1, pp. 27-53.

See No. 1197. 
1197. GYÖRFFY György: Honfoglalás elötti népek és országok Anonymus Gesta Hungarorumában [Pre-conquest period peoples and countries in the Anonymus's Gesta Hungarorum] = Ethn. $76(1965)$, pp. $411-434$. Reviewed by Cseres T. = ÉI $10(1966)$, No. 6, p. 10 . See No. 1196.

1198. GYÖRF FY György: A honfoglalás ról újabb történeti kutatások tükrében [The Hungarian conquest period in the light of recent historical research] $=\mathrm{Va}-$ loság 16:7 (1973), pp. 1-16.

1199. HORVÁTH János [jun]: A bajorok ês karantánok megtérése (Conversio Bagvariorum et Carantanorum); Regino Évkönyve; Fuldai Évkönyvek; Liudprand: Antapodosis; Ekkehard: Sankt Galleni történetek; Sankt Galleni Évkönyvek; Augsburgi Gerhard: Szent Udalrik élete; Widukind: A szászok története; Aventinus: Bajor Évkönyvek ['The convension of the Bavarians and the Carantanians; Regino's Annals; The Annals of Fulda; Liudprand:Antapodosis; Ekkehard: Saint Gallen Tales; The Annals of Saint Gallen; Gerhard of Augsbrug: The life of St. Udairik; Widukind: History of the Saxons; Aventinus: Bavarian Annals] = A magyarok elödeiról (1958), pp. 150-201 and 222-228. [Translation of excerpts and notes].

1200. HORVÁTH János: A magyarországi hun-történet és szerzóje [A Hungarian history of the Huns and its author] = ItK 67 (1963), pp. 446-476.

1201. HORVÁTH János: P. mester és müve [Master P. and his work] $=$ ItK 70 (1966), pp, 1-53 and 261-282.

1202. HORVÁTH, János: Die Persönlichkeit des Meisters P. und die politische Tendenz seines Werkes = AAnt. 19(1971), pp. 347-382.

1203. PAIS Dezső: Béla király jegyzóje: A magyarok cselekedeteiról [King Béla's scribe: "On the deeds of the Hungarians"] = A magyarok elödeiról (1958), pp. 95-138. [Translation of excerpts and notes].

See also No. 597.

\section{LOAN-WORDS}

\section{a/ General works}

1204. ABAEV, V. I.: K alano-vengerskim leksiCeskim svjazam = Europa et Hungaria. Congressus Ethnog raphicus in Hungaria (Budapest, 1965), pp. 517-537.

1205. ABAFFY Erzsébet, E.: Szóvégrendszerünk az ős-és az ómagyar korban. A szóvégi redukálódás [The system of word endings in Proto-and Old-Hungarian. Final reduction $]=\mathrm{MNy} \cdot 70(\mathbf{1 9 7 4 )})$ pp. $430-440$. 
1206. APOR Éva: V. I. Abaev, Istoriko-êtimologið̌skij slovarj osetinskogo jazyka. Tom I. A-K. Moskva-Leningrad, 1958. Review = NyK 66 (1964), pp. 452-455.

1207. BÁRCZI Géza: Régi magyar nyelvjárások [Old Hungarian dialects]. Budapest, 1947.

1208. BÁRCZI Géza: A magyar hangtörténet tárgyköréból. A török szóvégi $\underline{-q}$, $\underline{-g},-\gamma$ megfelelései [Studies in the field of Hungarian phonology. Correspondences of final $\underline{-\mathrm{q}}, \underline{-\mathrm{k}}, \underline{-\mathrm{g}}, \underline{-\gamma}$ in Turkic] = MNy. 46 (1950), pp. 223-227.

1209. BÁRCZI Géza: A magyar hangtörténet tárgyköréból. Az ôs magyar i i [Studies in the field of Hungarian phonology. Proto-Hungarian $i]=\mathrm{MNy} .46(1950)$, pp. 228-230.

1210. BÁRCZI Géza: A magyar szókincs eredete [The origins of the Hungarian vocabulary]. Budapest, 1951. 35 pp. 2nd enlarged edition: Budapest, 1958. 188 pp. /Egyetemi Magyar Nyelvészeti Füzetek/.

1211. BÁRCZI Géza: A tihanyi apátság alapítólevele mint nyelvi emlék [The foundation-deed of the Tihany abbey as a linguistic record]. Budapest, 1951. $231 \mathrm{pp}$. /Nyelvészati Tanulmányok 1./.

1212. BÁRCZI Géza: Török jövevényszavaink legrégibb rétegének kérdêsêhez [On the problem of the earliest layer of Turkic loan-words in the Hungarian language] = I. OK 2 (1952), pp. 347-359.

Remarks by Sz. Kispál Magdolna: pp. 359-363; Lakó György: pp. 363-369; Moór Elemér: 369-371.

1213. BÁRCZI Géza: Magyar hangtörténet. 2., bóvitett kiadás [Hungarian phonology. 2 nd, enlarged edition]. Budapest, 1958. 196 pp.

1211. BÁRCZI Géza: Magyar történeti szóalaktan. I. A szótövek [Hungarian historical morphology. I. Etymons]. Budapest, 1958. $63 \mathrm{pp}$.

1215. BÁRCZI Géza: Örmény jövevênyszavaink kérdéséhez [On Armenian loanwords in the Hungarian language $]=$ MNy. 56 (1960), pp. 304-310.

See No. 1404.

1216. Bủ RCZI Géza: A finnugor zárhangok ösmagyar kori történetéhez [History of Finno-Ugric plosives in Proto-Hungarian] = MNy. 58 (1262), pp. 1-10. Reviewed by Sauvageot, A. = BSL 59 (1964), fasc. 2., p. 267.

See No. 1217.

1217. BÂRCZI, Géza: Zur Geschichte der finnisch-ugrischen Verschlusslaute in urungarischer Zeit = MSFOu. 125 (1962), pp. 11-26.

Reviewed by Sauvageot, A. = BSL 59 (1964), fasc. 2, pp. 241-242. See No. 1216.

1218. BÁRCZI Géza: A magyar nyelv életrajza [The history of the Hungarian language ]. Budapest, 1963. 462 pp. $+38 \mathrm{pl}$. 2nd edition: Budapest, 1966. $162 \mathrm{pp}$. $+38 \mathrm{pl}$. 


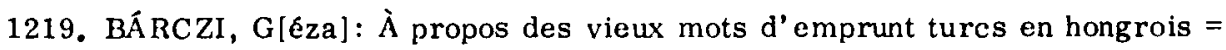
AOH 18 (1965), pp. 47-54.

1220. BÁRCZI Géza: A magyar nyelv régi török jövevényszavai [Old-Turkic loanwords in the Hungarian language] = Altnapoh (1965), pp. $5-6$.

1221. BÁRCZI Géza: Hangtörténet [Historical phonology] = A magyar nyelv története (Budapest, 1967), pp. 95-180.

1222. BÁRCZI, G[éza]: Le traitement de $\underline{s}$ et de $\underline{x}$ turcs dans les mots d'emprunt turcs du protohongrois $=$ St Turc. $(1 \overline{9} 71)$, pp. 39-46.

1223. BÁRCZI, Géza: Quelques conclusions tirées de l'étude des plus anciens mots d'emprunt tures du hongrois = AOH 25 (1972), pp. 383-390.

1224. BÁRCZI Géza - BENKÖ Loránd - BERRÁR Jolán: A magyar nyelv története. Szerk. Benkő Loránd [History of the Hungarian language. Ed by Loránd Benkő]. Budapest, 1967. 599 pp.

1225. BARLAY Szabolcs: A Clusiusnál található magyar növénynevek kérdése [The problem of Hungarian botanical terms in Clusius' workl = MNy. 44 (1948), pp. $151-153$.

1226. BENKÖ Loránd, Hangtani tanulmányok a magyar kettőshangzók köréböl [Phonetical studies in the field of Hungarian diphthongs] = NyK 54 (1952), pp. 37-62 .

1227. BENKÖ Loránd: A magyar ly hang története (The history of the Hungarian ly sound]. Budapest, $1953.83 \mathrm{pp}$. / NyelvtudÉrt. 1./.

1228. BENKÖ Loránd: A magyar szókészlet eredete [The origin of the Hungarian vocabulary] = A magyar nyelv története (Budapest, TK, 1967), pp. 259-350. See No. 1224.

1229. GRÉTSY László: A szóhasadás. Egy kevéssé szâmba vett szóalkotásmód típusai és szerepe irodalmi és köznyelvünk fejlödésében [Word splitting. Types and role of a little-considered way of word-formation in the Hungarian literary and everyday language]. Budapest, 1962. 286. pp.

1230. HíDV ÉG I Andrea, P.: A magánhangzók labializációja Anonymus magyar szórványaiban [The labialization of vowels in the Hungarian glosses of the Anonymous] = Magyar nyelvjárások 1. Szerkeszti Bárczi Géza (Debrecen, 1951), pp. 95-117.

1231. IMrE Samu: A Szabács Viadala [The "Siege of Szabács"]. Budapest, 1958. $332 \mathrm{pp}$. /Nyelvészeti Tanulmányok. 4./.

Reviewed by Papp László = Nyr. 83 (1959), pp. 356-360.

1232. KÁLMÁN, Béla: Die russischen Lehnwörter im Wogulischen. Budapest, 1961. 327. pp.

1233. KISPÁl, Magdolna, Sz.: Ugor-török érintkezés [Lgor-Turkic contacts) = NyK 53 (1951), ?n. 49-64. 
1234. KNIEZSA István: A magyar nyelv szláv jövevényszavai. I. kötet 1. rész és 2. rész. [The Slavic loan-words of the Ifungarian language. Volume I. Parts 1, 2.1. Budapest, 1955. $582 \mathrm{pp}$.

1235. KNIEZSA István: Szláv jövevényszavaink magánhangzó-kvantitása [The vowel quantity of the Slavic loanwords in Hungarian] = NyK 65 (1963), pp. 77-101. Reviewed by Sauvageot, A. = BSL 59 (1964), fasc. 2, p. 240. Contribution by Moór Elemér = NyK 66 (1964), pp. 43-57.

1236. KÖV ESI Magda, A.: A permi-elómagyar érintkezés kérdéséhez [On Permian - Proto-Hungarian contacts] = MNy. 64(1968), pp. 162-176.

1237. LIG kTI Lajos: Gombocz Zoltán, Honfoglalás elốtti bolgâr-török jövevényszavaink. Közzétette, előszót îrta -- [Pre-conquest Bulgaro-Turkic loanwords in Hungarian. Published with a preface by --]. Budapest, 1960, 30 pp. / NyelvtudÉrt. 24./.

1238. LIGETI Lajos: Nêhány megjegyzếs úgynevezett altaji jövevénys zavainkról [Some notes on the so-called Altaic loan-words in Hungarian] $=\mathrm{MNy} .56$ (1960), pp. 289-303.

See No. 1239.

1239. LIGETI, L[ajos]: À propos des éléments "altaiques" de la langue hongroise = ALH 11 (1961), pp. 15-41.

Reviewed by Sauvageot, A. = BSL 57 (1962), pp. $213-215$.

See No. 1238.

1240. LIGETI Lajos: Uráli török jövevénys zavaink kérdéséhez [Notes on the Turkic loan-words of the Uralic period in Hungarian] = MNy. 59 (1963), pp. 381-393.

1241. LIGE'TI Lajos: Turkológiai megjegyzések szláv jövevényszavainkhoz [Notes on the Slavic loan-words in Hungarian. A Turcological study] $=\mathrm{MNy} \cdot 63$ (1967), pp. 427-441.

1242. A magyar nyelv êrtelmezó szótára. Szerk. a MTA Nyelvtudományi Intézete [The explanatory dictionary of the Hungarian language. Edited by the Linguistic Institute of the Hungarian Academy of Sciences]. I - VII. kötet. Budapest, 1959-1962.

1243. A magyar nyelv történeti-etimolôgiai szótára. Fószerk. Benkő Loránd, szerkesztók Kiss Lajos, Papp László [An historical-etymological dictionary of the Hungarian language. Editor-in-chief: L. Benkö. Editors: L. Kiss and I. Papp]. I. A-Gy. Budapest, 1967. 1142 pp. II. H-O. Budapest, 1970. $1110 \mathrm{pp}$. [Turkic etymologies by Zsuzsa Kakuk. Revised by Lajos Ligeti].

1244-45. A magyar szókészlet finnugor elemei. Főszerk. Lakó György, szerkesztö Rédei Károly IThe Finno-Ugric elements of the Hungarian vocabulary. General editor: Gy. Lakó, editor: K. Rédei]. I. A-Gy. Budapest, 1967; II. H-M. Budapest, 1971. 455 pp. 
1246. MOÓR, E[lemér]: Studien zur Früh-und Urgeschichte des ungarischen Volkes = AEthn. 2(1951), pp. 25-142.

1247. MOÓR Elemér: Egy LX-X. századi magyar hangváltozás [A 9th-10th century phonetic change in Hungarian] $=$ MNy. 47 (1951), pp. 268-270.

1248. MOŌR, Elemér: Die Ausbiluung des ungarischen Konsonantismus = AOH $2(1952-53)$, pp. $1-94$ and $355-454$.

Reviewed by ltkonen, Erkki $=$ FUF 32 (1956), Anzeiger, pp. 67-73. Answer: Moór, E. = FUF 33 (1958-1960), Anzeiger, 1960, pp. 54-74. Reply: Itkonen, Erkki $=$ ibid. pp. 74-81. Review: Sauvageot, A. - BSL 57 (1962) : 2, pp. $224-226$.

1249. MOÓR, E[lemêr]: Die Ausbildung des urungarischen Volkes im Lichte der Laut - und Wortgeschichte. I = AIH 6(1956), pp. 279-341; II = ALH 7 (195758), pp. 147-168; III = ibid. pp. 341-377; IV = ALH 8 (1958), pp. 63-97; $\mathrm{V}=$ ibid. pp. 249-272; VI = ALH 9(1959), pp. 117-186; VII = ALH 10(1960), pp. 383-421.

Reviewed by Sauvageot, $A_{0}$ = BSL 56 (1961), pp. 270-272.

1250. MOÓR, Éllemér]: Die Ausbildung der Betriebsformen der ungarischen Landwirtschaft im Lichte der slawischen Lehnwörter $=$ StSl. $2(1956)$, pp. $31-117$.

1251. MOÓR Elemér: Török jövevényszavaink "legrégibb" rêtegének kêrdéséhez [Notes on the "earliest" layer of Turkic loan-words in the Hungarian language $]=$ NyK 61 (1959), pp. 281-301. Reviewed by Sauvageot, A. = BSI, 56 (1961), p. 259.

1252. MOÓR Elemér: A nyelvtudomány mint az ös-és nêptörténet forrástudománya [Linguistics as a source of Hungarian ancient historical and ethnological studies]. Budapest, 1963. 182 pp.

Reviewed by Katicić, Radoslav = Beiträge zur Namenforschung 16 (1965), p. 111; Kakuk, Zsuzsa = ALH 16 (1966), pp. 189-191.

1253. MOÓR, E[lemér]: Slawischer Einfluss auf das Fischerei-und Jagdwesen der Ungarn im Mittelalter im Lichte des sprachlichen Materials = A Ethn. 12 (1963), pp. 1-56. Author's summary = Demos 5(1964), p. 232.

1254. NÉM ETH [Gyula], J.: Zoltán Gombocz et la théorie des mots d'emprunts turks bulgares du hongrois = Études Finno-Ougriennes 8 (1971)-Mélanges offerts à Aurelien Sauvageot pour son soixante-quinzième anniversaire (Budapest, 1972), pp. 203-212.

Reviewed by Honti L. $=$ NyK 76 (1974), pp. 437-438.

1255. PAIS Dezső - BÁRC'ZI Géza - BENKÖ Loránd: A magyar ly hang kérdésếnez [On the problem of the Hungarian ly sound] = NyelvtudÉrt. 6 (1955), pp. $3-52$.

1256. PALLÓ, Margit K.: Hungaro-Tschuwaschica = UAJb. 31 (1959), pp. 239-258. 
1257. PALLÓ, Margit $\mathrm{K}_{\text {. }}$ : Die V'ertretung ung. $\mathrm{sz}-/ \mathrm{s} /<$ türk. $\mathrm{j}-$ in den alten türkischen Lehnwörtern der ungarischen Sprache = UAJb. $33(1961)$, pp. $128-135$.

1258. PAL1.O Margit, $\mathrm{K}$. : Az igésítö képzö́k kérdéséhez (Notes on the question of verb-forming suffixes) - MNv. 66 (1970), pp. 75-78.

1259. PAPP Ferenc: Töszókinesiink etimológiai rétegenkénti hangstatisztikája [The sound statistics of Hungarian simplexes according to etv mological layers| $=$ NyK 75 (1973), pp. 3-40.

1260. RÓNA-TAS András: A magvar nvelv régi török elemei és a csuvas nvelvtörténet néhínv kérdése (Early Turkic elements of the Hungarian language and some problems of the history of the Chuvash language] = NyelvitudErt. 58 (1967), pp. 172-177.

1261. SULÁN Bêla: A cseh szókines magyar elemeinek problematikája [The probiem of Hungarian elements in the Czech vocabulary] $=$ NyK 65 (1963), pp. 283-296.

See No. 1262 .

1262. SULLÁN, Béla: Les problèmes des éléments hongrois de la langue tchèque = StSl. 9(1963), pp. 9-26.

See No. 1261 .

1263. SZILÁGYI Ferenc: A magyar szókines regénye [A story of the Hungarian vocabulary l. Budapest, 197.1. $222 \mathrm{pp}$.

126.1. TAMÁS, Lajos: Ety molog isch-historisches Wörterbuch der ungarischen Elemente im Rumänischen. (Unter Berücksichtigung der Mundartwörter). Budapest, 1966. $937 \mathrm{pp}$.

See also Nos. 115, 182, 183, 1069, 1072-1075, 1089,1272,1307, 1309, 1310, 1381,1439 .

\section{b/ Etymologies}

1265. BALÁZS János: Gyermeki iegetés [The scaring of children with a boggy] = Nyr. $80(1956)$, pp. $478-480$.

1266. BALÁZS János: Mennyi idős az idő? [How old is the word idô ("time")?] = MNy. 61 (1965), pp. 404-412.

1267. BALÁZS, J[ános]: Zur Herausbildung der Benennungen für "Zeit" und "Stelle", "Platz, Raum" im ungarischen Wortschatz = ALH 24 (1974), pp. 73-79.

1268. BÁRCZI Géza: Jár ["Go, walk"] = MNy. 53 (1957), pp. 189-191.

1269. BÁRCZI Géza: Kék ["Blue"] = MNy. 53 (1957), pp. 191-192. 
1270. B[EKE] Ö|dön]: Ágvú ["Cannon"] = Ny r. 70 (1946), p. 30 .

1271. B[EKE] Ö[dön]: Búvájos ["Magical"] = Nvr. 70(1946), pp. 30-31.

1272. BEKE Ödön: Népnvelvkutatás és szótörténet [Dialectal studies and lexicologvl $=$ Nvr. 70 (1946), pp. 45-55, $101-107$. [bübájos, kantár, bájol ]

1273. B[EKE] Ö[dön]: Bübájos, bá jos ["Magical", "charming"] = Nvr. 70 (1946), p. 159.

1274. BEKE Ödön: Dól, diil ["To fall down", "idem"] = Nyr. 71 (1947), p. 18.

1275. BEKE Ödön: Átok és âldás [ "Curse" and "blessing"] = Nyr. 7.1 (1950), p. 291 .

1276. BkKE C̈dön: Idö ["Time"] = Nvr. Tt(1950), pp. 292-293.

1277. B|FKE] Ö|dön]: Török tezek - magvar tözeg [Turkic tezek - Hungarian tözeg ("peat")| = Nvr. 74(1950), pp. $461-462$.

1278. BEKE (̈)dön: Gaz ["Y"eed"] = Nyr. 76 (1952), pp. 5t-55.

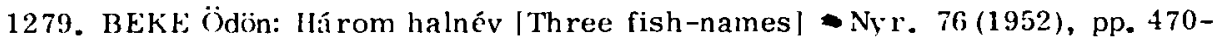
47. legri, siillö, szakal

1280. BEKF: (̇̀òn: Ölt, (̇ltés, öltö ["To stitch", "stitch", stitching"] = Nyr. $78(1954)$, p. 22 !).

See No. 1288.

1281. BEKE Ödön: Körte ["Pea r"] = Nyr. 83 (1959), p. 225.

1282. BENKÖ Loránd: Csokán ["Corn-cob"] = MNy. 15 (1949), p. 78.

1283. CSÉF KÓ Gyula: Ká rókatona ["Cormorant"] = Nyr. 71 (1947), pp. 109-110.

1284. CSEF Kó Gyula: Boszorkány ["Witch"] = MNv. 47 (1951), pp. 274-275.

1285. DIÓSZZEGI Vilmos: Samán |"Shaman"] = MNY. 13 (1947), pp. $211-212$.

1286. ERDÉLYi István: Táltos ["Shaman"] = NvK 62 (1960), pp. 328-331.

1287. EREN, Hasan: Török jövevényszók a magyarban |Turkic loan-words in Hlunga rian] $=\mathrm{MNy} .44(1948)$, pp. 34-47. [üvecs, gyomor]

1288. FEkF TE Péter, H.: (̈lt, öltés, öltó ["To stitch", "stitch", "stitcher"] = Nvr. $79(1955)$, pp. 232 .

See No. 1280.

1289. FöI.JES László: A telek "földteriilet" jelentéstörténete /A semantic histor of the word telek "piece of land"1 = MNy. 67(1971), pp. 118-431.

1290. GÁBOlRJÁN Alice: Veronika Gervers - Molnír. The Hungarian szür an archaic mantle of Eurasian origin. Toronto, 1973. Review = Ethn. $85(197 \cdot 4)$, pp. 56t-566. 
1291. G[ÁLII] L[ászló]: Gyapot - pamut ["Cotton" - "cotton yard"] = Nyr. 90 (1965), p. 328 .

1292. GREGOR Ferenc: A Besztercei Szójegvzék szlovák elemei? [Slovakian elements in the "Glossary of Beszterce"?] = MNy. 64(1968), pp. $196-501$. [csákány]

1293. G(XNI)A Béla: Tózeg szavunk tárgvtörténetéhez (Notes on the history of the Hungarian word tózeg ("peat")] = Nyr. 75 (1951), pp. 212-213.

1291. HADROVICS László: Kelengye ["Trousseau"] = MNy. 51 (1955), pp. 340-342. See No. 1295.

1295. HADROVICS Iászló: Kelengye ["Trousseau"] = NNv. 52 (1956), p. 358. See No. 1294.

1296. HEGEntis Lajos: Csal, csel ["To cheat", "trick"l = MNy. 46 (1950), pp. 123-129.

1297. MRE Samu: Gyepü, gyep ["Marchland", "grass"] = MNy. 52 (1956), pp. 213-214.

1298. JỉHÁSZ Jenó: Az "öröl családja (The word-family of öröl ("to grind")] = MNv. 44(1948), pp. 135-13i.

1299. JLHÁSZ Jenó: Gyöz l"'To be victorious"l = MNy. 50 (1954), pp. 159-160.

1300. JUHÁsz Jenö: Szómagra rázatok [Ltymologies] = NyK 60 (1958), pp. 65-68. [kövér, kevély, dưhös]

1301. JUHASZ Jenö: Buân ["Sin"] = MNv. 55(1959), pp. 409-413.

1302. Kí I MÁN Béla: Pá rhuzamos szóátrételek a magra rban [Parallel adoption of words in the Hungarian language] = Nvr. 74(1950), pp. 24-27. [vásár $\sim$ baziir, harang $\sim$ kazin

1303. KÁl.MÁN Béla: Kötelet ver ["To make rope"] = MNy. 48 (1952), pp. 150-151.

1304. KÁlMÁN Béla: Kanvaró ["Measles"] = MNy. ţ (1952), pp. 209-210.

1305. KIRÁlY, Pléter]: Professor B. Havránek über die Herkunft des Wortes tábor $=$ AL.H 5 (1955), pp. 225-226.

1306. I.AKÓ,Györgv: Strittige Etvmologien ungarischer Wörter = UAJb. 31 (1959), pp. 159-162. [kap- I

1307. I.IGETI I.ajos: A török szókészlet története és török jövevényszavaink. Gröng | The history of Turkic vocabulary and Turkic loan-words in Hungarian. Gröngr ("Pearl"). = MNv. \$2(1946), pp. 1-17.

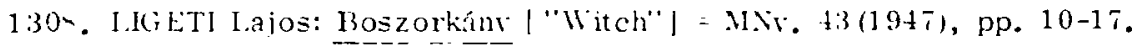


1309. LIG ETI Lajos: A török szófejtés és török jövevénys zavaink (Elôljáró megjegyzések. Magyar íz "artus, articulus", török yüz "ua."; gyưrû́; gyũs zû) [Turkic etymology and Turkic loan-words in Hungarian (Preliminary notes. Hungarian íz "artus, articulus" Turkic yüz "same"; Gyürư "ring"; gyứszu "thimble")] = MNy. 54 (1958), pp. 435-450.

1310. LIGETI Lajos: A török szófejtés és török jövevényszavaink. (Szêrú. A gyúrú és rokonsága. Ocsú) (Turkic etymology and Turkic loan-words in Hungarian (Szérü "barn yard". Gyürí "ring" and its kins. Ocsú "tailings")] = MNy. 55 (1959), pp. $4 \overline{51-457 .}$

1311. LIGETI Lajos: Bilincsek, bilincs ["Shackles", "shackle"] = MNy. 61 (1965), pp. 281-289.

See No. 1312 .

1312. LIGETI, L[ajos]: Noms turcs pour "fers; bracelet; begue" dans les langues slaves et dans le hongrois $=$ StSl, $12(1966)$, pp. 249-258.

See No. 1311.

1313. LIGETI Lajos: Az idó és társai (The word idö ("time") and its companions] = MNy. 62 (1966), pp. 385-398.

See No. 1382 .

1314. LIGETI Lajos: A harang mint csörgó, csengettyú és kolomp (The bell as rattle, hand bell, and cow bell] = MNy. 64(1968), pp. 75-78.

1315. LIGETl Lajos: A jó szagú gyopártól a havasi gyopírig [From the fragrant cottonweed to edelweiss! $=$ MNy. 65 (1969), pp. 136-144.

1316. LIGETI Lajos: Orsó szavunk török háttere [The Turkic background of the Hungarian word orsó ("spindle")] = MNy.66 (1970), pp. 412-421.

1317. LónINCZ Jenö: Órül ['To become mad'] = MNy. 60 (1964), pp. 477-478.

1318. MẢNDOKY Istvån: Bütui ["Butt-edge"] = MNY. 6s (1972), pp. 170-174. See No. 1320.

1319. MÁNDOKY István: Kozma ["Burn"] = MiNy. 6s (1972), pp. 299-303. See No. 1320.

1320. MÁNDOKY [István], É.: L'étymologie turque de deux mots hongrois = AOH 25 (1972), pp. $391-403$. [bütü, kozma]

See Nos. $1318,1319$.

1321. MÁNDOKY Kongur István: Cötkény ["Wolf's milk"] = MNy. 69 (1973), pp. 457-465.

1322. MIK ESY Sándor: Erdő gyapja, gyapjú, gyepú ["The wool of the forest", viz. "the trees of a forest selected for thinning", "wool", "hedge" $1=\mathrm{MNy}_{0}+1$ (1955), pp. 312-318.

1323. MINORSKJJ, V.F.: Tapqur $/$ Tabur $=$ AOH $12(1961)$, pp. 27-31. 
1321. MCÓR Elemér: Sajt ["Cheese"] = MNy. 17 (1951), pp. 290-292.

1325. MCÓR Elemér: Sárkány ['Dragon"] = MNy. 17 (1951), p. 293.

1326. MOĆR Elemer: Tükör ['Mirror"] = MNy. 55 (1959), pp. 521-527.

1327. MOÓR klemér: Hurok - tôr - less ["Noose" - "snare" - "lair"] = NyK 61 (1959), pp. 365-366.

1328. MOÓR Elemér: 'Teve és tenger, hornok és hajó ['Teve ("camel') and tenger ("sea"), homok ("sand") and hajo ("ship")] = MNy. 58 (1962), pp. 36-43. Reviewed by Sauvageot, A. = BSL 59 (1964), fasc. 2, pp. 267-268.

1329. MOÓR Elemér: Bor és szölö (A szölötermelés kialakulása népünknél az idetartozó szókészlet tükrében) (Wine and grape (The formation of Hungarian viticulture as reflected in the relevant vocabulary)] $=\mathrm{NyK} 65(1963)$, pp. $413-423$.

1330. MOÓR Elemér: A betû-tôl a könyv-ig (From the betú ('letter") to the könyv ('book")] = MNy. $\overline{68(1972)}, \overline{\mathrm{pp} .} \overline{150-160}$ and $275 \overline{-285}$.

See No. 1367.

1331. NÉMETH [Gyula], J.: Neuere Untersuchungen über das Wort tábor "Lager" = AL.H 3 (1953), pp. 431-446.

See Nos. $1332-1333$.

1332. NÉM ETH Gyula: Újabb kutatások a tábor sz6 történetéhez [New investigations concerning the history of the word tabor ("camp")] = NyK 56 (1954), pp. 117-128.

See Nos. $1331,1333$.

1333. NÉMETH [Gyula], J.: Die Herkunft des ung. Wortes tábor $=$ ALH 5 (1955), p. 224.

See Nos. $1331,1332$.

1334. NÉMETH Gyula: Nem török eredetü-e úr szavunk? [Is not the Hungarian word úr ("lord") of Turkic origin?] = Pais Emlk. (Budapest, 1956), pp. $358-364$.

1335. NÉMETH Gyula: A tolmács szó történetéhez [On the history of the word tolmács ("interpreter")] = NyK 60 (1958), pp. 127-132.

See Nos. $1336,1337$.

1336. NÉMETH [Gyula], J.: Zur Geschichte des Wortes tolmács "Dolmetscher" = AOH 8 (1958), pp. $1-8$.

See Nos. $1335,1337$.

1337. NÉMETH [Gyula], J.: P. Jyrkänkallio, Zur Etymologie von russ. tolmą "Dolmetscher" und seiner türkischen Quelle. Helsinki, 1952. /StOr. XVII:8./. Review = OLZ 53 (1958), col. 432 .

See Nos. 1335, 1336. 
1338. NÉM ETH Gyula: Egy ótörök jövevényszó a magyarban az állattenyésztés köréböl. Kêrődzik [An Old-Turkic loan-word in Hungarian pertaining to animal husbandry. Kérödzik ("To ruminate")] = MNy. 58 (1962), pp. 30-36. Reviewed by H[ellenbart, Gy.] = UAJb. 35 (1964), pp. 325-326.

1339. NÉMETH Gyula: Kérö, görbe, girhes ["Crumbling", "c rumbly crackling cone", "fragile"] = NyelvtudÉrt. 38 (1963), pp. 188-190.

1340. NÉMETH Gyula: Tarka ["Pied"] = NyelvtudÉrt. 40 (1963), pp. 279-281. See No. 1341.

1341. NÉMETH [Gyula], J.: Eine Benennung für scheckige Tiere bei Türken und Ungarn = ALH 15 (1965), pp. 79-84. [tarka]

See No. 1340 .

1342. NÉMETH Gyula: A bolgár-törökök ácsmestersége a magyar nyelv régi török jövevényszói tükrében [Carpentry of the Bulgar-Turks in the light of the OldTurkic loan-words in the Hungarian language] = Altnapok (1965), p. 1. [gyalu]

See No. 1343.

1343. NÉMETH [Gyula], J.: Das Zimmerhandwerk der Turko-Bulgaren im Spiegel der alttürkischen Lehnwörter der ungarischen Sprachen $=$ AOH 18 (1965), pp. $55-60$. [gyalu]

See No. 1342 .

1344. NÉM ETH [Gyula], J.: Ungarisch tüdő "Lunge" - ein bulgarisch-tiirkisches Lehnwort $=$ ALH $23(1973)$, pp. 1-5.

1345. NÉM ETH [Gyula], J.: Das Wolga-bulgarische Wort baq in Ungarn = Islam Tetkikleri Enstitüsü Dergisi 5 (1973), pp. 165-170.

1346. NÉM ETH [Gyula], J.: Das ungarische Zeitwort győz-ni "siegen" = ALH 24 (1974), pp. 273-275.

1347. NYÍRI Antal: A magyar nyár "aestas" eredetéröl fOn the origin of the Hungarian word nyár "aestas"] $=$ MNy. 60 (1964), pp. 414-423.

See No. 1348.

1348. NYÍRI A[ntal]: Zur Etymologie von ung. nyár "aestas: Sommer" = ALH 15 (1965), pp. 97-110.

See No. 1347.

1349. PAIS Dezső: Bocsát, bocsánik, búcsú ["To pardon", "to be pardoned", "indulgence" $=$ MNy. 43(1947), pp. 200-204.

1350. PAIS Dezső: Turul [a totemized bird of prey] = MNy. 44 (1948), p. 160. See No. 1351 .

1351. PAIS Dezső: Turul. Az Árpád-nemzetség totem-madara [Turul. The totem bird of the Arpad clan J = MNy. 45 (1949), pp. 37-43.

See No. 1350 . 
1352. PAIS Dezső: Magyar tábor, török tapqur (Hungarian tábor ("camp") and Turkic tapqur] $=\mathrm{MNy} .50(1954)$, pp. $167 \overline{-169}$.

See No. 1353.

1353. PAIS, Dezsô: Hongrois tábor. "camp", turc tapqur $=$ ALH 5 (1955), pp. 219223.

See No. 1352 .

1354. PAIS Dezsó: Az úr, szolga és jobbágy szóról (Notes on the words úr ("master"), szolga ("servant"), and jobbágy ("serf") = I.OK 7 (1955), pp. 260-263.

1355. PAIS Dezsö: A búcsú és a szabad. A jövevényszóvá létel és a szókiveszés jelenségéhez (The words búcsú ("indulgence") and szabad ("free"). The phenomena of becoming a loan-word and of becoming an obsolete wordl = MNy. 52 (1956), pp. $265-271$.

1356. PAIS Dezsö, Kégy kéd és aztán kör, söt kor [Kégy kéd, and the kör and kor] $=$ MNy. $54(1958)$, pp. $242-243$.

1357. PAIS Dezsó: A táltos meg az orvos (The tíltos ("shaman") and the orvos ("medicine man") $=\overline{\mathrm{O} . \mathrm{OK}} 12(1958), \mathrm{pp} .261-295$.

1358. PAIS Dezsó: Üldöz, kísért ["To pursue", "to haunt"] = MNy. $56(1960)$, pp. $76-85$.

1359. PAIS Dezsó: Túró ["Curd"l = MNV. $57(1961)$, pp. $221-223$.

1360. PAIS Dezsö: Ćr volt -e valóban Vrsuuru? (Was Vrsuuru really an úr ('lord')? |= MNy. 58 (1962), pp. 133-146.

1361. PAIS Dezsö: Az úr, valamint a bö, gyö és a bán méltóságjelölöink szó- és társadalomtörténetéhez [The lexicologic and social history of the titles úr, bö, gyö and bán $\}=$ NyelvtudÉrt. 38 (1963), pp. 82-123.

1362. PAIS Dezsó: A teker : takar és a KTSz. -beli tacaruta [The words teker: takar ('to wind", "to cover") and tacaruta in the language monument KTSz.] $\overline{\mathrm{MNy}}$. 60(1964), pp. 207-208.

1363. PAIS Dezsö: A Károly "kárvaly" is lehetett (Károly ("Charles") and "karvaly" ('sparrow-haw"'): a possible identityl = MNy. 60(1964), p. 363 .

1364. PAIS Dezsö: Órül: öröl ["To go mad"; "to grind"] = MNy. $60(1964)$, p. 480.

1365. PAIS Dezsö: Tündér ["Fairv"] = MNV. 61 (1965), pp. 289-298.

1366. PAIS Dezsö: A telek "földterület" jelentéstörténete [The semantic history of the word telek "piece of land"] = MNv. 67(1971), p. 512 .

1367. PAIS Dezsó: Moór Elemérnek |A response to Elemér Moñr $\mid=$ MNy. 68 (1972), pp. $383-381$.

See No. 1330 .

1368. PAIS Dezsö: Ål, álnok, alak ["False", "deceitful", "form"l = MNy. $70(1974)$, pp. 257-269. 
1369. PALIÓ Margit, $\mathrm{K}_{.}:$A magyar úr $\mathrm{sz} 6$ eredete [The origin of the Hungarian word úr ("lord")] = MNy. 52 (1956), pp. 157-167.

1370. PALló Margit, K.: 吕, üsző ["To chase", "heifer"] = MNy. 53 (1957), pp. 214-216.

1371. PALLó Margit,K.: "Vr ar Mihal archangal" = MNy. 54(1958), pp. 542-545.

1372. PALIŚ, Margit K.: Die sachlichen Grundlagen der Entlehnung des ungarischen Wortes sárkány (Drache) = AEthn. $6(1958)$, pp. 435-440.

1373. PALLÓ, Margit K.: Zum Problem der ungarischen Wortgruppe ëgyház /igykő, igyfon/; ügyüfa; ünnep, üdvöz; ünnepet ülni = ALH 11 (1961), pp. 163-173.

Reviewed by Sauvageot, A. = BSL 57 (1962), pp. 215-216.

1374. PALLÓ Margit, K.: Var szavunk etimológiájához IOn the etymology of the Hungarian word var ("scab")] = NyK63 (1961), pp. 217-219.

1375. PALLÓ Margit, K.: Gyarló, gyarlandó, gyarlik 「'Frail", "stumbling", "to stumble"] = MNy. $58 \overline{(1962)}$, pp. 487-490.

1376. PALLÓ Margit,K.: Telek "Grund" telek "Riemen" = NytudÉrt. 38 (1963), pp. $191-199$.

1377. PALIÓ Margit, K.: A váj ige és az a aj - áj nomen-verbum összefüggése [The verb váj ('to hollow") and its relation to the nomen-verbum aj-áj] = NyK 65 (1963), pp. 180-184.

1378. PALLÓ, Margit K.: Ein alttürkischer Fachausdruck der Fischerei in den ungarischen Urkunden = UAJb. 35 (1964), pp. 56-63. [ör - "mahlen"]

1379. PALLÓ Margit, K.: A magyar arat ige eredetéról (Notes on the origin of the Hungarian verb a rat ("to reap")] = Altnapok (1965), pp. 6-7.

See No. 1381.

1380. PALLó Margit, K.: Jár ["To go, to walk"] = NyK 68 (1966), pp. 433-436.

1381. PALLÓ [Margit], Margarete K.: Zu den ältesten alttürkischen verbalen Entlehnungen der ungarischen Sprache $=$ AOH 20 (1967), pp. 111-118. [arat-] See No. 1379.

1382. PALLÓ Margit, K.: "Az idó és társai"-hoz [Remarks on the article "The word idő ("time") and its companions"] = NyK 70 (1968), pp. 174-180. See No. 1313.

1383. PALLÓ Margit, K.: Nyargal ["To gallop"] = MNy. 65 (1969), pp. 459-462.

1384. PALló Margit, K.: Váz "madárijesztő" [The word váz "scarecrow"] = Nyr. 93 (1969), pp. $471-474$.

1385. PALLÓ Margit, K.: Megjegyzések a TESz. három címszavához [Notes on three entries in the TESz (Historical etyomological dictionary)] $=\mathrm{NyK} 71$ (1969), pp. 137-141. [gyóz, búza, gyarmat] 
1386. PALLÓ Margit, K.: Csipkeverő, kötélveró, marokverő ["Lace-maker",

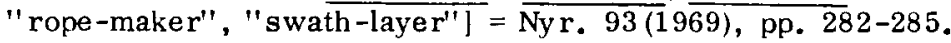

1387. PALLÓ Margit, K.: Agár ["Greyhound"] = Nyr. 94 (1970), pp. 471-474.

1388. PALló Margit, K.: Gyaláz ["To revile"]: MNy. 66 (1970), pp. 333-334.

1389. PALLÓ, Margit K.: Die Herkunft des ung. Wortes harang "Glocke" = UAJb. 42 (1970), pp. 46-52.

1390. PALLÓ Margit, K.: A TESz. arat, ápol, és borít igéjéhez [On the verbs arat ("to reap"), ápol ("to take care of') and borít ('to cover") in the TESz

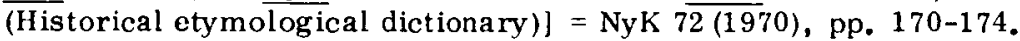

1391. PALLÓ Margit, K.: A Magyar Nyelvjárások Atlasza 78. gaz "mauvaise herbe" térképéhez [Notes on the 78th map: gaz "mauvaise herbe" of The Atlas of the Hungarian Dialects] $=\mathrm{NyK} 72$ (1970), pp. 431-436.

1392. PALLÓ, Margit K.: Ung. gyúl "sich entzünden" und gyújt "anzünden" und ih $r$ türkischer Hinterg rund $=$ StTurc. (1971), pp. 375-383.

1393. PALLÓ Margit, K.: A MSzFE és a TESz árt, ölt, és int szócikkeihez [Notes on the entries árt ("to do harm") ölt ("to stitch") and int ("to beckon") in the MSzFE (Finno-Ugric elements of the Hungarian vocabulary) and the TESz (Historical etymological dictionary)] $=\mathrm{NyK} 74$ (1972), pp. 427-433. [Résumé in F rench]

1394. PALLÓ [Margit], Margarete K.: Zur Etymologie des ungarischen Verbs üdül- $=$ AOH 25 (1972), pp. 405-412.

1395. PALLÓ Margit, K.: Verseny "der Wetteifer" - verseng "wetteifern" = NyK 74 (1972), pp. 197-199.

1396. PALLÓ Margit, K.: A ver és ver ${ }^{2}$ [The homograph ver "to beat" and "to spin"] = MNy. 68 (1972), pp. 294-299.

1397. PALLÓ Margit, K.: Az ondó etimológiájához [Notes on the etymology of the word ondó ("s perm") = MNy. 69 (1973), pp. 480-481.

See No. 1414.

1398. PALLÓ Margit, K.: Tojik ["To lay eggs"] = MNy. 69 (1ə73), pp. 216-217.

1399. PALLÓ Margit, K.: Farkas ordas ["Wolf"] = Nyr. 98 (1974), pp. 348-351.

1400. PALLÓ Margit, K.: Szemmel ver ["To cast an evil eye"] = Nyr. 88 (1974), pp. 236-238.

1401. PALLÓ, Margit K.: Ung. tor "Gastmahl, Bewirtung" zu alttürk. tod-"sich sättigen" = UAJb. 46 (1974), pp. 109-119.

1402. PALLÓ Margit, K.: A N. gyarat "ge rebenez" gyárt $\sim$ gyarapodik igék öszszefuiggése [The relationship between the dialect verb gyarat "to hackle" and the verbs gyárt ("to manufacture") gyarapodik ("to increase")] = MNy. $70(1974)$, pp. 206-209. 
1403. RÁSONYI, L[ászló]: L'origine du hongrois igen "oui" = AOH 25 (1972), pp. 413-414.

1404. SCHƯTZZ Ödön: Néhány örmény eredetû betegségnevỉnkröl. (Az Árpád-kori magyarországi örmények történetéhez) [Some Hungarian names for diseases of Armenian origin. (On the history of the Armenians of Hungary in the age of the Arpads)] = MNy. 54(1958), pp. 450-460. [piszok, kosz, csécs, keh] See No. 1215 .

1405. SCHƯTZ [Ödön], Edmond: Einige Bemerkungen zu den ungarischen Falkennamen = Die Jagd bei den altaischen Völkern. Asiatische Forschungen Bd. 26 (Bonn, 1968), pp. 105-118. [kiköcsén, hélya]

1406. SINOR Dénes: Hajó ["Ship"] = MNy. 57 (1961), pp. 169-1'73. Reviewed by Sauvageot, A. = BSL 58 (1963), pp. 290-291.

1407. SZENDREY Ákos: A magyar néphit boszolkánya [The witch of Hungarian popular belief]. Budapest, 1961. $488 \mathrm{pp}$. /KandÉrt. - Manuscript/. Theses. 1962. $15 \mathrm{pp}$.

1408. SZOLNOKY Lajos: A tiló [The flax-stripper] = NéprÉrt. 47 (1965), pp. 5-66. $+\mathrm{pl}$.

1409. TAKÁCS Lajos: Az irt és arat tárgyi hâtteréhez. [The material background of the word irt ("to root out") and a rat ("cut down")] = MNy. 69(1973), pp. $355-358$.

1410. TÁ LASI István: A magyar nép anyagi kultúrája Európában. (A folyamatos kutatások tükrében) (The material culture of the Hungarian people in Europe. (In the light of successive investigation)] = I.OK 21 (1964), pp. 3-22. [ünöm] See No. 1411.

1411. TÁLASI, I[stván]: Die materielle Kultur des ungarischen Volkes in Europa (Im Spiegel der sukzessiven Forschungen) = Europa et Hungaria (Budapest, 1965), pp. 27-57. [ünöm]

See No. 1410 .

1412. ÚRHEGYI Emilia: Kelengye [ "Trousseau"] = MNy. 63 (1967), pp. 482-486.

1413. VÁSÁRY István: Ászok ["Gauntry"] = MNy. 65 (1969), pp. 462-466.

1414. VÁSÁRY István: Ondó ["Sperm"] = MNy. 69(1973), pp. 88-92. See No. 1397.

1415. VELCSOV Mártonné: Antropometrikus mértéknevek a magyar nyelvben [Anthropometrical measure names in Hungarian] = NyelvtudÉrt. 84(1974). 108 pp. [karl

1416. ZSOLDOS Jenö: Zerge ["Chamois"] = Nyr. 88 (1964), pp. 55-60.

1417. Levélszekrény [Letter box] $=$ Nyr. 74(1950), p. 221. [búbájos]

See also Nos, $318,1046,1047,1204$. 


\section{c/ Onomastics}

1418. BABOSS Ernö: A magyar népnév ősmagyar-kori hangalakjához [On the phonetic form of the ethnony magyar in the old Hungarian period] $=\mathrm{MNy}$. 53 (1957), pp. 438-442.

1419. BÁRCZI, Géza: L'anthroponymie hongroise du Moyen Âge = VII $\mathbf{e}^{\mathbf{e}}$ Congrès International des Sciences Onomastiques (Firenze, 1963), III, pp. 109-124.

1420. BENKÓ Loránd: Árpád-kori személynevek [Personal names in the age of the Árpáds ] = Nyr. 74 (1950), pp. 18-24.

1421. BENKố Loránd: Az anonymusi hagyomány - és a Csepel név eredete [The Anonymus tradition - and the origin of the name Csepel] $=\mathrm{MNy} .62(1966)$, pp. 134-146, 292-305.

1422. BERRÁR Jolán: Nói neveink 1400-ig [Women's names in Hungarian up to $1400]=\mathrm{MNy} .47$ (1951), pp. 154-214.

See No. 1423 .

1423. BERRÁR Jolân: Női neveink 1400-ig: Bizonytalan és is me retlen eredetú nevek (Women's names in Hungarian up to 1400; Names of uncertain and unknown origin l = NévtudVizsg. (1958), pp. 179-190.

See No. 1422.

1424. BLAŠKOVIČ, J[ozef]: Some toponyms of Turkish origin in Slovakia $=$ AOH 27 (1973), pp. 191-199.

1425. CZEGLÉDY Ká roly: Géza nevünk eredete [The origin of the Hungarian name $\underline{\text { Géza }]=~ M N y . ~} 52(1956)$, pp. 325-333.

1426. CZ EGLÉDY Ká roly: A magyar népnév legrégibb elófordulásai a for rásokban [The earliest occurences of the ethnonym magyar in the sources] = Pais Emlk. (Budapest, 1956), pp. 268-275.

1427. CZEGLÉDY Károly: Nyugati türk eredetü méltóságnevek. Termacsu, barsbëg, jebu, baratur [Hungarian titles of Western-Türk origin. Termacsu, barsbëg, jebu, bayatur $]=$ NévtudVizsg. (1960), pp. 119-125.

1428. GAÁL László: Dentiimogyer $[\operatorname{geog} r]=$. MNy. 53 (1957), pp. 27-35.

1429. GYALLAY Domokos: A fehér ló szerepe a székely hagyományban (The role of the white horse in Széktly tradition I = Ethn. 73(1962), pp. 389-399. [Résumé in German]

1430. GYÓRFFY Dezsö: Tokaj nevének eredete [The origin of the name of Tokaj] = Borsodi Szemle 6 (Miskolc, 1962): 5, pp. 42-45.

Contribution by Marjalaki Kiss Lajos = ibid 7(1963):1, pp. 111-112.

1431. GYÖRFFY György: Jegyzetek Anonymus tulajdonneveihez (Notes on the personal names in the Anonymus chronicle $=\mathrm{MNy}$. 47 (1951), pp. 46-50. 
1432. GYÖRFFY György: Török női méltóságnév a magyar kútfókben [Turkic woman's title in Hungarian sources] $=\mathrm{MNy}$. 49(1953), pp. 109-111.

1433. GYÖRFFY György: A magyar törzsi helynevek [Hungarian place-names of tribal origin] $=$ NévtudVizsg. $(1960)$, pp. 27-34.

1434. KÁLMÁN Béla: Béla [prop.] = MNy. 57 (1961), pp. 86-88.

1435. KÁLMÁN, B[éla]: Ortsnamenerklärungen = StSl. 12 (1956), pp. 207-214.

1436. KÁLMÁN Béla: A nevek világa [The world of names]. Budapest, 1967; 2nd ed. 1969; 3rd. ed. 1973. 259 pp.

1437. KÁLMÁN Béla: Elöszállás [geogr.] = MNy. 69(1973), pp. 478-479.

1438. LADÓ János: Magyar utónévkönyv [The book of Hungarian Christian names]. Budapest, 1971. $257 \mathrm{pp}$.

1439. LIGETI Lajos: Török jövevényszavaink és a vitás etimológiák kérdése [Turkic loan-words in Hungarian and the problem of the doubtful etymologies] = Pais Emlk. (Budapest, 1956), pp. 336-346. [Torontál]

1440. LOTZ János: A magyar szó etimológiájának kérdéséhez [On the etymology of the word magyar] = NyK 65 (1963), pp. 385-389.

1441. MARTINKÓ András: Gyarmat [The Hungarian tribal name Gyarmat] = Nyr. 78 (1954), p. 234.

1442. MELICH János: Somló, Somlyó [geogr.] = NytudÉrt. 41 (1963), pp. 101-107.

1443. MELICH János: Kalocsa [geogr.] = NytudÉrt. 41 (1963), pp. 107-111.

1444. MOÓR Elemér: Kükuillő [geogr.] = MNy. 43 (1947), pp. 127-132.

1445. MOÓR Elemér: A magyar népnév eredetének kérdéséhez (Notes on the origin of the ethnonym magyar ] $=$ NyK 54 (1952), pp. 75-95.

1446. MOÓR, E[lemér]: Die Benennungen der Ungarn in den Quellen des IX. und X. Jahrhunderts = UAJb. 31 (1959), pp. $191-229$.

1447. MOÓR Elemér: Pais Dezső elóadásaihoz [Contribution to Dezső Pais's lectures ] $=$ NévtudVizsg. $(1960), \mathrm{pp} .116-118$.

See No. 1457.

1448. NÊM ETH Gyula: A török-magyar törzsnévadás korszakai [The periods of Turkic-Hungarian tribal eponymy] = NyelvtudÉrt. 70 (1970), pp. 229-235.

1449. NÉM ETH [Gyula], J.: Noms ethniques turcs d'origine totémistique = St Turc. (1971), pp. 349-359.

1450. OLAJOS Teréz: Adalék a $/ \mathrm{H} / \mathrm{ung} / \mathrm{a} / \mathrm{ri} / \mathrm{i} / \mathrm{népnév} \mathrm{és} \mathrm{a} \mathrm{késöi} \mathrm{avarkori} \mathrm{etnikum}$ történetéhez [Data on the ethnonym $/ \mathrm{H} / \mathrm{ung} / \mathrm{a} / \mathrm{ri} / \mathrm{i} /$ and the history of an ethnic group of the late Avar period] =AT 15(1968), pp. 87-90.

1451. PAIS Dezső: Dentumoger [geogr.] = MNy. $44(1948)$, pp. 63-64. 
1452. PAIS Dezsó: Nyék törzsneviink és ami köriilötte lehetett [The Hungarian tribal name Nyék and what could have been behind it $]=\mathrm{MNy} .49$ (1953), pp. $\overline{278-2} 93$ and NyelvtudÉrt. 5 (1955), pp. 55-70.

1453. PAIS Dezsö: Bulcsú [prop.] = MNy. 51 (1955), pp. 433-446. See No. 1454.

1454. PAIS Dezsö: Bulcsú [prop.] = MNy. 52 (1956), pp. 139-144. See No. 1453 .

1455. PAIS Dezső: Totem-halmozás Álmos vezér származása köriil? [The totemgrouping related to the birth of the chieftain Álmos?] = MNy. 55 (19.59), pp. 76-80.

1456. PAIS Dezső, Movareprs tehát nem volna "magyar"? [Could the word

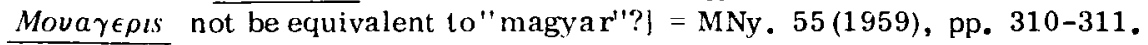

1457. PAIS Dezsó: Szempontok Árpád-kori személyneveink vizsgálatához [Some aspects of the investigation of Hungarian personal names from the age of the Árpáds] = NévtudVizsg. (1960), pp. 93-105.

Reviewed by Kelemen, B. = Cercetări de Lingvistică 6(1961), p. 468. See No. 1447.

1458. PAIS Dezsó: Cotoyd [geogr.] = MNy. 56 (1960), pp. 111-112.

1459. PAIS Dezső: Luby Margitnak. (Régen készült fєllelet egy régi kérdésre) [To Margit Luby. (An answer to an old question written long ago)] $=$ MNy. 57 (1961), p. 515. [Köcsön family name]

1460. PAIS Dezső: Ola [prop.] = MNy. $60(1964)$, pp. 282-290.

1461. PAIS Dezső: Névvizsgálatok a "Zala megve földrajzi nevei" címú kiadvány segitségével [An investigation of names based on the book "Geographical names of Zala county"] = MNy. 62 (1966), pp. 69-72.

1462. PAIS Dezsó: Az ozur és hozzátartozói / The ethnonym oyur and its relatives ] $=$ MNy. 66(1970), pp. 284-293.

See No. 1463.

1463. PAIS, D[ezső]: A propos de l'étymologie de l'éthnique ơur = StTurc. (1971), pp. $361-373$.

See No. 1462 .

1464. PALLÓ Margit, K.: A Töró vezetéknév kapcsán [Some notes on the family name Töröl $=$ MNy. $67 \overline{(1971)}$, pp. 213-216.

1465. RÁSONYI László: A székely név eredete [The origin of the name székely] ] = MNy. 56 (1960), pp. 186-194.

Reviewed by Sauvageot, A. = Revue Internationale d'Onomastique 13 (Paris, 1961), pp. 221-222; Ardeleanu, Elena-Teius, S. = Cercetări de Lingvistică $7(1962)$, p. 367 .

See No. 1.66 . 
1466. RẢSONYI, L[ászló]: L'origine du nom székely (Sicule) = ALH 11 (1961), pp. 175-187.

See No. 1465.

1467. RẢSONYI, L[ászló]: Über die geographischen Namen Tortillou und Tatrang = UAJb. 33 (1961), pp. 245-251.

1468. RÁSONYI Lászlo: Sekeller meselesi = Türk Kültürü 10(1972), pp. 289-294.

1469. REUTER Camillo: Csepel mint személynév [Csepel as a proper name] = MNy. 63 (1967), pp. 359-360.

1470. SIMONYI Dezső: Tárkány helységeink és az avarság (The Hungarian placenames Tárkány and the Avars] = MNy. 64(1968), pp. 438-445.

1471. SINOR Denes: Pusztaszer [geogr.] = MNy. 69 (1973), pp. 482-483.

1472. SZABÓ T. Attila: Koboz [gecgr.] = MNy. 53 (1957), pp. 224-225.

1473. ZSIRAI Miklós: A magyar népnév eredete [The origin of the ethnonym magyar $]=$ NyK $53(1952)$, pp. $64-74$.

See also Nos. $359,360,363,365,367-371,752,1131,1132,1134,1135,1137$, $1138,1341,1350,1351,1363,1559-1567$.

\section{THE HUNGARIAN RUNIFORM SCRIPT}

1474. BENKŐ Elek: Ęy újabb rovásírásos emlék Erdélyböl [A new runic monument from Transylvania] = MNy. 68 (1972), p. 453.

1475. CSALLÁNY Dezsó: Rovásírásos gyưrũk Magyarországon [Rings with runic writing in Hungary] = ArchÉrt. 82 (1955), pp. 79-85. [Résumé in Russian]

1476. CSALLÁNY Dezsó: A székely-magyar rovâsirás emlékei [Monuments of the Székely-Hungarian runic script] = A Nyiregyházi Jósa András Múzeum Évkönyve III. 1960 (1963), pp. 39-135. [Résumé in German]

1477. CSALLÁNY Dezső: A székely-magyar rovásírás történetéhez lOn the history of the Székely-Hungarian runic script] = ArchÉrt. 93 (1966), pp. 36-46. [Résumé in Gerinan]

1478. CSALLÂNY Dezső: Székely-magyar rovásjelek Bonyháról [Székely-Hungarian runes from Bonyha] $=$ ArchÉrt 94 (1967), pp. 198-199. [Résumé in Russian]

1479. CSALLÁNY Dezső: A magyar és az avar rovásírás [The Hungarian and the Avar runic script] = A Nyiregyházi Jósa András Múzeum Évkönyve 11 (1968), pp. 281-307. [Résumé in German]

1480. CSALLÁNY Dezső: Rovásírásos emlékek a Ká rpát-medencében [Runic monuments in the Carpathian Basin] = A Nyiregyházi Jósa András Múzeum Évkönyve 12-14 (1969-1971), pp. 135-160. 
1481. ERDÉLYI, I[stván]: Novaja runiCeskaja nadpisj iz Vengrii = Êpigrafika Vostoka 13 (1958), pp. 59-61.

See No. 1482.

1482. ERDÉLYI István: Új magyarországi rovásfelirat [A new runic inscription in Hungary] = ArchÉrt. 88 (1961), pp. 279-280.

See No. 1481.

1483. ERDÉLYI István: Türk rovásírásos felirat Környéröl [Türk runic inscription from Környe] = AT 16 (1969), pp. 209-210.

1484. ERDÉLYI, I[stván]: Hungary's Vinland Map = AEthn. 21 (1972), pp. 347-352.

1485. GYÖRFFY György: A magyar rovásírás [The Hungarian runic script] = ÉlTud. $19(1964)$, pp. $272-275$.

1486. [KIRÁLY Péter] Kiraj, Peter: K voprosu o glagoliCeskich pisjmenach v sisteme drevnevengerskich runiceskich znakov = Konstantin Kiril filosof.

Dokladi ot simpoziuma, posveten na 1100-godišninata ot smărtta mu (Sofia, 1971), pp. 205-213.

1487. LÁSZLÓ, Gyula: Die Anfänge der ungarischen Münzprägung = AnnHist. 4 (1962), pp. 27-52.

See No. 1488.

1488. LÁSZLÓ Gyula: A magyar pénzverés kezdeteiröl [Beginnings of Hungarian minting] = Száz. 97 (1963), pp. 382-397.

See No. 1487.

1489. MUSNAI László: Rovásírásos emlékeink [Runic monuments of Hungary] = MNy. 63(1967), pp. 73-76.

1490. NÉMETH Gyula: A székely írás egy új emléke: a homoródka rácsonyfalvi felirat ( A new monument of the Székely writing: the inscription at Homoródka rácsonyfalva $]=\mathrm{MNy} .41(1945), \mathrm{pp} .11-16 .+2 \mathrm{pl}$.

1491. PAIS Dezsó: A székely-derzsi rovásírásos tégla kora [Dating the brick with runic script from Székely-derzs] = MNy. 48 (1952), pp. 88-89.

1492. PÜSPÖKI NAGY Pêter: A felsőszemerédi rovásemlék [The runic monument of Felsőszemeréd] = Irodalmi Szemle (Bratislava, 1968), pp. 731-741. See Nos. 1493, 1494, 1495.

1493. PÜSPÖKI NAGY Pêter: A felsószemerédi rovásemlék [The runic monument of Felsőszemeréd]. Budapest, 1971,22 pp. / A Magyar Nyelvtudományi Társaság Kiadványai. 126./.

See Nos. $1492,1494,1495$.

1494. PÜSPÖKI NAGY Pêter: A felsószemerédi rovásemlék [The runic monument of Felsőszemeréd] = MNy, 67 (1971), pp. 1-17.

See Nos. $1492,1493,1495$. 
1495. PƯSPÖKI NAGY Pêter: Adalék a felsőszemerédi rovásemlêk történetêhez [Notes on the history of the runic monument of Felsószemered] $=\mathrm{MNy}, 67$ (1971), pp. 205-207. See Nos. $1492,1493,1494$.

1496. [VÁSÁRY] István, Vásárhelyi [sic!]: A török és a magyar rovásírás [Turkic and Hungarian runic script] $=$ ÉlTud. 28 (1973), pp. $51-55$.

1497. VÉRTES O. András: A bilabiális pergó hang magyar rovásjegyének eredete [The origin of the Hungarian runic symbol of the bilabial whirling sound] $=$ MNy. 57 (1961), pp. 207-208. Correction = ibid. p. 516 .

See also Nos. $227,634-638$.

\section{RELICS OF SHAMANISM IN HUNGARY}

1498. DIÓSZ EGI Vilmos: A viaskodó táltosbika és a sámán állatalakú életlelke [The struggling magic bull and the shaman's animal shaped life-spirit] = Ethn. 63 (1952), pp. 308-357. [Résumé in Russian and French]

See No. 1499.

1499. DIÓSZEGI, Vilmos: $\mathrm{K}$ voprosu o borjbe gamanov $\mathrm{v}$ obraze żivotnych $=\mathrm{AOH}$ 2 (1952), pp. 303-314.

See No, 1498 .

1500. DIósZEGI Vilmos: A honfoglaló magyar nép hitvilága ("ósvallásunk") kutatásának módszertani kérdései (Methodological problems in investigating the religious beliefs of the first Magyar settlers of Hungary] = Ethn. 65 (1954), pp. 20-68. [Résumé in Russian and English]

1501. DIÓsZEGI Vilmos: A sámánhit emlékei a magyar népi mûveltségben [Relics of shamanism in Hungarian popular culture]. Budapest, 1958. 472 pp. + $11 \mathrm{pl}$. Reviewed by Sandor I. = IndexEthn. $3(1958)$, p. 29; Vargyas, L. = AEthn. 7 (1958), pp. 439-440; Ákos K. = Valóság 1959:2, pp. 106-107; Paulson, I. = Ethnos 24 (1959), pp. 225-227; Sebeok, Th. A. = American Anthropologist 1959, pp. 313-314; Kodolanyi, J. = Demos 1960, p. 198; Köhalmi, K. = AOH $10(1960)$, pp. 314-317; Lükó $G_{\text {. }}=$ NyK $62(1960)$, pp. 199-208 and Anthropos 1960, p. 253; Klaniczay T. = Itk. 1962:1, p. 125; Schellbach, I., Zwei Standardwerke der ungarischen Folkloristik = FUF 34 (1962), pp. $100-$ 111.

See Nos. $1502,1503,1515$.

1502. DIÓSZEGI, Vilmos: Die Überreste des Schamanismus in der ungarischen Volkskultur = AEthn. 7 (1958), pp. 97-134. See Nos, $1501,1503$. 
1503. DIÓSZ EGI Vilmos: A sámánhit emlékei a magyar népi múveltségben [Relics of Shamanism in Hungarian popular culture]. Budapest, 1959. /KandÉrt. Manuscript/. - Theses 1959.

See Nos. $1501,1502$.

1504. DIÓSZEGI,Vilmos: Die Elemente des Schamanismus in der ungarischen Volkskultur $=$ Anth ropos $55(1960)$, p. 253.

1505. DIÓSzEGI Vilmos: A magyar néphagyomány és a sámánhit kapcsolatai [Connections between Hungarian popular tradition and Shamanism] $=\mathrm{Mu}$ veltség és hagyomány I-II (Debrecen, 1960), pp. 269-292. [Résumé in German ]

Reviewed by Vincze, I. = AEthn. $11(1962)$, p. 227.

1506. DIÓSZEGI Vilmos: Samanizmus [Shamanism]. Budapest, 1962, 118 pp., 12 pl. /Élet és Tudomány kiskönyvtár. 26./.

1507. DIósZEGI Vilmos: A magyar ósvallas nyomában [On the track of the ancient Hungarian religion] = Világosság $5(1964): 11$, pp. $672-679$.

1508. DIÓSZEGI Vilmos: A pogány magyarok hitvilága [Religious beliefs of the pagan Hungarians]. Budapest, 1967. $142 \mathrm{pp}$. and $14 \mathrm{pl}$./ Kórösi Csoma Kis könyvtár. 4./.

Reviewed by Kodolányi, J. = A Ethn. 18 (1969), pp. 417-418; Kóhalmi, K. U. = AOH 23 (1970), pp. 139-140.

1509. DIÓSZ EGI, Vilmos: Hungarian contributions to the study of shamanism = Mưveltség és hagyomány XIII-XIV (Debrecen, 1971), pp. 553-566.

1510. DIÓSZEGI Vilmos: A samanizmus-kutatás történeti tanulságai (A honfoglaló magyar hitvilág történeti rétegei) (Historical conclusions on the investigation of shamanism (The historical layers of the religious beliefs of the conquest-period Hungarians)] = Népi kultúra - népi társadalom $5-6$ (1971), pp. 344-351.

1511. DIÓSZEGI Vilmos: Az ősi magyar hitvilág. Válogatás a magyar mitológiával foglalkozó XVIII-XIX. századi mũvekből. Szerk. -- [Ancient Hunga rian religious beliefs. A selection from 18 th and 19 th century works on Hungarian mythology. Edited by --1. Budapest - Bratislava, 1971.

1512. GUNDA, B[éla]: Totemistische Spuren in der ungarischen táltos-Überlieferung $=$ Glaubenswelt (1963), pp. 45-56.

1513. KODOLÂNYI János, ifj. [jun]: A táltos a magyar néphagyományban [The táltos ("shaman") in Hungarian folklore] = Ethn. 56 (1945), pp. $31-37$.

1514. LÁSZLÓ Gyula: A népvándorlás lovasnépeinek ősvallása [Religious beliefs of the nomads of the migration period]. Kolozsvár 1946. 45 pp. Erdélyi Tudományos Intézet.

Reviewed by Diószegi Vilmos = Ethn. 60 (1949), pp. 339-341. 
1515. LÁSZLó Gyula: A magyar táltos alakjáról. Jegyzetek Diószegi Vilmos: A sámánhit emlékei a magyar népi múveltségben c. könyvếhez [On the Hungarian shaman. Notes on Vilmos Diószegi's "Relics on shamanism in Hungarian popular culture"] = Ethn. $70(1959)$, pp. 446-449. See No 1501.

1516. LÁSZLÓ Gyula: A honfoglalókról. Dísszegi Vilmos emlékének [The conquestperiod Hungarians: in memoriam Vilmos Diószegi]. Budapest, 1973. 76. pp. /Történelemtudomány - történelemtanítás/.

1517. LƯKÓ Gábor: Samanisztikus eredetũ ráolvasások a románoknál [Incantations of shamanic origin among the Rumanians] = Ethn. $72(1961)$, pp. 112-134.

1518. MÁNDOKI Lászlo: Szalmásút ["Strawy-way" (Milky Way)] = Pécsi Janus Pannonius Múzeum Évkönyve 1962 (1963), pp. 287-302.

1519. MÁNDOKI László: Honfogla lás elötti hitvilágunk emléke egy szólásban "Sokan vannak odakinn" [A relic of pre-conquest Hungarian religious beliefs in the idiom "Many (persons) are outside"] = Pécsi Janus Pannonius Múzeum Évkönyve $1967 \mathrm{pp}$. 75-79.

See also Nos. $990,991,975,1019,1020,1285,1286,1357$.

\section{RELICS OF ANCIENT POETRY}

1520. KATONA, Imre: Historische Schichten der ungarischen Volksdichtung. Helsinki, 1964. 36 pp.

1521. KEPES Géza: A magyar ösköltészet nyomairól [On the relics of ancient Hunga rian poetry] = ItK 68 (1964), pp. 1-21 and 171-172. [Résumé in English]

1522. Ósköltészet [Ancient poetry] = A magyar irodalom története 1600-ig (Budapest, 1964), pp. 11-32.

1523. LIGETT Lajos: Hozzászólás Tolnai Gábor"A realizmus kérdései ês a régi magyar irodalom" c. előadásához [Contribution to G. Tolnai's lecture "The problems of realism and Old Hungarian literature"] $=$ A realizmus kérdésel a magyar irodalomban (Budapest, 1956), pp. 85-89.

1524. LÓRINCZ László: A honfogla lás előtti magyar eposz kérdése (The question of the Hungarian epic in the preconquest period] = Keletkutatas 1973 (Budapest, 1974), pp. 27-35.

1525. LỨKó Gábor: A magyar népdalszövegek régi stగllusa [The archaic style of the texts of the Hungarian folk-songs] = Népr. Ért. 39 (1957), pp. 5-46. [Résume in Russian and English] Reviewed by Katona, Imre = Demos 3 (1962), pp. 97-98.

1526-27. VARGY AS Lajos: Szibériai hósének-elemek a magyar népmesekincsben [Siberian heroic epic elements in Hungarian folk-tales]=NéprKözl. 6:1 (1961), pp. 3-15. 


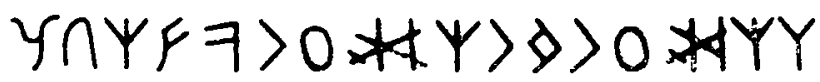 \\ Fix. V. Mank-inmeription 1 .}

\section{YXW}

Wig. VI. Fladindoription I1. (from Stribuk)

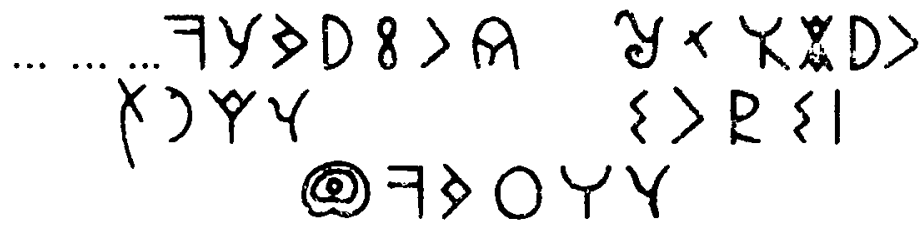

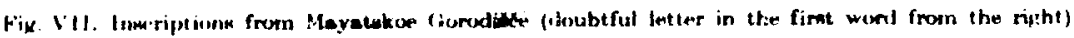

$$
\begin{aligned}
& \begin{array}{llllllllllllll}
14 & 13 & 12 & 11 & 10 & 9 & 8 & 7 & 6 & 5 & 4 & 3 & 2 & 1
\end{array}
\end{aligned}
$$

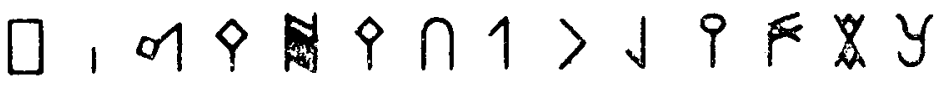

$$
\begin{aligned}
& \stackrel{\alpha}{\alpha} \\
& \text { or }
\end{aligned}
$$

From "The rumiform inscriptions from Nagy-Szent-Miklós and the runiform scripts in Eastern Europe." by J. Németh

(in ALH 21 (1971). See No. 644.) 
VI.

\title{
TURCO-HURGARAN RELATIONS IN THE RAIDDLE AGES
}

\author{
GENERAL WORKS
}

1528. GYÖRF FY György: A Vinland-térkép és a tatárföldi jelentés [The Vinlandmap and the Tatar relation] = ÉlTud. 24 (1969), pp. 291-294.

1529. GYÖRFFY György: Koppány lázadása [Koppány's revolt] = Somogy megye multjáb́́l (Kaposvár, 1970), pp. 5-30.

See No. 1530.

1530. GYÖRFFY, Gy[örgy ]: Der Aufstand von Koppány = StTurc. (1971), pp. $175-$ 211.

See No. 1529.

1531. GYÖRFFY, György: H.G.Göckenjan, Hilfsvölker und Grenzwächter im mittelsiterlichen Ungarn. Wiesbaden, 1972. Review = Südost-Forschungen 33 (1974), pp. 379-380.

1532. MOLNÁR Erik: A magyar társadalom története az Á rpád-kortól Mohácsig [A history of Hungarian society from the Arpadian age until the Battle of Mohács]. Budapest, 1949. 370. pp.

See also Nos. 377, 1099.

1. PECHENEGS AND CUMANS IN HUNG ARY
a/ Pochenegs

1533. ARTAMONOV, M. 1.: A magyarok te a besenyök /The llungarians and the rechenegs $]=$ SzRég. $20(1963)$, pp. $91-114$. 
1534. GYÖRFFY György: A besenyő nyelv emlékei [Relics of the language of the Pechenegs] = Altnapok (1965), p. 10.

See No. 1535.

1535. GYÖRF FY,G[yörgy]: Monuments du lexique petchénègue = AOH 18 (1965), pp. 73-81. Review $=$ Byzantion 35 (1965), pp. 369-370.

See No. 1534.

1536. GYÖRFFY György: A besenyők európai honfoglalásának kérdéséhez [The question of the Pecheneg European conquests] = TörtSz. 14 (1971), pp. 281-288.

See No. 1537.

1537. GYÖRFFY, Gy[örgy]: Sur la question de l'établissement des petchénègues en Europe $=\mathrm{AOH} 25(1972)$, pp. 283-292.

See No. 1536.

1538. NÉMETH, Gy[ula]: Peçenek ve Kumanların dili. Geviren J. Eckmann = TD sayı 14-15 (1950), pp. 98-106.

See also Nos, $373,549-557,643$.

\section{b/ Cumans}

1539. CZEGLÉDY Károly: A kunok eredetéról [On the origin of the Cumans] = MNy. 45 (1949), pp. 43-50.

1540. GYÖRFFY György: A kun és komán népnév eredetéhez [Notes on the origin of the ethnonyms kun and koman] = Antiquitas Hungarica 2 (1948), pp. 158-176. /A magyar táj és népismeret könyvtára 11./.

1541. GYÖRFFY György: A kunok feudalizálódása [The feudalization of the Cumans] = Tanulmányok a parasztság történetéhez Magyarországon ( $\mathrm{Bu}-$ dapest, 1953), pp. 248-275.

1542. GYÖRFFY György: A palócok eredete [The origin of the Palóc] = A palóc etnikum kialakulása. Módszerek ês feladatok (Eger, 1968), pp. 49-56.

1543. HAZAl György: A kun Miatyánk [The Cuman Lord's prayer] = ÉlTud. 18 (1963), pp. 459-460.

1544. HAZAI György: Milyen volt a kunok nyelve? [What was the language of the Cumans like?] = Rádiólexikon (1964), pp. 156-158.

1545. MÁNDOKY István: Nêhány kun eredetû́ nagykunsági tájszó [= Some dialect words of Cuman origin from Nagykunság ("Great Cumania")] = NyK 73 (1971), pp. 365-385. [Résumé in English]

1546. MÁNDOKY K. István: A hantos-széki kunok [The Cumans of Hantos-szék] = Székesfehérvár évs zázadi. 2. Középkor (Székesfehérvár, 1972), pp. 73-82. 
1547. MÁNDOKY István: A kun Miatyánk [The Cuman Lord's prayer] = Szolnok Megyei Múzeumi Évkönyv 1973 (Szolnok, 1973), pp. 117-125.

1548. MÁNDOKY István: A kun nyelv [The Cuman language] = Karcagi Várostörténeti Tanulmányok. Nagykunsági Füzetek I. (Karcag, 1974), pp. 35-44.

1549. MẢNDOKY [István], É.: Der Wandel zweier Konsonanten in der ungarländischen komanischen Sprache $=$ Protokollband (1974), pp. 391-395.

1550. NÉM ETH Gyula: Kun László király nyógérei [The Neugeri of king Ladislaus [V "the Cuman"] = MNy. 49 (1953), pp. 304-318.

See Nos. $1551,1552$.

1551. NÉMETH [Gyula], J.: Wanderungen des mongolischen Wortes nökür "Genosse" = AOH 3 (1953), pp. 1-23.

See Nos. $1550,1552$.

1552. NÉMETH [Gyula], J.: Eine türkish-mongolische Wortsippe und ih re ungarischen Beziehungen $=\mathrm{AOH} 15$ (1962), pp. 211-218.

See Nos. $1550,1551$.

1553. TÁLASI István: Egy kun Miatyánk-változat [A variant of the Cuman Lord's prayer] $=$ MNy. $43(1947)$, pp. 63-64.

1554. TÁLASI István: A magyarországi kunok etnikumához. (Hozzászólás Ju. V . Bromlej elöadásához) [Some comments on the Cumans as an ethnic group in Hungary. (Comments on the lecture of Ju. V. Bromlej)] = Népi kulturra Népi tá rsadalom (Budapest, 1971), pp. 485-490.

See also Nos. $552,643,1147,1155,1538$.

\section{$\alpha /$ Cuman onomastics}

1555. FEHÉRTÓI Katalin: Egy kis névvonatkoztatás [A small onomastic reference] $=$ MNy. 68 (1972), pp. 214-216. [Telebuga, Nohaj prop.]

1556. MIK ESY Sándor: Súr és Dáka [Súr and Dáka (place names)] = Ny r. $94(1970)$, pp. $242-244$.

1557. NÉMETH [Gyula], Julius: Reise um zwei kiptchakische Ortsnamen in Ungarn = UAJb. 33 (1961), pp. 122-127 [Karcag and Debrecen]

See Nos. 1558.

1558. NÉME'TH [Gyula], J.: Dva kipčakskich geograficeskich nazvanija v Vengrii. = Issledovanija po tjurkologii (Alma-Ata, 1969), pp. 26 -34 [Karcag and Debrecen ]

See No. 1557.

1559. RÁSONYI László: Mit mondanak Szolnok megye földrajzi nevei (What do the geographical names of the county of Szolnok indicate? ] = Jászkunság 3 (1956), pp. $75-80$. 


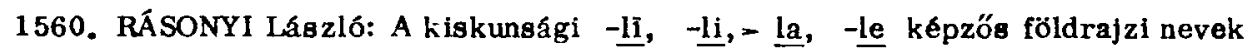
[Geographical names of the Kiskunság formed with suffixes $-\underline{1 i},-\underline{i}=-\underline{\text { a }}$, $-\underline{\text { le }]}=\mathrm{MNy} .52(1956)$, pp. 52-61.

1561. RÁSONYI László: Köncsög és Kötöny [prop.] = Pais Emlk. (Budapest, 1956), pp. 435-440.

1562. RÁSONYI, L[ászló]: Les noms toponymiques comans du Kiskunság = ALH 7 (1957-1958), pp. 73-146.

Reviewed by Kuryłzanov = IzvAN Kazachskoj SSR Ser. Fil. 1960, pp. 94-97.

1563. RÁSONYI László: Tantó [prop.] = MNy. 54 (1958), p. 545.

1564. RÁSONYI, L[ászló]: Kiskunság'da Kumanca yer adları = Németh Armał̆anı (Ankara, 1962), pp. 341-352.

See No, 1565.

1565. RÁSONYI László: A Kiskunság középkori helyneveihez [Notes on the medieval place-names of Kiskunság] = MNy. 62 (1966), pp. 164-170.

See No. 1564.

1566. RÁSONYI, L[ászló] : Kuman özel adları = Türk Kültürü Arastırmaları 3-6 (1966-1969), pp. 71-144.

1567. RÁSONYI, L[ászló]: Les anthroponymes comans de Hongrie = AOH $20(1967)$, pp. 135-149.

1568. SƯTó József: Kalapár [geogr.] = MNy. 44 (1948), pp. 65-66.

See also Nos. $359-361,363-371,752,1419,1420,1422-1424,1458,1461$.

\section{$\beta /$ The Alan Glossary}

1569. FEKETE, L[ajos]: Eine Konskription von den Jassen in Ungarn aus dem Jahre $1550=$ AOH $11(1960)$, pp. 115-143+3 pl.

1570. NÉMETH Gyula: Egy jász szójegyzék az Országos Levéltárban [A Jas glossary in the National Archives] $=1$. OK $12(1958)$, pp. $233-259+2$ pl. See Nos. $1571,1572,1573$.

1571. NÉM ETH Gyula: A jász szójegyzékhez [Additional notes on the Jas glossary] $=$ I. OK $13(1958)$, pp. 485-486.

See Nos. $1570,1572,1573$.

1572. NÉM ETH [Gyula], J.: Eine Wörterliste der Jassen, der ungarländischen Alanen. Berlin, 1959, 36 pp. +11 pl. /Abhandlungen d. Deutschen Akademie d. Wissenschaften zu Berlin, Klasse f. Sprachen, Literatur und Kunst, Jg. 1958, Nr. 4./.

Reviewed by Bouda, K. = OLZ 56 (1961), cols. 74-76.

See Nos. 1570, $1571,1573$. 
1573. NÉM ETH [Gyula], J.: Spisok slov na jazyke jasov, vengerskich alan. Ordžonikidze, 1960, 16 pp. /Severo-osetinskij Naurno-issledovatelskij Institut/. See Nos. $1570,1571,1572$.

\section{ISMAELITES IN HUNGA RY}

1574. CZEGLÉDY Ká roly: Az Árpád-kori mohamedánokról és neveikról [The Muslims and their names in the age of the Arpads] = NyelvtudÉrt. 70(1970), pp. 254-259.

1575. CZEGLÉDY Ká roly: Jerney János a magyarországi izmaelitákról [János Jerney on the Ismaelites in Hungary. Published by --1 . Budapest, 1971. Körösi Csoma Társaság. [Without pagination]

1576. HRBEK, I.: Ein a rabischer Bericht über Ungarn. Abū Hāmid Al-Andalusī Al-Garnāţi, 1080-1170 = AOH 5 (1955), pp. 205-231.

1577. SZÉKELY, Gy[örgy]: Les contacts entre Hongrois et Musulmans aux IX ${ }^{\mathbf{e}}$ $\mathrm{XII}^{\mathrm{e}}$ siècles $=$ The Mustim East (1974), pp. 53-74. 


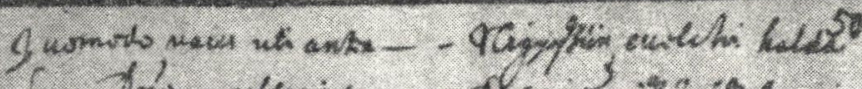

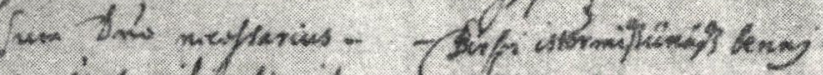

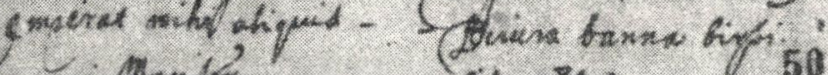

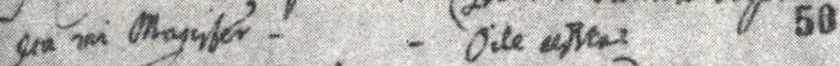

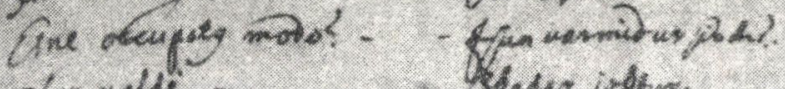

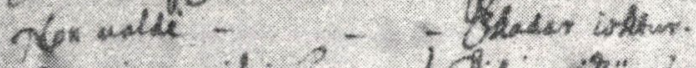

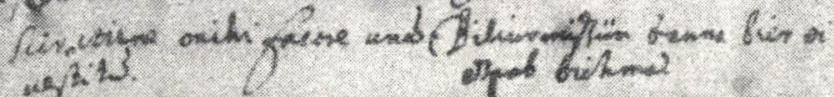

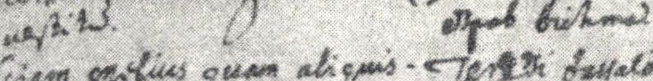

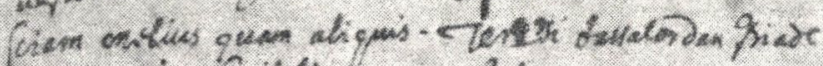
Lotst ni furits: Beliurum

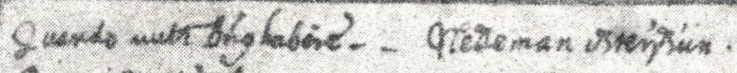

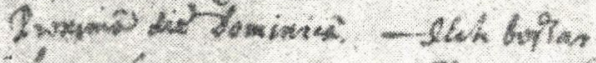

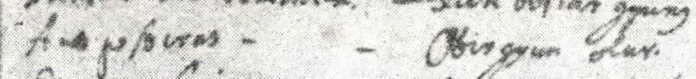

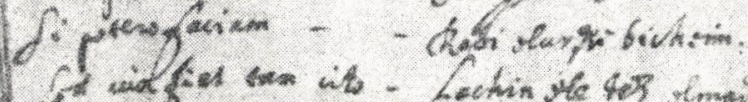

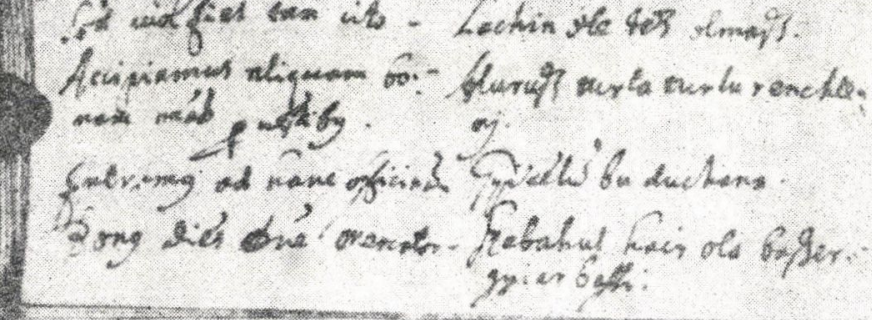

From "Die türkische Sprache in Ungarn im siebzehnten Jahrhundert" by J. Németh. Budapest-Amsterdam, 1970.

(See No. 697.) 


\title{
VII. \\ THE PERIOD OF THE OTTOMAN CONQUEST
}

\author{
1. HISTORICAL AND CULTURAL RESEARCHES \\ BASED ON TURKISH SOURCES
}

a/ Early Ottoman Turkish - Hungarian contacts (before 1526)

1578. HAZAI György: A Topkapu Szeráj Múzeum levéltá rának magyar vonatkozású török iratai (Documents concerning Hungary in the Topkapı Sarayı Muzesi A rchive ] = LK 26 (1955), pp. 286-295.

1579. HAZAI, Glyörgy]: Die Urkunde des Friedensvertrags zwischen König Mathias Corvinus und dem türkischen Sultan 1488 = Beiträge zur Sprachwissenschaft, Volkskunde und Literaturforgchung (Steinitz-Festschrift), Berlin 1965, pp. $141-145+2$ pl.

1580. HAZAI [György], Georg: Eine türkische Urkunde zur Geschichte der ungarisch-türkischen Beziehungen im XV. JH. = UAJb. 36 (1965), pp. 337-339 +2 pl.

1581. HAZAI, G[yörgy]: Onbeginci yüzyıl sonlarında Macar-Türk diplomatik münasebetleri uistüne $=$ VII. Türk Tarih Kongresi, Ankara, 25-29 Eylül 1970 . Bildiri Özetleri (Ankara, 1970), pp. 47-48. See No. 1582.

1582. HAZAI, G[yörgy]: XV. yüzyıl sonlarında Macar-Türk diplomatik ilişkileri üzerine = VII. Türk Tarih Kongresi, Ankara, 25-29, Eylül 1970. Kongreye sunulan Bildiriler, II Cilt (Ankara, 1973), pp. 596-601.

See No. 1581 .

1583. TARDY, Lajos: Ungarns antiosmanische Bündnisse mit Staaten des Nahen Ostens und deren Vorgeschichte $=$ Anatolica 4 (1971-72), pp. 139-156. 
b/ Ottoman sources in Hungary: edition of sources

$\alpha /$ Administrative and economic documents, letters etc.

1584. BENDA Kálmán: Gustav Bayerle, Ottoman Diplomacy in Hungary. Letters from the Pashas of Buda 1590-1593. Indiana University Bloomington, 1972. Review $=$ Száz. 108 (1974), pp. 733-735.

1585. FEHÉR, G[éza] : Macaristanla ilgili XVI. yüzyıldan kalma bir yazıt = Bilimsel Bildiriler 1966 (Ankara, 1968) pp. 165-169.

1586. FEHER, G[éza]: Kanunî'nin Macaristanla ilgili iki yazıtı = Önasya $5 / 50$ (1969), p. 5 .

1587. FEHÉRVÁRI Gyula: Az "Egri fetihname" az isztanbuli Topkapi Szeráj Múzeumban [The "Fetihname of Eger" in the Topkapı Sarayı Muzesi, Istanbul = Az Egri Múzeum Évkönyve 6 (1968), pp. 155-176.

1588. FEKETE, L[ajos]: Die Siyăqat-Schrift in der turkischen Finanzverwaltung. Beitrag zur türkischen Paläographie mit 104 Tafeln. Erster Bend. Einleitung, Textproben. Zweiter Band. Faksimiles. Budapest, 1955. 1. Bd. 910. pp. 2. Bd. 104 pls. /BOH 7./.

Reviewed by Hazai György = AOH 5 (1955), pp. 335-340, MTud, 1 (1956), pp. 452-453, I. OK 9(1956), pp. 217-224; Scheel, H. = ZDMG 106 N. F. 31 (1956), pp. 388-389; Kakuk Zsuzsa = NyK 59 (1957), pp. 277-278; Káldy-Nagy Gyula $=$ LK (1958), pp. 259-261; Perényi Jozsef = Szá. 90 (1956), pp. 269-271, Acta Historica 5 (1958), pp. 189-192.

See No. 1589.

1589. FEKETE Lajos: A siyāqat írástípus a török pénzưgyigazgatásban [The Siyāqat script of the Turkish financial administration] $=$ I. OK 8 (1956), pp. 1-83. See No. 1588.

1590. FEKETE Lajos - KÁLDY -NAGY Gyula: Budai török számadáskönyvek 15501580. Közzétették -- [The Turkish account books of Buda 1550-1580. Ed. --l. Budapest, 1962. 659. pp. Rewieved by: Hazai Gy = NyK 65 (1963), pp. 486-487 and UAJb. $35(1964)$, pp. 432; Décsy, Gy. = UAJb. 35 (1964), p. 122; Hegyi, Klára = AOH $17(1964)$, pp. 352-354; Gerő Gy.=ArchÉrt. 92 (1965), p. 105; Sinkovics I. = Száz. 103 (1969), pp. 112-116.

See No. 1591.

1591. FEKETE, L[ajos] - KÁLDY-NAGY, Gy[ula]: Rechnungsbücher türkischen Finanzstellen in Buda (Ofen) 1550-1580. Türkischer Text. Hrag. --. Budapest, 1962,838 pp. $+4 \mathrm{pl}$. 
Reviewed by Bálint Sándor = AUSz.SEL $7(1963)$, p. 183; Hazai György = NyK 65 (1963), pp. 486 487; Björkman, W. = OLZ 59(1964), cols. 587-590; Braun, H. = UAJb. $35(1964)$, pp. $431-432$; Hegyi, Klára = AOH $17(1964)$, pp. 352-354; Levis, B. = BSOAS 28 (1965), pp. 155-156; Scheel, H. = ZDMG 115 (1965), pp. 380-381; Sinkovics István = AHist. 14 (1968), pp. 199-205; Heyd, U. = Oriens 21-22 (1968-69), pp. 476-477. See No. 1590.

1592. FEKETE Lajos: A hatvani szandzsák 1550. évi adóösszeírása [The tax register of the sanjăq of Hatvan from 1550]. Jászberény, 1968. 89. pp. + 12 pl. /Jászsági Füzetek. 4./.

Reviewed by Kóhegyi Mihály = Ethn. $82(1970)$, pp. 608-609 and Száz, 106 (1972), pp. 474-475.

1593. GYÓRFFY Lajos: Adatok az Alföld törökkori telepiiléstörténetéhez (Az 1571 es szolnoki török defter fordítása) [Data on the history of the settlement of the Alfold under Ottoman-Turkish rule. (Tanslation of the Turkish defter of Szolnok from 1571)]. Szolnok, 1956, 63. pp. /Jászsági füzetek. 4./.

1594. HAZAI György - FEHÉR Géza: A Jászság hódoltságkori történetének török forrásai [Ottoman-Turkish sources on the history of the Jászság during Ottoman occupation] = Jászkunság 8 (1962), pp. 57-62.

1595. KÁLDY-NAGY Gyula: Baranya megye XVI. századi török adóösszeírásai [Ottoman-Turkish tax-rolls of the county of Baranya in the 16th century]. Budapest, 1960. 144. pp. /MNyTK 203./.

Reviewed by Köhegyi Mihály = Ag rártörténeti Szemle 1962. pp. 344-345; Fehér Géza = BiblOr. 21 (1964), p. 380; Győrffy Lajos = Ethn. 76(1965), pp. 623-624.

1596. KÁLDY -NAGY [Gyula], J.: Two Sultanic Hãșs estates in Hungary during the XVIth and XVIIth centuries $=$ AOH $13(1961)$, pp. $31-62$.

1597. KÁLDY-NAGY [Gyula], J.: The cash book of the Ottoman treasury in Buda in the years $1558-1560=\mathrm{AOH} 15$ (1962), pp. 173-182.

1598. KÁ LDY-NAGY Gyula: Török adólajstrom Baranyából a XVI. századból [An Ottoman-Turkish tax-roll of Baranya from the 16 th century] = Szigetvári Emlk. (Budapest, 1966), pp. 115-155.

1599. KÁLDY-NAGY, Gyula: Die türkischen Steue rkonskriptionen der Gegend von Szigetvár aus dem XVI. Jah rhundert = AnnHist. 9(1967), pp. 261-271. Reviewed by: N. Kiss István = Ag rártörténeti Szemle 13 (1971), pp. 583-584.

1600. KÁLDY-NAGY Gylula|: 1541-1566. A török hódítók első rendelkezései. Törökból forditotta -- [The first ordinances of the Ottoman conquerors. Translated from the Turkish --] = Magyar történeti szöveggyújtemény II $/ 1$. 1526-1790. (Ed. Sinkovics István, Budapest, 1968), pp. 41-48. 
1601. KÁLDY-NAGY Gy[ula]: 1577. Török adôöss zeírấs Szeged vá ros Szentmiklós és Madaras utcájának adófizetőiröl. Törökből fordította -- [Ottoman-Turkish tax levies on the taxpayers of Szentmiklos Street and Madaras Street in the town of Szeged. Translated from the Turkish by --] = Magyar törteneti szöveggyûjtemény II/1. 1526-1790. (Ed. Sinkovics István, Budapest, 1968), pp. 181-185.

1602. KÁLDY-NAGY, Gyula: Kanuni devri Budin tahrir defteri (1546-1562). Anka$\mathrm{ra}, 1971,374 \mathrm{pp}$.

Reviewed by Vass Elöd = LK 42 (1971), pp. 346-347; Mészáros László = NyK 76 (1974), pp. 470-472, Agrártörténeti Szemle 15 (1973), pp. 600-602, Száz. 108 (1974), pp. 274-280, AHist. 20(1974), pp. 234-237; Karadeniz, Sadan = Belleten 38 (1974), pp. $342-343$.

1603. KÁLDY-NAGY Gyula: A török hódoltság elbeszélő és okleveles kútfôi ról [Narrative and documentary sources on the Ottoman occupation in Hungary] = Száz. 106 (1972), pp. 647-652.

1601. MAKSAY Ferenc: Fekete Lajos, Az esztergomi szandzsák 1570. évi adóöszszeírása [The 1570 tax-register of the Esztergom Sanjak]. Budapest; 1943. Review = A Néprajzi Múzeum Országos Magyar Történeti Múzeum Néprajzi Tára Értesítője 35 (1943), (Budapest, 1947), p. 204.

1605. VASS, E[löd]: Türkische Beiträge zur Handelsgeschichte der Stadt Vác (Waitzen) aus dem 16. Jahrhundert $=A O H 24$ (1971), pp. 1-39.

1606. VASS, E[löd]: Zwei türkische Fährenlisten von Ráckeve und Dunaföldvár aus den Jahren 1562-1564= AOH 25 (1972), pp. 451-463.

1607. VASS Előd: Törökkoppány 1556. évi első török adóösszeírása [The first Ottoman-Turkish tax-roll of Törökkoppány in 1556] = Somogy megye multjấćl (Kaposvár, 1972), pp. 57-73.

1608. VASS Elöd: Török adatok Rákoscsaba és Rákoskeresztür hódoltságkori történetéhez [Ottoman-Turkish data on the history of the villages of Rákoscsaba and Rákoskeresztúr under Ottoman rule] = TBM 19(1972), pp. 87-111.

1609. VASS Előd: Székesfehérvár (Istulni Belgrád) XVI. századi török for rásai [16th century Ottoman-Turkish sources on Székesfehérvár (Istulni Belgrad)] = Fejêr megyei Történeti Évkönyv 7 (1973), pp. 275-298.

1610. VASS, E[lód]: Quatre documents ottomans concernant la contribution d'une puszta hongroise an $X_{\text {VII }}^{e}$ siècle $=A O H 28$ (1974), pp. 253-262.

See also Nos. $90-93,1641,1642,1644,1645,1648,1652,1667,1669,1673$.

\section{$\beta /$ Inscriptions and miniatures}

1611. FEHÉR, Géza [jun.]: Pierres commémorativea à inscriptions turques en provenance de Hongrie $=$ FolArch. 10 (1958), pp. 175-178 and XXV-XXVI. pl. 
1612. FEHÉR, Géza [jun]: Les cachets et anneaux sigillaires à inscription turque du Musée National de Hongrie = FolArch. $11(1959)$, pp. 187-196 and XXVXXVI. pl.

1613. F EHÊR, Géza [jun.]: Les coupes à inscriptions turques et arabes d' Esztergom-Szenttamáshegy = Németh Armałanı (Ankara, 1962), pp. 155-165.

See Nos. $1614,1615,1617$.

1614. FEHÉR, Géza [jun.] : XVI-XVII. yüzyıllarda Macaristandaki Türk sanatı II. Estergom-Szenttamashegy'deki yazitlar = Belleten XXVI/104(1962), pp. $701-710+6 \mathrm{pl}$.

See Nos. $1613,1615,1617$.

1615. FEHÉR, Géza [jun.]: Encore une fois sur les monuments à inscriptions d'Esztergom-Szenttamáshegy = TDAYB 1962 (1963), pp. 101-106.

See Nos. 1613, 1614, 1617.

1616. FEHÉR Géza [jun.] : A szigetvári hadjáratról írt XVI, századi török tör ténelmi mú miniatúrái [Miniatures of a 16 th century Turkish historical work on the campaign of Szigetvár] = Múvészet $7(1960): 9 . \mathrm{pp}, 2-5$.

1617. FEHÉR Géza [jun.]: Esztergom-szenttamáshegyi feliratos edények [Vessels with inscriptions from Esztergom-Szenttamáshegy] = A Komárom megvei múzeumok közleményei 1 (1968), pp. 329-339.

See No8. 1613, 1614, 1615.

1618. FEHÉR, Géza [jun.]: Miniatures turques du XVI siècle relatives à l'histoire de Hongrie = Ipermúvészeti Múzeum Évkönyve 12 (1969), pp. 227-236.

1619. FEHÉR Géza [jun.]: XVI. századi magyar tárgyá török miniatưrák [16th century Turkish miniatures of Hungarian subject matter $]=$ Mûveszet 11 (1970):6, pp. 2-5.

1620. F KKÉR, Géza [jun. ]: Kanuñ Sultan Süleyman preisende Inschriften zweier Buda-stammender Renaissance-Kunstgegenstände = Kanunî Armağanı (Ankara, 1970), pp. 201-206+11 pl.

1621. FEHÉR, Géza [jun.]: Recent data of the Turkish campaign of $1543=$ StTurc. (1971), pp. 161-178.

1622. FEHÉR Geza [jun.]: A mohácsi csata jelenete oszmán-török ábrázolásban [The battle of Mohács in Ottoman-Turkish depictation] = Múvészet 12 (1971): 7, pp. 3-7.

See No. 1623.

1623. FEHÊR, Géza [jun.]: The battle of Mohács in Turkish miniatures of the Osmanli period $=$ The New Hungarian Quarterly $13(1972)$, pp. 201-204 2 pi. Soe No. 1622 .

1624. FEHÉR Géza [jun.]: Az "Egri Győzelmi Irat" miriatúråi [The miniatures of the "Fethname of Eger"] = Múvészet 13 (1972):4, pp. 5-7. 
1625. FEHER, Gléza jun. ]: Hungarian historical scenes recorded in Turkish ch ronicle illustrations $=$ AOH 14 (1972), pp. 475-492.

See Nos. $1626,1628$.

1626. FEHÉ, Géza [jun.]: Türk minyatürlerinde Macar tarihi = Türkiyemiz 7 (Istanbul, 1972), pp. 2-11.

See Nos. $1625,1628,1631$.

1627. FEHẾR Géza [jun. ]: Az 1543. évi hadjárat XVI. századi török forrása: Matrakcsi Naszuh krónikaja IA 16th century Turkish source on the campaign of 1543. Matrak飞i Nasuh's chronicle] = TörtSz. 16 (1973), pp. 148-150.

1628. FEHÉR Géza [jun.]: Török krónikák és miniatúrák magyar vonatkozásai [Hungarian references in Ottoman-Turkish chronicles and miniatures] = FolHist. 1 (1973), pp. 11-22.

See Nos. $1625,1626$.

1629. FEHÉR, Géza [jun.]: Macar tarihine ait XVI. yüzyıl Türk minyatürleri = VII. Türk Tarih Kongresi, Ankara, 25-29, Eylül 1970. Kongreye sunulan Bildiriler. II. Cilt (Ankara, 1973), pp. $708-710+3$ pl.

1630. FEHER, Géza [jun.]: Hünemâmede Macar tarihi = Türkiyemiz 9 (Istanbul, 1973), pp. 2-5.

1631. FEHÉR, Géza [jun.]: Türk minyatürlerinde Macar tarihi II. = Tưrkiyemiz 10 (Istanbul, 1973), pp. 11-18.

1632. FEHÉR, Géza [jun.]: Hungarian history in islamic miniature painting = The Muslim East (1974), pp. 175-184 + I-XIII. pl.

1633. FEHÉR, Géza [jun.]: Türk vekay inâmelerinde Szigetvár = Türkiyemiz 13 (Istanbul, 1974), pp. 10-14.

1634. GERÓ Győző: Arabnyelvû feliratos emlékek Esztergomban [Epigraphic monuments of Esztergom in Arabic] = Esztergom Évlapjai 1960, pp. 45-56.

1635. [GERŐ, Győzó] : Macar bilginin Gerő Győző'nün konferansı [Macaristan'daki Türk eserleri] = Belleten XXVIII/109 (1964), p. 178 .

1636. GERŐ Győző: A szigetvári Szưlejmán szultán dzsámi [The Sultan Süleyman Jami in Szigetvár] = Múemlékvédelem 10(1966):2, pp. 111-117.

1637. GERŐ Győző: Az os zmán-török épitészet magyarországi eml€kei. (Dzsámik, türbék, fürdók) [Monuments of Ottoman-Turkish architecture in Hungary. (Jamis, türbes, bathes)]. /KandÉrt. - Manuscript/. Budapest, 1974.

c/ Edition of Ottoman sources not pertaining to Hungary

1638. ABRAHAMOWICZ, Z.: Four Turkish letters to the king and chancellor of Poland at the Svenska Riksarkivet in Stockholm $=$ AOH 13(1961), pp. 63-70. 
1639. ABUlaDZE, Cisana: S. Džikia, Gurdžistanis Vilāietis Didi Davtari. Cigni III. Tbilisi, 1958. Review = AEthn. 9 (1960), pp. 443-444.

1640. BAŞTAV, Şerif: Ordo Portae. (Görög leírás II. Mehmed szultán portájá ról és hadseregéról) (Ordo-Portae. (A Greek description of Sultan Mehmed II's court and army)] Budapest, 1947. 43 pp. /Magyar-görög tanulmányok 27./.

1641. BENDA Kálmán: Richard F. Kreutel - Otto Spies, Leben und Abenteuer des Dolmetschers Osman Aga. Eine tiurkische Autobiographie aus der Zeit der Grossen Kriege gegen Österreich. Bonn 1954. /Bonner Orientalische Studien. N.S. 2./. Review = Száz. 93 (1959), pp. 661-662.

1642. BENDA Kálmán: Richard F. Kreutel, Im Reiche des Goldenen Apfels. Des Türkischen Weltenbummlers Evliyâ Çelebi denkwürdige Reise in das Giaurenland und in die Stadt und Festung Wien anno 1665. /Osmanische Geschichtsschreiber 2./ Graz-Wien-Köln, 1957. Review = Száz. 94 (1960), p. 428 .

See No. 1667.

1643. CSORBA Tibor - FEKETE Lajos: N.P. Gracianskij - S. D. Skazkin, Középkori történeti chrestomathia. Fordította -- [N.P. Graciansky - S. D. Skazkin, A historical chrestomathy of the Middle Ages. Translated by - - . Budapest, 1956. 322. pp.

1644. FEHÉR, Géza [jun. ]: Richard Kreutel - Otto Spies, Der Gefangene der Giauren. Die abenteuerlichen Schicksale des Dolmetschers Osman Ağa aus Temeschwar, von ihm selbst erzält. Graz-Wien-Köln, 1962. Review = BiblOr. 1969:5-6, 431-432.

1645. FEKETE, Lajos: Tirk vergi tahrirleri. Çeviren Sadrettin Karatay = Belleten XI/2 (1947), pp. 299-328.

1646. FEKETE, L[ajos ]: Zur Geschichte der Grusiner des 16. Jah rhunderts $=$ AOH $1(1950)$, pp. $93-131+8$ pl.

See No. 1647.

1647. FEKETE Lajos: Adalékok a grúzok XVI. századi történetéhez [Contribution to the history of the Georgians in the sixteenth century] = I. OK 1 (1950), pp. 307-317.

See No. 1646.

1648. FEKETE, L[ajos]: Das Fetḥnāme über die Schlacht bei Varna. Zur Kritik Ferídūns $=$ ByzSl. $14(1953)$, pp. $258-270$.

1649. FEKETE,L[ajos]: A. Zajączkowski - J. Reychman, Zarys Dyplomatyki Os mansko-Tureckiej. Warszawa, 1955. Review = OLZ 51 (1956), cols . 539-543.

1650. FEKETE,L[ajos]: Herbert Busse, Untersuchungen zum islamischen Kanzleiwesen an Hand turkmenischer und safawidischer U'rkunden. Kairo, 1959. Review $=$ Der Islam $36(1961)$, pp. 289-296. 
1651. FEKETE, Lajos: Birtakim Farsça belgelerde bulunan bir ek-formülün açıklaması hakkında = Németh Armağanı (Ankara, 1962), pp. 389-393.

1652. FEKETE Lajos: A fetḥnăméröl [On the Fetḥname] = I. OK 19 (1962), pp.65-117.

1653. FEKETE, L[ajos ]: Tamma und seine Synonyme = Trudy II. (1963), pp. 374377.

1654. FEKETE, Lajos: Richard Kreutel, Osmanisch-Türkische Chrestomathie. Wiesbaden, 1965. /Porta Linguarum Orientalium 7./. Review = OLZ 63 (1968), cols. 580-581.

1655. FEKETE, L[ajos]: Hazim Sabanović, KrajiSte Isa-bega Ishakovića. Ibirni kateskarski popis iz 1455, godine. Sarajevo, 1964. /Orijentalni Institut u Sarajevu, Monumenta turcica historiam slavorum meridionalium illustrantia, tomus secundus, serija 2, defteri, kniga I./. Review = Oriens 21-22 (1968-69), pp. $474-476$.

1656. GÖKBILGIN, M. T.: Molla Gürânî ve pâdîşaha sunduğu yazılar = The Muslim East (1974), pp. 75-84.

1657. HAZAI, Glyörgy]: Arabische, türkische und persische Handschriften der Univers itätsbibliothek in Bratislava. Bea rbeiteten: unter der Redaktion Jozef Blałkovic's die a rabischen Handschriften Karel-Petrácek, die türkischen Handschriften Jozef Blaskovic, die persischen Handschriften Rudolf Veselý. Bratislava, 1961. Review $=$ AOH 14 (1962), pp. 335-337.

1658. HAZAI, Glyörgy]: 'Usâqîzâde's Lebensbeschreibungen berühmter Gelehrter unter Gottesmanner des osmanischen Reiches im 17. Jahrhundert (Zeyl-i Saqâ' iq) hrsg. u. eingeleitet von H.J. Kissling. Wiesbaden, 1965. Review = OLZ 64 (1969), cols. 587-588.

1659. HAZAI, Glyörgy]: Türkische Gewänder und osmanische Gesellschaft im achtzehnten Jahrhundert. Facsimile-Ausgabe des Codex "Les portraits des differents habillements qui sont en usage $a$ Constantinople et dans tout la Turquie" aus dem Besitz des Deutschen Archäolagischen Institutes in Istanbul. Vorwort von R. Naumann. Hrsg. und eingel. von K. Tuchelt. Graz, 1966. Review = DLZ 90 (1969), pp. 171-173.

1660. HAZAI, Glyörgy ]: Türkische Handschriften. Teil 1. Beschrieben von Barbara Flemming. Wiesbaden, 1968. - Teil 2. Beschrieben von Manfred Götz. Wies baden, 1968. Review = MIO 16 (1970), pp. 325-327.

1661. HAZAI Glyörgy]: J. Matuz, L'ouvrage de Seyfi Çelebi, historien ottoman du XVI siècle. Paris, 1968. Review = MIO 17 (1971), pp. 155-157.

1662. HAZAI, Glyörgy ]: Fr. Babinger, Aufsätze und Abhandlungen zur Geschichte Südosteuropas und der Levante I-II. München, 1962/66. Review $=$ OLZ 68 (1973), cols. 603-604.

1663. HEGYI Klára: Izvori za bălgarskata istorija. X. (Sofia, 1964); XII. (Sofia, 1966). Review = Világtörténet 1969:18, pp. 62-64. 
1664. HORVATH, Ann[a]: Uriel Heyd, Ottoman doouments on Palestine 1552-1615. A Study of the Firman according to the Mubimme Defteri. Oxford, 1960. Review $=$ AOH 18 (1965), pp. 389-391.

1665. KA LDY-NAGY [Gyula], J.: F. Taesohner, Gihlnnilima. Die altosmanische Chrontk des Meviant Mehemmed Neschri. Lolpzig, 1955. Review $=A O H 9$ (1959), pp. 335-336.

1666. KA LDY-NAGY [Gyula], J.: V. Minorsky, The Chester Beatty Library. A catalogue of the Turkish manuscripts and miniatures. Dublin, 1958. Review $=$ AOH 9 (1959), pp. 333-335.

:667. KÁL LY-NAGY, Gyula: R. F. Kreutel, Kara Mustafa von Wien. Das türkische Tagebuch der Belagerung Wiens, 1683 verfasst vom Zeremonienmeister der Johen Pforte. - Im Reiche des Goldenen Apfels. Des tilirkischen Weltenbummlers Evliyâ Çelebi denkwürdige Reise in das Giaurenland und in die Stadt und Festung Wien anno 1665. /Os manische Geschichtsechrelber 1., 2./ GrazWien-Köln, 1955-1957. Revlew $=$ AOH 10 (1960), pp. 308-310. See No. 1642 .

1668. KÁ LDY-NAGY, Gyula: R.F. Kreutel, Vom Hirtenzelt zur Hohen Pforte. Frulhzeit und Aufstleg des Osmanenreiches nach der Chronlk "Denkwilrdigkeiten und Zeitläufte des Hauses "Osman" von Derwish Ahmed, genannt 'Aફ̧ı-Paşa-Sohn. thers. eigeleitet und erklärt von --. /Osmanische Geschichtsscreiber 3.; Graz-Wien-Köln, 1959. Review = OLZ 61 (1966), cols. 394-396.

1669. KÁLDY-NAGY, Gy[ula]: Tureckije reest rovye knigi mukatła kak istoriceskije istoxniki = VostIst. 1 (1964), pp. 76-90.

1670. KÁ LDY-NAGY [Gyula], J.: N. Beldiceanu, Les actes des premiers sultans conservés dans les manuscrits turcs de la Bibliothèque Nationale à Paris. Tome I: Actes de Mehmed II et de Bayezid II du ms. fonds turc ancien 39. Paris, 1960. Tome Il: Règlements miniers 1390-1512. Paris, 1964. Review $=$ AOH 18 (1965), pp. 387-388.

1671. KÁ LDY -NAGY Gyula: Anyagnevek egy Földközi-tengeri török vámnaplobaan [Names of merchandises in a Meditterranean Ottoman-Turkish customs register] = Altnapok (1965), p. 14 .

See No. 1672 .

1672. KÁLDY-NAGY [Gyula], J.: Names of merchandises in a Mediterranean Turkish customs registe $\mathrm{r}=\mathrm{AOH} 18(1965)$, pp. 299-304. See No. 1671 .

1673. KÁLDY-NAGY Gyula: Josef Kabrda, Le système fiscal de l'église orthodoxe dans l'Empire ottoman (D'après les documents turcs). Brno, 1969. Review = StSI. 17 (1971), pp. 394-396 and Száz. 106 (1972), pp. 199-201.

1674. MATUZ, J.: Zur Sprache der Urkunden Süleymāns des Prächtigen $=A O H 26$ (1972), pp. 285-297. 
1675. VAJDA, G.: Quelques mots sur la version arabe d'un ouvrage médical turcottoman du XVII ${ }^{\mathrm{e}}$ siècle $=\mathrm{AOH} 27(1973)$, pp. 345-349.

See also Nos. $131,132,138,1578-1610$.

\section{d/ Studies pertaining to Hungary}

1676. BENDA Kálmán: Magyar utazók a török birodalomban a XVI-XVIII. században [Hungarian travellers in the Ottoman Empire in the 16th-18th centuries] = Magyar utazók (1973), pp. 51-61.

1677. DÁVID Géza: A simontornyai szandzsák a XVI. században [The Sanjaq of Simontornya in the 16th century]. Budapest, 1974. 194 pp. and LII +87 plates /Böles Ért. - Manuseript/.

1678. DÁVID, G[éza]: Some aspects of 16 th century depopulation in the Sanjäq of Simontornya $=$ AOH 28 (1974), pp. 63-74.

1679. FEKETE Lajos: Magyarorezág, törökség: kêt vilăgnêzet bajvívói 「Hungarians and Turks: champions of two ideologies ]. Budapest, 1947, 23. pp. /Acta Societatis Hungaricae Orientalis 13.

1680. FEKETE, Lajos: Osmanlı Türkleri ve Macarlar 1366-1699 = Belleten XIII/52 (1949), pp. 663-744.

1681. FEKETE, L[ajos]: Juill baba et le bektāš derk'äh de Buda $=\mathrm{AOH} 4$ (1954), pp. 1-18.

1682. FEKETE Lajos: Egy vidéki török úr otthona a XVL században [The home of a provincial Turkish notable in the 16th century] = I. OK 15 (1959), pp. 87-106. See Nos. 1683, 1695, 1696.

1683. FEKETE, L[ajos]: Das Heim eines türkischen Herm in der Provinz im XVI. Jahrhundert. Budapest, 1960. 30. pp. /Studia Historica Academiae Scientiarum Hungaricae. 29./.

Review: AHist. 8 (1961), p. 202.

See Nos. $1682,1695,1696$.

1684. FEKETE, L[ajos]: Berāt = The Encyclopaedia of Islam. New Edition. I. (London-Leiden, 1960), pp. 1170-1171.

1685. FEKETE, L[ajos $]:$ Budin = The Encyclopaedia of Lslam. New Edition. I.(London-Leiden, 1960), pp. 1284-1286.

1686. FEKETE Lajos: Latinok a XVI, századi Budân (Latins in Buda in the sixteenth century I $=$ MNy. $57(1961)$, pp. 20-25.

Reviewed by: Balázs, J. = UAJb. 33 (1961), p. 301.

1687. FEKETE, Lajos: Macaristan'da Türklerin mülk sistemi = IÜEFTTD $12(1961)$, pp. 25-42. 
1688. FEKETE, Llajos ]: Le commerce à Buda au temps des Turcs = Nouvelle Revue de Hongrie 55 (1963), pp. 321-331. See No. 1691.

1689. FEKETE Lajos: Budapest élete a törökkorban [Life in Budapest during the Turkish period] = Magvetó 1964, pp. 312-330.

See No. 1690.

1690. FEKETE, Lajos]: La vie à Budapest sous la domination turque, 1541-1686= Journal of World History 8(1964), pp. 525-547.

See No. 1689.

1691. FEKETE, L[ajos]: Torgovlja $v$ Bude $v$ period tureckogo gospodstva vo vtoroj polovine XVI. v. = VostIst. 1 (1964), pp. 91-118.

See No. 1688.

1692. FEKETE, L[ajos]: Gülbaba = The Encyclopaedia of Islam. New Edition. II. (London-Leiden, 1965), pp. 1133-1134.

1693. FEKETE, L[ajos]: Eszék = The Encyclopaedia of Islam. New Edition. II. (London-Leiden, 1965), pp. 715-716.

1694. FEKETE, L[ajos]: Esztergom = The Encyclopaedia of Islam. New Edition. II. (London-Leiden, 1965), pp. 716-717.

1695. FEKETE, L[ajos]: XVI. yüzyılda taşralı bir Türk efendisinin evi. Macarcadan çeviren: Sadrettin Karatay $=$ Belleten XXIX/116 (1965), pp. 615-638. See Nos. 1682, 1683, 1696.

1696. FEKETE, L[ajos]: Das Heim des 'Ali Čelebi, eines türkischen Defterbeamters in Buda = VostIst. 2 (1969), pp. 29-75. [Posthumus]. See Nos, $1682,1683,1695$.

1697. FEKETE Lajos - NAGY Lajos: Budapest története a török korban [The his tory of Budapest in Ottoman-Turkish times] = Budapest története. II. (Budapest, 1973), pp. 335-436.

1698. GÖKBILGIN, Tayyib: Nagy Szolimán 1566. évi Szigetvár elleni hadjáratának elózményei [Antecedents of Süleyman the Magnificent's campaign against Szigetvár in 1566] = Szigetvári Emlk. (Budapest, 1966), pp. 53-59.

1699. GÖKBILGIN, Tayyib: Szigetvár astroma és elfoglalása 1566-ban (Török források szerint) (The siege and capture of Szigetvár in 1566 (According to Ottoman-Turkish sources)] = HK 13 (1966), pp. 793-799.

1700. HALASI-KUN, T[ibor]: Unidentified medieval settlements in Southern Hungary. Ottoman: nam-i diğer $=$ StTurc. (1971), pp. 213-230.

1701. HAZAI György: A héttorony börtöne [The prison of Yedikule] = Rádiólexikon (1964), pp. 23-24. 
1702. HEGYI Klára: A török bírósági eljárások terminológiája a magyarországi emlekkekben [The terminology of Ottoman-Turkish judicial procedures in sources from Hungary] = Altnapok (1965), p. 17.

See No. 1703.

1703. HEGYI, Klára: The terminology of the Ottoman-Turkish judicial documents on the basis of the sources from Hungary = AOH 18 (1965), pp. 191-203. See No. 1702.

1704. HEGY I Klára: Kádik és civisek. Magyar városok a török uralom alatt [Kadis and burgers. Hungarian towns under Ottoman rule $]=$ ÉlTud. 1965:30, pp. $1406-1410$.

1705. HEGYI, Klára: Le condominium hungaro-ottoman dans les eyalets hongrois × Actes du 1 er Congrés des Études Balkaniques et Sud-est Européennes, III (Sofia, 1969), pp. 593-603.

1706. HEGYI, Klára: La juridiction autonome des villes hongroises sous la domination ottomane =VH. Türk Tarih Kongresi, Ankara, 25-29, Eyliil 1970 . Kongreye sunulan Bildiriler. II. Cilt (Ankara, 1973), pp. 629-636.

1707. HEGYI, Klára: Materialy dlja charakteristiki tureckoj sudebnopravovoj sistemy v Vengrii (1569-1686) : Vostist. 2 (1974), pp. 102-149.

1708. HORVÁTH, Anna: Le commerce dans l'eyalet de Buda durant la seconde moitié du XVI-ème siècle $=$ Tarih araģtırmaları dergisi 7 (1969), pp. 57-63.

1709. HORVÁTH, Ann[a]: The cattle trada of a Hungarian town (Szolnok) in the period of Turkish domination = StTurc. (1971), op. 235-240.

1710. KÁLDY-NAGY Gyula: Török-magyar kapesolatud [Turkish-Hungarian relations] = Diplomáciai és Nemzetközi Jogi Lexir (Budapest, 1959), pp. $521-524$.

1711. KÁLDY-NAGY Gyula: A dzsizje defterek és a tahrir defterek népességatatisztikai forrásértéke [The value of jizye-defters and tahrir-deftera for population statistics] = Történeti Statisztikai Közlemények 3 (1959), pp. $108-117$.

See No. 1712.

1712. KÁLDY-NAGY, Gyula: Bevölkerungsstatistischer Quellenwert der GizyeDefter und der Tahrīr-Defter $=$ AOH $11(1960)$, pp. 259-269.

See No. 1711.

1713. KÁLDY-NAGY Gyula: A Szeged környeki szultáni hász-birtokok mezógazdasági termelése a XVII. század második felében [Agricultural production in the Sultanic Hasses estates around Szeged in the second half of the 17th century] = Agrártörténeti Szemle 3(1961), pp. 457-513.

171. KÁLDY-NAGY Gyula: Tolna mezôváros gazdasági termelése a XVI, század derekán a török adójegyzékekben [Agricultural production in the market -town of Tolna in the middle of the 16th century according to Ottoman-Turkish taxrolls ! = Agrártörténeti Szemle 4(1962), pp. 579-601. 
1715. KÅLDY-NAGY Gyula: Magyarországi török adðösszeírások [Ottoman-Tu rkish tax-rolls in Hungary] Budapest, 1967. /Kand. Ert. - Manuscript/. Theses. 1967. - Report on the debate: Hegyi Klára=Száz. 102 (1968), pp. 824-828. See No. 1718.

1716. KÁLDY -NAGY [Gyula], J.: The administration of the şanjạq registrations in Hungary = AOH 21 (1968), pp. 181-223.

1717. KÁLDY-NAGY Gyula: Statisztikai adatok a török hódoltsági terillet nyugat feló irányuló áruforgalmá ról 1560-1564-ben [Statistical data on the western $t$ rade of Hungarian territories under Ottoman rule in 1560-1564] = Történeti Statisztikai Évkönyv (Budapest, 1968), pp. 27-98.

1718. KÁLDY-NAGY Gyula: Magya rországi török ad6összeírások lOttoman-Turkish tax-rolls in Hungaryl. Budapest, 1970. 104. pp. /Êrtekezések a történettudományok körából $52 . /$.

Reviewd by Vass Előd = Agrártërténeti Szemle 13 (1971), pp. 226-228; [V.K.] = Historický Casopis 1971. Rocnik 19, pp. 622-623; Kóhegyi M thály = Száz. 106 (1972), pp. 1409-1410; Ladány i Erzsébet = AnnHist. 13 (1972), pp. 375377.

See No. 1715 .

1719. KÅLDY-NAGY Gyula: Harács-szedők és ráják. Török világ a XVI. századi Magyarországon [Hara]-collectors and reäya. The Ottoman world in 16 th century Hungary]. Budapest, 1970. 198. pp. + 9 pl. /Körösi Csoma Kiskönyvtár $9 . \%$.

Reviewed by Gökbilgin, T. = Islam Tetkikleri Enstitulsui Dergisi N/3-4 (Istanbul, 1971), pp. 93-97; Ladányi Erzsébet = AnnHist. 13(1972), pp. 375-377.

1720. KÁLDY-NAGY, Gyula: Statistische Angaben über den Warenverkehr des turkischen Eroberungsgebiets in Lngarn mit dem Westen in den Jah ren 1560 $1564=$ AnnHist. 11 (1970), pp. 269-341.

1721. KÁLDY-NAGY, Gyula: Tark-Macar tarihî münasebetleri hakkında = Belleten XXXIV/136 (1970), pp. $696-697$.

See No. 1729.

1722. KÁLDY-NAGY, Gy[ula]: The effect of the timar-system on agricultural production in Hungary = StTurc. (1971), pp. 241-248.

See No. 1728.

1723. KÁLDY-NAGY, Gy[ula]: Macht und Immobiliarvermögen eines türkischen Beglerbegs im 16. Jahmundert $=$ AOH $25(1972)$, pp. 441-450.

Reviewed by V[ojtech], K. = Historický Casopis 1973, Rơnik 21, pp. $641-6+2$.

1724. [KALDY-NAGY, Guula] Fehér Géza [sic!] : XVI. yüzyulda Macaristan'da Padişah haslarına bağlı iki şehir = Belleten 36 (1972), pp. 469-482.

1725. KÁLDY-NAGY, Gy[ula] : XVI. yłuzyılda Osmanlı imperatorluğunda merkezi $y_{3}^{40}$ et in in başlica sorunlam = AÚDTCETAI) 7 (1973), pp. 49-55. 
1726. KÁLDY-NAGY, Gy[ula]: Macaristan'da 16. yüzyılda Türk yönetimi. Budapest 1974. 77. pp. /Studia Turco-Hungarica 1./.

1727. KÁLDY-NAGY, Gy[ula]: Formirovanie na rodonaselenija i seljskochozajstvennogo proizvodstva $v$ gorode Tolna v XVI. vv. = VostIst. 3 (1974), pp. 90-101.

1728. KÁLDY-NAGY, Gy[ula]: Timar sistemin in Macaristan'da tarimsal üretime etkisi $=$ Belleten 38 (1974), pp. 499-508.

See No. 1722 .

1729. KOŞAY, Hâmit Zübeyr: Türk-Macar tarihi münasebetleri hakkında, Türkolog ve Üniversite doçenti Nagy Gyula Kaldy'nin "Népszabadság" gazetes inin 15 Kasım 1970 nüshasında çıkan beyanat $1=$ Belleten XXXIV / 136 (1970),pp.696-697. See No. 1721 .

1730. PERÉNYI, József: Trois villes hongroises sous la domination ottomane au XVII ${ }^{e}$ siècle $=I^{e r}$ Congrès Interntional des Études Balkaniques et Sud-

Est Européennes. Résumés des communications. IV. Histoire (Sofia, 1966), pp. 23-40.

See Nos. $1731,1732$.

1731. PERÉNYI, József: Trois villes hongroises sous la domination ottomane au $\mathrm{XVII}^{\mathrm{e}}$ siècle = Actes du premier Congrès International des Études Balkaniques et Sud- Est Européennes. III. Histoire (Sofia, 1969), pp. 581-591. See Nos. 1730,1732 .

1732. PERÉNYI, József: Villes hongroises sous la domination ottomane aux $\mathrm{XVI}^{\mathrm{e}}-\mathrm{XVII}^{\mathrm{e}} \mathrm{s}$. Les chefs-lieux de l'administration ottomane $=$ La ville balkanique aux XV $\mathrm{XV}^{\mathrm{e}}-\mathrm{XIX}^{\mathrm{e}} \mathrm{s}$. (Sofia, 1970), pp. 25-31.

See Nos. $1730,1731$.

1733. PERÉNYI, József: Wirtschaftliche und soziale Umgestaltung in Ungarn unter der Türkenherrschaft im XVI. und XVII. Jahrhundert = Europae Centralis atque Orientalis Studia Historica 1. (Brno, 1971), pp. 85-103.

Reviewed by V[ojtech], K. = Historický Casopis 1972, Rőnik 20, pp. $642-643$.

1734. RÚZSÁS LAJOS: Szigetvári emlékkönyv. Szigetvár 1566. évi ostromának 400. évfordulójára. Szerk. - - [Szigetvár Memorial volume. Issued on the 400th anniversary of the battle of Szigetvár. Ed. by --] Budapest, 1966. 402. pp. /MTA Dunántúli Tudományos Intézete. Értekezések 1966./.

Reviewed by Kovács Sándor Iván, Az értelmes halál. Jegyzetek a Szigetvári Emlékkönyvről. 1566-1966. [The meaningful death. Notes on the "Szigetvári Emlékköny v" 1566-1966.] = Tis zatáj 20(1966), pp. 760-764; N. L. = HK 13 (1966), pp. 917-920; Vas Károly = Kortárs 9(1966), pp. 888-891; Andrásfalvy Bertalan = Ethn. 78 (1967), pp. 149-150; Román János = Száz. 102 (1968), pp. 264-267; Matuz, J. = OLZ 66 (1971), cols. 277-280.

1735. SZÉKELY, Gy[örgy: Les conséquences démographiques de la domination ottomane = Paysannerie française, paysannerie hongroise, $\mathrm{XVI}^{\mathrm{e}}-\mathrm{XX}^{\mathrm{e}}$ siècles (Budapest, 1973), pp. 99-101. 
1736. TAKÁCS Lajos: A dohánytermesztés Magyarországon [Tobacco-growing in Hungary]. Budapest, 1964. 463 pp. [Résumé in German]

1737. TAKẢTS Sándor: Mûvelödéstörténeti tanulmányok a XVI-XVII. századból. Sajtó alá rendezte Benda Kálmán [The cultural history of Hungary in the 16 th and 17 th centuries. Edited by Kálmán Benda]. Budapest, 1961. XIII + 419 pp. + pl. /Nemzeti Könyvtár. Müvelödéstörténet/.

1738. TARDY Lajos: Régi magyar követjárások Keleten [Early Hungarian embassies to the East]. Budapest, 1971. 221 pp. /Körösi Csoma Kiskönyvtár 11./. Reviewed by Vásáry, I. = AOH 26 (1972), pp. 395-396; Kovács Sándor Iván $=$ HK 1973 , pp. $485-487$.

1739. VAJDA, G.: La bibliothèque de poche d'un lettré ottoman de Hongrie = AOH 3 (1953), pp. 103-106.

1740. VASS, E[lód]: Éléments pour compléter l'histoire de l'administration des finances du vilayet de Buda au XVI ${ }^{e}$ siècle = StTurc. (1971), pp. 483-490.

1741. VASS Előd: Az Alföldról nyugatra irányuló á ruforgalom a váci vámnaplók alapján a XVI. században [The Westein trade of the Alföld on the basis of the 16 th century customs registers of Václ = Ag rártörteneti Szemle 14 (1972), pp. 120-155.

1742. VASS Elöd: Adatok a magyarors zági török postaszolgálat müködés éhez a XVII. szá zadban [Data on the 17th century Ottoman postal-service in Hungary $]=$ LevSz. $23(1973)$, pp. 251-252.

See also Nos. $101,1745,1752,1755,1762,1763$.
e/ History of the Ottoman Empire

1743. FEHMI Dzsihangỉ: A Török Köztársaság fél évszázada. Politikai és gazdasági átekintés [A half-century of the Turkish Republic. A political and economic surveyl. Budapest, 1974. $266 \mathrm{pp}$.

1744. FEKETE, L[ajos]: Podarki sultana Abdulchamida I. imperatrice Ekaterine II. = AOH 2 (1952), pp. 1 -21.

1745. FEKETE Lajos: Szülejmán szultán [Sultan Suleiman], Budapest, 1967. 121 pp. /Életek és korok 2./.

1746. GERMANUS Gyula: A féhold fakó fényében [In the pale light of the Crescent]. Budapest, 1957. 253 pp. ${ }^{2} 1958 ;{ }^{3} 1960 ;{ }^{4} 1963$.

1747. GERMANUS Gyula: Allah Akbar. I-II: Second Edition 1968. Budapest, Vol. I. 447. pp. ; Vol. Il. 391. pp. - Third Edition, Budapest, 1973. 672 pp.

1748. GYÖRFFY György: Bernard Lewis, The muslim discovery of Europe. Riassunti VII. Review = Száz. 91 (1957), pp. 361 . 
1749. HADROVICS, L[ászló]: Le peuple serbe et son Eglise sous la domination turque. Paris - Budapest, 1947. 167 pp. 'Bibliothèque de la Revue d'His toire Comparée 6.'.

1750. HAZAI György: Gül Baba = Rádiblexikon (1964), pp. 156-158.

1751. HAZAI György: A héttorony böriöne !The prison of Yedikule] = Rádiólexikon (1964), pp. 23-24.

1752. HAZAI,G[yörgy]: D. E. Pitcher, An historical atlas of the Ottoman Empire from the earliest times to the end of the sixteenth century. Leiden, 1972. Review $=$ DLZ $95(1973)$, pp. 890-891.

1753. HAZAI, Glyörgy ]: St. Shaw, Between old and new. The Ottoman Empire under Sultar Selin III 1789-1807. Cambridge, 1971. Review = OLZ 69 (1974), cols. 177-178.

1754. HAZAI, Glyörgr ]: R. H. Ünal, Les monumente islamiques anciens de la ville d'Erzurum. et de sa région. Paris, 1968. Review $=$ OLZ 69(1974), sols. 176-177.

1:55. HECYI klára: Szulejmán = ElTud. 1966: 18, pp. 819-823.

: 756. HEGYi Kilára: A. D. Noviéev, Tureija. Kratkaja istorija. Moskva, 1965. Review = Világtörténet 1967:14-15, pp. 123-126.

:557. HECY Klára: V. P. Mutafxieva - Str. Dimitrov, Sur l'etat du gystème des timars des XTII ${ }^{e}-X^{\prime}$ II $^{\mathrm{e}}$ ss. Sofia, 1968. Review = Vulágtörténet $1969: 18$, pp. $62-64$.

1758. HOPP Lajos: Rober. Mantran, Istanbul dans la seconde moitte du XT'II siècle. Paris, 1962. Review = Helikon 1964:1, pp. 147-148.

1759. KÁLDY-NAGY [Gyula!, J.: Mustafa Akdağ, Celali isyaniarı (2550-1603). Ankara, 1963. AÜDTCFY 144.'. Review $=$ AOH 19(1966), pp. 363-365 and Száz. 103 (1969), pp. 164-165.

i760. KÁLDY-NAGY Gyula: Adatol a levante: kereskedelem. XVII. század eleji történetéhez (Datá on the nistory of the Levantine trade in the early 17th century $]=$ Száz. 101 (1967), pp. $138-147$.

1761. KÁLDY-NAGY, Gylula]: Dannye $k$ istoris levantinsikoj torgovlì $v$ nacale XVII. stoletija $=$ Vostlst. $2(1969)$, pp. 322-337.

1762. KÁLDY-NAGY, Gyula: Suleimans Angriff auf Europa = AOH 2s (1974), pp. 163-212.

1763. KÁLDY-NAGY Gyula: Szulejmán. Budapest, 1974. 218. pp., 8 pl. Reviewed by Mészá ros László = HK 21 (1974), pp. 728-731; Lázár lastván = Úl $i \div(19-4)$, pp. $223-224$.

1764. KATús iászió: Musztafa Kemái Atatürk. Sudapest, I970. 229 pp. Ëletek és koroh isi. 
1765. MORAVCSIK Gyula: H. Hunger, Byzantinische Geisteswelt von Konstantin dem $G$ rossen bis zum Fall Konstantinopels. Baden-Baden, 1958. Review $=$ AT 6 (1959), pp.155-157.

1766. MUTAFČıVA, Vera P.: Sur le caractère du tĩmār ottoman $=A O H ~ 9(1959)$, pp. 55-61.

1767. PERÉNYI, J6́zsef: Quelques aspects de la coexistance des civilization balkaniques du XV ${ }^{\mathrm{e}}$ au XVIII ${ }^{\mathrm{e}}$ siècles = Actes du colloque international de civilisations balkaniques (Bucureşti, 1963), pp. 99-103.

1768. PERÉNYI, József: Kroatische Briefe türkischer Paschas an N. Jurisić vom Jahre 1539 = StSl. $12(1966)$, pp. 325-333.

1769. SCHÜTZ, Ö[dön]: Novye dannye o Gabriele Tokateci = Izvestija AN Armenskoj SSR 1961: 1, pp. 103-106.

1770. N. Todorov, Balkanskij gorod XV-XIX vv $v$ sostave Osmanskoj imperii = EtBalk. 1971. pp. 28-54. Review = Száz. 106 (1972), pp. 1188-1189.

See also Nos. 141, 366, 377, 1155, 1171, 1676-1742, 1777, 1903-1906.

f/ Crimean Tatars

1771. TARDY, L[ajos] - VÁSÁRY, I[stván]: Andrzej Taranowskis Bericht über seine Gesandtschafts reise in der Tartarei (1569) = AOH 28 (1974), pp. 213-252.

See also No. 858 .

\section{OTTOMAN TURKISH LOAN-WORDS IN HUNGARIAN}

a/ General works

1772. BENDA Kálmán: Pápai János törökországi naplói. Válogatta, sajtó alá rendezte, előszóval és jegyzetekkel ellátta -- [J. Pápai's diaries in Turkey. Selected, edited, prefaced and annotated by --1. Budapest, 1963. 467 pp. + $17 \mathrm{pl}$. /Magyar Századok./.

1773. FEHÉR, Géza [jun.]: La tente turque du Musée National Hongrois $=$ FolArch. $13(1951)$, рp. 213-223.

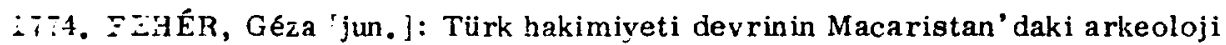
1:-ałtırma.arıủa ülciliğin ve etnografyanun rolü = Bilimsel Bildiriler 1963 (A):ara, 1964), pp. 51-55. 
1775. GÁ BORJÁN Alice: Két magyar hosszúszá rú lâbbelitípus viselettörténeti elemzése [An analysis from the perspective of historical costuming of two types of Hungarian long-legged boots] $=$ NéprÉrt. $40(1958)$, pp. 37-78. [Résumé in German]. Author's summary = Demos 3 (1962), pp. 50-51.

1776. GÁBORJÁN Alice: A magyar módra való bőrkikészítés problematikája (The question of tanning in the Hungarian style] = NéprÉrt. 44 (1962), pp. 97-138. [Résumé in German].

1777. HAZAI György: Mikes Kelemen, Törökországi levelek és misszilis levelek. Sajtó alá rendezte Hopp Lajos. A Török vonatkozások c. részt és a tárgyi jegyzetekben a török szó- és névanyag magyarázatait készitette - $\mid K$. Mikes, Letters from Turkey and correspondence. Edited by L. Hopp. The section "Turkish connections" and the annotation of Turkish words and names in the Notes were written by Gy. Hazai]. Budapest, 1966. $863 \mathrm{pp}$.

1778. KAKUK Zsuzsa: Fejezetek oszmán-török jövevényszavaink történetéböl [Studies in the history of Ottoman-Turkish loan-words in the Hungarian language]. Budapest, 1955. 276 pp. /KandÉrt. - Manuscript/. - Theses. 1955.

1779. KAKUK [Zsuzsa], Suzanne: Les mots d'emprunt turcs-osmanlis dans le hongrois et les recherches d'histoire phonétique de la langue turque-osmanlie $=$ AOH 5(1955), pp. 181-194.

1780. KAKUK Zsuzsa: A szláv közvetítés kérdése a magyar nyelv oszmán-török elemeiben [Slavic intermediation in the Ottoman-Turkish elements of the Hungarian language $=$ NyK 68 (1966), pp. 51-65.

See Nos. 1781, 1782 .

1781. KAKUK [Zsuzsa], S.: Die südslavische Vermittlung bei den osmanischtürkischen Lehnwörtern der ungarischen Sprachen $=-1^{\mathrm{cr}}$ Congrès international des Études Balkaniques et Sud-Est Européennes, Sofia, 26 août -1 septembre 1966. Résumés des Communications. Linguistique (Sofia, 1966), pp. $106-119$.

See Nos. $1780,1782$.

1782. KAKUK [Zsuzsa], S.: Die südslavische Vermittlung bei den osmanischtürkischen Lehnwörtern der ungarischen Sprache $=$ Actes du Premier Congres International des Études Balkaniques et Sud-Est Européennes. VI (Sofia, 1968), pp. 763-771.

See Nos. $1780,1781$.

1783. KAKUK Zsuzsa: Tanulmány az oszmán-török nyelv 16-17. századi történetéhez (A magyar nyelv oszmán-török elemeinek alapján) (Studies in the history of the Ottoman-Turkish language in the 16th and 17th centuries (On the basis of the Ottoman-Turkish elements in the Hungarian language)]. Budapest, 1969.726 pp. /DoktÉrt. - Manuscript/ - Theses. 1969. 9 pp. See Nos. 1784. 
1784. KAKUK [Zsuzsa], Suzanne: Recherches sur l'histoire de la langue osmanlie des XVI ${ }^{e}$ et XVII ${ }^{e}$ siècles. Les élements osmanlis de la langue hongroise. Budapest, 1973. 660 pp. /BOH 19./ / Near and Middle East Monographs 17, The Hague-Paris/.

Reviewd by Dilaçar, A. = TDAYB (1974), pp. 356-357; Kiss L. $=$ MNy. 70 (1974), pp. 487-490; Nasilov, D. M. = SovTjurk. 1974:2, pp. 96-100; Kononov, N. A.: VJaz. 1975:1, pp. 135-139.

See No. 1783.

1785. KAKUK, Zs[uzsa]: Die osmanisch-türkischen Elemente der ungarischen Sprache als Denkmäler der osmanisch-türkischen Sprache = Protokollband (1974), pp. 273-277.

See also Nos. $1210,1218,1227,1231,1234,1243,1255,1264$.

\section{b/ Etymologies}

1786. ANDRÁSFALVY Bertalan: Pekmez. Adatok a törökkori szőlökultúránk is meretehez [Pekmez. Data on Hungarian viticulture during the Ottoman occupation] = MTA Dunántúli Tudományos Intézete. Kisebb Tanulmányok (PÉcs, 1961), pp. 87-95.

1787. ANGYAL Endre: Duttyán [a kind of stall] = Nyr. 77 (1953), p. 313.

1788. BAKOS Ferenc: A török paradicsom (Solanum malongena) magyar elnevezései [Hungarian names for the "Turkish tomato" (i.e. aubergine)] $=\mathrm{MNy} .50$ (1954), pp. 94-105.

1789. BAKOS Ferenc: A magyar nyelv régebbi román elemei és a közvetlen nyelvi érintkezésen alapuló szókölcsönzés néhány kérdése [Early Rumanian elements in the Hungarian language and some questions of borrowing words through direct linguistic contact] $=$ NyK 73 (1971), pp. 65-111.

1790. BAKOS Ferenc: Újabb adalékok a magyar nyelv régebbi román elemeinek történetêhez [Further data on the history of early Rumanian elements in the Hungarian language] $=\mathrm{NyK} 74$ (1972), pp. 335-348.

1791. BÁRCZI Géza: Pajtás ["Mate") = MNy. 51 (1955), p. 363.

1792. BEKE Ödön: Csárdás ["Czardas" (a Hungarian folk-dance)] = Ny r. 74 (1950), p. 189.

1793. CSEFKÓ Gyula: Szavaink történetéhez és magyarázatához (Notes on the history and interpretation of Hungarian words $]=$ Nyr. $71(1947)$, pp. 35-38 and 93-96. Lklabodán, miszkál]

1794. DANKÓ, I[mre]: $K$ problematike vengerskogo slova hajdú "gajduk" = StSl. 6 (1960), pp. 169-191

See No. 1850. 
1795. DÉNES Szilá rd: Duttyán [a kind of stall] = Nyr. $75(1951)$, p. 362.

1796. DÖMÖTÖR Sándor: Tombácos malom [a kind of mill] = Nyr. 97 (1973), pp. 101-102.

See No. 1845.

1797. ERDÖDI József: Toldalék és előleg [Addition and anticipation] = MNy. 70 (1974), pp. 345-348. [pajtás]

1798. EREN, Hasan: Kesza ["Purse"] = MNy. 43 (1947), pp. 294-295.

1799. EREN, Hasan: Kâlmán körte [A kind of pear] = MNy. 43 (1947), p. 294.

1800. FEHÉRTÓI Katalin: Ujabb adatok a farazia szóhoz [Further data on the worć farazia $=$ MNy. 60 (1964), pp. 204-205.

1801. FEKETE Peter, H. Kajszinbarack ["Apricot"] = Nyr. 75 (1951), pp. 363-363.

1802. FEKETE Péter, H.: A duttyán a Hajdúságon [The duttyán a kind of stell in Hajdúság] = Nyr. $76(1952)$, pp. 395-396.

1803. F[ERENCZY] G[éza]: Joghurt ["Yoghourt"] = Ny r. 88 (1964), pp. 76-77.

1804. F[ERENCZY] G[éza]: Mináré ['Minaret"] = Nyr. 91 (1967), p. 504 .

1805. HADROVICS László: Dolmány ["Dolman"] = MNy. 52 (1956), pp. 357-358.

1806. HADROVICS László: Néhány megfejtetlen szláv szavunk [Some unsolved Slavonic words in the Hungarian language $]=$ NyelvtudÉrt. $40(1963), \mathrm{pp}$. 124-127.

1807. HADROVICS Lá zló: Jövevényszó-vizsgálatok [Loan-word studies]. Budapest, 1965. 116. pp. / NyelvtudÉrt. 50./.

1808. HIADROVICS Lás zló - KISS Lajos: Szótörténeti adaiékok [Lexicological data] $=$ MNy. $61(1965)$, pp. $482-491$.

1809. HADROVICS László: "Der Zauberkaften" ein mitteleuropäisches Wandermotiv = Serta Slavica in memoriam Aloisii Schmaus (München, 1971), pp. 223-228.

1810. HOLLOS, Alttila ]: Gogolevskoe slovo "leventarj" = StSl. $11(1965)$, pp. 149-151.

1811. JAKAB László: Parányi ["Minute" adj.] = MNy. 54(1958), p. 350.

1812. KAKUK Zsuzsa: Oszmán-török eredetấ kelme- és ruhanevek a magyarban [Ottoman-Turkish names for cloth and costume in the Hungarian language] - MNy. $50(1954)$, pp. 76-83.

1813. KAKUK Zsuzsa, N.: Kamuka [a special cloth-name] = Nyr. 79(1955), pp. $226-227$.

1814. KAKUK Zsuzsa, N.: Konok ['Obstinate"] = PaisEmlk. (1965), pp. 315-318. 
1815. KAKUK Zsuzsa, N.: Kihalt oszmán-török jövevényszavak [Extinct OttomanTurkish Loan-words] = MNy. 53 (1957), pp. 416-423.

1816. KAKUK Zsuzøa, N.: Oszmán-török jövevényszavak egy budai basa magyar nyelvư levelében [Ottoman-Turkish loan-words in a Hungarian letter from a pasha of Buda] = MNy. 58 (1962), pp. 43-50.

1817. KAKUK Zsuzsa, N.: Szekszena, szekszinás (A kind of saddle; "tipsy, matchmaker"] = NyelvtudÉrt. $40(1963), \mathrm{pp} .154-157$.

1818. KAKUK Zsuzsa: Az uszmán-török rézmüvesség terminolóğảja a balkáni nyelvekben és a magyarban [The terminology of Ottoman-Turkish coppersmithing in the Balkan languages and in Hungarian $]=$ Altnapos. $(1965)$, pp. 11-12.

See No. 1819.

1819. KAKUK [Zsuzsa], Suzanne: Les monuments de la dinaniterie furque dans le: langues balkaniques et le hongrois $=$ AOH 19(1966), pp. 67-77.

See No. 1818.

1820. KAKUK, Zsuzsa: Osmanlicadan Macarcaya geçmiş olan keslımelt:r : TOAY 1968 (1969), pp. 65-80.

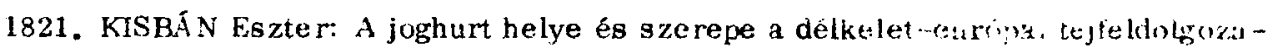
si rendszerekben ('The place and role of the yoghou $x \mathrm{t}$ in sinut. instern European dairy-farming] = Ethn. $78(1967)$, pp. $81-94$.

1822. KISS Lajos: Pazarol ["To squander"] = MNy. 51 (1955), pr. 2.:5: 22t.

1823. KISS Lajos: Nem a törökböl származik-e sisak szavunk'? ils the re not a Turkish origin for the Hungarian word sisak ("helmet")? i Ny $r$. 32 (1950), pp. 233-235.

1824. KISS Iajos: Kátrány ['Ta $\left.{ }^{\prime \prime}\right]=\mathrm{Ny} r .82(1958), p p .373-37 f$.

1825. KISS Lajos: Bekecs [Fur lined short overcoat] $=$ Ny r. $84(1 \mathrm{j}$ rio, pp. $477-479$.

1826. KISS Lajos: Baráber ["Floater"] = Nyr. 85 (1961), pp. 92-93.

1827. KISS, L[ajos]: Proishoždenije slov bekeła, kurma, salas i sisak = Etimologiceskie issledovanija 4 (Moskva, 1963), pp. $48-65$.

1828. KISS Lajos: Etimológiai és szótörténeti jegyzetek (Etymolog ıcal and lexicological notes] = NyelvtudËrt. 38 (1963), pp. 175-187.

1829. KISS Lajos: Az albánok elnevezései a magvarban (Hungarian names for the Albanians $]=$ MNy. 60 (1964), pp. 472-475.

1830. KISS Lajos: Polonis ztikai megjegyzések a faráziá-hoz (The word tarazia obgervations from the perspective of Polish studies] $=\mathrm{MNy} .60(1964), \mathrm{pp}$. 205-206.

1831. KISS Lajos: Hatvanhêt Bzómagyarăzat [Sixty-seven etymologies]. Budapest, 1970. 98 pp. / NyelvtudÉrt. 71./. 
1832. KISS Lajos: Huszonhárom magyar szófejtés [Twenty-three Hungarian etymologies] $=$ NyK 75 (1973), pp. 41-56.

1833. KNIEZSA István: Kocsány és kocs onya ["Peduncle" and "Yelly"] $=$ Ny r. 86 (1962), pp. 209-212.

1834. KÓs Károly: A kalotaszegi muszuj [The muszuj ('a kind of cloth") of Kalotaszeg] = Mứveltség és Hagyomány. /Studia ethnologica Hungariae et Centralis ac Orientalis Europae 6./ Budapest - Debrecen, 1964, pp. 153-178. [Résumé in German ]

1835. MELICH János: Tárkony ['Tarragon"] = NyelvtudÉrt. 38 (1963), pp. 142-150. See No. 1836.

1836. MELICH, J[ános]: Hongrois tárkony "estragon" = ALH 13 (1963), pp. 201-212. See No. 1835.

1837. MÓDY György: Adatok a betyár szó tartalmi változásához [Data on the semantic change of the word betyár ("highwayman")] = Ethn. 68 (1957), pp. 349-351.

1838. MOÓR Elemér: A bocskortól a topánkáig (From the bocskor ('a kind of mocassin") to the topánka ('lady's evening slipper") $=\mathrm{Nyr} .87(1963)$, pp. $116-122$.

1839. MOÓR Elemér: Maszlag ["Thorn-apple"] = Ethn. 75 (1964), pp. 473. Contribution by Gunda Béla = ibid. pp. 473-474.

1840. MOÓR Elemér: Hara ["Hair-bag"] = MNy. 61 (1965), p. 94.

1841. NAGY Jenö: Farazia, fereschi [a kind of woman's cloak] = MNy. 61 (1965), pp. 94-96.

1842. NÉM ETH Gyula: Két török 3 zó a Szabács Viadalmában [Two Turkish words in the "Battle of Szabács"] = MNy. 52 (1956), pp. 307-310. See No. 1843.

1843. PAIS Dezső: Mit jelent és milyen eredetú a Szabács Viadala kwtez és vetez szava? [The meaning and origin of the words kwtez and vetez figuring in the "Battle of Szabács"] = MNy. 53 (1957), pp. $\overline{151-153}$.

See No. 1842.

1844. PÉTER László: Duttyán és társai (The word duttyán ('a kind of stall") and its companions] $=$ Nyr. $76(1962)$, p. 396.

1845. REUTER Camilio: Tombász $\sim$ tombác [a kind of boat] = Nyr. 96 (1972), p. 232.

See No. 1796.

1846. REYCHMAN, Jan: Pajtás ["Mate"] = Nyr. 78 (1954), p. 226.

1847. SIMON Györgyi: Pajtás, bajtárs ["Mate", "Companion"] = M Ny. 50 (1954), pp. 171-173. 
1848. SULÁN Béla: Pajtás ["Mate"] = MNy. 53(1957), pp. 480-484.

1849. SULÁN, B|éla]: Zum Ursprung und zur Semantik des mitteleuropäischen Wortes pajdas $\sim$ pajtás $=$ StSl. 4(1958), pp. 409-415.

1850. SULÁN, B[éla]: Zu der Streitfrage über den Ursprung der mittel- bzw. südosteuropä ischen Wörter hajdư $\sim$ hajduk $\sim$ hajdut usw. = StSl. 7 (1961), pp. 177-186.

See No. 1794.

1851. SULAN, B[éla]: K psevdotureckomu êtimologiceskomu istolkovaniju nekotorych slov cesskogo slova rja = Slavica 2 (1962), pp. 109-125.

1852. SZABÓ T. Attila: Parányi ["Minute" adj.] = MNy. 49 (1953), pp. 479-480.

1853. SZABÓ T. Attila: Para, parácska, parányi (Para ("Turkish coin"), parácska (diminutive of para), parinyi ${ }^{\prime}$ minute adj.) $]=M N y .55(1959), \mathrm{pp}^{\prime}$ $126-128$.

1854. SZABÓ T. Attila: Még valamit a parányi-ról [Further notes on the word parányi ("minute" adj.)] = MNy. $56(1960)$, p. 374 .

1855. SZABÓ T. Attila: A parányi a Debreceni Grammatikában [The word parányi ("minute" adj.) in the Grammar of Debrecen] = MNy. 60 (1964), p. 103 .

1856. TAMÁS Lajos: Az erdélyi román népnyelv magyar elemeihez (Notes on the Hungarian elements of the Rumanian popular speech of Transvlvania] = Nyr. $71(1947)$, pp. 46-49.

1857. TAMÁS, Lajos: Notes d'étymologie roumaine = Beiträge zur romanischen Philologie I. (Berlin, 1961), pp. 209-219.

1858. TAMÁS, Lajos: Ein ostmitteleuropäisches Wanderwort. (Zur Ursprungsfrage von ung. tüiszó) $=$ Cercetări de Lingvistiç III, 1958, supl. [1962], pp.491496.

1859. UZSOKI András: Török kori rablánc a Xántus János Múzeumban [A chain for captives from the period of Turkish rule in the Xantus János Museum] = Arrabona 5 (1963), pp. 193-202. [Résumé in German, English and Russian]. lcsincsér ]

1860. ZSOLDOS Jenó: Pápai János néhány szava [Some words of János Pápai] = Nyr. 88 (1961), pp. 321-324.

1861. Levélszekrény [Letter box] = Nyr. 74(1950), p. 472. [musta, bicske]

1862. A Nyelvőr postája [Correspondence of the Nyelvőr] $=$ Nyr 76 (1952), p. 238. [dévánkozik]

See aiso Nos. $1261,1291,1302,1736$. 
c/ Onomastics

1863. EREN, Hasan: Susol [prop.] = MNy. 42 (1946), p. 57.

1864. INCZEFI Géza: Szeged környékének földrajzi nevei. Szerk. Kázmér Miklós [Geographical names in the region of Szeged. Edited by M. Kázmér]. Budapest 1960. 108 pp. + 1 map. /NyelvtudÉrt. 22./.

Reviewed by Kálmán Béla = MNyj. 7 (1961), pp. 171-172; Diokenmann, Ernst $=\mathrm{BzN} 12$ (1961), pp. 219-220.

1865. KAKUK Zsuzsa, N.: Tabán [geogr.] = Nyr. $79(1955)$, p. 105.

1866. KÁLMÁN Béla: Sis mánd [geogr.] = MNy. 70(1974), pp. 205-206.

1867. MIKESY Sándor: Rézmán [prop.] = MNy. 58 (1962), pp. 209-214.

1868. NÉM ETH Gyula: Feriz bég = I. OK 13 (1958), pp. 89-94.

See Nos. $1869,1875$.

1869. NÉMETH [Gyula], J.: Feriz Beg von Krußevac, $1454=$ Der Islam 39 (1964), pp. $192-196$.

See Nos. $1868,1875$.

1870. REUTER Camillo: A török hódoltság emléke a baranyai helynevekben [Traces of the Turkish occupation in the place-names of Barany ] = Szigetvári Emlk. (Budapest, 1966), pp. 107-114.

1871. REUTER Camillo: Turbék [geogr.] = Nyr. 96(1872), pp. 477-481.

1872. R[UBINYI] M[ózes]: Arszlán [prop.] = Nyr. 76 (1952), p. 478.

1873. SCHEIBER Sándor: Arszlán [prop.] = Ny r. 77 (1953), pp. 468-469.

1874. SUGÁR Istvân: Az Egerben 1687. után megtelepedett tơrökök személynevei [Personal names of the Turks settled in the town of Eger after 1687] = MNy. 69(1973), pp. 203-210.

1875. TOMPA József: Feriz bég = Nyr. $83(1959)$, pp. 350-351. See Nos. $1868,1869$.

See also Nos. $749-753$.

\section{d/ Phraseology}

1876. CSEFKÓ Gyula: Dárius kinese és Mohammed koporsója [Darius's treasure and Muhammed's coffin] = ItK 1948:2, pp. 100-111.

1977. CSEFKÓ Grula: Mohammed koşorsóia Muhammad's coffin! = Nyr, 75 (1951), ว?. $\angle 03-\div 05$.

:\$78. ECKHARDT Sándor: "Erốs, mint Esztergom vára" "' Strong as the castie of Esztergom" (A proverb)] $=$ MNy. $59(1963)$, pp. 340-341. 
1879. FEKETE Lajos: A barátom barátja: barátom... [My friend's friend: my friend.... J = MNy. 57 (1961), pp. 475-477.

See No. 1880.

1880. FEKETE, L[ajos]: Drug moego druga - moj drug = Slavica 8 (1968), pp. 69-72. See No. 1879.

1881. KÓH EGYI Mihály: Több is veszett Mohácsnál ["More was lost at Mohács" (A proverb)] $=$ Nyr. 87(1963), pp. 367-368.

1882. MELICH János: Nyelvet fogni ["To catch a spy"] = MNy. 52 (1956), pp. 475-477.

1883. MORAVCSIK Gyula: Nyelvet fogni ["To catch a spy"] = MNy. 53(1957), pp. 211-213.

See No. 1884.

1884. MORAVCSIK, Gyula: Zur Geschichte des Ausdruckes vzjatj jazyka = International Journal of Slavonic Linguistics and Poetics 4 ('S-Gravenhage, 1961), pp. 34-37.

See No. 1883.

1885. PAPP László: A barátom ba rátjának ... [My friend's friend ...] $=\mathrm{MNy}$. $58(1962)$, p. 370 .

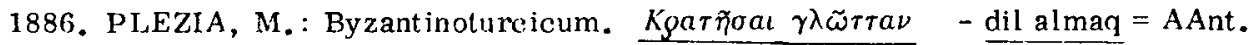
10(1962), pp. 399-402.

1887. SCHEIBER Sándor: "Lebeg, mint a Mohammed koporsója" ["It soars as Muhammad's coffin"] = MNy. 49 (1953), pp. 477-479.

1888. SCHEIBER Sándor: A barátom barátja: barátom... (My friend's friend: my friend] $=\mathrm{MNy}, 61(1965)$, pp. 221-222.

See No. 1879.

e/ Hungarian elements in Turkish

1889. BLASKOVICS, J[ozef]: Türkische Quellen das Wort kuruc betreffend = StTurc. (1971), pp. 73-88.

1890. LIGETI Iajos: Evlija Cselebi magyar szójegyzéke [Evliya Chelebi's IIungarian word-list] $=$ MNy. 67 (1971), pp. 394-409.

1891. [SULĀN Béla], Sulan, B.: Dalo li vengerskoe tó slavjanskoe -ov? = Slavica 1 (1961), pp. 43-54.

See No. 1892.

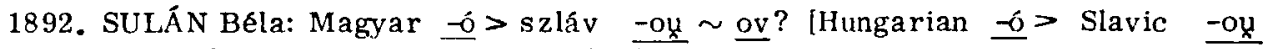
$\sim$-ov?] = NyK 64(1962), pp. 209-221.

See $\overrightarrow{\text { No. }} 1891$. 
1893. SZABÓ T. Attila: Sarampó, sorompó ["Barrier"] = Nyr. 87 (1963), pp. 122-127.

\section{OTTOMAN INF LUENCE IN LITERATURE AND MUSIC}

1894. BETHLENFALVY Géza - WOJTILLA Gyula: Bidpai és Lokman indiai históriái és költött beszédei. Közreadja -- [Bidpai and Lokman's Hindu tales and poetic speeches. Edited by --]. Körösi Csoma Társaság. Budapest, 1972. [Without pagination]

1895. BETHLENFALVY, G[éza]: The Pañçatantra in Hungary = AOH 27 (1973), pp. 127-129.

1896. EREN, Hasan: Balint Balassa'nun türkçe manzumeleri = Tercüme 1953. See No. 686 .

1897. Ġazel-i türki we-mağari = RMKT 3 (1961), p. 12 and 557.

1898. Madžarì türki = RMKT 3 (1961), p. 11 and pp. 555-557.

1899. RELKOVIĆ, Davorka: A Szent Gellért legenda emléke a törököknél és a délszláv költészetben [The survival of the Saint Gerald legend among the Turks and in South-Slavic poetry] = Ethn. 58 (1947), pp. 120-121.

1900. SAYGUN, A. Adnan: La genèse de la mélodie = Studia Musicologica Academiae Scientiarum Hungaricae 3 (1962), pp. 281-300.

1901. SAYGUN, A. Adnan: Quelques réflexions sur certaines affinités des musiques folkloriques turque et hongroise $=$ Studia Musicologica Academiae Scientia rum Hunga ricae 5 (1963), pp. 515-524.

1902. VARGYAS Lajos: Keleti párhuzamok Tar Lörinc pokoljárásához [Oriental parallels to L. Tar's descent to hell] = Müveltség és hagyomány 5 (1963), pp. 37-54.

See also Nos. $686,687,690,691$. 


\section{VIII. \\ LATER TURCO-HUNGARIAN RELATIONS}

\section{RÁKÓCZI AND THE REFUGEES IN THE OTTOMAN EMPIRE}

1903. HOPP Lajos: Ibrahim Müteferrika (1674/75?-1746), a török könyvnyomta tás megalapítója [Ibrahim Müteferrika, the founder of Turkish printing] = Magyar Könyvszemle 90:1-2 (1974), pp. 126-131.

1904. KÁLDY-NAGY, Gylula]: Beginnings of the Arabic letter-printing in the Islamic world $=$ The Muslim Last (1974), pp. $201-211$.

1905. SIMONFFY, V. Aladár: Ibrahim Müteferrika, Türkiyede Matbaacılı̆̆ın Bânisi. Anka ra, 1945. 32 pp. / Başbakanlık Basım ve vavıı genel müdürlüğü yayinlarindan. 14./.

1906. SzABÓ-PAP Lóránt: Ibrahim Mütefarrika = ÉlTud. $2 x(1973)$, pp. 129-132. See also No. 1777 .

\section{KOSSUTH ANI THE REFUGEES IN TURKEY}

1907. KAKUK Zsuzsa: Kossuth kéziratai a török nyelvröl [Kossuth's manuscripts on the Turkish language]. Budapest, 1967. $136+8$ pp. /Körösi Csoma Kiskönyvtár. 3./.

Reviewed by Vásáry, I. = AOH $23(1970)$, p. 136.

See Nos. 1908, 1909 .

1908. KAKUK, Zs[uzsa]: Lajos Kossuth'un Türkce grameri = Bilimsel Bildiriler 1966 (1968), pp. 159-163.

See Nos. 1907, 1909.

1909. KAKUK [Zsuzsa], Suzanne: les manuscrits inédits de Kossuth sur la langue turque $=$ AOH 22 (1969), pp. 81-105.

See Nos. 1907, 1908.

1910. Tó'TH, Imre: Lajos Kossuth'un Türkiye'ye sı̆̆mması. 1s.18 Macar Thtilâlının 120. yıldönümü dolayısiyle (15. 3. 1848-15. 3. 1968) - Türk Kültiirii $70(1968$ agustos). pp. 81:3-814.

Sec also Nos. 300,801 . 


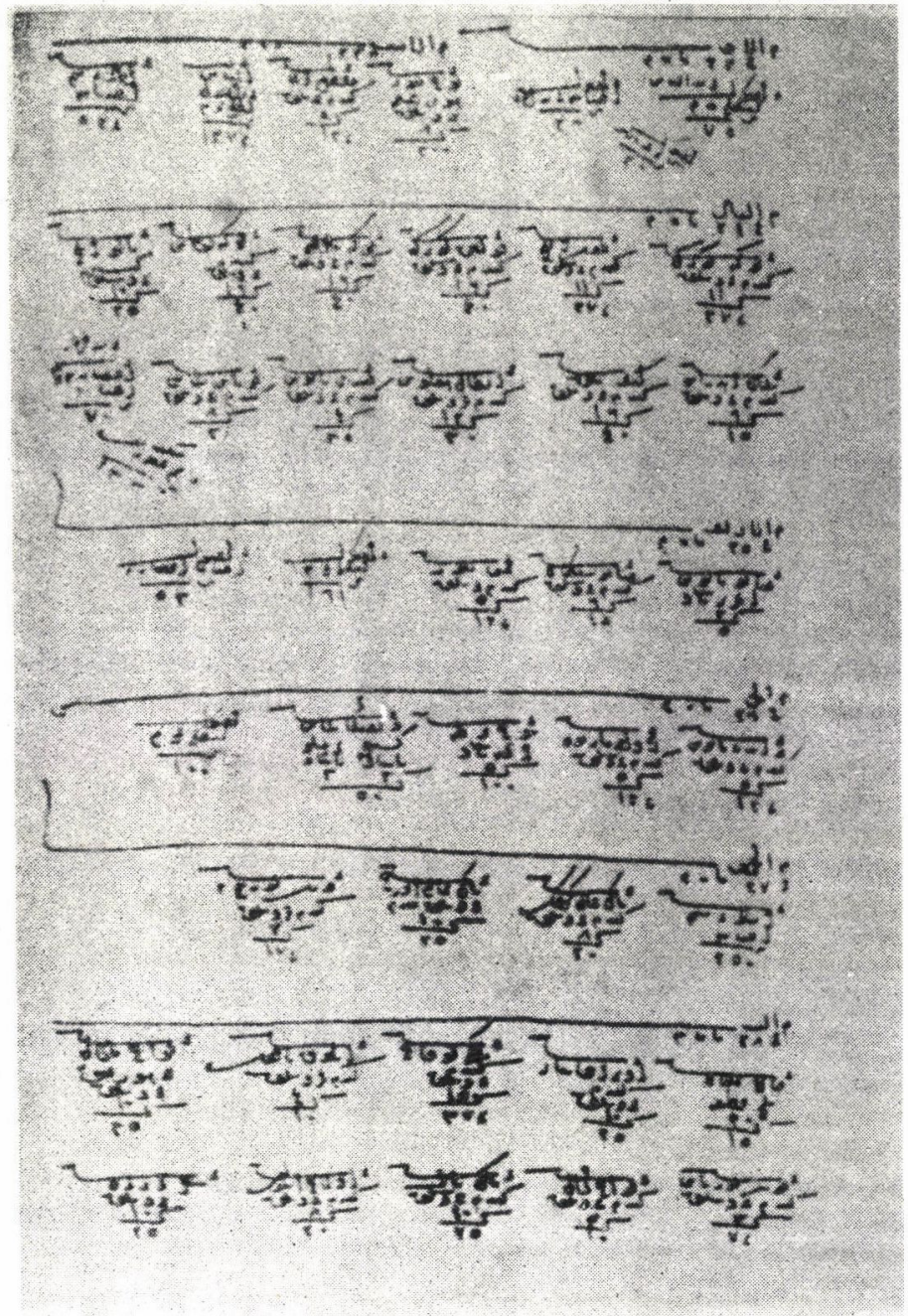

From "Die Siyāqat-Schrift in der Türkischen Finanzverwaltung" by L. Fekete. Budapest, 1955. 2. Bd. T. XLVII. (See No. 1588.) 


\section{INDEX OF NAMES}

Aalto, Pentti 470

Abaev, V.I. 1204, 1206

Abaffy Erzsébet, E. 1205

Abdurahmảnov, D. 944

Abrahamowicz, Z. 1638

Abramzon, S. M. 913

Abuladze, Cisana 1639

Acaroğlu, Türker 17

Adamović, M. 646

Aganin, P. 780

Agazade, N. 697

Áhi Jolán 1061

Akdağ, Mustafa 1759

Ákos K. 1501

Aksenov, A.N. 969

Aksoy, Ömer Asım 756

Aljkaeva, L. 780

Almásy György 145

Altheim, Franz $387,392,1147$

Andrásfalvy Bertalan 1734, 1786

Andreev, M.S. 945

Angyal Endre 140, 1787

Antal László 293

Apor Éva 10, 1206

Ardeleanu, Elena-Teius, S. 1465

Árpád Imre 787

Artamonov, M.I. 604, 605, 607, 1533

Árvay János 917

Ašnin, D. $17,212,847$

Asmarin, N. I. 1041

Aubin, F. 1024
Babinger, Fr. 1662

Baboss Ernó 1418

Baicura, U.S. 864,865

Bainbridge, M. 738

Bajrakta rević, F. 738

Bakos Ferenc 1788, 1789, 1790

Balassa Iván $866,937,938,939$, 1069,1070

Balázs Béla 894

Balázs János 1265, 1266, 1267

Balázs János 533, 1686

Bálint Gábor 146,147

Bálint Sándor 1591

Balogh Sándorné 940

Banner János 189

Bárczi Géza 148, 149, 158, 192, 1207, $1208,1209,1210,1211,1212$, $1213,1214,1215,1216,1217,1218$, $1219,1220,1221,1222,1223,1224$, $1230,1255,1268,1269,1419,1791$

Barkan, P. 17

Barlay Szabolcs 1225

Bartha Antal $41,42,273,289,606$, $607,608,609,610,1071,1072$, $1073,1074,1075$

Bartócz Ilona 781

Bartók Béla 150

Başgöz, Ilhan 813

Baskakov, N. A. 128, 338, 965

Baştav, Şerif 1640

Battal-Taymas, A. 332 
168

Bayerle, Gustav 162, 1584

Bazin, Louis 290, 291, 519

Bede Anna 975

Beke Ödön $154,1036,1037,1270$, $1271,1272,1273,1274,1275,1276$, $1277,1278,1279,1280,1281,1792$

Beldiceanu, N. 1670

Belicer, V.N. 869

Benda Kálmán 2,1584, 1641, 1642 , $1676,1737,1772$

Bendefy László 1124

Benedicty, R. 201

Benkó Elek 1474

Benkő Loránd $148,149,1224,1226$, $1227,1228,1243,1255,1282,1420$, 1421

Benzing, Johannes $14,16,17,332$, $530,588,693,734$

Bereczki Gábor 1038

Berk, Ithan 799

Berrár Jolán 1224, 1422, 1423

Beschkovitsch, A.S. 914

Bese Lajos 251, 292

Besevliev, V. 202, 596

Besse János 151, 152

Bethlenfalvy Géza $83,84,1894,1895$

Bicari, Hasan $774,775,838,839,840$

Bihari József 941

Bikžaiova, M. A. 939

Bíró Margit 543, 544

Björkman, W. 1591

Blagova, G.F. 17

Blaskovið, Jozef $680,1424,1657,1889$

Boba, I. 1191

Bodrogligeti András 428, 429, 515, 520, $523,524,525,526,527,535,536,538$, $564,565,566,567,568,569,570$, $571,572,573,647,757,776,860$

Bogyay, T. 273

Bokarev, E. A. 324,336

Bolgár Magda 1064

Bombaci, A. 430,667

Bonne rjea, R. 252

Boratav, F.N. 778, 803

Boross Marietta 702
Borovkov, A. K. 528

Borsa Gedeon 3

Bouda, K. 1572

Boyle, J.A. 545

Bödey, Joseph 777

Böhtlingk, O. 1028

Brands, W. 588

Braun, H. 1591

Brockelmann, Carl 153, 516, 517

Brodszky Erzsébet 536, 789

Bromlej, Ju. V. 1554

Budenz József 154

Busse, Herbert 1650

Caferoğlu, A. 332,738

Çağatay, S. 588

Celjniker, S. S. 738

Cerkasskij, M.A. 17

Cernecov, V.N. 994

Chasenov, A. 17

Chieh-Hsien Ch'en 64

Clauson, Sir Gerard 431, 738

Csallány Dezső $634,635,636,637,638$, $1475,1476,1477,1478,1479,1480$

Csefkó Gyula $1283,1284,1793,1876$, 1877

Cseres T. 1130,1197

Csikai Valéria 235, 885

Csinády Geró 239, 250

Csongor Barnabás 18, 167, 293, 432, $471,472,473$

Csorba Tibor 1643

Czeglédy Károly $18,47,85,86,140$, $153,155,163,179,294,358,372$, $373,374,377,378,379,380,381$, $382,419,433,434,435,436,437$, $438,439,440,441,442,443,444$, $474,521,549,550,551,600,611$, $612,613,614,615,616,617,618$, $619,620,621,1076,1077,1078$, $1079,1080,1081,1082,1104,1123$, $1159,1164,1165,1166,1167,1168$, $1169,1170,1176,1177,1178,1179$, $1180,1192,1425,1426,1427,1539$, 1574,1575

Dán Róbert 10 
Danko, I. 1794

Daškevic, J. 588

Dávid Géza 177, 1677, 1678

Daws on, Chr. 1129

Debec, G.F. 1010

Décsy Gyula $129,270,1590$

Deedes, Wyndham 826

Deér József 1083, 1092

Dégh Linda 778,779

Dénes Szilárd 1795

Deny, Jean 329, 586, 766

Dercsényi D. 1093

Dersi Tamás 918

Dešeriev, Ju. D. 324,336

Dezső László 251, 284

Dickenmann, Ernst 1864

Dienes István 1084

Dilâçar, A. 1784

Dimitrov, Str. 1757

Diószegi Vilmos $68,69,70,71,72$, $73,156,157,910,915,919,976$, $977,978,979,980,981,982,983$, $984,985,986,987,988,989,990$, $991,992,993,994,995,996,1006$, $1007,1008,1085,1106,1130,1285$, $1498,1499,1500,1501,1502,1503$, $1504,1505,1506,1507,1508,1509$, $1510,1511,1514,1515,1516$

Dobos Éva $942,943,944$

Dobos Ilona 781,895

Dobrovits Aladár 18

Doerfer, G. 258, 341, 346, 348, 558, $595,680,738$

Dolgich, Boris Osipovit 1010

Dopie rala, K. 588

Dömötör Ákos 780,1031

Dömötör Sándor 1796

Dragomir, A.I. 994

Drimba, VI. 851,854

Dubiński, A. 852

Duda, Herbert W. 17,361

Dujzev, I. 377

Duljzon, A.P. 1009
Dvornik, F. 1156

Dy renkova, N. P. 997, 998

Dzikia, S. 1639

Eberhardt, W. 803, 994

Eckhardt Sándor 383, 597, 1878

Eckmann János 30, 213, 529, 537, $538,686,1538$

Ecsedy Andorné 879, 896, 920

Ecsedy Ildikó [Hilda] 10, 35, 87, 88, $89,381,384,385,420,421,445$, $446,447,448,449,450,451,475$, $476,477,478,479$

Egorov see Jegorov

Egyed Edit 781

Elbert János 921, 922

Elekes Lajos 1123

Elian, Alexandru 377

Erdélyi István $74,75,203,273,452$, $622,623,867,868,869,916,1086$, $1087,1088,1125,1126,1127,1128$, $1286,1481,1482,1483,1484$

Erdey-Grúz Tibor 117

Erdődi József $130,253,323,870,1009$, 1039,1797

Eren, Hasan 19, 158, 214, 236, 295, $703,741,1287,1798,1799,1863$, 1896

Erzakovic, B. G. 890

Eyice, Semavi 377

Fábián László $536,782,783,820$

Fabricius-Kovács Ferenc 324

Fazylov, E. I. 524, 558, 571

Fedotov, M.R. 603

Fehêr Ferenc 923

Fehér Géza 159, 160, 161, 1181

Fehér Géza (jun.) 17, 624, 1104, 1585, $1586,1594,1595,1611,1612,1613$, $1614,1615,1616,1617,1618,1619$, $1620,1621,1622,1623,1624,1625$, $1626,1627,1628,1629,1630,1631$, $1632,1633,1644,1724,1773,1774$

Fehér J. M. 381

Fehér Pál E. 924, 925 
Fehértói Katalin 1555,1800

Fehérvári Gyula 1587

Fehmi Dzsihangir 1743

Fekete Lajos 18, 48, 49, 90, 91, 92, $93,131,132,162,163,164,165$, $166,167,168,169,170,171,172$, $173,339,733,749,750,751,1569$, $1588,1589,1590,1591,1592,1604$, $1643,1645,1646,1647,1648,1649$, $1650,1651,1652,1653,1654,1655$, $1679,1680,1681,1682,1683,1684$, $1685,1686,1687,1688,1689,1690$, $1691,1692,1693,1694,1695,1696$, $1697,1744,1745,1879,1880$

Fekete Péter, H. 1288, 1801, 1802

Feoktistov, A. P. 867

Ferenczy Géza 1803,1804

Fettich Nándor 386

Flemming, Barbara 1660

Fodor István 293

Fodor Sándor 603

Fokos-Fuchs Dávid 174,175, 176, 254, $255,256,257,258,259,260,261$, $262,263,1078$

Földes Lászl6 1089, 1289

Gaál Lászlo 1428

Gabain, Annemarie von $17,31,332$, $340,363,465,466,479,480,486$, 491,504

Gábori M. 273

Gáborján Alice 1290, 1775, 1776

Gáldy László 1291

Gáliczky Éva 879, 896, 920

Galla Endre 50

Germanus Gyula 29, 94, 177, 178, 1746,1747

Gerő Győző 1590, 1634, 1635, 1636, 1637

Gerő L. 1093

Gerőné Fazekas Erzsébet 1108

Gervers-Molnár Veronika 1290

Goldziher Ignác 179,180
Gombocz Zoltán 181, 182, 183, 184, $344,1237,1254$

Göckenjan, H.G. 1531

Gökbilgin, Tayyıb 1656, 1698, 1699, 1719

Götz, Manfred 1660

Gracianskij, N.P. 1643

Grannes, A. 742

Gregor Ferenc 1292

Grétsy László 1229

Grigorjev-Eszrely Sz. G. 1062

Grönbech, Kaare 329,531

Grunin, T.I. 589

Gulya János 251, 273

Gulya Viktória 4

Gumilev, L. N. 394, 625, 626

Gunda Béla 1089, 1293, 1512, 1839

Gurszky István 881

Guzev, V.G. 697

Gyallay Domokos 1429

Gyóni Mátyás 388, 389, 1152, 1193

Győrffy Dezső 1430

Györffy György 453, 552, 559, 1090 , $1091,1092,1093,1094,1095$, $1096,1097,1098,1129,1130$, $1146,1156,1159,1193,1194$, $1195,1196,1197,1198,1431$, $1432,1433,1485,1528,1529$, $1530,1531,1534,1535,1536$, $1537,1540,1541,1542,1748$

Györffy Lajos 1593, 1595

Györgyi E. 988

Hadrovics László 1294, 1295, 1749, $1805,1806,1807,1808,1809$

Haj dú Péter $33,133,200,251,264$, $265,266,267,268,269,276$, $284,422,423,1078,1104,1146$

Halasi-Kun Tibor 236, 767, 769, $870 / \mathrm{a}, 1700$

Halász Gyula 186, 228, 237, 240, 249

Halikova, J.A. 601

Halmos István 969 
Hambis, Louis 363

Hamilton, J. 454

Ha rmatta János 51, 155, 159, 160, $204,205,208,387,388,389,390$, $391,392,393,455,456,481,553$, $627,1123,1159,1164$

Havránek, B. 1305

Hazai György $5,6,7,8,9,17,21,22$, $23,24,25,31,36,50,52,53,54$, $55,56,57,58,93,95,96,97,98$, $119,134,135,136,146,198,199$, $215,216,241,242,243,296,297$, $325,326,327,341,424,455,457$, $458,482,483,484,485,486,487$, $488,489,490,522,530,539,540,560$, $571,648,649,650,651,652,653$, $654,655,656,657,658,659,660$, $661,662,663,664,665,666,667$, $668,669,670,671,672,673,674$, $675,676,677,678,679,680,681$, $682,683,697,704,705,706,707$, $708,709,710,711,712,713,714$, $715,716,717,718,719,733,738$, $743,744,745,746,747,758,759$, $760,761,762,763,784,785,786$, $787,788,789,790,791,792,793$, $794,808,816,841,842,861,887$, $897,913,955,970,971,994,1028$, $1041,1063,1099,1171,1172,1173$, $1174,1543,1544,1578,1579,1580$, $1581,1582,1588,1590,1591,1594$, $1657,1658,1659,1660,1661,1662$, $1701,1750,1751,1752,1753,1754$, 1777

Heckenast Gusztáv 1072

Hegedũs József 99, 100

Hegedils Lajos 1296

Hegyi Imre $328,394,945,972,1010$

Hegyi Klára 164, 1590, 1591, 1663, $1702,1703,1704,1705,1706$, $1707,1715,1755,1756,1757$

Hellenbart Gy. 1338

Hernig Margit 845
Hervay Ferenc 3

Hauser, Fr. 765, 768

Heyd, Uriel 1591, 1664

Hídvégi Andrea, P. 1230

Hikmet, Nazim 795

Hofer Tamás 886

Hofman, H. F. 9

Holl Béla 3

Hollós Attila 1810

Honti László 1254

Hopp Lajos 59, 101,1758, 1777, 1903

Hoppál Mihály 994

Horváth Anna 1664, 1708, 1709

Horváth János 1100, 1199, 1200, 1201 , 1202

Horváth László 814

Hrbek, I. 1576

Hřebiłek, L. $680,738,769$

Hunger, H. 1765

Ikeda, Tsunev 1026

Imre Samu 1231, 1297

Inczefi Géza 1864

Inokuchi, T. 486

İ̌aev, A. 944

Istvánovits Márton 554, 555, 973, 1175

Itkonen, Erkki 1248

Ivánka, Dr. E.v. 1155

Ivanov, S.V: 1007

Jakab László 1811

Jandułkin, S. 137

Jánossy István 881

Jarring, G. 959, 963

Jávorszky Béla 796

Jäschke, G. 738

Jegorov (Egorov), V.G. 185, 1044, 1045,1059

Jenkins, R. J.H. 1148, 1156, 1158

Jeremiás Éva 797

Jerney János 186, 1575

Johanson, L. 680

Johansons, A. 990

Joki, A.J. 967

Jokinen, R. 258 
Juhász Jenó $270,1298,1299,1300$, 1301

Jusupov G.V. 871,872

Jy rkänkallio, P. 1337

Kabrda, Josef 1673

Kádár Zoltán 206, 623, 639

Kahane, H. 758

Kahane, R. 758

Kakuk Zsuzsa (Suzanne) 17, 31, 37, 38, $39,60,102,103,163,191,217,329$, $459,720,721,722,723,724,725$, $733,738,752,753,798,799,800$, $801,838,873,946,956,957,958$, $959,960,1243,1252,1588,1778$, $1779,1780,1781,1782,1783,1784$, $1785,1812,1813,1814,1815,1816$, $1817,1818,1819,1820,1865,1907$, 1908,1909

Káldy-Nagy Gyula 29, 32, 138, 166, 167, $178,764,769,1588,1590,1591$, $1595,1596,1597,1598,1599,1600$, $1601,1602,1603,1665,1666,1667$, $1668,1669,1670,1671,1672,1673$, $1710,1711,1712,1713,1714,1715$, $1716,1717,1718,1719,1720,1721$, $1722,1723,1724,1725,1726,1727$, $1728,1729,1759,1760,1761,1762$, 1763,1904

Kálmán Béla 218, 278, 990,1123, 1232, $1302,1303,1304,1434,1435,1436$, $1437,1864,1866$

Kałużyński, St. 1030

Kamphoevener, Elsa Sophia von 779

Kara György $18,26,61,62,63,76$, $77,104,105,106,107,147,298$, $307,381,491,492,966,990,1029$

Karadeniz, Şadan 31,1602

Karamanlıŏ̆iu, A.F. 571

Karatay, Sadrettin $375,376,1645$, 1695

Katičić, Radoslav 1252

Katona Edith 881

Katona Imre 1520,1525
Katus László 1764

Kázmér Miklós 1864

Käfer István 3

Kelecsényi Âkos 3

Kelemen B. 1457

Kelly, James M. 571

Kemény Ferenc 819

Kenesbaev, S. 17

Kenessey Mária $684,685,829,830$

Képes Géza 460, 1521

Kerimov, M. 780

Király Péter $95,1182,1183,1305$, 1486

Kisbán Eszter 1821

Kiselev, S.V. 1006

Kispál Magdolna, Sz. 1212, 1233

Kiss Attila 628

Kiss István, N. 1599

Kiss Jenő 874

Kiss József 244

Kiss Lajos 1184, 1243, 1784, 1808, $1822,1823,1824,1825,1826$, $1827,1828,1829,1830,1831$, 1832

Kissling, H.J. 1658

Klaniczay Tibor 1501, 1522

Kleinmichel, S. 680

Klíma, O. 558

Kljastornyj, S.G. $447,461,462$

Kmoskó, M. 1176

Knežević, A. 747

Kniezsa István $187,1123,1185$, $1234,1235,1833$

Kodolányi János 268, 273, 983, 990, $994,1101,1313,1501,1508$

Kononov, A. N. 35, 37, 139, 188, $352,680,738,1784$

Kopěan, V. 697

Korenchy Éva 1160

Korkmaz, Zeynep 802

Kornmumpf, H.J. 8

Korogly, Ch.G. 31

Koroknai Zsuzsa 926 
Korompay Bertalan 210

Koryürek Péter 788

Kóe Károly 1834

Koß̧ay, Hâmit Zübeyr $108,161,381,1729$

Kovách János 189

Kovács Ágnes 803, 972

Kovács Sándor Iván 1146,1734, 1738

Kovalovszky Miklós 181

Kozocsa Sándor 11

Köhalmi Katalin (Käthe), U. 17, 40, $76,77,156,278,299,974,975$, $1011,1012,1013,1014,1015,1016$, $1017,1018,1019,1020,1021,1032$, $1033,1501,1508$

Kőhegyi Mihály 381, 1592, 1595, 1718, 1881

Köprulüzade Mehmet Fuat 190

Kövesi Magda, A. 1236

Krader, L. 289, 333

Kreutel, Richard, F. 769, 1641, 1642, $1644,1654,1667,1668$

Kristó Gyula 1130

Kristó Nagy István 927

Kriza Ildikó 890,996

Krueger, J.R. 326

Kubinyi A. 1093

Kúnos Ignác 191,791,873

Kuryłžanov, A.K. 1562

Kyzlasov, L. R. 421

Ladányi Erzsébet 1718, 1719

Ladányi Mihály 1064

Ladó János 1438

Lakó György 273, 1102, 1103, 1212, 1244,1306

Láng Anikó 917

Lang Dezső 629

Láng János 271, 272

Láng Sandor 229

Lászl6 Ferenc 463

Lászlo Gyula 269, 273, 274, 275, 276, $277,640,641,642,1072,1104$, $1105,1106,1107,1119,1123,1487$, $1488,1501,1514,1515,1516$

Laude-Cirtautas, Ilse 351,947
Lavrov, L. I. 1175

Lázár István 1763

Lees, R. B. 767

Lengyel Béla 804

Leszev Irén 848

Leszkovszky Márta, N. 898

Lovend, Agâh Sirrı 30

Levin, M.G. 1008, 1022

Lewis, Bernard 1156, 1591, 1748

Lewis, G. L. 764

Libby, D. 994

Lidderdale, H. A. 672

Ligeti Lajos (Louis) $18,19,27,31,36$, $109,110,111,112,113,167,168$, $169,187,192,193,194,195,196$, $197,219,220,225,230,278,300,301$, $302,303,304,342,343,344,345,346$, $347,348,375,376,377,395,396$, $397,398,399,400,401,402,403$, $493,494,495,496,497,498,499$, $500,501,502,503,561,562,574$, $575,578,688,831,832,833,948$, $949,950,1030,1131,1132,1237$, $1238,1239,1240,1241,1243,1307$, $1308,1309,1310,1311,1312,1313$, $1314,1315,1316,1439,1523,1890$

Lipták Pál 1123

Livšic, V. A. 462

Lot-Falck, E. 994

Lotz János 144,1440

Lórincz László $28,305,306,349$, 680,1524

Lörincz Jenó 1317

Luby Margit 1459

Luikő Gábor $1042,1501,1517,1525$

Lytkin, V.I. 1043

Mackerras, C. 476,478

Maenchen-Helfen, O. 405

Makkai László 1091

Maksay Ferenc 1604

Mándoky (Kongur) István 843,855 , $856,857,862,880,888,899,911$, $928,1034,1318,1319,1320,1321$, $1545,1546,1547,1548,1549$

Mándoki László 307, 308, 1518, 1519 
Mansuroğlu, Mecdut $30,198,199$

Mantran, Robert 1758

Marinov, V. 702

Marjalaki Kiss Lajos 1430

Marót Károly 207

Martinkó András 279, 1109, 1441

Mátrai László 208

Matuz, J. 1661, 1674, 1734

Melich János $598,1117,1442,1443$, $1835,1836,1882$

Melles Kornélia 64

Menges, K. H. $31,332,333,337,961$, $962,990,1014$

Merpert, N.Ja. 630

Messerschmidt, D.G. 424

Més záros László 1602, 1763

Meszerics István 929

Meyer, I. 678

Mezey Láśzló 115:

Mijatev, P. 17, 170, 738

Mikesy Sándor $1322,1556,1867$

Miklós Pál 432

Minissi, N. 280

Minorsky, V. $615,834,1323,1666$

Mirzäzadä, H. 829

Módy György 1837

Molchanova, O. 66

Mollova, Mefküre 726,727

Molnár Erik 1110, 1111, 1112, 1113, 1123,1532

Molnár József 13

Nolnár Nándor 330

Moór Elemér 200,404, 405, 406, $1104,1114,1115,1116,1133$, $1212,1235,1246,1247,1248$, $1249,1250,1251,1252,1253$, $1324,1325,1326,1327,1328$, $1329,1330,1367,1444,1445$, $1446,1447,1838,1839,1840$

Morarcsik Grula $201,202,203,204,205$, $206,207,208,209,372,377,407,408$, $+55,556,576,577,639,734,1091$, $1092,1123,1147,11+8,1149,1150$, $1151,1152,1153,1154,1155,1156$, $1157,1158,1159,1160,1765,1883$, 1884
Morawski, K. 1146

Mroczko, E. 1025

Munkácsi Bernát 210,211, 270

Musnai László 1489

Musset, L. 1096

Mutaf̌̌ieva, Vera P. 1757,1766

Nagy Jenó 1841

Nagy Lajos 1697

Nahodil, O. 999, 1000

Nasilov, D. M. 680,1784

Nåsirov, S. 944

Naumann, R. 1659

Navaan, D. 74

Németh Gyula (Julius) $14,15,18,30$, $78,114,115,116,117,118,140,180$, $182,183,190,212,213,214,215$, $216,217,218,219,220,221,222$, $223,236,258,281,331,332,333$, $350,351,352,353,359,360,361$, $362,409,410,411,412,413,425$, $426,464,465,466,467,468,504$, $516,517,531,563,593,643,644$, $686,687,688,689,690,691,692$, $693,694,695,696,697,728,729,730$, $731,732,733,734,735,736,737$, $738,739,740,765,766,767,768$, $769,770,771,806,807,858,951$, $961,967,1044,1134,1135,1136$, $1137,1138,1161,1162,1254$, $1331,1332,1333,1334,1335$, $1336,1337,1338,1339,1340$, $1341,1342,1343,1344,1345$, $1346,1448,1449,1490,1538$, $1550,1551,1552,1557,1558$, $1570,1571,1572,1573,1842$, 1868,1869

N. L. 1734

Noviðev, A. D. 1756

Nuriachmetov, A.Ch. 649,650 , 1171

Nyíri Antal 268, 1347, 1348

Obolensky, D. 1156

Ojtozi Eszter 623

Olajos Teréz 417,1450

Ónody Bertalan 224

Oravecz Imre 1064 
Orosz Lajos 1163

Paasonen, H. 1054

Pais Dezsö $140,1117,1118,1203$, $1255,1349,1350,1351,1352$, $1353,1354,1355,1356,1357$, $1358,1359,1360,1361,1362$, $1363,1364,1365,1366,1367$, $1368,1451,1452,1453,1454$, $1455,1456,1457,1458,1459$, $1460,1461,1462,1463,1491$, 1843

Palló Margit, K. 211, 1045, 1046, $1047,1256,1257,1258,1369$, $1370,1371,1372,1373,1374$, $1375,1376,1377,1378,1379$, $1380,1381,1382,1383,1384$, $1385,1386,1387,1388,1389$, $1390,1391,1392,1393,1394$, $1395,1396,1397,1398,1399$, $1400,1401,1402,1464$

Papp Ferenc 1259

Papp László $1231,1243,1885$

Paulson, I. 1501

Penkov, Minko 859

Perényi József $141,1139,1140,1186$, $1187,1188,1189,1190,1588$, $1730,1731,1732,1733,1767,1768$

Péter László 1844

Petrácek, Karel 1657

Pinks, E. 477

Pitcher, D. E. 1752

Plezia, M. 1886

Poppe, N. 296, 332

Potapov, L. P. 1001, 1002, 1008

Poucha, Pavel 142

Pritsak, O. 332, 734

Puhov, I.V. 1031

Pusztay János 975

Püspöki Nagy Péter 1492, 1493, 1494 , 1495

Rab Zsuzsa 1064

Radlov, V.V. 39

Radó György 11

Radványi Ervin 881
Rás onyi László $16,17,119,120,140$, $143,150,184,225,229,231,232$, $233,234,245,331,363,364,365$, $366,367,368,369,370,371,414$, $532,733,772,773,808,809,1141$, $1142,1403,1465,1466,1467,1468$, $1559,1560,1561,1562,1563,1564$, $1565,1566,1567$

Rassadin, V.I. 966

Ratkos, I. 1094

Rátz Ottó 1119

Raun, A. 282

Räsänen, M. 40, 354, 425, 968, 1143

Rédei Ká roly 602,1244

Redhouse, [ J.] 771

Relković, Davorka 1899

Repin, B. 680

Reuter Camillo $698,1469,1845,1870$, 1871

Reviczky Károly 226

Reychman, Jan 17, 226, 588, 1048, 1649,1846

Ritoók Zsigmond 208

Ritoók Zsigmondné 3, 699

Ritter, Hellmut 806

Rohan-Csermák, Géza de 268

Román János 1734

Róna-Tas András $1,33,43,76,77$, $79,80,81,82,121,122,185,283$, $284,309,310,311,312,313,314$, $315,316,335,354,505,602,603$, $891,892,962,963,1019,1023$, $1024,1025,1026,1049,1050$, $1051,1052,1053,1054,1065$, 1066,1260

Roux, Jean-Paul 1027

Rubin, B. 377

Rubinyi Mózes 246, 1872

Rubovszky Edit 810,811

Rudenko, S. I. 886

Runciman, S. 1156

Rúzsás Lajos 1734

Rybova, A. 391

Rypka, J. 812 
Såabdurahmånov, S. 944

Saadiev, S.M. 17

Sabanović, Hazim 1655

Sándor István 336, 1093, 1501

Sanžeev, G. D. 193

Saria, B. 1091

Sarjó Sándor 930

Sárközi Alice 506

Sauvageot, A. $256,257,258,260,268$ $1055,1139,1216,1217,1235$, $1239,1248,1249,1251,1328$, $1373,1406,1465$

Saygun, A. Adnan 1900, 1901

Scerbak, A. M. 541, 632, 633

Scheel, Helmuth 329, 1588, 1591

Schefild, K. 389

Scheiber Sándor $853,1873,1887$, 1888

Schelken Pálma 227

Schellbach, I. 268, 273, 1093, 1501

Schlachter, W. 258

Schmitt, G. 415

Schuitz Ödön (Edmond) $63,123,317$, $545,546,547,548,571,579,580$, $581,582,583,584,585,586,587$, $588,589,590,591,697,700,701$, $797,813,1404,1405,1769$

Sebeok, Th.A. 129, 1501

Sebestyén Gyula 227

Sebestyén Irén N. 174, 278

Sechin, Jagchid 64

Ser, Ja. A. 420

Serebrennikov, B. A. 285, 286, 355, $875,1055,1056,1057$

Sertoğlu, Midhat 138

Şevket 765,768

Sevortjan, E.V. 836,837

Shaw, St. 1753

Simó Jenö 814

Simon Györgyi 1847

Simon Róbert 815

Simonffy V. Aladár 1905

Simony i Dezső 1470

Sinkovics István $171,1590,1591,1600$, 1601
Sinor Dénes 287, 292, 294, 313, 318, $319,322,1406,1471$

Sipos István 648

Siraliev, M. S. 38, 835

Skaljić, A. 744

Skazkin, S. D. 1643

Somlyó György 816

Soproni Sándor 1091

Spies, Otto $332,1641,1644$

Spuler, B. 588

Stachowski, St. 738,746

Stein Aurél 228, 229, 230, 231, 232, 233,234

Steinitz, W. 876,877

Steue rwald, K. 759

Stiehl, R. 392,1147

Sturminger, Walter 2

Suchareva, O.A. 937, 939

Sugár István 1874

Sulán Béla 1261, 1262, 1848, 1849, $1850,1851,1891,1892$

Suitő J6́zsef 1568

Syzdykova, P. 17

Szabadfalvi J6zsef 1120,1121

Szabó-Pap Lóránt 1906

Szabó T. Attila $755,1472,1852$, $1853,1854,1855,1893$

Szabolcsi Bence 1123

Szádeczky-Kardoss Samu 416, 417 , 599,1160

Szalmási Pál 817

Székely András 145, 151, 224, 238

Székely György 34, 209, 221, $222,1577,1735$

Szende Tamás $797,818,823$

Szendrey Ákos 1407

Szépe György 144

Szertel, Szabiha 819

Szilágyi Éva 194

Szilágyi Ferenc 1263

Szilágyi J. 388

Szkoszirev, P. $\mathbf{8 4 8}$

Szoboszlay B. 1146 
Szolnoky Lajos 1408

Taeschner, F. 332, 1665

Takács Imre 931

Takáca Lajos 1409, 1736

Takáts Sandor 1737

Tálasi Istuán 1410,1411, 1553, 1554

Tálanine Varga A. 17

Tamia Lajos $688,748,1264,1856$, 1857,1858

Tandori Dezổ 820

Tardy Lajo: 1583,1738, 1771

Tarisznyás Györgyi 917

Taunád! Edit $509,542,797,815,821$, $822,823,844,900,901,932,955$

Tekin, Talet $320,469,518$

Telegdi 'Zsigmand $18,688,952$

Temir, A. 332

Teniľev, E. 356,964

Terjek Jozsef 26, 124

Tezcan, Semih 507

Thomsen, K. 357

Thomsen, Vilhelm 426

Thúry Jozeof 235, 236, 1079

Tichonov, A. N. 941

Tietze, A. $17,363,738,758,769$, 770,798

Tihomirov, M. N. 1060

Timár György 824

Todorov, N. 1770

Togan, Zeki Velidi 329, 332, 1165

Togay, Necil 820

Tokarev, S. A. 328

Tolnal Gábor 1523

Tolsztov, Sz. P. 533

Tomka Péter 321

Tompa J6zsef 1875

Tornai J6zzef 787

I'óth Imre 1910

T'óth Tibor 288

Török Gyula 1119

Trencsényi-Waldapfel Imre 117, 902 , 903, 904, 905
Tryjarski, Edward 557, 586, 588, 590,594

Tuchelt, K. 1659

Tugal, Ziya 236

Tuguð̌eva, L.Ju. 508

Ujfalvy Ká roly 237, 238

Ungvickaja, M. A. 973

Uray Géza 44, 125, 126, 223, 1122

Úrhegyi Emília 1412

Uzăqov, H. 944

Uzsokł András 1859

Ünal, R. H. 1754

V. L. M. 588

Váczy Péter 418

Vajda G. 1675, 1739

Vajda L. 990

Vajn§tejn, S.I. 1003, 1004

Vakarelszki, H. 738

Vámbéry Ármin $239,240,241,242$, $243,244,245,246,247,248,946$

Vándor Anna 8.45

Varga Mária 157

Varga Mihály 933

Vargyas Lajos 1093, 1501, 1526, 1902

Vas István 825

Vas Károly 1734

Vásáry lstván 152, 322, 337, 427, $469,571,592,593,594,615$, $697,1144,1160,1191,1413$, $1414,1496,1738,1771,1907$.

Vasiljev, L. A. 868

Vass Elôd 127, 172, 173, 1602, 1605, $1606,1607,1608,1609,1610$, $1718,1740,1741,1742$

Vécsey Zoltán 247

Vekerdi József 509

Velcsov Mártonné 1415

Vértes Edit 175

Vértes O. András 1145,1497

Vesela-Prenosilovă, Z. 697

Veselý, Rudolf 1657

Vihar Béla 248 
Vikár László 882, 1067, 1068

Vincze I. 1505

Voigt Vilmos $955,1005,1027$

Vojtech, K, 1718, 1723, 1733

Vorobjev, N. I. $866,878,1058$

Werner, E. 680

Wickman, B. 268

Winkelman, F. 377

Wojtilla Gyula 1894

Yamada, Nobuo 510

Zahemszky László 845

Zaicz Gábor 1101

Zaimov, J. 743
Zając zkowski, I. 534,570,631,1649 Zástĕ rová, Bohumila 377

Ždanko, T. A. 910

Zejnalov, P. 830

Zenker, J. Th. 762

Zhukovskaya, N. 66

Zichy Jenő 249, 250

Zieme, Peter 23, 31, 483, 484, 486, $488,507,511,512,513,514$

Žirmunskij, W.M. 951

Zólyomi Bálint 273

Zsirai Miklós 1123, 1473

Zsoldos Jenő 1416,1860 


\section{ABBREVIATIONS}

AAnt. AArch.

AASt. A Ethn.

AHist. AkK

ALH

Altnapok.

AnalLingu. AnalOr.

Anntist .

AnnLingu.

$\mathrm{AOH}$

ArchÊrt.

ArchOr.

Archott.

Arrabona

$A T$

Attila ve Hunları
Acta Antiqua Academiae Scientiarum Hungaricae. Budapest. Acta Archeologica Academiae Scientiarum Hungaricae. Budapest.

Asian and African Studies. Bratislava.

Acta Ethnographica Academiae Scientiarum Hungaricae. Budapest.

Acta Historica Academiae Scientiarum Hungaricae. Budapest. Akadémiai Kiadó. Budapest [=Publishing House of the Hur.garian Academy of Sciences].

Acta Linguistica Academiae Scientiarum Hungaricae. Budapest.

Altajisztikai napok 1965 I=Altaic Studies Days. 1965 (Summaries of the lectures)] Budapest, 1965.

Analecta Linguistica. Redigit A. Róna-Tas. Budapest.

Analecta Orientalia memoriae Alexandri Csoma de Körös dicata. Edendo operi praefuit L. Ligeti. Budapestini, 1942-1947. BOH 5.

Annales Lniversitatis Scientiarum Budapestinensis de Rolando Eötrös Nominatae. Sectio Historica.

Annales Iniversitatis Scientiarum Budapestinensis de Rolando Eötrös Nominatae. Sectio I.inguistica.

Acta Orientalia Academiae Scientiarum Hungaricae. Budapest. Archaeologiai Értesitó. Budapest.

Archív Orientálni. Praha.

Archivum Ottomanicum. The Hague, Lisse.

Arrabona. A Gvoóri Xantus János Múzeum Évkönyve [=Arrabona. Annual of the Jânos Xantus Museum, Gvör].

Antik Tanulmánvok. Studia Antiqua. Budapest.

J. Németh, Attila ve Hunları. Tercüme eden Serif Baştav. Istanbul, 1962. 328 pp. / AÜDTCFY Sayı 106/. 


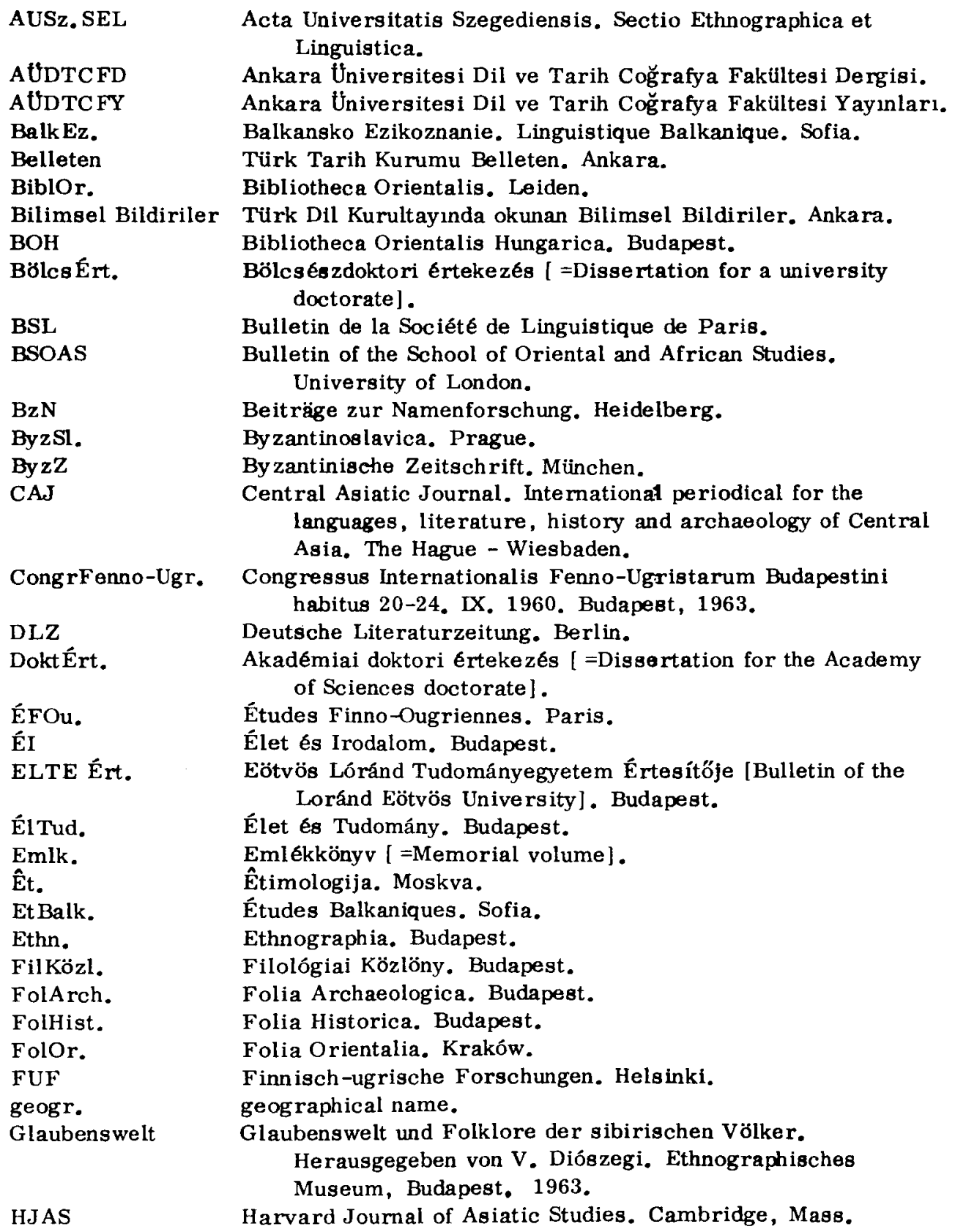


HK

II. OK

Index Ethn.

I. OK

ItK

IỨEF

IÜEF TDED

IÜEFTTD

IzvAN OLJa.

\section{JA}

JAH

JAOS

JRAS

JSFOu.

$\mathrm{K}$

KandÉrt.

Klny .

LevSz.

LK

A magyarok elődeiról

Magyar utazók

MIO

MKsz.

$\mathrm{MNy}$.

MNyj.

MNyTK
Hadtörténelmi Közlemények. Budapest.

A Magyar Tudományos Akadémia Társadalmi és Történeti Tudományok Osztályának Közleményei [ =Transactions of the Department of Social and Historical Sciences of the Hungarian Academy of Sciences]. Budapest.

Index Ethnographicus. Budapest.

A Magyar Tudományos Akadémia Nyelv- és Irodalomtudományi Osztályának Közleményei [ =Transactions of the Linguistic and Philological Department of the Hungarian Academy of Sciences]. Budapest. Irodalomtörténeti Közlemények. Budapest. Istanbul UUniversitesi Edebiyat Fakuiltesi

Istanbul Úniversitesi Edebiyat Fakültesi Türk Dili ve Edebiyatı Dergisi.

Istanbul Üniversitesi Edebiyat Fakültesi Türk Tarih Dergisi. Izvestija Akademii Nauk SSSR. Otdelenie literatury i jazyka. Moskva.

Journal Asiatique. Paris.

Journal of Asian History. Wiesbaden.

Journal of the American Oriental Society. Baltimore.

Journal of the Royal Asiatic Society. London.

Journal de la Société Finno-Ougrienne. Helsinki.

Kiadó [= Publishing House] .

Kandidátusi értekezés [ =Dissertation for the degree of "candidates"].

Különnyomat [ $\Rightarrow$ Offprint $]$.

Levéltári Szemle [ =Archival Review]. Budapest.

Levéltári Közlemények [=Archival Communications]. Budapest.

A magyarok elödeiról és a honfoglalásról. Kortársak és krónikások híradásai. Sajtó alá rendezte Györffy György. [=Sources on the ancestors of the Hungarians and the conquest of Hungary. Reports by contemporaries and chroniclers. Ed. by Gy. Györffy]. Budapest, Gondolat Kiadó, 1958. 266 pp.

Magyar utazók, földrajzi felfedezók. Szerk.: Havasné Bede Piroska - Somogy i Sándor [ =Hungarian travellers geographical explorers. Ed. by P. Bede and S. Somogyi]. Budapest, 1973.

Mitteilungen des Instituts für Orientforschung. /Deutsche

Akademie der Wissenschaften zu Berlin/.

Magyar Könyvszemle. Budapest.

Magyar Nyelv. Budapest.

Magyar Nyelvjárások. Debrecen, Budapest.

A Magyar Nyelvtudományi Társaság Kiadványai [ =Publications of the Hungarian Linguistic Society]. Budapest. 


MSFOu.
MTA
MTud.
The Muslim East
MứvÉrt.
NarAzAfr.
NéprÉrt.
NéprKözl.
NévtudVizgg.

Nyelvtudért. NyK

Nyr.

OLZ

PécsiMÉvk.
PIAC News.
Popular beliefs
prop.
PrOr.
Protokollband

Rádiólexikon

RégDolg.
Mémoires de la Société Finno-Ougrienne. Helsinki. Magyar Tudományos Akadémia [ =Hungarian Academy of Sciences]. Magyar Tudomány. Budapest.

The Muslim East. Studies in Honour of Julius Germanus. Ed. by Gy. Káldy-Nagy. Budapest, 1974.

Múvészettörténeti Értesítö. Budapest.

Narody Azii i Afriki. Istorija, êkonomika, kultura. Moskva. Néprajzi Értesítő. Budapest.

Néprajzi Közlemények. Budapest.

Névtudományi Vizsgálatok. A Magyar Nyelvtudományi Társaság névtudományi konferenciája. Budapest, 1958. Pais D. közremưködésével szerk.: Mikesy Sándor [ =Onomatologic investigations. Onomatologic Conference of the Hungarian Linguistic Society. Edited by Sándor Mikesy with the collaboration of D. Pais]. Budapest, 1960.

Nyelvtudományi Értekezések [ =Linguistic Papers]. Budapest. Nyelvtudományi Közlemények. Budapest. Magyar Nyelvór. Budapest. Orientalistische Literaturzeitung. Monatsschrift für die Wissenschaft vom ganzen Orient und seinen Beziehungen $z u$ den angrenzenden Kulturkreisen. Berlin.

A Janus Pannonius Múzeum Évkönyve [ =Annual of the Janus Pannonius Museum]. Pécs.

Permanent International Altaistic Conference. Newsletter. Bloomington.

Popular beliefs and folklore tradition in Siberia. Ed, by V. Diószegi. Budapest, 1968.

proper name.

Przegląd Orientalistyczny. Warszawa.

Schriften zur Geschichte und Kultur des alten Oriens, 5. Sprache, Geschichte und Kultur der altaischen Völker. Protokollband der XII. Tagung der Permanent International Altaistic Conference 1969 in Berlin. Ed. G. Hazai P. Zieme. Berlin, 1974.

Itt a Rádiólexikon! Válogatta és szerkesztette az 1959-1962 évi rádióadások anyagából Simonffy Géza [ =Here is the Rádiólexikon (The Encyclopaedia of the radio)! Selected and edited from the broadcasts of the years 1529-1962 by Géza Simonffy]. Budapest, 1964.

Régészeti Dolgozatok az Eörvös Lóránd Tudományegyetem Régészeti Intézetéböl. Dissertationes Archaeologicae ex Instituto Archaelogico U'uiversitalis de Rolando Eötvös nominatae. Budapest. 
RMKT

RO

Slavica

SovTjurk.

StHist.

StOr.

StSl.

StTurc.

Száz.

Szigetvári Emlk.

SzNépr.

Sz Rég.

TBM

TD

TDAYB

TDKY

TK

TörtSz.

Trudy

U AJb.

UAS

Úf

VIL

Régi Magyar Költők Tára. XVII. század, I-VII. köt. Szerk.: Klaniczai Tibor, Stoll Béla I = The Thesaurus of Old Hungarian Poets. 18th century. Volumes I-VII. Edited by T. Klaniczai and B. Stoll]. Budapest.

Rocznik Orientalistyczny. Kraków.

Slavica. Annales Instituti Philologiae Slavicae Universitatis Debreceniensis de Ludovico Kossuth nominatae.

Sovetskaja Tjurkologija. Baku.

Studia Historica. Budapest.

Studia Orientalia. Hels inki.

Studia Slavica Academiae Scientiarum Hungaricae. Budapest.

Studia Turcica. Edited by Louis Ligeti. Budapest, BOH XVII.

Századok. Budapest.

Szigetvári emlékkönyv. Szigetvár 1566. évi ostromának 400. évfordulójára. Szerk.: Rúzsás Lajos [=Szigetvár Memorial volume. Issued on the 400th anniversary of the battle of Szigetvár. Ed. by L. Rúzsás]. Budapest, 1966.

Szovjet Néprajz [ =Soviet Ethnography]. Budapest.

Szovjet Régészet [ =Soviet Archeology]. Budapest.

Tanulmányok Budapest Múltjából | =Studies from the Past of Budapest]. Budapest.

Türk Dili. Ankara.

Türk Dili Araştırmaları Yıllıgı - Belleten. Ankara.

Türk Dil Kurumu Yayınları. Ankara.

Tankönyvkiadó

Történelmi Szemle. Budapest.

Trudy dvadcatj-pjatogo mežduna rodnogo kongressa vostokovedov. Moskva 9-16 avgusta 1960. Moskva, 1962. I-V.

Ural-Altaische Jah rbücher. Wiesbaden.

Uralic and Altaic Series. Bloomington.

Új Írás. Budapest.

Világirodalmi Lexikon. Főszerk.: Király István I =Encyclopaedia of World Literature. Editor-in-Chief: I. Király]. I. Budapest, 1970. $1248 \mathrm{pp}$; II. Budapest, 1972. $1344 \mathrm{pp}$.

Világjáró magyarok Halász Gyula, Világjáa ró magyarok [ =Hungarian globetrotters]. Budapest, 1945.

Vir.

VJaz.

Virittäjä. Helsinki.

Voprosy Jazykoznanija. Akademija Nauk SSSR. Institut Jazykoznanija. Moskva.

VostIst.

WZKM

Vostocnye istocniki po istorii narodov jugo-vostoðnoj i centraljnoj Evropy. Pod. red. A.S. Tveritinovoj. Moskva.

Wiener Zeitschrift für die Kunde des Morgenlandes. Wien. 
184

$\mathrm{XX} . \mathrm{sz}$.

ZBalk.

ZDMG

ZentrSt.

ZSI.

ZSIPhil.
A huszadik század külföldi írói. Szerk. Köpeczi Béla, Pók Lajos [ =Foreign writers of the 20th century. Edited by B. Köpeczi and L. Pók]. Budapest, 1968. Zeitschrift für Balkanologie. München. Zeitschrift der Deutschen Morgenländischen Gesellschaft. Wiesbaden. Zentralasiatische Studien des Seminars für Sprach- und Kultur-wissenschaft Zentralasiens der Universität Bonn. Zeitschrift für Slawistik. Berlin. Zeitschrift für slavische Philologie. Leipzig, Heidelberg. 


\section{CONTENTS}

Introduction $\ldots \ldots \ldots \ldots \ldots \ldots \ldots \ldots \ldots \ldots \ldots \ldots \ldots \ldots \ldots \ldots \ldots \ldots$

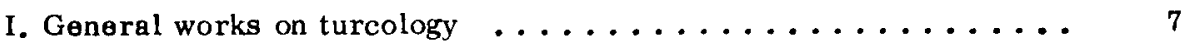

1. Bibliographies ..................... 7

2. Periodicals, series, collected papers ............. 9

a/ Hungarian publications $\ldots \ldots \ldots \ldots \ldots \ldots \ldots$

b/ Reviews on collected papers edited abroad ........... 10

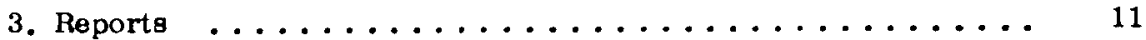

a/ Conferences held in Hungary ................. 11

b/ Hunga rian participation in inte mational meetings ...... 11

c/ Yourneys, fleld-work and expeditions ............ 12

4. Reports on turcological research ................. 14

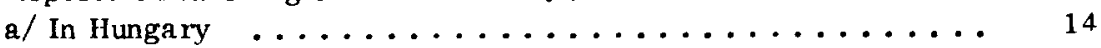

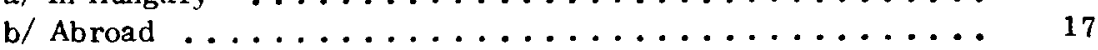

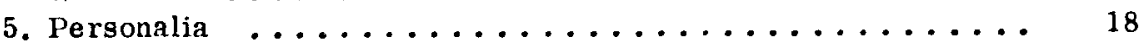

II. On Turkic peoples and languages in general ............ 29

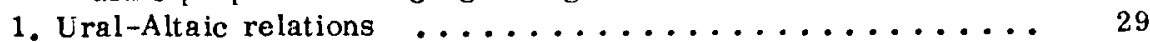

2. Altaic relations $\ldots \ldots \ldots \ldots \ldots \ldots \ldots \ldots \ldots \ldots \ldots$

3. Reference works ..................... 35

4. Comparative linguisties: Turkic phonetics, morphology and le-

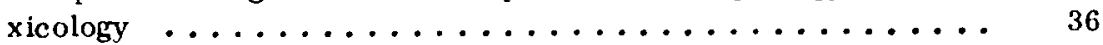

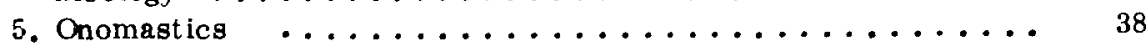

IIr. Ancient Turkic peoples and languages $\ldots \ldots \ldots \ldots \ldots \ldots \ldots$

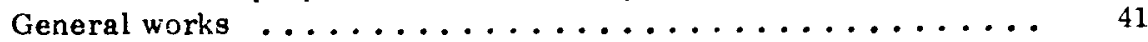

1. T'o-pa, Hsiung-nu, Juan-juan, Hephtalites, Karluks; European

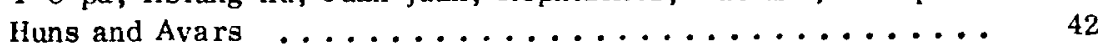

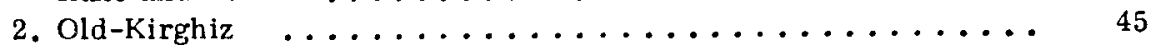

3. Eastern Turks $\ldots \ldots \ldots \ldots \ldots \ldots \ldots \ldots \ldots \ldots \ldots$

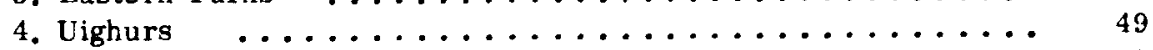

5 . The Niddle Turkic period $\ldots \ldots \ldots \ldots \ldots \ldots \ldots \ldots \ldots$

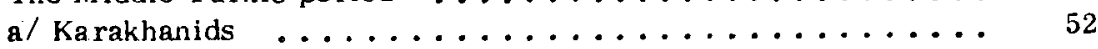

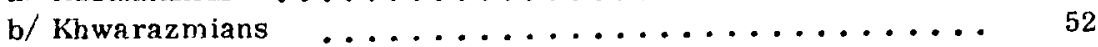

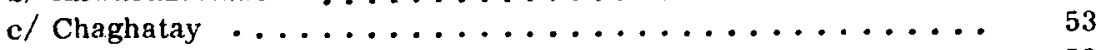

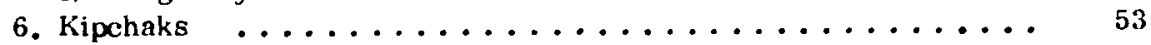

a/ Pechenegs and Cumans .................. 54 
b/ The Codex Cumanicus $\ldots \ldots \ldots \ldots \ldots \ldots \ldots \ldots$

c/ Mamluk monuments .................. 55

d/ Armeno-Kipchak monuments $\ldots \ldots \ldots \ldots \ldots \ldots$

7. Weatern Turkic peoples and languages ............. 58

a/ Turco-Bolgars ...................... 58

$\alpha /$ Danubian Bolgars $\ldots \ldots \ldots \ldots \ldots \ldots \ldots$

$\beta /$ Volga Bolgars $\ldots \ldots \ldots \ldots \ldots \ldots \ldots \ldots \ldots \ldots$

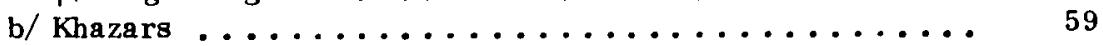

c/ Runiform insciptions in South-Eastern Europe ........ 61

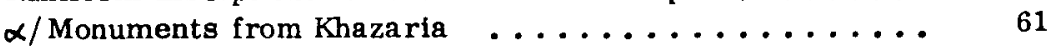

ß/ The Nagyszentmiklós Treasure ............. 61

$\gamma /$ Monuments in Hungary from the Avar Period ........ 62

IV. Modern Turkic peoples and languages ............... 63

1. Turkish (Ottoman, Anatolian, Rumelian etc.) .......... 63

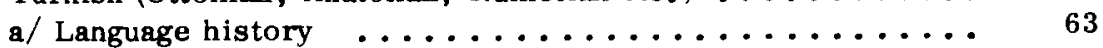

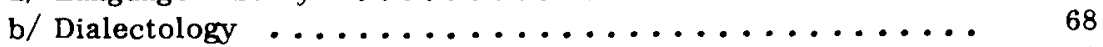

c/ Turkish loan-words in the Balkan languages .......... 71

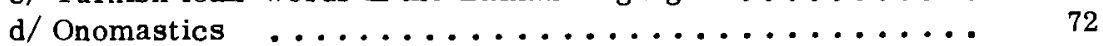

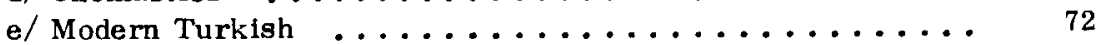

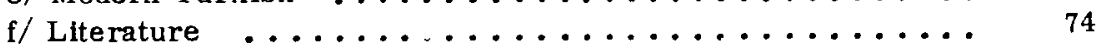

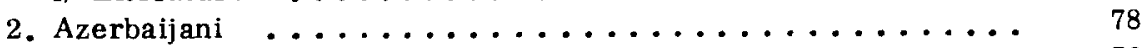

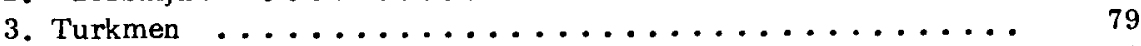

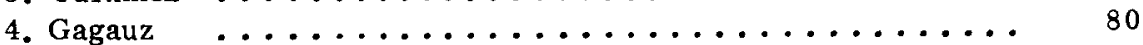

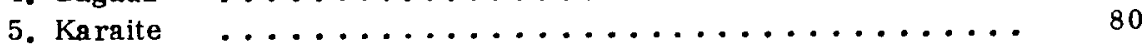

6. Crimean Tatar and Tatar of Dobrudja ............ 80

7. Karachay-Balkar, Kumyk, Noghay ............. 81

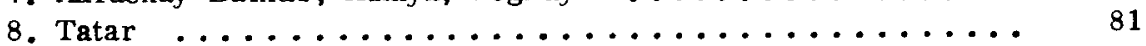

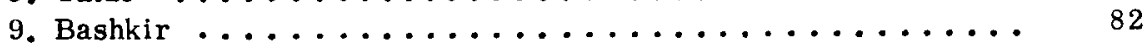

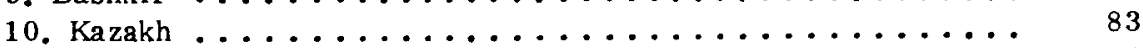

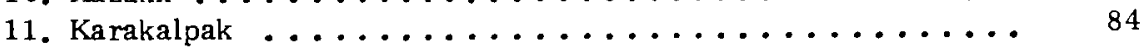

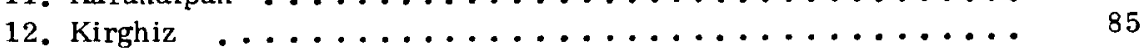

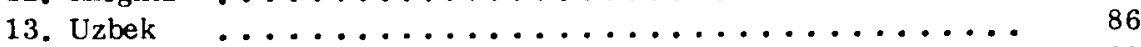

14. Modern Uighur, Salar, Yellow Uighur ............ 88

15. Altai-Turk, Khakass, Tuva ................. 88

Shamanis $m$ amongst the South-Siberian Turks ........ 89

The ethnog raphy of the Sout-Siberian Turkic peoples ...... 92

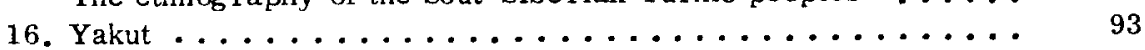

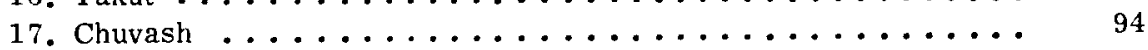

V. Pre-10th-century Turco-Hungarian relations $\ldots \ldots \ldots \ldots \ldots \ldots 9$

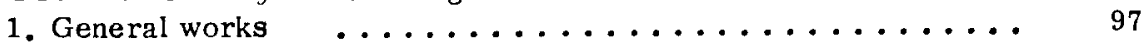

2. "Magna Hungaria" . . . . . . . . . . . . . . . . . . . . . . . . . . . . . . . . . . . . . . . . . .

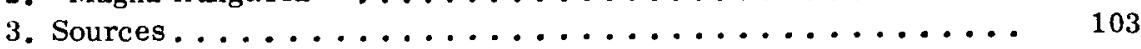

a/ Byzantine sources $\ldots \ldots \ldots \ldots \ldots \ldots \ldots \ldots$

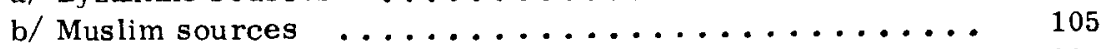

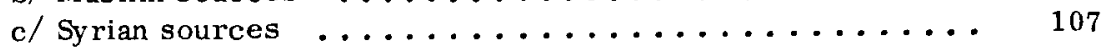


d/ Armenlan and Georgian sources $\ldots \ldots \ldots \ldots \ldots . \ldots \ldots$

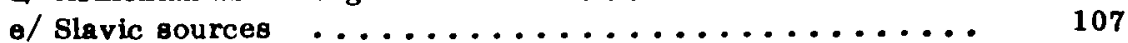

f/ Latin sources $\ldots \ldots \ldots \ldots \ldots \ldots \ldots \ldots \ldots$

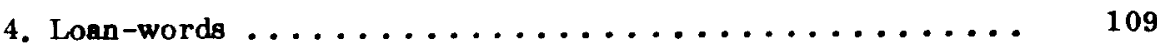

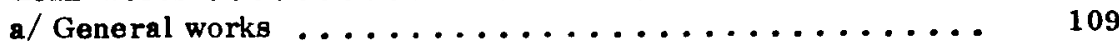

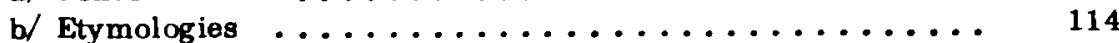

c/ Onomastics $\ldots \ldots \ldots \ldots \ldots \ldots \ldots \ldots \ldots \ldots \ldots \ldots \ldots$

5. The Hungarian runiform script $\ldots \ldots \ldots \ldots \ldots \ldots \ldots \ldots$

6. Relics of shamanism in Hungary ................. 130

7. Rolics of ancient poetry .................... 131

VI. Turco-Hungarian relations in the middls Ages ........... 133

General works $\ldots \ldots \ldots \ldots \ldots \ldots \ldots \ldots \ldots \ldots$

1. Pechenegs and Cumans in Hungary ............... 133

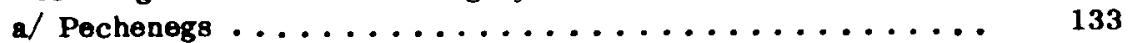

b/ Cumans $\ldots \ldots \ldots \ldots \ldots \ldots \ldots \ldots \ldots \ldots \ldots \ldots \ldots$

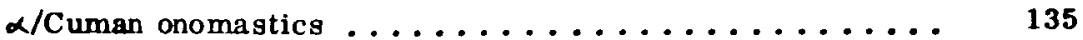

$\beta /$ The Alan Glossary ..................... 136

2. Ismaelttes in Hungary ..................... 137

VII. The perlod of the Ottoman conquest .................. 139

1. Historical and cultural researches based on Turkish sources .. 139

a/ Early Ottoman-Turkish-Hungarian contacts (before 1526) . . 139

b/ Ottoman sources in Hungary: edition of sources . . . . . . . 140

$\alpha /$ Administrative and economic documents, letters etc. . . . 140

$\beta /$ Inscriptions and miniatures ................ 142

c/ Edition of Ottoman sources not pertaining to Hungary ..... 144

d/ Studies pertaining to Hungary ................ 148

e/ History of the Ottoman Empire $\ldots \ldots \ldots \ldots \ldots \ldots \ldots$

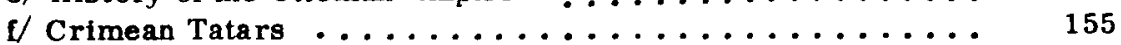

2. Ottoman Turkish loan-words in Hungarian ........... 155

a/ General works $\ldots \ldots \ldots \ldots \ldots \ldots \ldots \ldots \ldots \ldots$

b/ Etymologies $\ldots \ldots \ldots \ldots \ldots \ldots \ldots \ldots \ldots \ldots \ldots \ldots$

c/ Onomastics $\ldots \ldots \ldots \ldots \ldots \ldots \ldots \ldots \ldots \ldots \ldots \ldots \ldots$

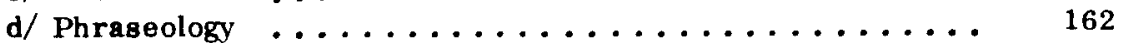

e/ Hunga rian elements in Turkish ................ 163

3. Ottoman influence in literature and music ............. 164

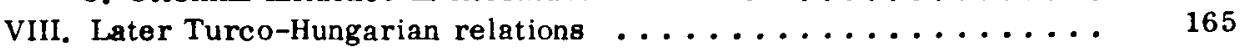

1. Rákóczi and the refugees in the Ottoman Empire ......... 165

2. Kossuth and the refugees in Turkey ............... 165

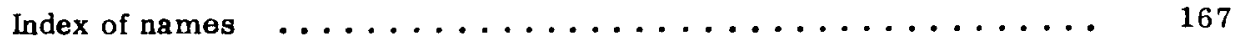

Abreviations $\ldots \ldots \ldots \ldots \ldots \ldots \ldots \ldots \ldots \ldots \ldots \ldots \ldots \ldots$

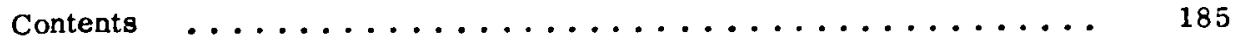


Alak B/5 - Terjedelem 16,6 (A/5) iv Megjelenés 1981. Példányszám: 800

Feleloos kiadó: az MTA Könyvtára fóigazgatója Készult az MTA Könyvtára házi sokszorositó részlegêben 


\section{KELETI TANULMÁNYOK - ORIENTAL STUDIES}

1. Terjék József: Kórösi Csoma dokumentumok az Akadémiai Könyvtár gyưjteményeiben. Bp. 1976.226 p.

2. Jubilee Volume of the Oriental Collection 1951-1976. Ed. by Éva Apor Bp.1978. 224 p.

3. Terjék József: Collection of Tibetan MSS and Xylographs of Alexander Csoma de Körös. Bp. 1976. 116 p.

4. Kasantatarische Volkslieder (Auf Grund der Sammlung von Ignác Kunos) Hrsg. von Zsuzs a Kakuk. Bp. 1980. 142 p. 


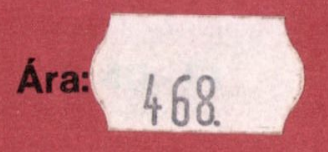

